
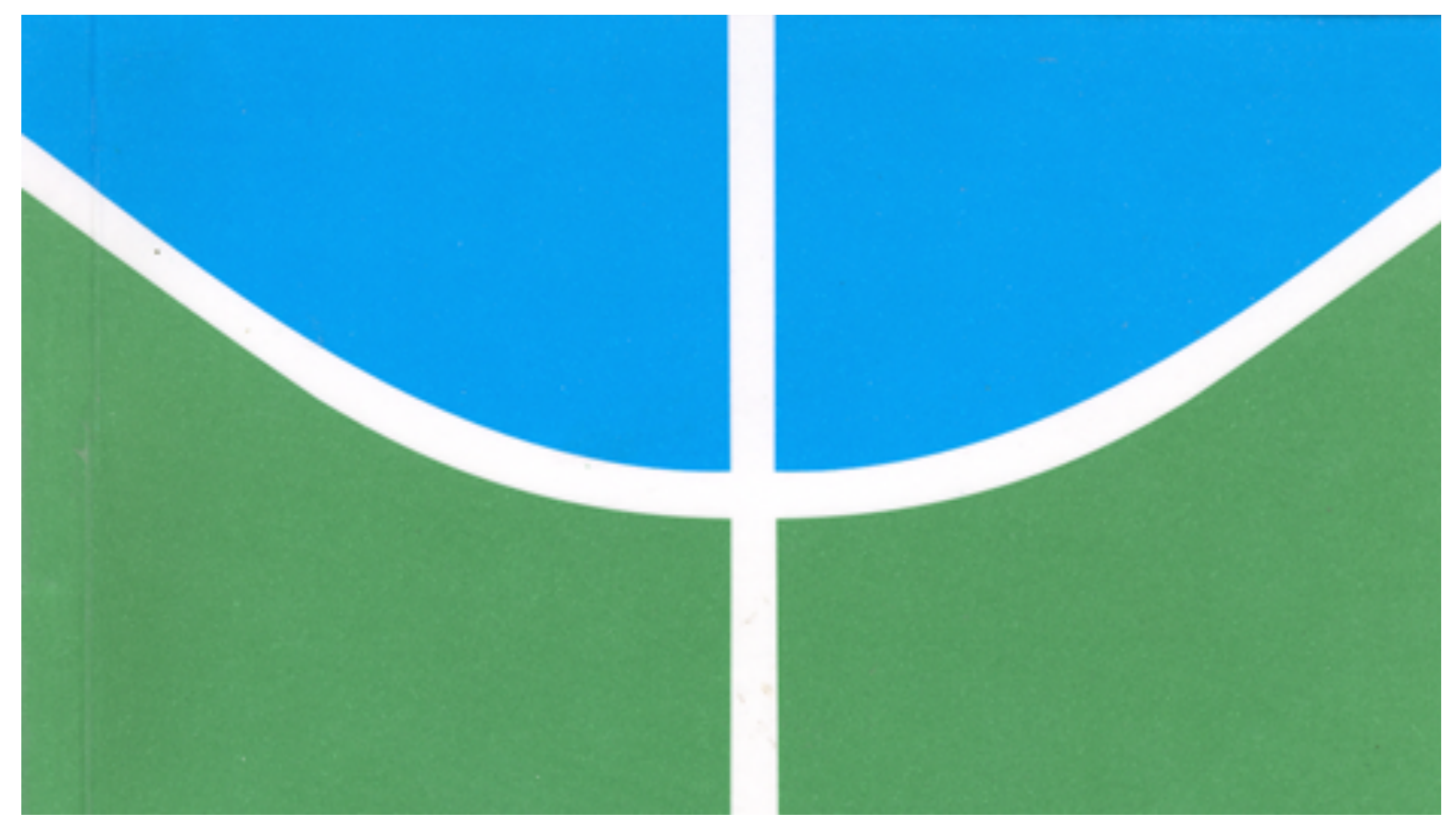

\title{
UM MODELO PARA AFERIR O NÍVEL DE MATURIDADE NA ADOÇÃO DE SOA
}

CLAYNOR FERNANDO MAZZAROLO

TESE DE DOUTORADO EM ENGENHARIA ELÉTRICA DEPARTAMENTO DE ENGENHARIA ELÉTRICA 
UNIVERSIDADE DE BRASÍLIA

FACULDADE DE TECNOLOGIA

DEPARTAMENTO DE ENGENHARIA ELÉTRICA

UM MODELO PARA AFERIR O NÍVEL DE MATURIDADE NA ADOÇÃO DE SOA

CLAYNOR FERNANDO MAZZAROLO

ORIENTADOR: RICARDO STACIARINI PUTTINI

TESE DE DOUTORADO EM ENGENHARIA ELÉTRICA

PUBLICAÇÃO: PPGEE.TD097/2015

BRASÍLIA, DF, JANEIRO/2015 


\section{UNIVERSIDADE DE BRASÍLIA FACULDADE DE TECNOLOGIA DEPARTAMENTO DE ENGENHARIA ELÉTRICA \\ UM MODELO PARA AFERIR O NÍVEL DE MATURIDADE NA ADOÇÃO DE SOA

\author{
CLAYNOR FERNANDO MAZZAROLO
}

TESE DE DOUTORADO SUBMETIDA AO DEPARTAMENTO DE ENGENHARIA ELÉTRICA DA FACULDADE DE TECNOLOGIA DA UNIVERSIDADE DE BRASÍLIA, COMO PARTE DOS REQUISITOS NECESSÁRIOS PARA A OBTENÇÃO DO GRAU DE DOUTOR.

APROVADA POR:

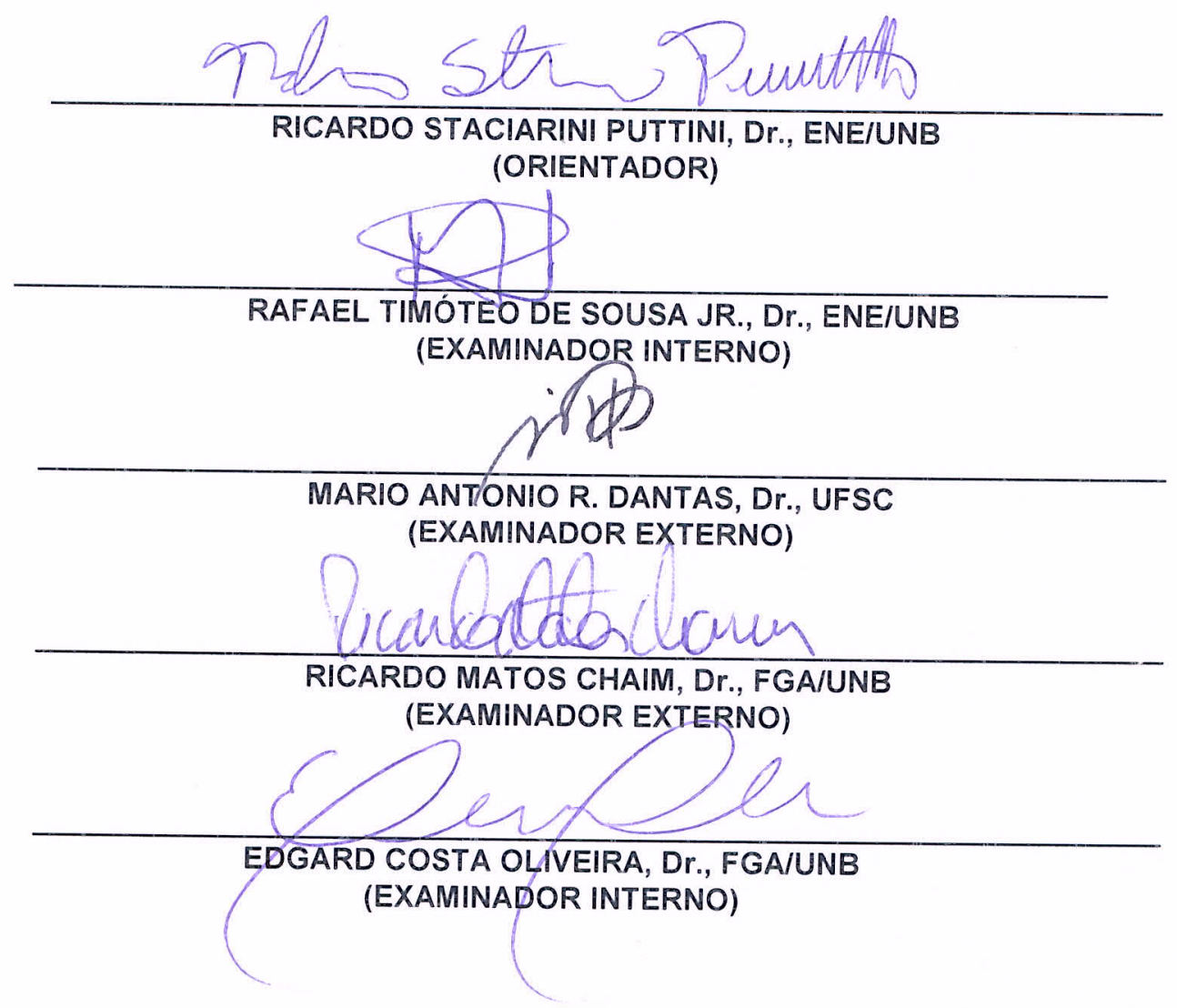

Brasilia, 29 de janeiro de 2015. 
FICHA CATALOGRÁFICA

MAZZAROLO, CLAYNOR F.

Um Modelo para Aferir o Nível de Maturidade na Adoção de SOA. [Distrito Federal] 2015. xv, 259p., 210 x 297mm (ENE/FT/UnB, Doutor, Tese de Doutorado Universidade de Brasília. Faculdade de Tecnologia).

Departamento de Engenharia Elétrica

1. Arquitetura Orientada a Serviços.

2. Modelo de Maturidade.

3. Aplicações Distribuídas

I. ENE/FT/UnB.

4. Avaliação e Monitoração.

II. Título (Série)

\section{REFERÊNCIA BIBLIOGRÁFICA}

MAZZAROLO, Claynor F. (2015). Um Modelo para Aferir o Nível de Maturidade na Adoção de SOA. Tese de Doutorado em Engenharia Elétrica, Publicação PPGEE.TD097/2015, Departamento de Engenharia Elétrica, Universidade de Brasília, Brasília, DF, 259p.

\section{CESSÃO DE DIREITOS}

AUTOR: Claynor Fernando Mazzarolo TÍTULO: UM MODELO PARA AFERIR O NÍVEL DE MATURIDADE NA ADOÇÃO DE SOA.

GRAU: Doutor

ANO: 2015

É concedida à Universidade de Brasília permissão para reproduzir cópias desta Tese de Doutorado e para emprestar ou vender tais cópias somente para propósitos acadêmicos e científicos. $\mathrm{O}$ autor reserva outros direitos de publicação e nenhuma parte desta tese de doutorado pode ser reproduzida sem a autorização por escrito do autor.

CLAYNOR FERNANDO MAZZAROLO

SIG Quadra 6 Lote 2150

70610-46, Brasília, DF, Brasil. 


\section{AGRADECIMENTOS}

Ao orientador e amigo Professor Ricardo Staciarini Puttini, pela orientação durante todo o período de elaboração desta tese, sempre com paciência, perseverança e confiante de que alcançaria meu objetivo.

Aos professores do Programa de Pós-Graduação em Engenharia Elétrica, que emprestaram sua paciência e repassaram ensinamentos que me envolveram e serviram de estímulo até aqui.

Aos meus pais, Arminio e Cleodes.

Ao meu filho, Adrian, pelo seu carinho.

À minha mulher, Sirlei, pelo apoio incondicional durante todo o tempo, sempre me dando coragem para seguir em frente e realizar este sonho.

Ao Instituto Brasília de Tecnologia e Inovação (IBTI) e sua equipe, pela motivação e apoio para o desenvolvimento desta tese.

Ao amigo Valério Aymoré Martins, pela sua disponibilidade e pela troca de conhecimentos sobre o tema.

Aos amigos que contribuíram com seus conhecimentos e pelo incentivo e participação.

À Universidade de Brasília, patrocinadora fundamental para a realização do projeto de pesquisa.

Agradeço a todos que, de forma direta ou indireta, torceram pelo meu sucesso neste trabalho. 
À minha mulher, Sirlei. 


\title{
RESUMO
}

\section{UM MODELO PARA AFERIR O NÍVEL DE MATURIDADE NA ADOÇÃO DE SOA}

\author{
Autor: Claynor Fernando Mazzarolo \\ Orientador: Ricardo Staciarini Puttini \\ Programa de Pós-graduação em Engenharia Elétrica \\ Brasília, janeiro de 2015.
}

Esta tese propõe um modelo para aferir e acompanhar a evolução do nível de maturidade na adoção de arquitetura orientada a serviços $(S O A)$ nas organizações. O modelo é concebido por parametrização de base de conhecimento de melhores práticas, visando suportar a avaliação, o planejamento e o acompanhamento da evolução da maturidade organizacional. Sua concepção estende significativamente o modelo The Open Group Service Integration Maturity Model (OSIMM), de modo a permitir o monitoramento direto dos objetivos estratégicos de SOA (agilidade, redução de custos, interoperabilidade, padronização e alinhamento entre negócio e tecnologia) e de suas práticas fundamentais (ciclo de vida de serviços e aplicação dos princípios de projeto). O modelo proposto está dividido em sete domínios (negócio, organização e governança, métodos e práticas, aplicações e arquitetura, informação, tecnologia e infraestrutura, operação e gerenciamento). A avaliação é realizada de modo qualitativo e quantitativo, com aplicação dos conceitos de avaliação de maturidade definidos pelo Capability Maturity Model Integration (CMMI), com classificação, por domínio, em cinco níveis (inicial, gerenciado, definido, gerenciado e otimizado). O modelo proposto se distingue do CMMI por focar práticas e especificidades de orientação a serviços e, também, a representação da maturidade foi concebida para diferenciar seu nível se em evolução ou estabilização. A aplicação do modelo foi suportada por uma solução de software que disponibiliza os questionários eletrônicos da base de conhecimento e realiza classificação de maturidade através de um método heurístico próprio. O modelo apresentado foi empregado em estudo de caso em uma organização no Brasil, de modo a demonstrar a sua aplicabilidade prática. 


\title{
ABSTRACT \\ A MODEL TO ASSESS THE MATURITY LEVEL IN SOA ADOPTION
}

\author{
Author: Claynor Fernando Mazzarolo \\ Supervisor: Ricardo Staciarini Puttini \\ Electric Engineering Graduate Program \\ Brasilia, January 2015
}

This thesis presents a model for maturity assessment using Service Oriented Architecture (SOA). The model is designed through the parameterization of best practices knowledge base in order to support the continued evaluation, planning and monitoring of the organizational maturity's evolution. Its concept significantly extends The Open Group Service Integration Maturity Model (OSIMM), allowing direct monitoring of SOA's strategic goals (agility, cost reduction, interoperability, standardization and alignment between business and technology) and its fundamental practices (services lifecycle and design principles). The proposed model is divided into seven domains (business, organization and governance, methods and practices, applications and architecture, information technology and infrastructure, operation and management). The evaluation is carried out qualitatively and quantitatively, applying maturity assessment concepts defined by the Capability Maturity Model Integration (CMMI) which are classified, per domain, in five levels (initial, managed, defined, managed and optimizing). The proposed model distinguishes itself from CMMI by focusing on service orientation's practices and specificities, and also on the maturity's representation - which was conceived in order to differentiate its level, whether in evolution or stabilization. The application of the model is supported by a software system that provides the knowledge base's electronic questionnaires and performs classification of maturity through its own heuristic method. In order to demonstrate its practical applicability, the presented model was employed in a case study within a Brazilian organization. 


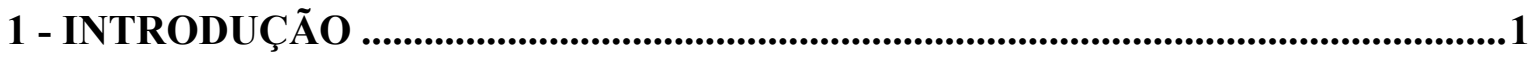

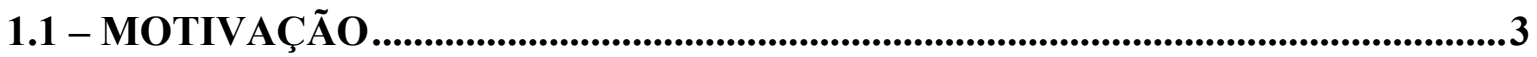

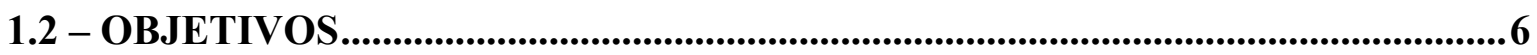

1.2.1 - Objetivo geral .................................................................................................................6

1.2.2 - Objetivos específicos ..............................................................................

1.2.3 - Benefícios esperados ...............................................................................

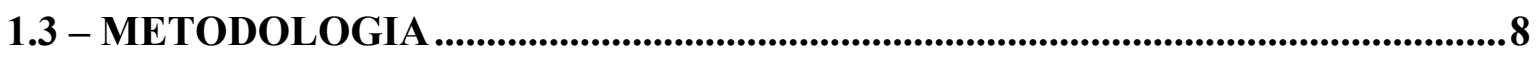

1.3.1 - $1^{\text {a }}$ Etapa - Revisão Bibliográfica e dos Modelos de Maturidade Existentes........9

1.3.2 - $2^{\mathrm{a}}$ Etapa - Definição da Estrutura Conceitual Básica: Domínios,

Controles e Itens de Avaliação..................................................................................................10

1.3.3 - $3^{\text {a }}$ Etapa - Estudo e Seleção dos Métodos Heurísticos e Quantitativos.....11

1.3.4 - $4^{\mathrm{a}}$ Etapa - Sistematização do Processo de Avaliação ...................................12

1.3.5 - 5 ${ }^{\mathrm{a}}$ Etapa - Realização de Estudo de Caso .....................................................13

1.4 - LIMITAÇÕES E RESTRIÇÕES DO ESTUDO..............................................15

1.5 - ORGANIZAÇÃO DO TRABALHO ..........................................................16

2 - CONCEITOS E FUNDAMENTAÇÃO TEÓRICA ...................................................17

2.1 - ARQUITETURA ORIENTADA A SERVIÇOS (SOA) ...................................17

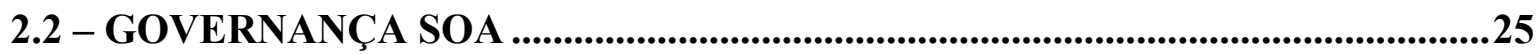

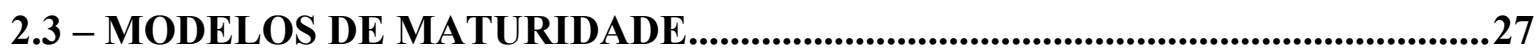

2.4 - USO DE QUESTIONÁRIOS ESTRUTURADOS ..............................................31

2.5 - METODOLOGIA PARA TOMADA DE DECISÃO A PARTIR DE

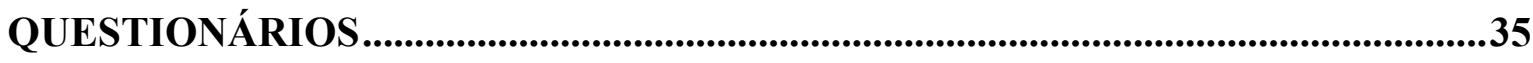

2.6 - AGREGAÇÃO DE CONTROLES EM DOMÍNIOS PELO EMPREGO DE MÉTODOS HEURÍSTICOS NA AVALIAÇÃO DE MATURIDADE .........................38 3 - INTERPRETAÇÃO DA PROPOSTA DOS MODELOS DE MATURIDADE

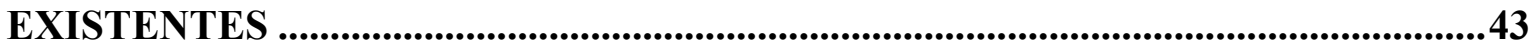


3.2 - MODELOS EXISTENTES PARA AVALIAÇÃO DE MATURIDADE SOA ...53

3.3 - HISTÓRICO DA MATURIDADE NA ADOÇÃO DE SOA .59

4 - PROPOSTA DE MODELO PARA AVALIAÇÃO DE MATURIDADE SOA ......61

4.1 - MODELO DE AVALIAÇÃO ............................................................................62

4.1.1 - Níveis de Maturidade...............................................................................64

4.1.2 - Domínios ................................................................................................68

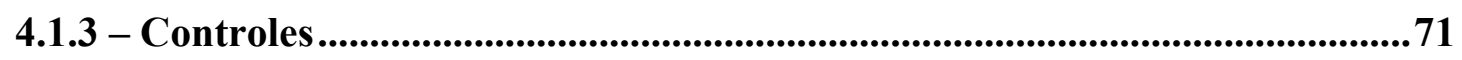

4.1.4 - Itens de avaliação: Questionários .................................................................76

4.2 - HEURÍSTICA DE AVALIAÇÃO ................................................................79

4.2.1 - Avaliação de Controles ....................................................................................79

4.2.2 - Avaliação de Nível de Maturidade de Domínios ..............................................80

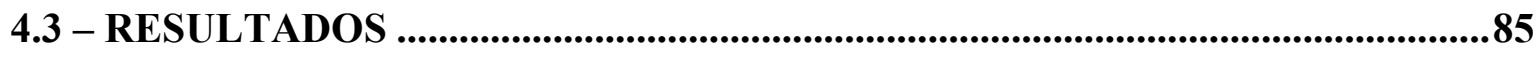

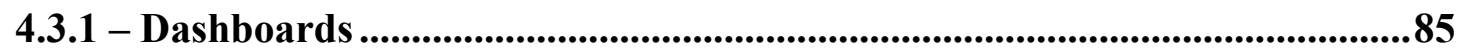

4.3.2 - Geração de Roteiros de Evolução ...................................................................89

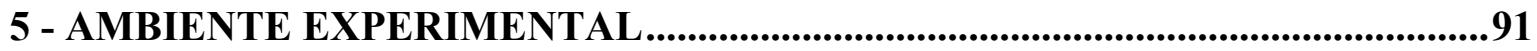

5.1 - PROCESSO DE AVALIAÇÃO......................................................................................91

5.1.1 - Coleta de Dados.......................................................................................................92

5.1.2 - Geração de Resultados e Análise ........................................................................92

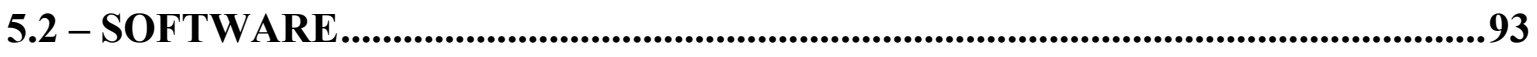

5.2.1 - Módulos do Sistema de Software ...........................................................................94

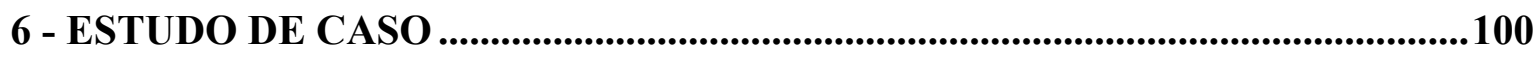

6.1 - DESCRIÇÃO DO ESTUDO DE CASO REALIZADO ......................................100

6.1.1 - Caracterização do Estudo de Caso .........................................................100

6.1.2 - Plano de adoção de SOA da instituição avaliada ..................................103

6.1.3 - Evolução da adoção de SOA e avaliações de maturidade realizadas......104 
6.2.1 - Coleta de dados ....................................................................................................107

6.2.2 - Heurística de avaliação .....................................................................................109

6.2.3 - Resultados e discussões.....................................................................................115

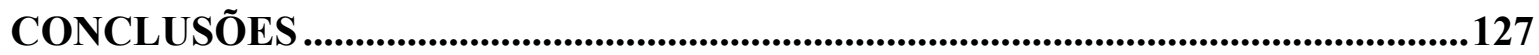

REFERÊNCIAS..............................................................................................................133

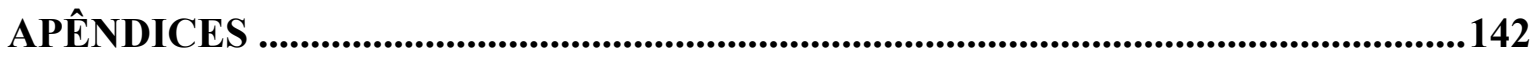

APÊNDICE A - COMPILAÇÃO DOS ASSUNTOS FUNDAMENTAIS

ANALISADOS EM CADA MODELO DE MATURIDADE DE SOA..........................143

APÊNDICE B - MODELO DOS QUESTIONÁRIOS PROPOSTOS POR

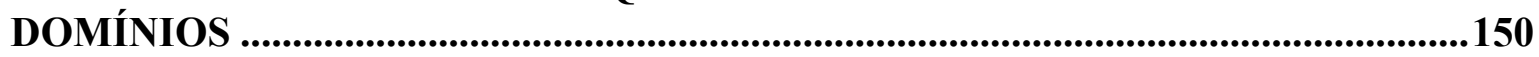

APÊNDICE C - RESULTADO DO ESTUDO DE USO DA ORGANIZAÇÃO

AVALIADA .....................................................................................................................199

APÊNDICE D - DOCUMENTAÇÃO DO PROJETO E DESENVOLVIMENTO DO

SOFTWARE ......................................................................................................210 


\section{LISTA DE QUADROS}

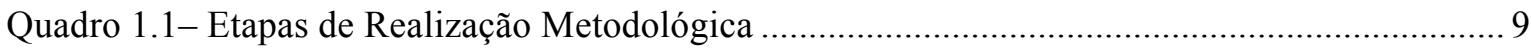

Quadro 3.1 - Compilação dos domínios dos frameworks estudados .................................................... 45

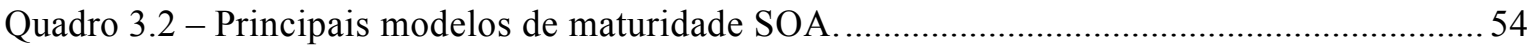

Quadro 3.3 - Inter-Relação percebida entre os níveis de maturidade utilizados por Framework para SOA 57

Quadro 4.1 - Níveis de Maturidade e seus Focos. 64

Quadro 4.2 - Níveis de Maturidade na Estabilização e na Evolução 67

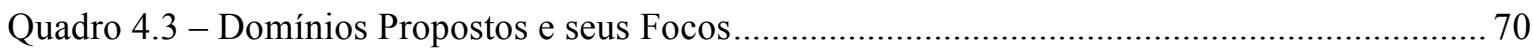

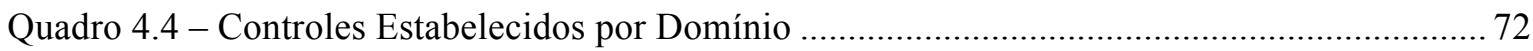

Quadro 4.5 - Extrato do Questionário de Avaliação ....................................................................... 78

Quadro 4.6 - Formação do Quadro de Distribuição de Frequências considerando seus Pesos .................. 81

Quadro 4.7 - Situações típicas reconhecidas pela heurística de avaliação de Domínios .................. 82

Quadro 4.8 - Situações representativas na valoração da maturidade entre Domínios ...................... 88

Quadro 5.1 - Perfis Organizacionais sugeridos para Preenchimento nos Domínios......................... 92

Quadro 6.1 - Distribuição de Frequência no Domínio D01 ……………………………….......... 115

Quadro 6.2 - Distribuição de Frequência no Domínio D02 …………………………………........ 116

Quadro 6.3 - Distribuição de Frequência no Domínio D03 ............................................................... 117

Quadro 6.4 - Distribuição de Frequência no Domínio D04 …………………………………....... 118

Quadro 6.5 - Distribuição de Frequência no Domínio D05 ……...................................................... 119

Quadro 6.6 - Distribuição de Frequência no Domínio D06 …………………………………........ 120

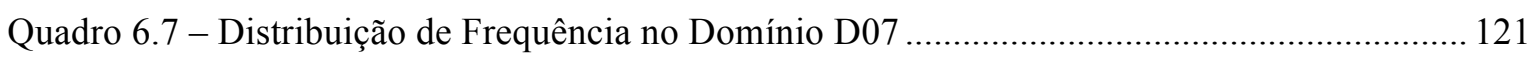

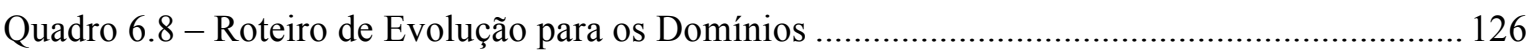




\section{LISTA DE FIGURAS}

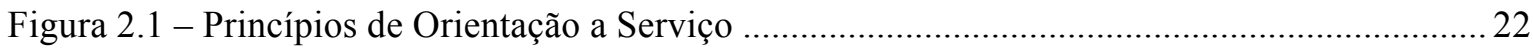

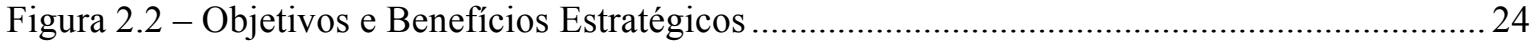

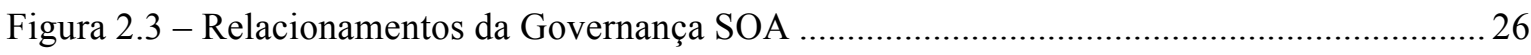

Figura 2.4 - Relação entre a Governança Corporativa, a de TI e a de SOA ….................................. 27

Figura 2.5 - Representação Contínua e em Estágios do CMMI v 1.3 ............................................... 30

Figura 2.6 - Distribuição de Frequência e Valores Atípicos ............................................................... 42

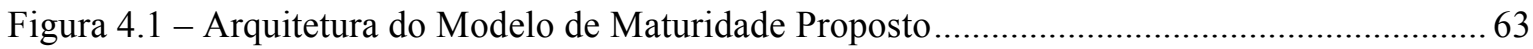

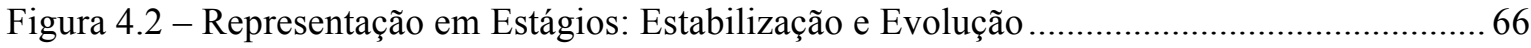

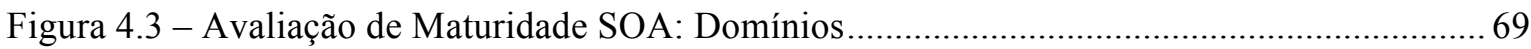

Figura 4.4 - Heurística de Avaliação da Maturidade do Domínio ...................................................... 84

Figura 4.5 - Exemplo de Gráfico de Barras para indicar Nível de Maturidade Atingido em cada

Controle de um Domínio, em três avaliações distintas (2/12/2011, 17/9/2014 e 10/6/2014).. 85

Figura 4.6 - Exemplo de Gráfico em Radar para indicar de Nível de Maturidade Atingido em cada Domínio 86

Figura 4.7 - Exemplo de Gráfico em Radar para indicar de Nível de Maturidade Atingido em comparação com o Nível de Maturidade Almejado. 86

Figura 4.8 - Exemplo de Gráfico de Barras para indicar Nível de Maturidade Atingido em

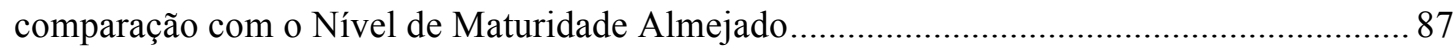

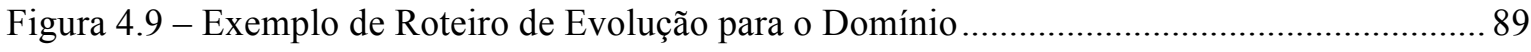

Figura 5.1 - Processo de Avaliação e Maturidade Proposto ............................................................ 91

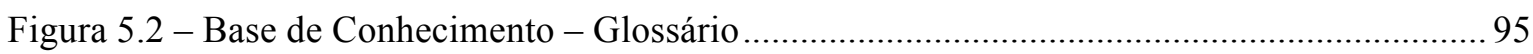

Figura 5.3 - Exemplo das Abas dos Questionários Estruturados ....................................................... 96

Figura 5.4 - Exemplo de Distribuição de Frequência e Heurística ..................................................... 96

Figura 5.5 - Exemplo de Gráficos: Nível Atual e Nível Almejado.................................................. 97

Figura 5.6 - Exemplo de Gráfico Domínios e Controles .................................................................. 98

Figura 5.7 - Exemplo de Gráfico: Evolução no Tempo - Domínios ................................................. 98

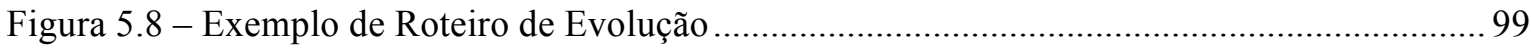

Figura 6.1 - Agregação de Valores de Itens de Avaliação para o Controle ........................................ 111

Figura 6.2 - Histograma de Frequência para uma situação ESTÁVEL ........................................ 112

Figura 6.3 - Histograma de Frequência para uma situação de DESORDEM ................................. 112

Figura 6.4 - Eliminação de valores atípicos a maior ........................................................................ 113

Figura 6.5 - Histograma de Frequência para uma situação de EXCEÇÃO ..................................... 113

Figura 6.6 - Histograma de Frequência para uma situação (EM) EVOLUÇÃO ............................. 114

Figura 6.7 - Histograma de Frequência para uma situação (EM) ESTABILIZAÇÃO................... 114 
Figura 6.8 - Representação em Estágios e Nível de Maturidade Atual e Almejado 115

Figura 6.9 - Histograma da distribuição nos anos 2011, 2012 e 2014 para o domínio D01 116

Figura 6.10 - Histograma da distribuição nos anos 2011, 2012 e 2014 para o domínio D02 117

Figura 6.11 - Histograma da distribuição nos anos 2011, 2012 e 2014 para o domínio D03 ........ 118

Figura 6.12 - Histograma da distribuição nos anos 2011, 2012 e 2014 para o domínio D04 ........ 118

Figura 6.13 - Histograma da distribuição nos anos 2011, 2012 e 2014 para o domínio D05 ........ 119

Figura 6.14 - Histograma da distribuição nos anos 2011, 2012 e 2014 para o domínio D06 ........ 120

Figura 6.15 - Histograma da distribuição nos anos 2011, 2012 e 2014 para o domínio D07 ........ 121

Figura 6.16 - Modelo de Maturidade - Avaliação Ciclo 2/12/2011 …………………………....... 122

Figura 6.17 - Modelo de Maturidade - Avaliação Ciclo 17/9/2012 …........................................... 122

Figura 6.18 - Modelo de Maturidade - Avaliação Ciclo 10/6/2014 …………………………....... 123

Figura 6.19 - Evolução dos Controles do Domínio Informações e Modelos de Dados D05 .......... 123

Figura 6.20 - Evolução dos Controles do Domínio Métodos e Práticas D03 .................................. 124

Figura 6.21 - Evolução do nível de Maturidade dos Domínios ....................................................... 124 


\section{LISTA DE SÍMBOLOS, NOMENCLATURA E ABREVIAÇÕES}

BAM

Business Activities Monitoring - Monitoramento das Atividades de Negócios, elemento sistêmico e arquitetural disponibilizado pelas plataformas modernas de SOA que provê informações básicas sobre as atividades de serviço envolvidas.

CADSUS Sistema de Cadastramento de Usuários do SUS.

CMM

Capability Maturity Model.

CMMI

Capability Maturity Model Integration.

CNS

CNES

Projeto Cartão Nacional de Saúde.

COBIT

Cadastro Nacional de Estabelecimentos de Saúde.

COSO

Control Objectives for Information and Related Technologies.

EA

Committee of Sponsoring Organizations of the Treadway Commission.

FUB

Governança da Arquitetura Empresarial.

GRC

Fundação Universidade de Brasília

IBM

Governance, Risk and Compliance.

IC/ICT CMF

International Business Machines.

ISO

Management Capability Maturity Framework.

ITGI

International Organization for Standardization.

ITIL

IT Governance Institute.

MS

NSOAMM

Information Technology Infrastructure Library.

Ministério da Saúde

OASIS

New Service-Oriented Architecture (SOA) Maturity Model.

Organização para o Avanço na Padronização de Informações

Estruturadas - Organization for the Advancement of Structured Information Standards - Organização voltada à definição de padrões e processos para Tecnologia da Informação.

OGC

Office for Government Commerce.

OSIMM

The Open Group Service Integration Maturity Model.

PDCA

Planejamento, Execução, Verificação e Controle.

RES

Projeto do Registro Eletrônico de Saúde.

SOA

Service Oriented Architecture - Arquitetura Orientada a Serviços. 

Objetos.

SOC Service Oriented Computing.

SOMM Service-Orientation Maturity Model.

TI Tecnologia da Informação.

UnB Universidade de Brasília.

W3C World Wide Web Consortium - Comunidade internacional onde as organizações-membros, funcionários de tempo integral, e agentes de setores públicos trabalham juntos para desenvolver padrões para Web (Web standards).

XML Extensible Markup Language - Linguagem de marcação extensível. 


\section{1 - INTRODUÇÃO}

Arquitetura Orientada a Serviços (SOA - Service Oriented Architecture) é entendida como um modelo que busca maximizar a integração dos processos de negócios com a infraestrutura de recursos de Tecnologia da Informação (TI), na forma de componentes seguros e padronizados - usualmente webservices - que podem ser reutilizados e combinados para dar agilidade às rápidas mudanças de prioridades do negócio (BIEBERSTEIN, 2005).

Presente nas discussões de TI desde os anos 80, foi a partir de uma revisão, em 2005, que SOA obteve coerência estrutural quando Erl (ERL, 2005) fundamentou sua aplicação por meio de princípios que estabelecem o entendimento de "orientação a serviços".

Esses princípios alinham os objetivos estratégicos do negócio com a contínua aplicação de tecnologia e suas melhorias, estimulado pela existência de unidades individuais autônomas que realizam contextos funcionais únicos e podem ser agrupadas na forma de composições para a realização de tarefas complexas, até a execução de todos os processos de negócio.

Assim, o sucesso na adoção e uso de SOA está relacionado à transferência das capacidades de TI para os processos de negócio. Porém, para que essa transferência seja assertiva, é necessário acompanhar e mensurar a melhoria de desempenho dos processos que seus serviços atendem (JANIESCH et al. 2009). Nesse sentido, a adoção dessa arquitetura deve ser conduzida por meio de atividades governadas e mensuradas, (JANIESCH et al., 2009; JOSUTTIS, 2007; MARKS, 2008) com o propósito claro de se obter o máximo retorno dos investimentos.

Para governar e mensurar as atividades relacionadas às práticas de determinada competência, modelos de maturidade são ferramentas úteis. Os modelos de maturidade são apresentados na forma de frameworks, utilizados como referência para a comparação dos processos de uma organização contra um conjunto claro de benchmark externos. Becker et al. (2009) apontam que Modelos de Maturidade são valiosos instrumentos de gestão, pois permitem avaliar como está a situação de uma empresa, bem como identificar medidas de melhoria e, posteriormente, controlar o andamento de sua implementação. Manes (2007) também 
reafirma essa necessidade de mensuração na efetiva adoção de SOA, pois "métricas proporcionam visibilidade e comprovam a execução da política de SOA", e que a organização "deve estabelecer essa cultura, que suporta os processos de governança".

É importante salientar que modelos orientados a controles, como o Capability Maturity Model Integration (CMMI) (CARNEGIE MELON SOFTWARE ENGINEERING INSTITUTE, 2006) e o Control Objectives for Information and Related Technologies (COBIT) (ISACA, 2012) tornaram-se referência para as organizações de TI e os modelos associados estabeleceram um padrão de fato. Todavia, observou-se que os modelos de maturidade disponíveis apresentavam carências em relação às características próprias e distintas práticas de engenharia de software de SOA.

Seguindo prática consolidada na indústria de TI, este trabalho propõe um modelo para avaliar a maturidade organizacional da aplicação de SOA, baseado em controles organizados em domínios. Para facilitar a compreensão das terminologias utilizadas ao longo do trabalho, entende-se por:

\footnotetext{
Domínios: Representam as áreas de conhecimento organizacional. Esta definição permite classificar e organizar as práticas de SOA e seus efeitos. Os domínios são os conjuntos que permitem avaliar de forma eficaz todos os aspectos de adoção ou uso de SOA, segundo as visões organizacionais (HP, 2006).

Controle: É um conjunto de procedimentos pelo qual o resultado de determinada prática é medido, comparando-o com um valor almejado, atuando no mesmo de forma a aperfeicoá-lo, novamente medindo o resultado e assim sucessivamente (HP, 2006).
}

O propósito é estabelecer um modelo de maturidade para a aplicação e a integração dos componentes que suportam os princípios de orientação a serviços, de modo semelhante ao modelo aplicado pelo COBIT (ISACA, 2012).

Para tornar concreto o entendimento da situação em uma organização e identificar medidas de melhoria, adota-se uma escala que representa o nível de maturidade. Para cada nível de maturidade, é definido um conjunto de práticas que devem ser executadas e que indicam o patamar a ser atingido pela organização na adoção de SOA.

O modelo proposto é aplicado nas organizações por meio de questionários estruturados e organizados por domínios. Um conjunto de heurísticas é então aplicado de modo a valorar 
os controles, comparando-os com um valor almejado e o nível de maturidade expresso de forma quantitativa. Como resultado da aplicação do modelo, cada domínio tem seu nível de maturidade indicado. O resultado permite avaliar a situação presente na organização, bem como sugerir roteiros de evolução para aperfeiçoar as práticas e assim atingir níveis mais elevados de maturidade.

Assim, o modelo proposto neste trabalho busca assegurar um arquétipo que permita estruturar a estratégia de análise de capacidade em cada domínio organizacional por meio de controles.

Entende-se que o desafio a ser superado ao propor um modelo de maturidade baseado em controles para SOA está em identificá-los e em sistematizar a avaliação desses controles.

Para endereçar o rol de controles a ser utilizado no modelo, foram observados os aspectos relevantes encontrados no referencial teórico, na interpretação dos modelos de maturidade disponíveis (APÊNDICE A) e, principalmente, no enquadramento dos controles dentro de cada domínio.

A conceituação e o contexto da problemática do trabalho abordam desafios na adoção de uma arquitetura evolutiva, a qual requer processos específicos de desenvolvimento, o uso de tecnologia apropriada e capital humano devidamente capaz. O pressuposto é que o emprego de controles - definidos pelas melhores práticas -, ordenados através de domínios - áreas de conhecimento da organização -, avaliados com o uso de indicadores que interpretem seus resultados, possibilitam administrar e gerenciar a adoção de SOA em estágios progressivos de evolução.

\section{$1.1-\operatorname{MOTIVAÇ\tilde {AO}}$}

Modelos de maturidade específicos para SOA se tornaram essenciais, pois modelos como o CMMI não são capazes de endereçar todas as especificidades da arquitetura. SOA tem características próprias e distintas práticas de implementação.

Os modelos de maturidade, como o The Open Group Service Integration Maturity Model (OSIMM) (THE OPEN GROUP, 2011), desenvolvido por profissionais vinculados a um 
consórcio de organizações que assumiu e evoluiu o modelo de maturidade da empresa IBM (2005), e o New Service-Oriented Architecture Maturity Model (NSOAMM) (2005), criado através da cooperação de empresas líderes na indústria de SOA: Sonic Software, Amber Point, Systinet e Bearing Point são exemplos de iniciativas desenvolvidas para comparar as semelhanças ou disparidades das melhores práticas nas organizações, que passou a existir com a introdução dessa arquitetura tecnológica.

Posteriormente, em uma iniciativa de Thomas Erl e do Software Engineering Institute, da Carnegie Melon University, foi constituído um grupo de trabalho para criar um modelo de maturidade denominado Service-Orientation Maturity Model (SOMM) (APQC, 2011), com as premissas de ser imparcial do ponto de vista de fornecedores ou tecnologia. Esse grupo se reuniu durante a realização do $4^{\text {th }}$ International SOA Symposium, em Brasília, no dia 27 de abril de 2011, ocasião em que foi apresentado o SOMM Program Charter.

A missão do Grupo de Trabalho SOMM era criar um roteiro de atividades, mudanças relacionadas às melhores práticas que conduzem a um estado futuro almejado. $\mathrm{O}$ modelo previa definir as características de maturidade que a organização espera atingir em cada etapa da jornada, com entendimento, linguagem comum e visão compartilhada.

A proposta do projeto era um modelo imparcial do ponto de vista de fornecedores e tecnologia, que fosse um modelo de maturidade de facto. O SOMM pretendia ajudar as organizações a medir objetivamente os níveis atuais de maturidade e fornecer orientações práticas para os processos em curso, com adoções bem sucedidas para sustentação de SOA e orientação a serviços.

Essa iniciativa foi descontinuada pelos seus patrocinadores, mas a pesquisa iniciada nos trabalhos deste charter indicava a ausência de um modelo de avaliação de maturidade objetivo, compatível e comparável com modelos clássicos existentes (e. g. CMMI e COBIT). A proposição preliminar desenvolvida pelo grupo foi adotada pelo modelo ora proposto.

No planejamento e preparação do referido simpósio houve a percepção de que não haviam informações disponíveis sobre o estágio de adoção de SOA no Brasil. Mediante essa constatação, foram analisadas surveys sobre adoção de SOA em outros países. Essas análises forneceram a base para se conduzir um estudo similar com relação à situação de 
adoção da arquitetura no Brasil; para tanto, organizou-se uma sondagem junto a organizações brasileiras (MAZZAROLO et al., 2014).

Essa sondagem foi realizada mediante uma abordagem baseada em questionários publicados na internet, de forma a permitir livre acesso aos possíveis interessados. Como SOA tem um foco estratégico, optou-se por orientar o preenchimento da pesquisa por representantes da área de negócio, auxiliados ou não pela área de TI. Além disso, respeitando os diferentes níveis de maturidade das organizações, foram disponibilizados questionários adequados a essa realidade. Assim, foram disponibilizadas duas versões de questionários a ser respondidos: a) o primeiro questionário foi direcionado para as organizações que se consideram como um caso de uso em SOA; b) o segundo questionário, uma versão simplificada do primeiro, constituiu-se de questões aplicáveis às organizações que não possuíam iniciativa em SOA, mas que planejavam a adoção dessa arquitetura, ou, então, de organizações que possuíam algum projeto iniciado, mas que, naquele momento, conseguiam perceber baixo nível de benefícios.

Na interpretação dos resultados da pesquisa realizada sobre a adoção de SOA no Brasil, um dos cenários identificados foi que as organizações no País não estavam conscientizadas com a natureza estratégica de SOA, ou seja, a obtenção de benefícios como resultado da conquista de maturidade em um período mais longo de tempo (MAZZAROLO et al., 2014).

As iniciativas existentes e sua aplicação na prática concreta de SOA, especialmente a participação no charter do SOMM, e a condução de uma pesquisa em nível nacional para analisar a adoção de SOA no Brasil contribuíram para identificar a problemática do trabalho.

Nesse contexto, o modelo proposto neste trabalho para aferir o nível de maturidade na adoção de SOA representa uma extensão significativa dos modelos existentes - apresentados de forma detalhada no capítulo 3 deste estudo - (IBM, 2005; SONIC, 2005; BEA, 2006; HP, 2006; ACCENTURE, 2007; MICROSOFT, 2007; ORACLE, 2007; GARTNER, 2009; THE OPEN GROUP, 2011; ITANA, 2013). 
Nesses modelos, percebe-se a disparidade na definição de domínios, controles, e da escala de níveis utilizada nos modelos de maturidade na prática de adoção de SOA. Nota-se também a tendência de priorizar as áreas de tecnologias e operações, com significativo prejuízo ao atendimento das áreas de negócios.

Como SOA "é um processo distribuído espacialmente e temporalmente" (MARKS; BELL, 2006), esta tese propõem uma revisão no conceito de representação de maturidade em SOA. A representação pode ser em Evolução: quando uma melhoria está sendo conduzida para atingir um nível maior de maturidade em determinado domínio; ou em Estabilização: quando a organização está empenhada em estabilizar um nível de maturidade antecipadamente planejado.

Desse modo, para empregar as características propostas, o modelo oferece a construção dinâmica de roteiros de referência (roadmaps) associados aos níveis de maturidade - evolução e/ou estabilização -, realçando os pontos fortes e fracos existentes em relação a um nível de maturidade projetado e apontando as ações necessárias para corrigir as inconformidade identificadas.

Assim, o modelo proposto, organizado de forma hierárquica por domínios e controles, apresenta-se como uma solução para avaliar o resultado da correta e integrada adoção de SOA em seus estágios e sua evolução na escala de maturidade (MAZZAROLO et al., 2015).

\section{2 - OBJETIVOS}

\subsection{1 - Objetivo geral}

Esta tese apresenta um modelo para avaliar a maturidade organizacional na adoção de Arquitetura Orientada a Serviços (SOA). A proposta está em conformidade com o método PDCA (plan-do-check-act) para melhoria de processos, através de ciclos de planejamento, execução, monitoramento e transformação. A avaliação dá-se a partir da verificação da situação informada em relação às melhores práticas de SOA, sendo o resultado obtido o nível de maturidade indicado. Desse resultado, infere-se a evolução esperada, expressa através de roteiros de ações a serem executadas para atingir o nível de maturidade projetado. 
Assim, o objetivo desta tese é:

- Propor um modelo para aferir e acompanhar a evolução do nível de maturidade na adoção de arquitetura orientada a serviços (SOA) nas organizações.

\subsection{2 - Objetivos específicos}

- Avaliar a fundamentação teórica e interpretar propostas dos modelos de maturidade existentes;

- Desenvolver Base de Conhecimento composta das boas práticas conhecidas, dos princípios da arquitetura, do modelo proposto com seus domínios e controles, de questionários de avaliação e glossário;

- Propor um modelo de avaliação de maturidade como extensão significativa dos modelos existentes, organizado de forma hierárquica por domínios, controles e itens de avaliação.

- Desenvolver ambiente experimental, com a aplicação do processo de avaliação e software; e

- Demonstrar a aplicabilidade do modelo proposto em estudo de caso único.

\subsection{3 - Benefícios esperados}

- Suportar metodologicamente o processo de avaliação do nível de maturidade da adoção de SOA, com roteiro que permita dirigir a evolução na adoção dessa arquitetura;

- Garantir mecanismos para que as organizações suportem as atividades da adoção de SOA na evolução de seus sistemas arquiteturais de forma correta e adequada;

- Permitir a visão holística sobre a execução da estratégia da adoção de SOA; 
- Formar e disponibilizar uma base de conhecimento inicial, que suporte o modelo de avaliação de maturidade SOA com facilidades incrementais, o que permite o uso em estudos futuros;

- Sistematizar um modelo que reduza a complexidade e as dificuldades na adoção de SOA, e dar transparência e flexibilidade no uso dessa arquitetura pelas organizações; e

- Facilitar a elaboração de projetos SOA, oferecendo suporte às análises de impacto e de ciclo de vida dos serviços.

\section{3 - METODOLOGIA}

O método desenvolvido neste trabalho é de natureza aplicada, com uma abordagem qualitativa e descritiva do problema. Do ponto de vista dos objetivos, trata-se de uma pesquisa exploratória, que tem como principal finalidade desenvolver, esclarecer e modificar conceitos e ideias, tendo em vista a formulação de problemas mais precisos (GIL, 2008).

Assim, a pesquisa exploratória envolve levantamento bibliográfico e documental, entrevistas não estruturadas e estudo de caso. Esse tipo de pesquisa é realizado especialmente quando o tema escolhido é pouco explorado e torna-se difícil sobre ele formular hipóteses precisas e operacionalizáveis.

Muitas vezes, as pesquisas exploratórias constituem a primeira etapa de uma investigação mais ampla. Quando o tema escolhido é bastante genérico, tornam-se necessários seu esclarecimento e delimitação, o que exige revisão da literatura, discussão com especialistas e outros procedimentos. O produto final desse processo passa a ser um problema mais esclarecido, passível de investigação mediante procedimentos mais sistematizados.

Para demonstrar a aplicabilidade e viabilidade do modelo proposto, foi adotada a abordagem de estudo de caso único com enfoque holístico, o que permitiu compreender as habilidades da organização na sua totalidade e não como uma coleção de partes. Segundo Schramm (1971 apud YIN, 2001), "a essência de um estudo de caso, a principal tendência em todos os tipos de estudo de caso, é que ela tenta esclarecer uma decisão ou um conjunto de decisões: o 
motivo pelo qual foram tomadas, como foram implementadas e com quais resultados".

A formação do conhecimento que dá bases para a elaboração do modelo de solução proposto neste estudo foi desenvolvido a partir de cinco etapas, resumidas no Quadro 1.1 e detalhadas a seguir.

Quadro 1.1- Etapas de Realização Metodológica

\begin{tabular}{|l|l|}
\hline \multirow{4}{*}{$\begin{array}{l}\text { 1-a ETAPA } \\
\text { Revisão }\end{array}$} & $\begin{array}{l}\text { 2- Etapa } \\
\text { Definição da Estrutura Conceitual Básica: Domínios, Controles e } \\
\text { Bibliográfica e dos } \\
\text { Itens de Avaliação }\end{array}$ \\
\cline { 2 - 2 } $\begin{array}{l}\text { Modelos de } \\
\text { Maturidade }\end{array}$ & $\begin{array}{l}\text { Etapa } \\
\text { Extudo e Seleção dos Métodos Heurísticos e Quantitativos }\end{array}$ \\
\cline { 2 - 2 } & $\begin{array}{l}4^{\text {a }} \text { Etapa } \\
\text { Sistematização do Processo de Avaliação }\end{array}$ \\
\cline { 2 - 2 } & $\begin{array}{l}5^{\text {a }} \text { Etapa } \\
\text { Realização de Estudo de Caso }\end{array}$ \\
\hline
\end{tabular}

\subsection{1 - 1ª Etapa - Revisão Bibliográfica e dos Modelos de Maturidade Existentes}

A primeira etapa teve o propósito de identificar as práticas essenciais e a sua organização lógica e sistematização. Isso permitiu a identificação de fontes candidatas para domínios e controles no modelo proposto.

Essa etapa envolveu a identificação das fontes sobre o tema de arquitetura orientada a serviços; dos modelos de governança organizacional e de tecnologia de informação; gerenciamento de riscos; conformidade; dos modelos de maturidade em tecnologias e processos em geral. Assim, a presente pesquisa se inicia por essa revisão bibliográfica e pelos modelos de maturidade existentes, de forma a estruturar a lógica do trabalho.

Durante a revisão bibliográfica realizada esteve-se atento aos fundamentos utilizados pelos demais trabalhos de referência e aos assuntos que apareceram em mais de uma ocasião. Como exemplo, foram conhecidas visões distintas para organizar os controles em dimensões ou domínios, apresentados frequentemente como o elemento de maior importância a ser quantificado, no qual o modelo está baseado.

Assim, foi possível capturar essa construção no modelo proposto. Ressalte-se que a característica recorrente desta pesquisa e a revisão da bibliografia existente continuam durante todo o processo de construção até o término do estudo. 
No que se refere à interpretação dos modelos de maturidade existentes, foram estudadas contribuições de institutos tecnológicos (CMMI), associações profissionais (OSIMM) e da indústria de TI, tanto proposições de modelos de maturidade como modelos voltados a governança de TI e SOA (LUFTMAN, 2013; WEILL; ROSS, 2004; BIEBERSTEIN et al., 2005; BRAUER; KLINE, 2013; IBM, 2006; BEA, 2006; ORACLE, 2007; HP 2006; GARTNER, 2009).

A primeira etapa está apresentada nos Capítulos 2 e 3 do presente trabalho.

\subsection{2 - 2ª Etapa - Definição da Estrutura Conceitual Básica: Domínios, Controles e Itens de Avaliação}

Esta etapa consistiu na consolidação dos conhecimentos obtidos na revisão do referencial teórico e na interpretação das propostas dos modelos de maturidade existentes, que contribuíram para identificar as áreas de conhecimento organizacionais em que a aplicação das práticas de SOA ocorrem e servem de parâmetro para a proposta do modelo ora apresentado.

O propósito, nessa etapa, foi sistematizar a base de conhecimento dos controles (práticas), organizá-los em domínios e verificar se oferecem um conjunto completo e consistente de critérios para a avaliação do uso de melhores práticas de SOA, bem como estruturar o rampa de evolução que oriente atividades relacionadas às melhores práticas para um incremento no nível de maturidade.

Nessa etapa, foi adotada técnica de entrevistas e oficinas com grupo focal (GIL, 2008) para complementar a base de conhecimento, definir a estrutura conceitual básica do modelo e sua composição por meio do compartilhamento de experiências vivenciadas na condução de projetos.

Nas oficinas realizadas com o grupo focal foi utilizada a técnica de coleta de dados de uma pesquisa qualitativa, a partir de experiências acadêmicas e profissionais dos membros. Esse grupo, como técnica de pesquisa, utilizou sessões de discussão de tópicos relacionados ao trabalho, debatidos entre os participantes para atualizar e construir novos conceitos. 
O grupo focal foi composto por profissionais doutores, mestres e pós-graduados, com larga experiência no uso de SOA, que participaram de forma voluntária nas oficinas. É importante destacar que além das titulações acadêmicas os membros do grupo possuem certificados nas seguintes habilidades: Arquiteto SOA; Analista SOA; Consultor SOA; Especialista em Segurança de SOA; Especialista em Governança SOA.

O grupo realizou diversos encontros, que proporcionaram aos participantes uma imersão no tema proposto. $\mathrm{O}$ objetivo principal dessas oficinas foi identificar, interpretar, sugerir, propor e organizar as práticas reconhecidas de SOA em domínios e seus controles e, assim, povoar a base de conhecimento.

Essa etapa está apresentada no Capítulo 4 deste estudo. Em especial, o Capítulo 4 e os APÊNDICES A e B apresentam as fontes para as estruturas conceituais e a base de conhecimento do modelo proposto, de modo a demonstrar a forma como foi compilada.

\subsection{3 - 3ª Etapa - Estudo e Seleção dos Métodos Heurísticos e Quantitativos}

Nessa etapa, foram avaliados e escolhidos os métodos heurísticos quantitativos para a obtenção dos valores indicativos de maturidade. A problemática consistiu na agregação sucessiva e quantificada dos itens de avaliação com o uso de questionários estruturados, para avaliar os elementos quantificáveis do modelo: os controles, e, finalmente, indicar o nível de maturidade dos domínios.

Foram avaliados, especialmente, os algoritmos derivados da teoria de tomada de decisão sob incerteza: Critério Maximax ou Critério de Otimismo; Critério Maximin ou Critério de Pessimismo; Critério de Hurwicz ou Critério de Realismo; Critério Minimax ou Critério de Regressão; e Critério de Laplace ou Critério de Racionalidade (LISBOA, 2002).

Teve-se, então, como resultado dessa etapa, um modelo matemático configurável, como um sistema construído a partir dos elementos estruturais do modelo de menor granularidade de avaliação (itens de avaliação), agregados por controles que, por sua vez, foram agregados por domínio; esses representando a maior granularidade para avaliação quantitativa dos níveis de maturidade. Cada elemento do modelo, item de 
avaliação, controle, domínio e organização foi carregado em base de conhecimento. Essa base é utilizada no fluxo de avaliação heurístico.

Essa etapa também está apresentada no Capítulo 4 do presente trabalho.

\subsection{4 - 4- Etapa - Sistematização do Processo de Avaliação}

A construção do sistema do processo de avaliação foi sustentado pelo referencial teórico e pela interpretação dos modelos existentes. Nessa fase, identificaram-se as formas de aferir as melhores práticas de adoção de SOA pela organização em relação a indicadores de referência de maturidade, concluindo-se por adotar um modelo de natureza comparativa, suportado por questionários estruturados. Nesse sentido, o processo de avaliação foi planejado e estruturado para ser executado em passos com tarefas claras e distintas.

A aplicação do modelo foi efetuada de forma sequencial. Foram identificados os seguintes passos, a serem estruturados: (1) Coleta de Dados - através da aplicação dos questionários estruturados; (2) Valoração de Maturidade por Controles e Domínios - pela aplicação de um conjunto de Heurísticas de Avaliação; (3) Geração de Resultados - indica a representação dos resultados da avaliação de modo adequado para interpretação e análise; e (4) Geração de Roteiro de Referência (roadmap) - associado ao nível de maturidade de evolução e/ou estabilização projetado.

Essa etapa contemplou ainda o desenvolvimento de um software especialista para sistematização do processo de avaliação. Esse sistema foi desenvolvido em uma única iteração aplicada segundo uma metodologia clássica em cascata. No APÊNDICE D é apresentada a documentação referente aos processos de projeto e desenvolvimento do sistema, composta por:

- documento de visão - que dá descrição básica da fase de iniciação na concepção do sistema;

- documento de requisitos - resultante da aplicação de técnicas de engenharia de requisitos, tais como listas de requisitos funcionais e não-funcionais, bem como de sua matriz de rastreabilidade; 
- documento de projeto - no que se refere à descrição das camadas arquiteturais do modelo cliente-servidor utilizado;

- documento de análise de dados e sua persistência - através de um Modelo de EntidadeRelacionamento Conceitual e sua devida expressão Relacional (normalizada);

- $\quad$ arquitetura de software - visão estática do sistema através de Casos de Uso e seus diagramas; e dinâmica, através de técnicas de BPM dos macroprocessos e diagramas de sequência internos dos procedimentos sistêmicos.

Em relação à fase de testes, cabe relatar que os mesmos foram executados através da própria realização dos processos sistêmicos em estudo de caso, apoiada por validações matemáticas e suas interpretações realizadas à parte, como descrito na Capítulo 6 deste trabalho.

Uma visão básica das saídas sistêmicas é apresentada na seção 4.2.3 deste documento, na forma de representação diagramática do tipo radar e roteiro de evolução de melhorias sugeridas.

Por fim, destaca-se da visão dinâmica do sistema que seu detalhe essencial, o fluxo de tomada de decisão, é apresentado na Figura 4.3.

A implementação do software deve prover questionários na forma de formulários acessados via $w e b$, a base de conhecimento com matrizes de controles $\mathrm{x}$ domínios x níveis, um modelo de pontuação ponderada, um conjunto de ferramentas compostas por módulos de atualização e saídas na forma de representação diagramática do tipo radar e roteiro de evolução de melhorias sugeridas.

Essa etapa se encontra no Capítulo 5 deste estudo.

\subsection{5 - 5 ${ }^{\text {a }}$ Etapa - Realização de Estudo de Caso}

Após a sistematização do processo de avaliação e o desenvolvimento do software, iniciou-se o processo de validação do modelo. Devido à natureza exploratória da pesquisa, uma 
validação de natureza quantitativa se mostrou inviável. De fato, a complexidade do processo de aplicação da avaliação e a dificuldade de se obter adesão de organizações dispostas a responder os questionários e participar da pesquisa representaram restrições importantes nesse modelo. Outro aspecto relevante para a validação do modelo consistiu na aplicação sucessiva da avaliação, em uma mesma organização, mas em momentos distintos.

O objetivo foi verificar a capacidade do modelo proposto em acompanhar a evolução da maturidade organizacional, ao longo do tempo. Esse aspecto tornou a avaliação do modelo ainda mais difícil, pois além de conseguir a adesão de organizações dispostas a participar da pesquisa, essa adesão deveria ser duradoura e estender-se por longos períodos, já que a evolução de maturidade só é perceptível após trabalho continuado e consistente na organização, que leva meses ou mesmo anos para apresentar resultados. Por último, mas não menos relevante, tem-se o fato de que o modelo proposto é bastante abrangente e incorpora largo espectro de aspectos organizacionais a serem avaliados concomitantemente.

Diante do exposto, optou-se por uma validação com o objetivo de demonstrar a viabilidade e aplicabilidade do modelo através de aplicação em estudo de caso único. Desse modo, pretendeu-se uma investigação cuidadosa do caso único em potencial para minimizar as chances de uma representação equivocada e para maximizar o espaço necessário para se coletar as evidências do estudo de caso (YIN, 2001).

O pré-requisito para a condução do estudo de caso único era que a unidade analisada satisfizesse todas as condições necessárias para a validação do modelo proposto. Portanto, o estudo de caso foi realizado em uma organização pública de grande porte, com infraestrutura tecnológica adequada, sistemas de informação utilizados por perfis diferenciados como pessoas físicas, governo, prestadores de serviços. E, ainda, que oferecesse as condições para testar o modelo de maneira completa, abrangente, e que fosse possível aplicar o modelo em uma série temporal para se conhecer o comportamento dos domínios ao longo do tempo em relação à sua maturidade.

O estudo de caso selecionado permitiu cumprir uma avaliação completa e holística da aplicação do modelo, pois: (1) envolveu uma organização parceira que esteve aderente com os objetivos da pesquisa; (2) possibilitou a avaliação abrangente em cada momento, com a devida resposta de todos os itens de avaliação propostos; (3) permitiu a avaliação 
em momentos diferentes de tempo, mais especificamente, ao longo de três anos da execução de um Programa de Adoção de SOA estruturado, onde a evolução da maturidade era objetivo explícito e estruturado.

Desse modo, o estudo de caso único selecionado teve acesso a uma situação previamente inacessível à observação científica. Dessa aplicação de estudo de caso buscou-se investigar situações, em particular, com a possibilidade de abordagem mais detalhada, preservando-se suas características reais (YIN, 2001).

Essa etapa está apresentada no Capítulo 5 do presente trabalho.

\section{4 - LIMITAÇÕES E RESTRIÇÕES DO ESTUDO}

Para obter os conhecimentos sobre SOA e propor um modelo de maturidade para a sua adoção e uso, foi utilizada a abordagem de pesquisa qualitativa, com aplicação de estudo de caso único. Segundo Yin (2001), na condução de um estudo de caso único, observar a tecnologia no ambiente de trabalho prestará uma ajuda inestimável para se compreender os limites ou os problemas dessa tecnologia. Tal escolha decorre dos desafios encontrados para elaboração e experimentação do modelo proposto, em especial:

- a disponibilidade limitada de tempo; pois na abordagem qualitativa as técnicas de análise são indutivas, orientadas pelo processo, e os resultados não são generalizáveis;

- a reduzida disponibilidade de organizações aptas para a condução do estudo de caso; pois as unidades a serem analisadas devem satisfazer as condições para testar o modelo de maneira completa e abrangente;

- a dificuldade em encontrar ambientes com o conteúdo necessário para validar a completude do modelo e a análise comparativa com as bases disponíveis na literatura;

- a impossibilidade de avaliação pormenorizada de assuntos relacionados a governança, especialmente de tecnologia da informação, SOA e gerenciamento de risco, pois o escopo do estudo seria aumentado de forma demasiada. 
Por se tratar de uma pesquisa acadêmica, sem patrocínio financeiro, não houve possibilidade de ampliar a quantidade de organizações para validar o modelo e a consequente transformação da pesquisa em abordagem quantitativa, o que pode ser apropriado para estudos futuros. Assim sendo, com uma amostra significativa de casos será possível a comparação e a possibilidade de análises estatísticas.

\section{5 - ORGANIZAÇÃO DO TRABALHO}

Este trabalho trata dos principais assuntos pertinentes ao tema proposto, explicando sua estrutura de funcionamento e utilização. Para melhor entendimento e organização, está dividido em sete Capítulos, a contar desta Introdução e inclusive as Conclusões, conforme a seguir.

No Capítulo 2 explicitam-se os conceitos e sua fundamentação teórica, o estado da arte relacionado ao tema de Governança e a gestão, e da avaliação de Governança junto aos princípios de conformidade.

No Capítulo 3 são apresentadas as interpretações das propostas dos modelos de maturidade existentes atualmente.

No Capítulo 4 é apresentado o modelo de maturidade proposto neste estudo, com foco na formação da base de conhecimento dos itens e suas características estatísticas a serem utilizadas no processo de avaliação dos patamares de maturidade em SOA.

No Capítulo 5 são demonstradas as atividades do ambiente experimental desenvolvido para o processo de avaliação e implementação do software.

No Capítulo 6 é apresentado o estudo de caso único e seus resultados, com uma análise do impacto junto à renovação da base de conhecimento inicial para a plataforma integrada.

$\mathrm{Na}$ sequência, apresentam-se as conclusões oriundas da pesquisa realizada e apontadas algumas oportunidades para estudos futuros. 


\section{2 - CONCEITOS E FUNDAMENTAÇÃO TEÓRICA}

Neste Capítulo são apresentados os conceitos e os termos empregados no presente estudo e são apontados os referenciais temáticos utilizados. Assim sendo, é apresentada a análise dos conceitos e estado da arte sobre os modelos, metodologias, técnicas e aplicações que envolvem a Governança SOA, com especial destaque à avaliação do nível de maturidade em projetos de adoção referentes a essa arquitetura.

Dessa forma, são abordados conceitos e o estado da arte de Governança SOA e de sua gestão; dos modelos contemporâneos de avaliação focados na conformidade legal e normativa; no gerenciamento de riscos empresariais e nos projetos; e, sobretudo, dos princípios utilizados para a mensuração do grau de maturidade quanto à adoção de melhores práticas, técnicas e metodologias de projetos de SOA na organização.

\section{1 - ARQUITETURA ORIENTADA A SERVIÇOS (SOA)}

O termo Orientação a Serviço tem sido usado há bastante tempo e em diversos contextos no âmbito organizacional. Em especial, em Tecnologia da Informação (TI), é associado ao conceito de Computação Orientação a Serviço. Esse uso diverso da orientação a serviços e suas abordagens distintas em conjunto com o seu entendimento como computação tem provocado uma profusão de conceitos que embora na maioria das vezes não sejam antagônicos exploram diferentes domínios do termo para diferentes propósitos.

Por ora, é entendido que o alinhamento de uma filosofia orientada a serviços com os objetivos e contexto de negócio da organização é um fator estratégico de sucesso. Arsanjani (2013) descreve a filosofia de orientação a serviços como um conjunto de padrões e diretrizes para a criação de serviços de baixo acoplamento alinhados ao negócio, fornecendo flexibilidade na capacidade de resposta aos desafios dos negócios.

Papazoglou (2007) aponta que a execução de operações de negócio compreende uma série de invocações de diferentes componentes, possivelmente com tecnologias de computação distribuída distintas, muitas vezes, de forma orientada a eventos ou assíncrona, refletindo as necessidades dos processos de negócios subjacentes. 
Segundo Erl (2005), o uso de SOA se baseia em um conhecimento comum de que "a lógica necessária para resolver um problema de grande porte pode ser adequadamente construída, implementada e gerenciada, se decomposta em uma coleção de partes menores relacionadas, cada uma abordando parte do problema específico".

O Gartner Group, no seu roadmap de adoção de SOA (GARTNER, 2009), apresenta uma definição mais próxima dos conceitos de TI, no qual define que "SOA é um estilo de arquitetura de software suportada por processos baseados em servidores, utilizando componentes consumidores de negócios independentes que provêm um acesso a lógicas remotas de forma interativa, documentada e controlada, através de interfaces programáticas”.

Assim, SOA favorece o princípio de uso de arquiteturas modulares e distribuídas (GARTNER, 2009) através de aspectos tecnológicos oferecidos pela Computação Orientada a Serviços (Service Oriented Computing - SOC) que proporciona a reusabilidade de lógicas funcionais em um mesmo serviço e atende a um contexto funcional como um meio efetivo de garantir o aumento do retorno nos investimentos (ERL, 2005).

Papazoglou e Georgakopoulos (2003) consideram SOC um paradigma computacional que utiliza serviços como elementos fundamentais para o desenvolvimento de aplicações cujo uso promove a integração de componentes, formando, assim, uma rede de serviços flexíveis, desacoplados e distribuídos dentro do ambiente organizacional e plataformas tecnológicas existentes. Assim, a infraestrutura e os recursos que a SOC disponibiliza são mais ágeis e adaptativos do que outros existentes no mercado.

Como resultado direto, ao investir em SOA, toda organização tem a expectativa de obter retorno superior ao custo do investimento. Esse retorno deve ser mensurado pelo resultado da iniciativa em apoio à área de negócio, levando-se em consideração as escolhas de prioridade, metas e estratégias da organização, haja vista que um dos principais objetivos da Governança SOA "é garantir o alcance das iniciativas de SOA e das metas do negócio" (ERL, 2011). Dessa forma, busca atingir equilíbrio maior entre custos e riscos, atuando junto a sua questão central: o contínuo gerenciamento do portfólio de soluções de TI já existentes (BRANDON, 2013). 
Porém, para atingir os objetivos do paradigma da SOC, é necessário que a estratégia adotada de SOA seja governada pelos princípios de Orientação a Serviços, pois apenas a utilização de serviços não garante que a aplicação seja orientada a serviços (JOSUTTIS, 2007). Diversos autores, a exemplo de Arsanjani (2013) e Papazoglou e Heuvel (2013c), entre outros, definem e priorizam esses princípios.

Erl (2008) agrupou e condensou as práticas mais aplicadas de orientação a serviços, formando o alicerce de seu emprego através de oito princípios por ele preconizados para a correta adoção de SOA pelo uso de boas práticas, a saber:

a) Contrato de Serviço Padronizado: o contrato padronizado é responsável por expressar informações que explicitam a finalidade, as funcionalidades e as capacidades exercidas pelo serviço de forma padrão. Dessa maneira, durante o processo de projeto são levadas em consideração as políticas e as regras que regulamentam a formação de cada serviço, assim como a especificação corporativa de modelos de dados que estabelecem padrões de mensagens de entrada e saída para as capacidades de todos os serviços desenvolvidos no âmbito de uma organização.

b) Baixo Acoplamento: o termo acoplamento refere-se à dependência e relacionamento entre componentes, módulos ou serviços. O nível de acoplamento afeta a flexibilidade e a estabilidade do sistema, tornando-o mais ou menos vulnerável às falhas (ROSEN; LUBLINSKY; SMITH, 2008). Erl (2008) define baixo acoplamento como uma propriedade que possibilita que um serviço seja utilizado juntamente com outro, ainda que ambos sejam projetados para atuar totalmente independentes. Portanto, acoplamento pode ser entendido como o nível de dependência existente entre os serviços. Serviços desenvolvidos com baixos níveis de acoplamento são menos dependentes e, consequentemente, mais flexíveis e reutilizáveis. Quando se desenvolve serviços mais flexíveis e com poucas dependências, tanto suas modificações como suas falhas deverão impor poucas consequências aos demais serviços ou sistemas aos quais estejam interligados.

c) Abstração: entende-se como a capacidade de ocultar informações de serviços que não são necessárias para que outros serviços ou usuários o utilizem corretamente. 
Enfatiza que é de fundamental importância esconder o máximo possível os detalhes de implementação de um serviço.

\begin{abstract}
Projetar e construir serviços com uma boa abstração proporciona redução de acoplamento, acomodação de mudanças e facilidade na separação de interesses. Isso pode ser observado em serviços de alto nível, que escondem a complexidade e os detalhes de implementação por trás de uma interface consistente que é especificada e desenvolvida de acordo com os processos de negócio (ROSEN; LUBLINSKY; SMITH, 2008).
\end{abstract}

d) Reusabilidade: parte-se do princípio de que reuso é fazer com que um serviço seja capaz de realizar mais do que uma única finalidade (ERL, 2008). A aplicação desse princípio busca aumentar a capacidade de acomodar futuros requisitos sem que haja grandes esforços de adaptação para o seu uso em novos processos. Logo, serviços devem ser projetados para desempenhar mais do que apenas uma única finalidade, dentro de um mesmo contexto funcional, isso é, esses "contêm e expressam lógica agnóstica e podem ser posicionados como recursos corporativos reutilizáveis" (ERL, 2008). Nesse sentido, o reuso é fundamental também para a composição de serviços, considerando que por meio do agrupamento lógico de serviços novos serviços surgem, constituindo novas composições que são capazes de realizar novos requisitos de negócios. Nunca antes o reuso foi tão enfatizado quanto com orientação a serviço, de tal modo que isso se tornou parte central do processo de projeto (ERL, 2008).

e) Autonomia: representa a habilidade de autogoverno. Uma máquina que é autônoma tem a liberdade e o controle para tomar suas próprias decisões, sem a necessidade de aprovação ou envolvimento externo (ERL, 2008). No contexto de serviço, autonomia representa a capacidade de realizar a lógica do serviço de forma independente; assim, o mesmo pode ser implantado, modificado e mantido, independentemente de outros serviços ou aplicações que o esteja utilizando, pois buscam atuar compartilhando o mínimo possível a infraestrutura subjacente necessária para realizar suas capacidades.

f) Independência de Estado: durante a execução de determinada lógica, normalmente, o serviço necessita processar uma série de informações e dados. Nesse período de execução, a utilização desse conjunto de dados é determinada como estado de um serviço. Caso um serviço mantenha seu estado por longo período de tempo, certamente terá sua disponibilidade afetada (ERL, 2008). Esse princípio propõe que 
os serviços sejam desenvolvidos sem estado, o que significa que não deve manter os dados e informações utilizadas no processamento de sua tarefa por longo período de tempo, devendo liberá-los o mais brevemente possível para o serviço poder ser reutilizado em novo contexto, em novo estado. Caso haja a necessidade de retenção de dados e informações pelo serviço, os estados devem ser persistidos, tornando-os passíveis de serem passivados.

g) Visibilidade de Serviços: refere-se ao processo de procurar e encontrar uma solução lógica dentro de um ambiente específico; é conhecido como descoberta. Um componente arquitetural desenvolvido adequadamente é facilmente descoberto (ERL, 2008). Para que um serviço seja descoberto dentro de uma organização é necessário que esteja provido com meta-informação que torne o serviço capaz de ser introduzido dentro do escopo de pesquisa e descoberta. Isso se relaciona diretamente com a qualidade dessas meta-informações, contidas no contrato do serviço, e, também, da estruturação adequada do inventário de serviços. Esses serão os principais fatores que contribuirão para que os consumidores em potencial o localizem e reutilizem serviços já existentes.

h) Composabilidade: refere-se ao processo de combinar serviços existentes com o objetivo de formar novo serviço de alto nível. A composição de serviços facilita o desenvolvimento de novos processos, permitindo que as empresas possam adotar novos processos de negócio, tornando-os mais eficientes e, consequentemente, melhorando o nível dos serviços oferecidos a clientes e parceiros (BROWN, 2008). Assim, serviços são combinados em composições de maior complexidade. Um dos fatores para a adoção desse paradigma é que a composição possibilita que serviços já existentes sejam combinados para implementar novas funções de negócio, e, assim, essa nova capacidade também minimiza custos e esforços por parte da TI durante o processo de desenvolvimento. 
A Figura 2.1 ilustra esses princípios e seus impactos na formação de serviços SOA.

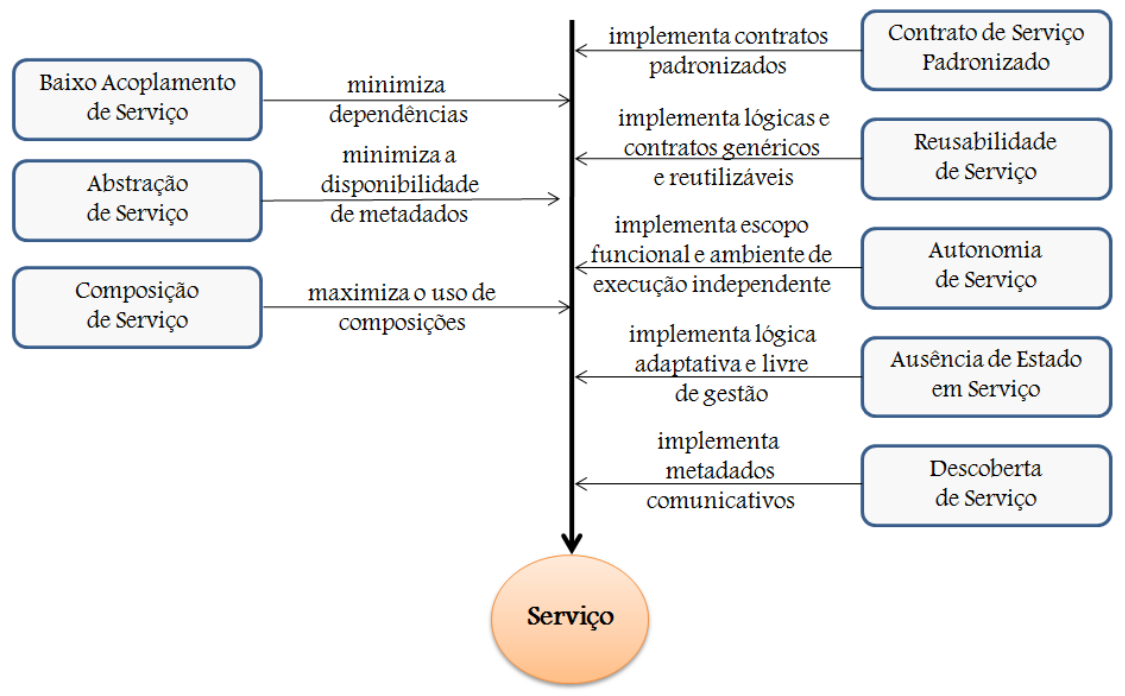

Figura 2.1 - Princípios de Orientação a Serviço

Fonte: ERL (2008).

Segundo Erl (2008), a aplicação disciplinada e governada desses princípios de Orientação deve garantir a obtenção dos objetivos e benefícios estratégicos da Computação Orientada a Serviços em uma organização que adote essa arquitetura. $\mathrm{O}$ autor destaca entre esses objetivos e benefícios estratégicos:

a) Maior Interoperabilidade Intrínseca: basicamente, se refere à possibilidade e à facilidade de compartilhamento de dados. Quanto mais interoperáveis forem os componentes, mais as informações poderão ser compartilhadas. No atendimento dessa perspectiva, o objetivo da orientação a serviço é justamente prover a interoperabilidade de forma nativa, eliminando ou reduzindo a necessidade de integração. Padronização dos contratos, escalabilidade e previsibilidade de comportamento, são alguns dos requisitos de projeto de serviço SOA que facilitam essa interoperabilidade.

b) Maior Federação: um ambiente federado é um ambiente nos quais recursos e aplicativos trabalham de forma conjunta, embora mantenham sua autonomia e governança individual. SOA visa a aumentar a perspectiva federada da organização em qualquer medida em que é aplicada. Isso se faz por meio da implantação generalizada de serviços padronizados e combináveis, cada qual encapsulando um segmento da empresa. 
c) Maiores Opções de Diversificação de Fornecedores: significa a possibilidade que a organização possui de optar por inovações tecnológicas ou novos produtos a qualquer tempo, independentemente de fornecedor. Essa proposta visa a garantir que essa decisão não será afetada por limitações da infraestrutura, a exemplo de padrões e protocolos de comunicação. É a liberdade e flexibilidade que a organização utiliza para ampliar e adaptar sua infraestrutura tecnológica de acordo com as suas necessidades e oportunidades de mercado, sem correr o risco de comprometer as soluções já existentes. Esses benefícios certamente aumentarão o tempo de vida das soluções e possibilitarão melhor retorno do investimento em TI.

d) Maior Alinhamento entre Negócio e TI: à medida que os requisitos de negócios de TI são cumpridos é frequentemente associada com a precisão com que a lógica de negócio é expressa e automatizada pela lógica da solução. Apesar de aplicações iniciais serem tradicionalmente projetadas para atender necessidades imediatas e táticas, historicamente, tem sido um desafio mantê-las alinhadas com a necessidade de negócio quando a natureza e direção dos negócios mudam.

e) Maior Retorno de Investimentos: a Computação Orientada a Serviços defende a criação de uma solução lógica agnóstica para qualquer finalidade e, portanto, útil para múltiplos fins. Essa lógica polivalente ou reutilizável aproveita totalmente a natureza intrinsecamente interoperável de serviços. Serviços agnósticos têm aumentado seu potencial de reutilização, permitindo-lhes ser repetidamente montados em diferentes composições, para automatizar processos de negócios distintos, como parte de diferentes soluções orientadas a serviços. A despesa inicial e esforço são investidos em cada pedaço de lógica de solução, de forma a posicioná-lo como um ativo de TI, com o objetivo de repetíveis retornos financeiros no longo prazo.

f) Maior Agilidade Organizacional: a SOC é focada no estabelecimento de agilidade organizacional; assim, quando a orientação a serviço é aplicada em toda a empresa resulta na criação de serviços que são altamente padronizados e reutilizáveis e, portanto, independente de processos de negócios e ambientes de aplicativos específicos. 
g) Redução na Carga de TI: aplicação consistente da orientação a serviços resulta em uma área de TI com redução de desperdício e redundância, menor tamanho e custo operacional e redução da sobrecarga associada à sua governança e evolução. Em essência, a realização dos objetivos estratégicos permite a formatação de uma TI mais enxuta, mais ágil, que é menos onerosa para a organização, tornando-a um membro efetivo no atingimento dos objetivos estratégicos dessa.

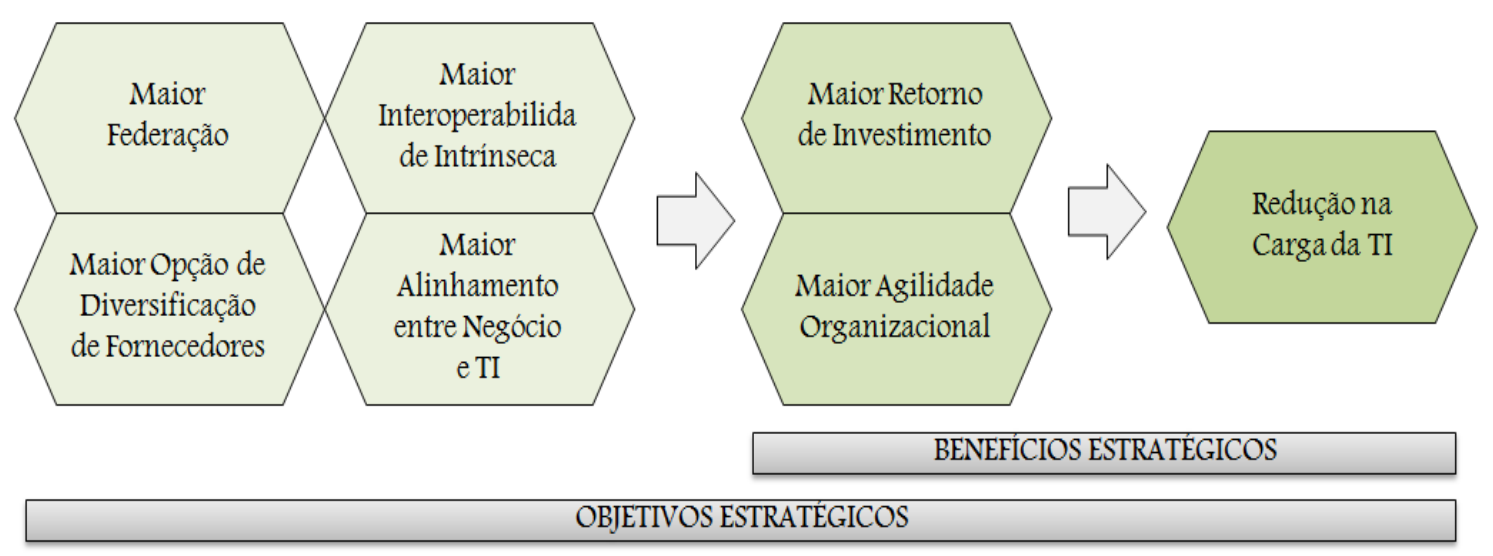

Fonte: ERL (2008).

Figura 2.2 - Objetivos e Benefícios Estratégicos

Pelos benefícios e objetivos elencados, observa-se que SOA impacta e sofre impactos das relações organizacionais, principalmente no que se refere ao alinhamento das necessidades do negócio com os resultados da aplicação de TI.

A aplicação consistente de orientação a serviço resulta em uma TI corporativa com a redução de desperdício e redundâncias, de tamanho e custo operacional e de overhead associado com sua governança e evolução. Esse tipo de TI corporativa possibilita benefícios organizacionais por meio do aumento significativo da capacidade de resposta e da efetividade dos custos (ERL, 2005).

Entende-se que o atendimento rígido dos aspectos de Governança é fundamental para que se cumpram requisitos obrigatórios visando ao pleno atingimento desses benefícios e objetivos, pois a visão moderna proposta por SOA não apenas favorece, mas exerce atividades mandatórias de aplicação dos seus princípios, em destaque aos princípios de reuso e de padronização. 
Para se avaliar a correta adoção de SOA é necessário então que se destaque o escopo da Governança que deve ser aplicada junto ao seu modelo arquitetural, identificando as suas relações, similaridades e diferenças com outras esferas de Governança, conforme a seguir.

\section{2 - GOVERNANÇA SOA}

Brauer e Kline (2013) colocam que Governança SOA é um conjunto de soluções, políticas e práticas que capacitam a organização a implementar e gerenciar uma arquitetura orientada a serviços corporativa. Complementando essa definição de Governança SOA, Marks (2008) define que "se refere a processos, organização, políticas e métricas necessárias para o gerenciamento adequado da arquitetura SOA e obtenção dos objetivos do negócio, estabelecendo regras comportamentais e diretrizes para a organização". Essas regras e diretrizes surgem da definição de políticas específicas de cada empresa com relação a itens como segurança, tecnologia e serviços operacionais; todos estabelecidos no contexto dessa arquitetura. Assim, a Governança SOA inclui mais requisitos e processos do que a pura Governança de TI, gerando número bem superior de interessados e envolvidos e, consequentemente, maior complexidade (MARKS, 2008).

A Figura 2.3 ilustra essa perspectiva de que a Governança SOA deve ser vista como a aplicação da Governança de Negócios (ou Corporativa), de Governança da TI e da Governança da Arquitetura Empresarial (EA) para Arquitetura Orientada a Serviços (SOA). Com efeito, Governança SOA estende Governança de TI e EA assegurando que os benefícios exaltados por SOA sejam cumpridos (THE OPEN GROUP, 2011). Isso requer que se governe em conjunto e simultaneamente não só os aspectos de execução de SOA, mas também as atividades de planejamento estratégico. 


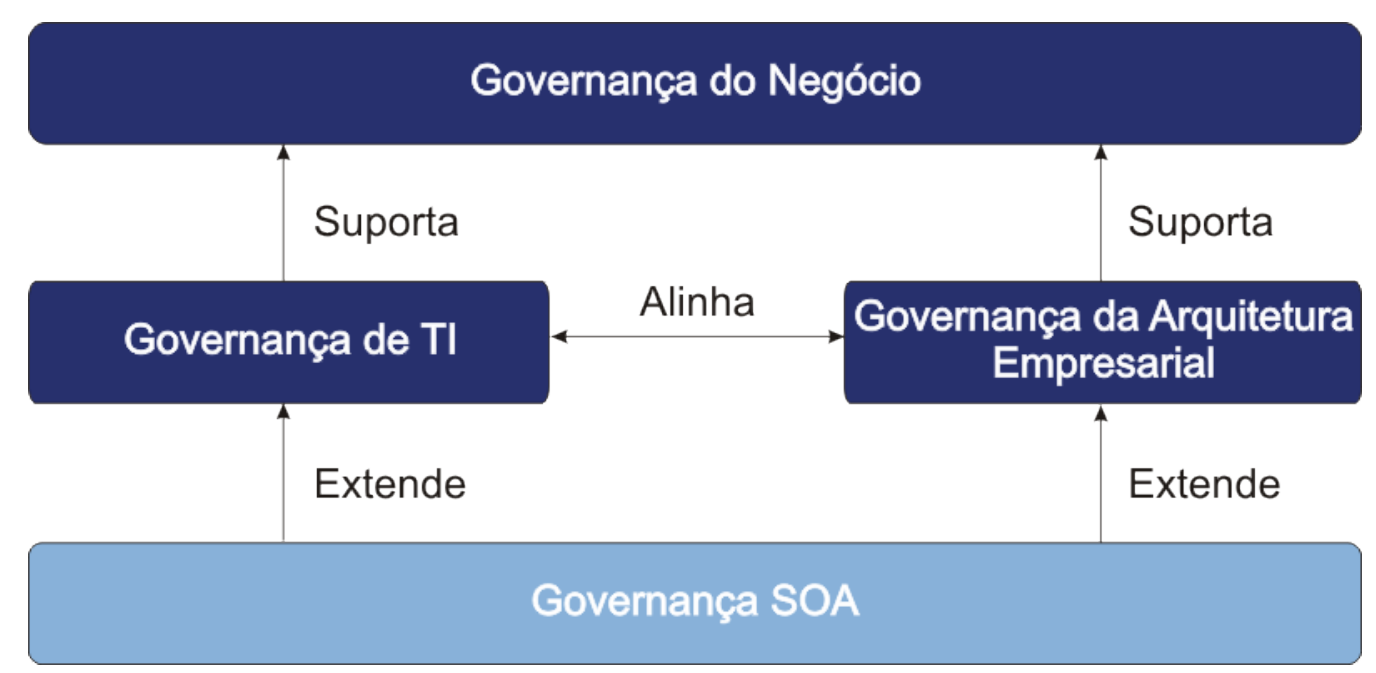

Figura 2.3 - Relacionamentos da Governança SOA

Fonte: The Open Group (2011).

a) Governança do Negócio (Business Governance) é o conjunto de processos, costumes, políticas, leis e instituições que afetam a forma como uma organização é dirigida, administrada ou controlada.

b) Governança da Arquitetura Empresarial (EA Governance) é a prática e orientação pela qual arquiteturas empresariais e outras arquiteturas são geridas e controladas em nível corporativo.

c) Governança de TI (IT Governance) inclui os direitos de decisão, estrutura e processos de prestação de contas, para incentivar o comportamento desejável no uso de TI.

\footnotetext{
Valor, risco e controle constituem a essência da governança de TI. A Governança de TI consiste em aspectos de liderança, estrutura organizacional e processos que garantam que a área de TI da organização suporte e aprimore os objetivos e as estratégias da organização (TCU, 2010 apud COBIT 4.1).
}

Porém, a maioria das definições de Governança SOA convergem para interpô-la como uma extensão da Governança de TI, de forma a suprir lacunas entre a Governança Corporativa e a TI. Schropfer e Schonherr (2008) apresentam sua visão de interação entre a Governança Corporativa, a de TI e a de SOA, representada pela Figura 2.4 a seguir: 


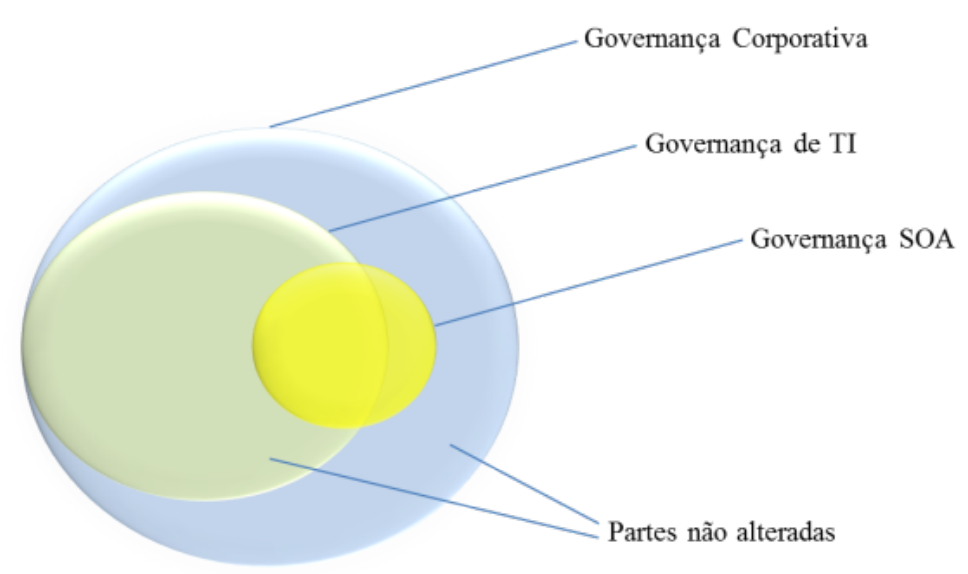

Figura 2.4 - Relação entre a Governança Corporativa, a de TI e a de SOA Fonte: Schropfer e Schonherr (2008).

Observa-se na Figura 2.4 que a parte mais significativa das atividades de Governança SOA tende a ficar no domínio de TI, pois se entende que a TI é o principal suporte para obtenção de algumas das principais características de SOA, como o reuso de componentes, interoperabilidade, flexibilidade da arquitetura e melhoria da qualidade dos recursos de TI, com a consequente redução de custos (ERL, 2005).

Assim, mesmo SOA sendo um modelo arquitetural com foco estratégico, seus requisitos de controle e avaliação encontram-se intimamente associados à aplicação de boas práticas e métodos junto a Governança de TI.

Reforçando esse foco, Brown (2008) aponta Governança SOA como uma extensão da Governança de TI. Esse autor expõe ainda que "a Governança SOA atribui decisões corretas, políticas de mensuração, processos e ciclo de vida dos serviços, compreendendo a análise, definição, projeto, implantação, operação e descarte do serviço". Esse é o entendimento que o pesquisador deste estudo decidiu adotar neste trabalho, reforçando as características técnicas, tecnológicas e metodológicas para entender "as qualidades inerentes à melhoria contínua de sua aplicação, de forma interativa e incremental" (THE OPEN GROUP, 2009).

\section{3 - MODELOS DE MATURIDADE}

O processo de melhoria exige análise permanente do posicionamento da organização em relação aos seus recursos de TI e na qualidade dos seus produtos e serviços. Tem-se como regra geral que esse posicionamento envolve uma comparação desses aspectos de TI com 
os objetivos da empresa, as exigências externas, e com diversos pontos de referência tecnológica e de boas práticas (BECKER et al., 2009).

Nesse sentido, constitui-se tarefa difícil avaliar a posição da TI em relação a uma estratégia. Para cada aspecto da TI sob investigação surgem questões que precisam ser medidas e comparadas a referenciais específicos de boas práticas, a fim de se quantificar a qualidade ou estabelecer um grau específico de maturidade. Modelos de maturidade são ferramentas úteis para abordar essas questões (DE BRUIN et al., 2005).

De Kreger et al. (2013) entendem que um modelo de maturidade é útil para compreender o nível atual de uma organização contra um conjunto-padrão de definições. Esses modelos ajudam a organização a compreender o que ganham, e quais objetivos de negócio são atingidos pela mudança para um nível mais elevado de maturidade.

$\mathrm{Na}$ gestão de TI, os modelos de maturidade e os scorecards têm há muito tempo se revelado como instrumentos importantes, porque permitem melhor posicionamento da TI junto à organização (DE HAES; VAN GREMBERGEN, 2004). Ao longo dos últimos anos, centenas de modelos de maturidade têm sido desenvolvidos para apoiar a gestão de TI, sendo referenciais reconhecidos os modelos associados ao CMMI (DE BRUIN et. al., 2005; CARNEGIE MELON SOFTWARE ENGINEERING INSTITUTE, 2006) e utilizados como base de formação do IS/ICT Management Capability Maturity Framework (IC/ICT CMF), um modelo de maturidade para gerenciamento de TI (RENKEN, 2004).

O CMMI é um modelo de maturidade de melhoria de processo para o desenvolvimento de produtos e serviços. Ele consiste de melhores práticas que contemplem o desenvolvimento e a manutenção de atividades que cobrem o ciclo de vida e qualquer produto, desde a concepção até a entrega e manutenção (CARNEGIE MELLON SOFTWARE ENGINEERING INSTITUTE, 2013).

O processo de melhoria em uma organização é diferencial estratégico quando aplicado como um modelo de maturidade que contém e unifica as práticas utilizadas em disciplinas específicas, tais como: Engenharia de Sistemas, Engenharia de Software, Desenvolvimento de Produtos e Processos Integrados, entre outras (CHRISSIS, 2003). O CMMI é uma evolução do Capacity Maturity Model (CMM) e procura estabelecer um modelo único para 
o processo de melhoria corporativo com foco na TI, integrando diferentes modelos e disciplinas (CARNEGIE MELON SOFTWARE ENGINEERING INSTITUTE, 2006). Esse modelo é uma forma natural de mercado para tentar entender e avaliar a maturidade da TI em geral.

De modo geral, um modelo de maturidade é composto por uma sequência de níveis e representa um caminho de evolução esperado, almejado, ou mesmo caminhos típicos em forma de estágios discretos. Na forma de estágios discretos, os modelos de maturidade apresentam uma escala - baseada em requisitos - para dar suporte quantitativo à avaliação do estado de maturidade estabelecido pelo modelo. Assim, um framework de maturidade, como o CMMI, acomoda múltiplas disciplinas e é flexível o suficiente para suportar duas representações diferentes (CARNEGIE MELLON SOFTWARE ENGINEERING INSTITUTE, 2013):

a) Representação em Estágios

A Representação em Estágios provê uma sequência bem definida de melhoria, cada um servindo como base para o próximo. Oferece uma forma sistemática e estruturada para melhoria dos processos (CARNEGIE MELLON SOFTWARE ENGINEERING INSTITUTE, 2013).

A representação em estágios utiliza conjuntos predefinidos de áreas de processo para definir um caminho de melhoria para uma organização. Esse caminho de melhoria é caracterizado por níveis de maturidade, e, assim, cada nível de maturidade fornece um conjunto de áreas de processo que caracteriza diferentes comportamentos organizacionais. Determinado nível de maturidade é definido pelo conjunto de áreas de processo dentro do nível em questão.

Nessa representação, por ser pontual, a ordem de melhoria é rígida e os estágios são cumulativos e dependentes dos anteriores. Para alcançar o nível de maturidade, uma empresa precisa ter implementado todos os processos do nível anterior, e esses precisam estar em conformidade com o nível de capacidade atual e a todos os processos desse nível. Por oferecer uma sequência bem definida de melhoria de processos, a representação em estágios é mais habitual para as organizações (CARNEGIE MELLON SOFTWARE ENGINEERING INSTITUTE, 2013).

b) Representação Contínua 
A Representação Contínua oferece a maior flexibilidade, pois permite selecionar a área de processo a ser melhorada ou a ordem em que as melhorias serão feitas.

A Representação Contínua permite que a organização selecione uma área de processo (ou grupo de áreas de processo) e atue na melhoria de processos nesse escopo. Essa representação também utiliza níveis de capacidade para caracterizar a melhoria de processos individuais (CARNEGIE MELLON SOFTWARE ENGINEERING INSTITUTE, 2013).

Assim como os domínios dos modelos de maturidade, cada processo tem o seu próprio nível de capacidade. Essa representação é indicada quando se conhece bem os problemas da organização - quais são os processos que precisam ser melhorados e as dependências entre eles são bem conhecidas.

Observado sob a ótica de um ciclo contínuo de melhoria, os dois modelos se sobrepõem na medida em que um modelo em evolução (em busca de um novo estágio) está relacionado à representação contínua, enquanto a representação em estágio define uma posição estável ou em estabilização dentro do modelo. A Figura 2.4 ilustra o relacionamento entre os estágios do CMMI, e a Figura 2.5 ilustra um processo contínuo entre os marcos da representação em estágios.

\begin{tabular}{|c|c|c|}
\hline CMMI V 1.3 & $\begin{array}{c}\text { Representaçäo Continua } \\
\text { Nivel de Capacidade }\end{array}$ & $\begin{array}{c}\text { Representaçäo em Estágios } \\
\text { Nivel de Maturidade }\end{array}$ \\
\hline Nivel 0 & Incompleto \\
\hline Nivel 1 & Realizado & Inicial \\
\hline Nivel 2 & Gerenciado & Gerenciado \\
\hline Nivel 3 & Definido & Definido \\
\hline Nivel 4 & Gerenciado Quantitativamente & Gerenciado Quantitativamente \\
\hline Nivel 5 & Otimizando & Otimizando \\
\hline
\end{tabular}

Figura 2.5 - Representação Contínua e em Estágios do CMMI v 1.3

Fonte: Disponível em: <http://qualitynotion.com/wp-content/uploads/2013/02/CMMI-HM-in-a-Cont.Rp.1.jpg>. Acesso em: 10 fev. 2013. 


\section{4 - USO DE QUESTIONÁRIOS ESTRUTURADOS}

Segundo Becker et al. (2009), a aplicação dos modelos de maturidade pode ser suportada por procedimentos adequados, tais como questionários estruturados. Nesse sentido, existem diversos modelos (HP, 2006; MICROSOFT, 2007; THE OPEN GROUP, 2011; ITANA, 2013) que apontam o uso de questionários durante processos de consultoria específicos, na forma assistida - com interação pessoal.

De Yarenko et al. (1986 apud GÜNTHER, 2009) tem-se que questionários podem ser definidos como "um conjunto de perguntas sobre um determinado tópico que não testa a habilidade do respondente, mas mede sua opinião". Em geral, é composto de perguntas concretas a serem apresentadas, que se referem a itens de avaliação no qual deve existir uma relação recíproca entre os conceitos em avaliação e esses itens.

$\mathrm{Na}$ quantificação dos resultados de questionários, esses itens de avaliação dependem do tipo de variáveis (conceitos) que constituem seus dados, e são construídos baseados em quatro tipos de escalas distintas (LOPES, 2011):

- Nominal: onde o foco é a categorização do dado;

- Ordinal: construída a partir de escalas nominais quando existe paralelismo evidente entre a escala nominal e uma sequência crescente ou decrescente com significado;

- Por intervalo: usada com dados quantitativos, tanto discretos como contínuos, sendo que a distância entre os valores que constituem os intervalos deve ser igual; e

- Por rácios: escalas que têm as mesmas propriedades que as escalas por intervalos para variáveis contínuas e, adicionalmente, apresentam a característica de possuírem um zero absoluto como valor mínimo, de modo que as razões entre duas medidas têm sempre o mesmo valor, qualquer que seja a unidade utilizada.

O uso de questionários na avaliação de maturidade SOA não é uma novidade. Modelos como o da HP (2006) advogam o uso de questionários baseados em itens de avaliação do tipo "verdadeiro, parcial ou falso", atribuindo pontuação correspondente (um, meio ou 
zero) e determinando diretamente "por intervalo" o nível indicado para a organização dentro de um domínio.

O The Open Group (2011), um consórcio global de organizações, também por um questionário guiado realiza o processo por meio de entrevistas com o pessoal-chave na organização; é baseado em questões de avaliação básicas fornecidas pelo modelo OSIMM, que ajudam a mapear os indicadores de atributos de maturidade. E, ainda, o nível de maturidade atual e o valor de pontuação variam em uma escala ordinal de 10 pontos e utilizam recursos de média ponderada dentro de cada domínio; pontuação final essa que é agregada por meio de domínios para definição de um estado global para a organização.

Entende-se que o uso de questionários baseados em valores por intervalos suporta heurísticas que podem ser aplicadas utilizando critérios de regressão em modelos matemáticos avaliativos, baseadas nos resultados das respostas obtidas, de forma a incorporar os aspectos subjetivos avaliados pela Governança Corporativa e de TI na avaliação final se forem determinadas faixas coerentes em relação aos itens de questionário.

Adicionalmente, do uso de questionários para suportar as respostas quantificáveis, uma primeira preocupação é o critério de tomada de decisão a ser imposto no modelo de avaliação de cada controle, que determina o critério de regressão a ser utilizado. Assim, da análise dos resultados da aplicação dos questionários e quantificação dos controles tem-se um princípio de tomada da decisão a partir de resultado associado ao conceito de pesquisas operacionais. Pesquisa operacional é um processo que ajuda a tomada de suas decisões, fornecendo-lhe as informações quantitativas necessárias, com base no método científico de análise sistemático, dirigido por uma estrutura básica - um modelo (GUPTA; HIRA, 2009).

O uso da teoria de tomada de decisão fornece uma abordagem racional ao lidar com problema de quantificação, confrontando essa decisão com a incerta e imperfeição do conhecimento das situações futuras (SONKAR, 2013). Assim, sob condições de incerteza, a tomada de decisão apresenta os estados da natureza que podem acontecer mas não têm o conhecimento sobre as probabilidades de sua ocorrência. São consideradas técnicas para tomada de decisão sob incerteza (LISBOA, 2002): 
- Critério Maximax ou Critério de otimismo: se baseia em uma visão otimista do problema. Escolhido determinado modelo, supõe-se que ocorrerá o melhor evento possível - a alternativa será escolhida como aquela que tem a melhor entre as melhores opções de todas as alternativas. Em outras palavras, deve-se determinar o lucro máximo para cada alternativa e, em seguida, escolher a alternativa com o maior lucro máximo.

- Critério Maximin ou Critério de pessimismo: se baseia em uma visão pessimista do problema. Supõe-se que escolhido determinado modelo ocorrerá o pior evento possível. A alternativa será escolhida como aquela que tem a melhor entre as piores opções de todas as alternativas - deve-se determinar o menor valor para cada alternativa e, em seguida, escolher a alternativa com o maior valor dos mínimos.

- Critério de Hurwicz ou Critério de realismo: é intermediário entre o mais pessimistas (Maximin) e o mais otimista (Maximax). Dado um coeficiente de otimismo, v, o índice de cada alternativa é calculado, conforme mostrado na equação 2.1:

$$
\mathrm{x}=\mathrm{v} \mathrm{x}_{\max }+(1-\mathrm{v}) \mathrm{x}_{\min }
$$

onde x é o índice resultante relativo à alternativa considerada, xmax é o índice máximo da alternativa e xmin é o índice mínimo. O índice de otimismo é um valor real entre 0 e 1 , onde $\mathrm{v}=0$ indica pessimismo extremo (critério Maximin) e $\mathrm{v}=1$ indica otimismo extremo (critério Maximax).

- Critério Minimax ou Critério de regressão: procura determinar o arrependimento máximo de cada escolha. Para montar a matriz de arrependimentos, determina-se o lucro máximo de cada evento. Para todos os eventos, calcula-se a diferença entre o lucro máximo e o lucro da alternativa em questão. Monta-se então uma matriz com as diferenças entre o lucro máximo e os lucros das alternativas. Pelo critério de Minimax, a opção a ser escolhida é aquela que minimiza o arrependimento máximo.

- Critério de Laplace ou Critério da racionalidade: é baseado no axioma em que todos os estados da natureza têm uma probabilidade de ocorrência, e postula que, se não há informação disponível sobre as probabilidades dos vários resultados, é razoável 
supor que eles são suscetíveis de ocorrerem de forma igual. Portanto, é um critério de decisão não probabilístico, no qual se houver $\underline{\text { n }}$ resultados a probabilidade de cada é $\underline{1 / n}$. Essa abordagem sugere que o tomador de decisão deve calcular o retorno esperado para cada alternativa e selecionar a alternativa com o maior valor de retorno. O critério de Laplace é o primeiro a fazer uso explícito de avaliações de probabilidade sobre a probabilidade de ocorrência dos estados da natureza. Como resultado, é o primeiro modelo elementar para utilizar toda a informação disponível na matriz de igual retorno.

Algumas metodologias de quantificação são baseadas em risco, tais como a teoria dos jogos. Como Haimes (1998) menciona na sua Modelagem de Risco, Avaliação e Gestão, existem critérios de decisão para administrar o risco e a incerteza sem pedir o envolvimento de probabilidades: maximizar o ganho mínimo (Maximin), minimizar a perda máxima (critérios Minimax), maximizar o ganho máximo (a regra Maximax). A prática em avaliação de maturidade impõe uma visão pessimista. Desse modo, no modelo proposto é explorada a adoção de um critério Minimax.

Em processos decisórios multiatributos, o método Minimax é comumente usado quando todos os atributos são comparáveis, julgados com base em um único critério (LINKOV; RAMADAN, 2004). O método de regressão Minimax é uma estratégia que procura evitar o pior desempenho possível - deve-se evitar o custo máximo. Isso é conseguido mediante a atribuição total de importância para os critérios no qual uma alternativa se apresenta como pior, ficando todas as alternativas pela força do seu atributo mais fraco. Essa alternativa é a preferida para os casos em que a pontuação do seu atributo mais fraco é o ponto mais focal.

Outra possibilidade para favorecer uma estratégia de beneficiar o pior desempenho possível é a aplicação da regra Hurwitz com um baixo índice de otimismo. A regra de Hurwitz, ou regra de compromisso, aplica um índice $(0<$ índice $<1)$ para definir o nível de otimismo da decisão. Nessa regra, o critério de realismo - do pessimismo ao otimismo - é realizado através da fórmula (índice)+(1-índice).(mínimo valor retornado de uma alternativa).

Esse processo de regressão oferece uma alternativa prática para as abordagens Bayesianas, já que a inferência bayesiana apresenta dificuldades em cálculo dos valores esperados de 
funções particulares dos parâmetros que resumem convenientemente a densidade $a$ posteriori. Isso se dá porque na inferência bayesiana os limites ou restrições lineares sobre os parâmetros de saída são muito mais difíceis de se obter, atualizar e suportar por uma computação eficaz de regressões (VISMARA, 2007).

Adicionalmente, em um questionário de avaliação de maturidade, depois de avaliadas as questões pertinentes a cada controle e formados valores de nível de maturidade em cada controle, esses controles podem indicar níveis de maturidade diferentes dentro de cada domínio. Assim, é no conjunto dos resultados de outra análise do conjunto de controles de um domínio que a maturidade específica de um domínio pode ser calculada, e na qual recomendações de atividades de melhoria ou roteiros de evolução (roteiros 'to-be' ou 'todo lists') podem ser derivadas na busca do atingimento de patamares mais elevados de maturidade dentro de cada domínio (IT GOVERNANCE INSTITUTE, 2007 apud BECKER; KNACKSTEDT, 2009).

\section{5 - METODOLOGIA PARA TOMADA DE DECISÃO A PARTIR DE QUESTIONÁRIOS}

Existem vários tipos de abordagens voltados para questões que abrangem problemas de tomada de decisão. Entre essas abordagens, pode-se destacar a Metodologia Multicritério de Apoio à Decisão. Trata-se de um conjunto de métodos e técnicas que tem o objetivo de auxiliar ou apoiar a tomada de decisões no que diz respeito à multiplicidade de critérios e largo espaço amostral. $\mathrm{O}$ uso de qualquer método multicritério presume a necessidade de caracterização anterior dos objetivos pretendidos pela decisão, quando comparadas às alternativas do problema (BANA; COSTA, 1992).

De acordo com Zeleny (1994), “a distinção entre as metodologias multicritérios e as metodologias tradicionais de avaliação é o alto grau de incorporação dos valores subjetivos nos modelos de avaliação" que permite a análise de um espaço amostral de forma diferente, conforme os critérios de valor individuais. Assim sendo, a tomada de decisão pode ser considerada "um esforço para tentar resolver problemas cuja presença de vários fatores impede a existência de uma solução ótima, e conduz a procura de uma solução de compromisso" (ZELENY, 1994). Para Roy e Vanderpooten (1996), a utilização de uma Metodologia Multicritério de Apoio à Decisão é bem significativa quando usada em 
problemas complexos, especialmente naqueles em que existem diversas decisões a serem analisadas, tendo como foco um processo decisório de difícil mensuração. Em muitos casos, têm de utilizar variáveis de ordem qualitativa.

Segundo Martinez (1998), uma análise de apoio à decisão multicritério compreende os seguintes elementos envolvidos:

- um conjunto finito de alternativas estáveis, geralmente finitas, em que se assume que cada um deles está perfeitamente identificado, embora não necessariamente sejam conhecidas todas as suas consequências quantitativas e qualitativas de forma exata ou completa;

- uma família de critérios de avaliação (atributos ou controles) que permita avaliar cada uma das alternativas (analisar suas consequências), de acordo com pesos atribuídos a esses pesos; pesos esses que refletem a importância (relevância) de cada critério;

- uma matriz de decisão que resume a avaliação do impacto de cada alternativa em cada critério na formação de soluções à luz de cada um dos critérios, onde a escala de medição de avaliações pode ser quantitativa ou qualitativa e a ação resultante pode ser expressa em escalas cardinais (razão e intervalo), ordinal, nominal e probabilística;

- uma metodologia ou modelo de agregação, de preferência em uma síntese global, triagem, classificação, partição, ou classificação, em que ensaios devem ser realizados (simulações) para determinar a solução que recebe as melhores avaliações globais; e

- um processo de tomada de decisão que realiza negociação consensual entre atores ou

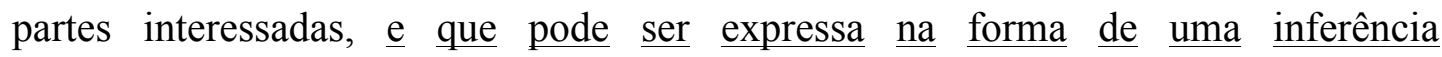
computacional (grifo do autor).

Assim sendo, uma das maiores dificuldades para tomada de decisão é o estabelecimento dos atributos inerentes a essa decisão. Segundo Kruskal e Wish (1978), existem muitos métodos para a construção de escalas fundamentadas em avaliações subjetivas. 
Considerável parcela das metodologias de múltiplos critérios utiliza a formação de uma lista de atributos criados a partir da opinião de especialistas que colaboram por meio de comparações paritárias dos atributos e alternativas envolvidos na questão.

Segundo Costa, Risicato e Torres (2006), considerando-se os atributos $E_{1}, E_{2}, \ldots, E_{n}$, que contribuem para a consecução de determinado objetivo, a metodologia Multicritério de Apoio à Decisão é fundamentada em uma comparação da importância relativa entre um conjunto de atributos, sempre atribuindo maior peso ao atributo que se julga mais importante. "A análise comparativa deverá se realizar aos pares de atributos, onde devemos identificar dentro de uma escala a distância em importância entre os diversos atributos" (COSTA; RISICATO; TORRES, 2006). Portanto, essas comparações devem estar embasadas em questionamentos a quem cabem as decisões (no caso, os especialistas), que cumprem "normas pré-estabelecidas para a atribuição de valores".

Assim, cada especialista deve construir uma Matriz de Julgamento (Eq. 2.2):

$$
\mathrm{A}=\left[\mathrm{a}_{\mathrm{ij}}\right]
$$

Nesse tipo de matriz, $a_{i j}$ representa a importância relativa do atributo $E_{i}$ em relação ao conceito geral de atributos E. De modo geral, refere-se a um valor de peso atribuído ao atributo $E_{i}$, de modo que $a_{i j}>1$, se, e somente se, $E_{i}$ for mais importante do que $E_{j}$, e $a_{i j}=$ $1 / a_{j i}$ para qualquer par $(i, j)$. Então, para a tomada de decisão, essa matriz de julgamento é transposta no suporte ao modelo e realizada através de métodos discretos de avaliação e de decisão multicritério.

Segundo Martinez (1998), tem-se como principais métodos discretos de avaliação e de decisão multicritério:

- Ponderação Linear: um método com uma fundamentação teórica ortodoxa e direta que pode resolver situações de incerteza ou com níveis modestos de informações, que é a construção de uma função de valor para cada alternativa. $O$ método de ponderação linear assume transitividade das preferências ou a comparabilidade. É um método totalmente compensatório, e pode ser dependente da atribuição de pesos para os critérios ou avaliações escala de medição. 
- Utilidade Multiatributo: um método em que para cada atributo da função de utilidade correspondente é determinada de forma parcial e, em seguida, acrescentase uma função de utilidade multiatributo aditiva ou multiplicativa. Ao determinar a utilidade de cada alternativa, a ordenação completa do conjunto finito de alternativas é alcançada. O método de utilidade multiatributo assume transitividade das preferências ou a comparabilidade; em geral, usa "escalas intervalares" e aceita o princípio de "preservação da ordenação" (rank preservation).

- Análise Hierárquica: o processo de Análise Hierárquica (AHP) decompõe uma situação complexa e não estruturada em seus componentes, ordenando esses elementos em uma hierarquia; em seguida, executa comparações binárias, atribuindo valores numéricos subjetivos aos julgamentos (acerca da importância relativa de cada variável) e a sintetiza agregando soluções parciais. A AHP usa uma “escala de razão" e não suporta o princípio da "preservação de ordenação". Esse método permite uma análise de sensibilidade interessante em que, normalmente, os objetivos (critérios) são classificados da forma mais geral e menos controlável para o mais específico e controlável.

- Relações de Superação: esse método é um instrumento relativamente simples para um grupo pré-definido de alternativas (escolhas) muito grande. Nele, o tamanho do conjunto de soluções eficientes é reduzido por meio de uma partição em subconjuntos (núcleos) de alternativas "mais favoráveis" e "menos favoráveis".

\section{6 - AGREGAÇÃO DE CONTROLES EM DOMÍNIOS PELO EMPREGO DE MÉTODOS HEURÍSTICOS NA AVALIAÇÃO DE MATURIDADE}

Um domínio é a primeira dimensão específica ao longo da qual o nível de maturidade SOA de uma organização pode ser medido e avaliado (THE OPEN GROUP, 2011). Cada domínio tem então um ou mais controles que identificam a situação de cada característica de uma adoção mais madura de SOA.

Assim, o nível de maturidade de cada domínio pode ser abstraído a partir da fatoração dos níveis de maturidade individuais dos controles dentro de cada domínio, pois os níveis de maturidade serão medidos pela realização dos objetivos específicos e 
genéricos que se aplicam a cada conjunto predefinido de áreas de processo - cada domínio (TUTORIALSPOINT, 2012).

Como os resultados obtidos no cálculo da maturidade de cada controle são discretos e finitos $(1,2,3,4,5)$, pode-se aplicar técnicas para análise de frequência sob o reduzido universo de controles em cada domínio, considerando-os um conjunto de valores discretos, com faixa de mínimos e máximos de níveis de maturidade estabelecidos nos modelos.

No suporte à quantificação para a tomada de decisão, práticas modernas vêm sendo aplicadas em pesquisas baseadas em questionários envolvendo o conceito de análise de sensibilidade. A análise de sensibilidade examina o grau em que uma decisão depende de suposições ou estimativas através de probabilidades. Nessa análise, um modelo matemático é definido por uma série de equações, variáveis de entrada e parâmetros que visam a caracterizar algum processo sob investigação (SALTELLI, 2000). A análise de sensibilidade ajuda a solucionar o problema desempenhando papel de ordenação pela importância da força e das relevâncias das entradas para determinar a variação da saída (SALTELLI, 2006).

Praticamente, todos os casos de análise de sensibilidade consideram uma saída univariada (SALTELLI, 2000); das técnicas utilizadas, destacam-se: a análise por regressão (regression analysis) e os métodos baseados em variância (variance-based methods). Os métodos baseados em variância são uma classe de abordagens probabilísticas que quantificam as incertezas de entrada e saída como distribuição de probabilidades e decompõem a variância da saída para partes atribuíveis às variáveis de entrada e suas combinações (TRIANTAPHYLLOU, 2000).

Porém, para uma tomada de decisão, esse processo, mesmo que usando uma simples abordagem probabilística, é tipicamente um exercício complexo, caracterizado por tradeoff entre os diversos impactos que os elementos têm entre si e o seu resultado final (LINKOV; RAMADAN, 2004).

Como o tratamento se dá indiferente do grau de interferência de cada controle, é necessário se resumir e visualizar a distribuição de frequência do conjunto de dados de cada domínio, sem levar em conta as características individuais de cada controle. 
No conjunto de heurísticas de probabilidade baseada em um conjunto de valores limitados e discretos, diversas técnicas estatísticas podem então ser utilizadas, principalmente tomando como foco uma implementação de software:

- Domínio: é a diferença entre o maior e o menor da distribuição de frequência.

- Amplitude Total ou Intervalo Total: é a diferença entre o maior e o menor valor das observações.

- Variância: para análise do grau de variabilidade dos valores e assim perceber desempenhos iguais, muito próximos ou muito distantes entre controles de mesmo grupo (dimensão).

- Moda: é o valor que detém o maior número de observações - o valor ou valores mais frequentes, ou ainda "o valor que ocorre com maior frequência num conjunto de dados, isto é, o valor mais comum" (SPIEGEL, 1976). Moda é uma das maneiras de representação de um valor comum através do valor de ocorrência mais frequente da variável. No caso de uma análise de frequências, a classe de maior frequência é chamada de classe modal. A moda não é necessariamente única, ao contrário da média ou da mediana; assim, no que se refere a moda, podemos ter como resultados as seguintes situações: amodal - que não possui moda -; moda única ou unimodal - que possui um único valor modal -; e multimodal - que possui mais do que dois valores modais.

- Desvio-Padrão: mostra o quanto de variação ou "dispersão" existe em relação à média (ou valor esperado), e, assim, baixo desvio padrão indica que os dados tendem a estar próximos da média, já um desvio padrão alto indica que os dados estão espalhados por uma gama de valores.

- Quartis: outra forma de caracterizar quantitativamente uma distribuição e que consiste em encontrar os valores abaixo dos quais está 25\% dos dados (Primeiro Quartil), 50\% dos dados (Mediana) e 75\% dos dados (Terceiro Quartil). 
- Assimetria: é uma medida que indica o grau de assimetria de uma distribuição de frequência em relação a uma expectativa de distribuição normal. É avaliada através do coeficiente de assimetria de Pearson.

- Curtose: é uma medida de dispersão que caracteriza o pico ou "achatamento" da curva da função de distribuição de probabilidade, e estabelece se as funções são equivalentes à distribuição normal (mesocúrticas), mais alta (afunilada) e concentrada do que a distribuição normal (leptocúrticas) ou mais achatada do que a distribuição normal (platicúrticas).

Dessa forma, para descrever adequadamente a distribuição de frequências de uma variável quantitativa, além da informação do valor representativo da variável (moda da tendência central), é necessário dizer também o quanto esses valores variam - o quão eles são dispersos (SPIEGEL, 1976).

Adicionalmente, e em reforço ao uso de critérios pessimistas, técnicas adicionais, tal como a exclusão de valores atípicos, podem ser utilizadas para eliminação de valores discretos segundo um critério de afastamento de um modelo de distribuição. Controles de uma mesma dimensão podem ser usados ou eliminados em situações em que são encontrados valores muito inferiores ou superiores à média geral.

Os elementos quantificáveis (controles) então podem ser considerados exclusivamente ou excluídos dos cálculos estatísticos seguintes, e, assim, podem influenciar na determinação dos patamares numéricos calculados. Para identificação desses elementos esparsos (valores atípicos), que podem provocar uma situação multimodal ou amodal, ou mesmo extrema assimetria na distribuição, e que acarretariam distorções na inferência estatística, então devem-se utilizar técnicas para identificar valores que são "dispersos, discrepantes ou aberrantes" (OLIVEIRA, 2008). A Figura 2.6 ilustra duas distribuições de frequência: sem valores atípicos e com valores atípicos nos dois extremos da distribuição. 


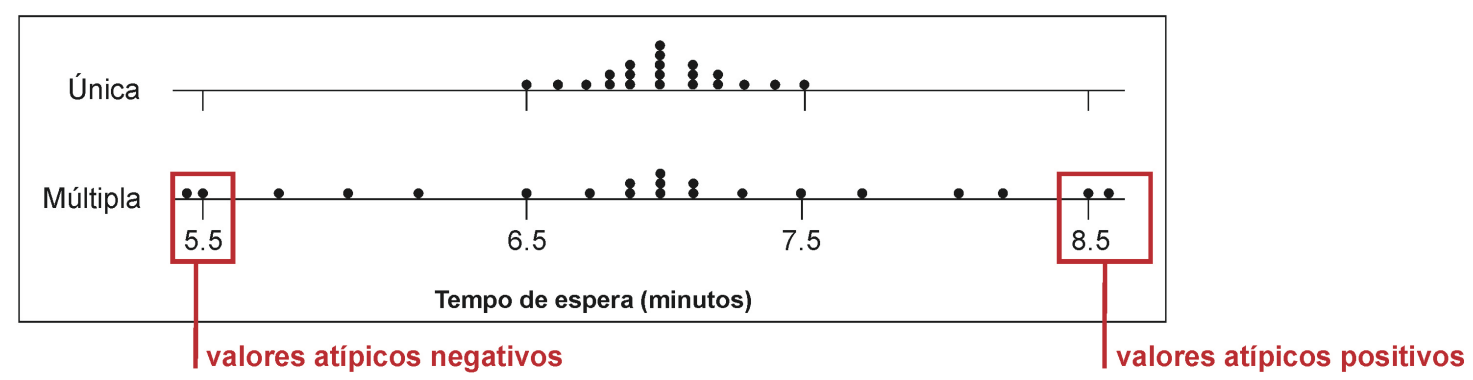

Figura 2.6 - Distribuição de Frequência e Valores Atípicos

Nesse sentido, considerada como pressuposto uma expectativa de pequena amostra de dados e uma distribuição com características de distribuição $\mathrm{t}$ de Student, não é aconselhado aplicar procedimentos inferenciais baseados no Teorema do Limite Central (FERREIRA, 2005). Assim, outras técnicas baseadas em princípios heurísticos são aplicadas para selecionar esses elementos esparsos, bem como para reconhecer as situações multimodais ou amodais.

Esses princípios de heurísticas suportam tanto o modelo de avaliação de maturidade posicional no tempo (cálculo de maturidade em um momento de avaliação, chamado modelo 'as-is') quanto os roteiros de evolução (guia de próximos passos que consideram um modelo 'to-be').

Essa geração de roteiros refere-se à emissão de roteiro (roadmaps) com atividades precisas para atingimento de uma nova meta de maturidade, pelo uso do último referencial encontrado em cada domínio. Trata da disponibilização de um fluxo de atividades controlados (i.e. um 'to do list') de próximos passos. 


\section{3 - INTERPRETAÇÃO DA PROPOSTA DOS MODELOS DE MATURIDADE EXISTENTES}

\section{1 - FRAMEWORKS DE GOVERNANÇA SOA E SEUS ITENS DE AVALIAÇÃO}

Reconhecida a importância de uma correta e ampla Governança nas iniciativas de adoção de SOA nas organizações, foi natural o surgimento de diversos frameworks específicos para a Governança SOA. Desses frameworks, enquanto uma porção significativa de autores defende uma abordagem mais estratégica - como mudanças organizacionais -, a exemplo de Bieberstein et al. (2005), outros enfocam em uma investida mais técnica - como o gerenciamento do ciclo de vida de serviços, caso do modelo da BEA (2006), que posteriormente foi incorporado pela Oracle (2007).

O The Open Group (2011) publicou um modelo elaborado por diversos profissionais, incluindo alguns que já haviam trabalhado em outros modelos, como o da IBM (2005) e da Oracle (2007). Esse modelo procurava convergir as características que julgaram significativas nos principais modelos existentes à época. Embora o modelo do Open Group seja estruturado mais como uma norma técnica, defendendo fortemente a padronização, a sua complexidade e a possibilidade de atendimento integral às necessidades básicas das organizações o posiciona como um framework de referência. Além disso, esse framework incentiva a personalização do modelo às características específicas da organização que tem a intenção de adotá-lo. Segundo Janiesch et al. (2009), o framework OSIMM posicionava-se como "o framework desenvolvido mais promissor em atenção à Governança SOA”.

Tomando-se por base as especificidades desse framework, a Governança SOA deve estender os modelos de governança de TI e da EA existente para "atender aos novos ativos e políticas de SOA" (THE OPEN GROUP, 2011). Estendendo esses modelos de governança existentes, reduz-se o risco de que as organizações criarão regimes descoordenados de governança, que potencialmente poderão duplicar áreas de cobertura existentes de seus regimes de governança principais. Exige então que se governem as atividades de planejamento estratégico, bem como os aspectos de execução de SOA. 
Baseado em trabalhos de Afshar (2013) e Marks e Bell (2006), Niemann et al. (2010) oferecem sua visão de que a estruturação de políticas de Governança de SOA tenha foco em seis domínios:

- Arquitetura: que inclui arquitetura de referência, mecanismos de avaliação de arquitetura, diretrizes para aplicações bem como projetos de arquitetura.

- Infraestrutura Tecnológica: compreende aspectos como a estratégia das plataformas de SOA e de governança, migração de sistemas legados e projeto e implementação de infraestrutura de serviços.

- Organização: cobre todos os aspectos relacionados a recurso humano e estrutura organizacional, tais como: incentivos para os funcionários, definição de papéis e responsabilidades, treinamentos e definição dos proprietários dos serviços e processos.

- Portfólio: trata dos portfólios de projetos SOA, de serviços e de legados, para o planejamento estratégico de SOA e suporte para gerenciamento de projetos.

- Informações e Dados: determina as regras para a propriedade de dados, arquitetura de serviços de dados, formatos e padrões de dados, formalização da descrição dos requisitos de dados em acordos de níveis de serviço - SLA (do inglês Service Level Agreement) e também da qualidade dos dados.

- Execução de Projetos: aborda todas as questões relacionadas com projetos, como: seleção, alinhamento de competência e formalização do controle do ciclo de vida de processos de negócio e políticas.

Porém, é importante que se analise as características mais relevantes junto às áreas que afetam e que são afetadas pelos padrões de Governança SOA. Nesse sentido, Dahlberg e Kivijärvi (2006) e Niemann (2008) elaboraram uma comparação entre esses frameworks, que se utiliza junto com outros referenciais já citados para a elaboração do Quadro 3.1, a seguir. 
Quadro 3.1 - Compilação dos domínios dos frameworks estudados

\begin{tabular}{|c|c|c|c|c|c|c|c|c|c|}
\hline \multirow[b]{2}{*}{ Domínio } & \multirow{2}{*}{$\begin{array}{l}\text { Domínios } \\
\text { Tratados por } \\
\text { cada Modelo }\end{array}$} & \multicolumn{8}{|c|}{ Modelo de Maturidade SOA } \\
\hline & & IBM & ORACLE & HP & $\begin{array}{c}\text { THE OPEN } \\
\text { GROUP }\end{array}$ & GARTNER & ISOAMM & ITANA & BEA IT \\
\hline Negócios & 7 & $\mathrm{X}$ & & $\mathrm{X}$ & $\mathrm{X}$ & $\mathrm{X}$ & & $\mathrm{X}$ & $\mathrm{X}$ \\
\hline Arquitetura & 8 & $\mathrm{X}$ & $\mathrm{X}$ & $\mathrm{X}$ & $\mathrm{X}$ & & $\mathrm{X}$ & $\mathrm{X}$ & $\mathrm{X}$ \\
\hline Organização & 5 & $X$ & $\mathrm{X}$ & & $\mathrm{X}$ & & & & $\mathrm{X}$ \\
\hline Estrutura empresarial & 2 & & & & & & $\mathrm{X}$ & & $\mathrm{X}$ \\
\hline Finanças e portfólio & 2 & & $\mathrm{X}$ & & & & & & $\mathrm{X}$ \\
\hline Processos & 2 & $\mathrm{X}$ & & & & & & & $\mathrm{X}$ \\
\hline Execução de projetos & 1 & & $X$ & & & & & & \\
\hline Gerenciamento de programa & 1 & & & $\mathrm{X}$ & & & & $\mathrm{X}$ & \\
\hline Pessoas & 3 & & $\mathrm{X}$ & $\mathrm{X}$ & & & & $\mathrm{X}$ & \\
\hline Governança & 7 & & $\mathrm{X}$ & $\mathrm{X}$ & $\mathrm{X}$ & & $\mathrm{X}$ & $\mathrm{X}$ & $\mathrm{X}$ \\
\hline Métodos & 3 & $\mathrm{X}$ & & & $\mathrm{X}$ & & & & \\
\hline Aplicações & 4 & $\mathrm{X}$ & & & $\mathrm{X}$ & & & & $\mathrm{X}$ \\
\hline Solução & 1 & & & & & $\mathrm{X}$ & & & \\
\hline Desenvolvimento de serviço & 2 & & & & & & $\mathrm{X}$ & & $\mathrm{X}$ \\
\hline Informação & 5 & $\mathrm{X}$ & $\mathrm{X}$ & & $\mathrm{X}$ & $\mathrm{X}$ & & & \\
\hline Tecnologia & 3 & & & $\mathrm{X}$ & & $\mathrm{X}$ & & $\mathrm{X}$ & \\
\hline Infraestrutura & 5 & $\mathrm{X}$ & $\mathrm{X}$ & & $\mathrm{X}$ & & $\mathrm{X}$ & & \\
\hline Suprimento e demanda & 1 & & & $\mathrm{X}$ & & & & & \\
\hline Operações & 3 & & $\mathrm{X}$ & $\mathrm{X}$ & & & & $\mathrm{X}$ & \\
\hline
\end{tabular}

Fonte: compilado de DAHLBERG; KIVIJÄRVI (2006); NIEMANN (2008); IBM (2005); BEA (2006); HP (2006); ORACLE (2007); GARTNER (2009);THE OPEN GROUP (2011); ITANA (2013). 
Dessas comparações, destacam-se os elementos de Governança SOA desses frameworks, tendo como foco a TI:

a) Estratégias de TI direcionadas pelas estratégias de negócio - Alinhamento da TI aos requisitos do negócio (LUFTMAN, 2013; DAHLBERG; KIVIJÄRVI, 2006)

Trata da maturidade da correlação entre as estratégias e arquiteturas de negócio e a de TI, que deve ser medida e ter sua evolução acompanhada. Em geral, utiliza-se o método de alinhamento de indicadores entre a estratégia do negócio e os indicadores operacionais e táticos (DAHLBERG; KIVIJÄRVI, 2006).

Tal é a relevância da questão que Luftmann (2013) propõe um modelo de avaliação da maturidade desse alinhamento junto às estratégias organizacionais através de seis critérios de avaliação de Maturidade: Comunicação, que é a eficácia da comunicação existente entre as áreas de negócio e de TI; Medição de Competência/Valor, que se refere à capacidade de mensurar e controlar adequadamente a eficiência da área de TI; Governança, que é o nível de governança existente na organização, isso é: se existem processos isolados, se os custos são medidos, se controles existem, etc.; Parceria, que avalia o nível de comprometimento e integração existente entre as áreas de negócio e TI; Arquitetura, que avalia o atendimento da infraestrutura de TI às necessidades de negócio; Competências, que analisa a relação perfil/risco/recompensa entre os profissionais de negócio e TI.

b) Gestão do Contexto do Ciclo de Vida do Negócio (BRAUER; KLINE, 2013; WEBMETHODS, 2013)

Fortemente associada à Maturidade da Governança de Luftmann (2013), esse fator de governança está associado à necessidade de acompanhar e controlar itens tais como: a revisão constante dos direcionadores de negócio; a existência e revisão da Arquitetura Empresarial em toda sua extensão; e as estratégias e políticas voltadas para SOA, Arquitetura dos Processos de Negócio, visão e objetivos do negócio e seu alinhamento com TI, práticas financeiras e ROI, estrutura de competências e definição de responsabilidades, entre outros.

Brauer e Kline (2005) enfatizam que serviços de negócio requerem um ciclo de vida altamente colaborativo para incrementar e/ou otimizar a flexibilidade e agilidade ao 
negócio proporcionadas por SOA; assim, colocam que os profissionais de negócios, desenvolvedores e operadores precisam ter as mesmas informações disponíveis, mas cada um em seu próprio contexto, seja negocial, seja técnico. Essa informação viria na forma de um modelo que pode ser atualizado por qualquer um desses componentes, tais como os eventos (técnico, negocial ou não) ocorram. Atualizações para esse modelo irão propagar as ações tomadas por outros dentro da cadeia de prestação de serviços para apoiar eficazmente as alterações feitas para o serviço de negócio.

c) Equilíbrio de Custos e Acompanhamento do ROI (WEILL; ROSS, 2004; DAHLBERG; KIVIJÄRVI, 2006)

Recursos finitos e cada vez mais dispendiosos vêm fazendo com que novos investimentos em TI sejam submetidos não apenas a um teste mínimo de ROI, mas exigindo uma mensuração de sua contribuição de valor estratégico para a organização (DAHLBERG; KIVIJÄRVI, 2006; TARANTINO, 2008). Em muitas organizações, aplicações estratégicas são focadas em seus principais processos de negócio e, em grandes organizações, esses processos abrangem múltiplas funções e unidades de negócio (WEILL; ROSS, 2004). Esses autores afirmam ainda que essas aplicações têm a finalidade de melhorar os processos de negócio da organização e seu valor resulta da capacidade de mudar 'como' as organizações operacionalizam seus negócios.

Decisões sobre essas aplicações envolvem a identificação dos principais processos de negócio e, entre eles, quais processos e aplicações podem contribuir com benefícios significativos para a organização. Assim, esses são então os fatores que devem ser analisados e constantemente monitorados para garantir o equilíbrio dos custos com o retorno e benefícios esperados pelo suporte da área de TI.

\section{d) Suporte a Tomadores de Decisão (WEILL; ROSS, 2004; BIEBERSTEIN et al., 2005)}

A IBM (2006) aponta que algumas práticas de governança SOA devem ser consideradas conducentes, ou seja, indispensáveis para o sucesso de projetos nessa arquitetura; destacando-se o necessário envolvimento da cúpula dirigente da organização com esse projeto. Esse trabalho especifica que os representantes nos processos de tomada de decisão devem ser mantidos envolvidos em cada aspecto do planejamento e execução do modelo. 
Assim, a visão da Governança Corporativa do estágio reconhecido de adoção de SOA sua opinião - se faz necessária junto a qualquer iniciativa de avaliação.

Nesse sentido, Weill e Ross (2004) e Bieberstein et al. (2005) ressaltam a importância da disponibilização de informações de Governança SOA e seu real estágio de adoção no apoio aos processos de tomada de decisão, fortalecendo o vínculo entre a Governança Corporativa e as áreas de negócio e de TI, garantindo assim o encaminhamento correto de ações nos projetos SOA em desenvolvimento.

e) Balanceamento e Controle de Riscos e Oportunidades em Ambientes Dinâmicos (WEILL; ROSS, 2004; DAHLBERG; KIVIJÄRVI, 2006)

Dahlberg e Kivijärvi (2006) propõem sete fatores de governança de TI/áreas de responsabilidade de gestão apresentadas como modelo de processo. São eles: 1. alinhamento de negócios e TI; 2. monitoramento de recursos de TI; 3. riscos e gestão; 4. acompanhamento de medição de desempenho de TI; 5. avaliação de entrega de valor de negócio (benefícios-custos); 6. avaliação de oportunidades de negócios (oportunidades e riscos); 7. desenvolvimento de governança de TI. Nesse sentido, Dahlberg e Kivijärvi (2006) reforçam a importância da gestão de riscos e monitoramento de desempenho de negócio e oportunidades como fatores relevantes para entrega real de valor ao negócio.

Marks (2008) e Racz et al. (2011) defendem fortemente a Gestão de Risco como fator crítico de sucesso de conformidade na Governança. Uma definição amplamente aceita de Gestão de Risco ou Enterprise Risk Management (ERM) foi publicada pelo Committee of Sponsoring Organizations of the Treadway Commission (COSO). Assim, ERM

[...] é um processo efetuado pela diretoria, gestores e outros profissionais, aplicado na definição de estratégia e em toda a empresa, desenhado para identificar potenciais eventos que possam afetar a entidade, e gerir os riscos que estejam em seu 'apetite de risco', para fornecer uma garantia razoável quanto à realização dos objetivos.

Dada a natureza tecnológica de SOA, a disponibilização rápida de novas tecnologias como serviços, tecnologias de comunicações móveis, sistemas e outras que ainda virão, criam riscos e oportunidades estratégicas (WEILL; ROSS, 2004). 
Assim, o correto balanceamento e controle desses riscos e oportunidades, o uso de análises baseadas em métricas e informações confiáveis e um suporte adequado dos procedimentos de governança possibilitam melhor mitigação dos riscos e melhor aproveitamento das oportunidades, fazendo com que a TI agregue valor de fato ao negócio da organização. Um ponto importante é que riscos vão ser gerados pelo próprio ciclo de vida de adoção de SOA (VOM BROCKE; ROSEMANN, 2010).

f) Atendimento de pontos internos de conformidade e externos de regulação (ORACLE, 2007)

Niemann (2013) afirma que esses atendimentos visam a garantir conformidade às regulações legais aplicáveis, regulações técnicas e normativas internas, através de controles efetivos. Segundo Frigo e Anderson (2009), o ambiente de negócios ao longo dos últimos anos tem experimentado uma série sem precedentes de problemas, surpresas e acontecimentos negativos, que aumentaram o foco na adequação da governança das organizações, riscos e atividades de controle. $\mathrm{O}$ foco cada vez maior na conformidade de regulações legais, melhores práticas e normas internas têm levado muitas organizações a aumentar os seus orçamentos e pessoal para as funções de conformidade e, ao mesmo tempo, aumentos nas funções de auditoria interna e de gestão de riscos.

Nesse ponto, cabe apontar o entendimento da definição de conformidade legal como atendimento a leis e normas que garantam o controle externo. Assim, considera-se conformidade normativa aquelas referentes às práticas de auditoria e controle interno, fortemente relacionadas à política organizacional e ao uso de práticas e padrões que serão tratados a seguir.

g) Foco no uso de padrões e políticas metodológicas (ORACLE, 2007; THE OPEN GROUP, 2009)

A importância da aplicação de frameworks de Governança específicos para TI é ressaltada por diversos autores (DAHLBERG; KIVIJÄRVI, 2006; LUFTMAN, 2013; RIBBERS et al., 2002; VAN GREMBERGEN, 2004), principalmente aqueles baseados em uma perspectiva de processos, pois oferecem a flexibilidade e independência na rápida reestruturação organizacional necessária, o que é fator positivo na melhor adoção 
de SOA. Niemann (2008) elenca alguns desses, que são de uso comum e que focam nos diferentes aspectos da TI:

- Control Objectives for Information and Related Technologies (COBIT): framework de governança e controle do IT Governance Institute (ITGI), que é mais fortemente alinhado aos objetivos de negócio da organização do que a questões operacionais e, por isso, segundo Niemann (2008), se tornou um padrão de fato para as organizações de TI.

- ValIT: framework de governança baseado no COBIT e publicado pelo ITGI, que inclui orientações e processos de suporte relacionados à avaliação e seleção de investimentos de negócio viabilizados por TI, bem como os benefícios da realização e entrega de valor.

- Information Technology Infraestructure Library (ITIL): conjunto de boas práticas mantido pela Office for Government Commerce (OGC) e que observa os processos de infraestrutura, operação e manutenção de serviços de TI.

- ISO 20.000: é a primeira norma editada pela International Organization for Standardization (ISO) que versa sobre gerenciamento de qualidade de serviços de TI com foco no Gerenciamento de Serviços de TI.

- ISO 17.799: é uma norma que padroniza a gestão de Segurança da Informação. Em 2007, foi atualizada e formatada em uma série de normas complementares sob numeração ISO/IEC 27000.

h) Especificação clara de estrutura de responsabilidades e direitos (WEILL; ROSS, 2004).

Weill e Ross (2004) retratam dois lados da governança de TI: o comportamental e o normativo. O lado comportamental define as relações formais e informais e atribui os direitos de decisão para determinados indivíduos ou grupos de indivíduos. O lado normativo define mecanismos que formalizam as relações e criação de regras e procedimentos operacionais para garantir que os objetivos sejam cumpridos. A determinação clara da estrutura de competências, responsabilidades e direitos facilitará a implementação de 
processos e controles que diminuirão os riscos e contratempos de projetos em andamento e viabilizarão melhor definição de ações corretivas.

Adicionalmente, a adoção de SOA define uma série de novos perfis e papéis, com responsabilidades claras junto a essa arquitetura. No modelo proposto por Erl (2005), encontram-se perfis tecnológicos e de governança específicos para gestão e aplicação dos princípios de orientação a serviços, tais como Arquitetos e Analista SOA; Especialistas em Governança, Segurança, Políticas e Garantia da Qualidade SOA; bem como Guardiões e Responsáveis por Inventários, Serviços e Capacidades nos serviços desenvolvidos. Note-se que papéis em projetos de SOA têm relações comuns com fases específicas do ciclo de vida de um projeto de SOA típico (PUTTINI et al. 2013).

i) Gerenciamento do Ciclo De Vida dos Serviços SOA (IBM, 2005; BEA, 2006; MARKS, 2008)

Em sua abordagem de Governança SOA, a IBM (2005) enfatiza a necessidade do gerenciamento do ciclo de vida dos serviços. Em seu framework, intitulado SOA Governance and Management Method (SGMM), apresenta propostas para a definição, concepção e implementação da Governança de SOA e da gestão do ciclo de vida de serviços. O escopo do processo de ciclo de vida de serviços, segundo a IBM, inclui os processos que são necessários para identificar, desenhar, desenvolver, testar, implantar e gerenciar serviços.

Marks (2008) acrescenta que Governança SOA significa estabelecer funções e responsabilidades para itens como financiamento e orçamento, gerenciamento de portfólio, propriedade e ciclo de vida dos serviços. No entanto, quando a Governança SOA é estabelecida, dependendo do nível de maturidade da organização, deve-se focar em áreas críticas, as quais devem ter prioridade no controle e gestão. Algumas áreas inicialmente indispensáveis são processos de EA, os padrões de projeto e de interoperabilidade de serviços, e atribuições de responsabilidade clara para vários tipos de serviços.

Pode-se dizer, então, que Governança SOA, além dos princípios arquiteturais e tecnológicos que a estabelecem, deve ainda observar o alinhamento da TI aos requisitos do 
negócio; a gestão do contexto do ciclo de vida do negócio; o equilíbrio de custos e acompanhamento do ROI; o suporte a tomadores de decisão, com destaque na disponibilização de indicadores sobre a adoção de SOA; o balanceamento e controle de riscos e oportunidades; o atendimento de marcos regulatórios; o uso de padrões e políticas metodológicas com a aplicação de melhores práticas de gestão e gerenciamento da TI; a clara especificação de estrutura de responsabilidades e direitos em perfis, papéis e competências bem definidos; e o gerenciamento completo do ciclo de vida de serviços SOA. Assim, adicionam-se aos elementos característicos da arquitetura outros controles que permitem a mensuração da qualidade de adoção de SOA em uma organização.

E mais, em se tratando de estruturação das políticas de Governança, identifica-se uma separação do foco do controle a ser realizado pela mesma nos modelos referentes à Negócios, Arquitetura, Organização, Estrutura Empresarial, Finanças e Portfólio, Processos, Execução de Projetos, Gerenciamento de Programa, Pessoas, Governança, Métodos, Aplicações, Solução, Desenvolvimento de Serviço, Informação, Tecnologia, Infraestrutura, Suprimento e Demanda, Operações. Essa separação permite um primeiro entendimento dos distintos elementos organizacionais a serem avaliados para definição do estágio de SOA.

Nesse sentido, associando esse conjunto com a definição da Governança de TI, todos esses focos abrangem as diversas características a serem observadas por essas para atender aos princípios essenciais de qualquer Governança (TARANTINO, 2008).

Modernamente, o crescente número de leis e regulamentos, os riscos aumentados de que as organizações têm de lidar com, e as preocupações crescentes com governança, induziram as organizações a repensar as abordagens convencionais separadas para a governança, gestão de riscos e conformidade (FRIGO; ANDERSON, 2009 apud RACZ et al, 2011). Já em 2007, Derler e Weinreich (2013) apontavam que ferramentas para governança de SOA e sua gestão estão evoluindo para ser o cerne da empresa.

Assim, tendo como foco a Governança de TI e o suporte a Governança Corporativa, que no conjunto compõem a Governança SOA, essas preocupações vêm sendo agrupadas em um único modelo de Gestão, representado por meio de uma abordagem integrada em framework de GRC. Nesses frameworks, as funções de GRC compartilham objetivos 
comuns que, em última análise, são a criação e a preservação de partes interessadas no valor, que junto com risco e controle são as principais metas da organização quando aplica os princípios de gestão (BEASLEY; FRIGO, 2007; FRIGO, 2008).

Para tratar de questões estratégicas, algumas organizações consultivas têm desenvolvido iniciativas referidas como soluções de GRC, que agrupam o contexto de atividades de Governança nos seus princípios, olham através de seu risco e funções de controle de forma holística, e procuram aumentar a sua eficiência e eficácia (RACZ et al., 2011). Assim, os frameworks SOA e suas orientações têm induzido muitas empresas na construção de soluções para ajudar a automatizar os esforços e o escopo no suporte a essa Governança (RACZ et al., 2011).

Racz et al. (2011) elencam uma lista de componentes que são consenso das questões mais críticas abertas, e que são recorrentes nas soluções de GRC. Destaquem-se os principais: Gestão Operacional; Gerenciamento de Conformidade e Auditoria; Gerenciamento e Testes de Controles Financeiros; Pesquisas e Questionários Avaliativos; Gerenciamento de Fluxo de Processos, Atividades e Tarefas; e Suporte a Governança Corporativa.

Em uma pesquisa das soluções existentes que implementam o framework SOA foram compiladas as questões fundamentais analisadas em cada modelo de maturidade de SOA estudado, que estão listadas no APÊNDICE A.

Porém, como um modelo arquitetural, a aplicação de SOA se dá de forma continuada, suportada por avaliações tempestivas que patrocinam ciclos de melhoria. Essas avaliações buscam mitigar a possibilidade de fracasso na construção dos elementos fundamentais dessa arquitetura. Assim, o conceito de modelo de maturidade está associado diretamente ao resultado dessas avaliações.

\section{2 - MODELOS EXISTENTES PARA AVALIAÇÃO DE MATURIDADE SOA}

Com a evolução do uso de SOA, seus métodos e princípios, diversos trabalhos recentes buscam estabelecer um modelo de nível de maturidade SOA. No Quadro 3.2 são elencados, em ordem cronológica, os modelos de maturidade SOA analisados. 
Quadro 3.2 - Principais modelos de maturidade SOA.

\begin{tabular}{|c|c|c|}
\hline Ano & Modelo & Princípios do Framework \\
\hline 2005 & $\begin{array}{l}\text { IBM SOA Service } \\
\text { Integration } \\
\text { Maturity Model } \\
\text { (SIMM) (2005) }\end{array}$ & $\begin{array}{l}\text { Analisa a adoção de SOA em cinco estágios que se sobrepõem: ad hoc, } \\
\text { em adoção da tecnologia, em formação das linhas de negócio em SOA, } \\
\text { em adoção empresarial de SOA, e em adoção de redes de valores com } \\
\text { parceiros, fornecedores e terceiros. }\end{array}$ \\
\hline 2005 & $\begin{array}{l}\text { Sonic-AmberPoint- } \\
\text { BearingPoint- } \\
\text { Systinet New } \\
\text { Service-Oriented } \\
\text { Architecture } \\
\text { Maturity Model - } \\
\text { NEW SOAMM } \\
\text { (2005, revisado do } \\
\text { SOAMM }\end{array}$ & $\begin{array}{l}\text { Apresenta um modelo de maturidade diretamente associado ao CMMI } \\
\text { (cinco níveis de maturidade SOA), tratando progressivamente o impacto } \\
\text { dessa adoção nos negócios da seguinte forma: Serviços Iniciais, } \\
\text { Serviços sob Arquitetura, Serviços Empresariais e Serviços } \\
\text { Colaborativos, Serviços de Negócios Medidos, e Serviços de Negócios } \\
\text { Otimizados. }\end{array}$ \\
\hline 2006 & $\begin{array}{l}\text { BEA SOA Evolution } \\
\text { Model (2006, } \\
\text { adquirido e adaptado } \\
\text { pela Oracle) }\end{array}$ & $\begin{array}{l}\text { Dá foco no crescimento das habilidades técnicas no desenvolvimento de } \\
\text { soluções, tratando desde o desenvolvimento de aplicações Web, } \\
\text { passando pelo uso de princípios de composição de serviços, até o } \\
\text { atendimento da automação do processo de negócio. }\end{array}$ \\
\hline 2006 & $\begin{array}{l}\text { HP SOA Maturity } \\
\text { Model - SOAMM } \\
(2006)\end{array}$ & $\begin{array}{l}\text { Para avaliar de forma eficaz todos os aspectos da adoção de SOA, essa } \\
\text { proposição de modelo identifica um conjunto de oito domínios de SOA. } \\
\text { A partir dessa visão geral de domínios SOA, o modelo examina as } \\
\text { capacidades e ativos que são críticos para o sucesso na adoção de SOA, } \\
\text { bem como o impacto sobre a agilidade dos negócios de cada parte da } \\
\text { empresa. . Posteriormente, em } 2007 \text {, Yawalkar da CTS/HP apresenta a } \\
\text { recomendação de um produto da HP para auto-avaliação de Maturidade } \\
\text { em SOA. }\end{array}$ \\
\hline 2007 & $\begin{array}{l}\text { Accenture } \quad S O A \\
\text { Diagnostic (2007) }\end{array}$ & $\begin{array}{l}\text { Difunde o serviço de Diagnóstico (Accenture SOA Diagnostic) como uma } \\
\text { fase do Roadmap SOA da Accenture, envolvendo um Roteiro para } \\
\text { Adoção SOA da Accenture que ajuda empresas e agências } \\
\text { governamentais a definir passos prudentes porém imediatos para que essas } \\
\text { possam criar um plano de negócios sólido para a SOA. Parte desta oferta é } \\
\text { o serviço de Diagnóstico SOA Accenture baseado na ferramenta de } \\
\text { diagnóstico SOA Accenture, que torna possível a coleta de dados } \\
\text { fundamentais para a adoção de SOA, e baseado em roteiros permitem } \\
\text { pesquisas adaptadas às necessidades do cliente. }\end{array}$ \\
\hline 2007 & $\begin{array}{lr}\text { Microsoft } & \text { Services } \\
\text { Assessment } & \text { and } \\
\text { Roadmap } & \text { for } \\
\text { Service } & \text { Oriented } \\
\text { Architecture } & (2007)\end{array}$ & $\begin{array}{l}\text { A avaliação de SOA da Microsoft fornece uma perspectiva independente } \\
\text { das capacidades de SOA existentes e futuras. Essa avaliação oferece um } \\
\text { roteiro para adoção de SOA com recomendações prioritárias, apoiado } \\
\text { pela documentação dos resultados da avaliação do uso empresarial de } \\
\text { SOA, bem como reporta um inventário dos controles, suas } \\
\text { dependências e níveis de adoção distintos. Divide o tratamento da } \\
\text { maturidade SOA em três áreas distintas: Administração, Uso/Consumo e } \\
\text { Implementação. }\end{array}$ \\
\hline 2007 & $\begin{array}{lr}\text { Oracle } & \text { SOA } \\
\text { Maturity } & \text { Model - } \\
\text { SOAMM } & (2007, \\
\text { revisado } & \mathrm{em} \\
\text { Set/2013); } & \end{array}$ & $\begin{array}{l}\text { O Modelo de Maturidade SOA da Oracle utiliza também o conceito de } \\
\text { domínios para classificar e organizar os recursos relacionados, e considera } \\
\text { seis níveis, iniciando com um nível de inexistência de SOA. Adicionalmente } \\
\text { a esses conceitos, o modelo Oracle analisa ainda a abordagem de escopo } \\
\text { utilizada nessa adoção, classificando-a em: Nível Empresarial quando a } \\
\text { adoção atravessa toda organização; Nível Intradepartamental quando a } \\
\text { adoção implementa recursos compartilhados entre múltiplos departamentos } \\
\text { da organização; Nível Departamental, quando as capacidades são } \\
\text { implementadas consistentemente em um departamento ou unidade de } \\
\text { negócio; Nível de Programa, quando um grupo de projeto compartilha as } \\
\text { implementações e capacidades; Nível de Projeto, quando a abordagem é por } \\
\text { projetos individuais. }\end{array}$ \\
\hline
\end{tabular}




\begin{tabular}{|c|c|c|}
\hline Ano & Modelo & Princípios do Framework \\
\hline 2009 & $\begin{array}{l}\text { Gartner's } \\
\text { Roadmap to SOA } \\
(2009)\end{array}$ & $\begin{array}{l}\text { Defende que a adoção de SOA e os serviços web sejam implementados } \\
\text { através de estratégias diferenciadas de adoção, dada as necessidades ou } \\
\text { foco estratégico da organização. São essas estratégias: Minimalista - } \\
\text { Adoção padrão de aplicativos e ferramentas de fornecedores para mudar } \\
\text { suas soluções para arquitetura SOA sem tomar medidas proativas para } \\
\text { explorar estas capacidades até que eles são difundidos; Focado na } \\
\text { Integração - Usa serviços para facilitar a integração de sistemas internos, } \\
\text { sendo essa atualmente a abordagem mais comum para a adoção ativa de } \\
\text { serviços; Focada para o Exterior - Identifica as interfaces do sistema } \\
\text { externos usadas por parceiros de negócios e clientes de forma a oferecê- } \\
\text { los como serviços da web; e Radical - Busca oportunidades de } \\
\text { exploração de SOA e de serviços, incluindo a cobrança pelo acesso } \\
\text { nesses serviços. Os candidatos para essa abordagem são empresas de } \\
\text { alta tecnologia, especialmente para promover modelos de negócios com } \\
\text { base em software por assinatura. }\end{array}$ \\
\hline 2009 & $\begin{array}{l}\text { Open Group } \\
\text { Service Integration } \\
\text { Maturity Model - } \\
\text { OSIMM (2009), } \\
\text { gerado em } \\
\text { conjunto pela IBM, } \\
\text { BEA, HP, EDS e } \\
\text { Capgemini) }\end{array}$ & $\begin{array}{l}\text { O Modelo de Maturidade de Integração do Open Group para SOA } \\
\text { (OSIMM) fornece aos consultores e profissionais de TI um meio de } \\
\text { avaliar a Arquitetura Orientada a Serviços de uma organização segundo } \\
\text { o seu nível de maturidade. Esse modelo define um processo para criar } \\
\text { um roteiro de adoção incremental que maximiza os benefícios de } \\
\text { negócios em cada etapa ao longo do ciclo de maturidade. O modelo } \\
\text { consiste em sete níveis de maturidade e sete dimensões de análise que } \\
\text { representam visões significativas de negócio e capacidades de TI, onde a } \\
\text { aplicação de princípios de SOA é essencial para a implantação de } \\
\text { serviços. O OSIMM atua como um modelo quantitativo para auxiliar na } \\
\text { avaliação da situação atual e do estado futuro almejado de maturidade. }\end{array}$ \\
\hline 2013 & Itana.org (2013) & $\begin{array}{l}\text { Expõe na Internet, através de recurso de Wiki, um Questionário } \\
\text { Eletrônico usado por instituições acadêmicas (Universidades de } \\
\text { Berkeley, Michigan, Cornell, Georgetown, Ohio State, Colorado, } \\
\text { Indiana e entre outros) para realizar um avaliação do estágio de adoção } \\
\text { de SOA nas mesmas. Esse modelo dá foco nos assuntos: Maturidade } \\
\text { SOA na instituição; Uso vertical de padrões de indústria; } \\
\text { Disponibilização de Serviços de Integração com SOA; Governança; } \\
\text { Governança de dados, Gerenciamento de Acesso e Identidade; } \\
\text { Princípios de Projeto SOA; Tecnologias; e Abordagem da Análise de } \\
\text { Custo-Benefício Utilizada }\end{array}$ \\
\hline
\end{tabular}

Fonte: compilado de IBM (2005); SONIC (2005); BEA (2006); HP (2006); ACCENTURE (2007); MICROSOFT (2007); ORACLE (2007); GARTNER (2009); THE OPEN GROUP (2011); ITANA (2013).

$\mathrm{Na}$ análise dos modelos citados, no que se refere à qualificação do estágio de maturidade, observa-se que a identificação dos níveis de maturidade é analisada segundo duas óticas:

a) Pela aderência em estágios de maturidade no uso de tecnologia de serviços web no suporte à aplicação dos princípios e paradigmas de SOA (e.g. IBM, 2005; BEA, 2006; MICROSOFT, 2007; THE OPEN GROUP, 2009; ACCENTURE, 2007; GARTNER'S ROADMAP TO SOA, 2009). Nesses referenciais estão impostas escalas que avaliam o menor ou o maior uso de tecnologias de SOA. 
b) Pela associação direta ou indireta a referência tradicional de maturidade organizacional em TI, tal como o CMMI (e.g. ORACLE, 2007; HP, 2006; ITANA, 2013) e seus elementos de avaliação. Esses modelos de maturidade para SOA são afetos em quantidade e forma de avaliação aos níveis tradicionais do CMMI (CARNEGIE MELLON SOFTWARE ENGINEERING INSTITUTE, 2006).

Nesses trabalhos citados, os desafios são de ir além de uma simples categorização de acordo com algumas similaridades do CMMI, e de justificar porque SOA como técnica pode ser instanciada como definida, reproduzível ou otimizada. "Isso é muitas vezes fácil de fazer, devido à natureza aberta e interpretável das descrições de cada nível de maturidade CMMI" (IBM, 2009).

Welke et al. (2011), no entanto, contrapõem o uso do CMMI para avaliação de maturidade em SOA, pois entendem que os níveis de maturidade CMMI refletem as transições de uma aplicação ad hoc de determinada prática para um modelo que é repetitivo, medido, gerenciado e otimizado; enquanto em SOA, quanto mais as organizações se tornam maduras no uso dessa arquitetura, "eles se movem em direção a mais plena realização da capacidade SOA de contribuir para as operações de negócios e na orientação da organização do serviço como um todo" (WELKE, 2011).

A partir de Vukmanovic e Kalpic (2012) e dos referenciais que declaram os modelos citados neste trabalho, faz-se uma compilação da interpelação percebida entre os níveis de maturidade SOA utilizados por cada framework, conforme se observa no Quadro 3.3.

Adicionalmente, como um modelo que avalia capacidades em contexto diferenciado, o modelo de maturidade SOA compreende também o relacionamento dessa maturidade com os aspectos diferenciados que tratam áreas de processo e/ou práticas específicos. Desde a publicação de sua primeira versão, o CMMI v1.1 tem sido ampliado pela aplicação de marcos de melhora em diferenciados domínios de capacidades. Em geral, esses domínios de capacidades do CMMI envolvem áreas de processo, e o modelo CMMI-DEV v1.2 contém 22 (vinte e duas) áreas de processo (CARNEGIE MELLON SOFTWARE ENGINEERING INSTITUTE, 2006). 
Quadro 3.3 - Inter-Relação percebida entre os níveis de maturidade utilizados por Framework para SOA

\begin{tabular}{|c|c|c|c|c|}
\hline CMMI & NSOAMM & Oracle & HP & ITANA \\
\hline Ad hoc & Serviços iniciais & Oportunístico & Ad hoc & Ad hoc \\
\hline Gerenciado & Serviços arquitetados & Sistemático & Básico & Básico \\
\hline Definitivo & $\begin{array}{c}\text { Serviços de negócio } \\
\text { colaborativos }\end{array}$ & Empresarial & Padronizado & Padronizado \\
\hline $\begin{array}{c}\text { Quantitativamente } \\
\text { Gerenciado }\end{array}$ & $\begin{array}{c}\text { Serviços de negócio } \\
\text { mensuráveis }\end{array}$ & Mensurado & Gerenciado & Gerenciado \\
\hline Otimizado & $\begin{array}{c}\text { Serviços de negócio } \\
\text { otimizados }\end{array}$ & Industrializado & Adaptado & Adaptado \\
\hline
\end{tabular}

Fonte: NSOAMM (2005); HP (2006); ORACLE (2007); ITANA (2013).

Porém, no que se refere à SOA, a maturidade no uso de serviço relaciona-se com capacidades de integração entre os vários elementos e/ou processos de negócio e de TI métodos, arquitetura de aplicações, infraestrutura, portfólio de serviços, entre outros (IBM, 2005; NIEMANN et al., 2010).

Nos frameworks citados, essas capacidades de integração são analisadas como visões diferenciadas e são chamadas de dimensões ou domínios. Diferentes modelos e frameworks têm definido de forma diferente o escopo desses domínios de capacidade (VUKMANOVIC; KALPIC, 2012). Ainda apresentam semânticas diferenciadas em cada modelo: enquanto alguns modelos não priorizam a definição (SONIC, 2005), o modelo OSIMM define esses domínios de capacidade como Dimensão e associa o termo domínio com uma subdivisão; o modelo Microsoft (2007) associa essa visão ao próprio conceito de Capacidade (Capability) do CMMI; já o Gartner (2009) chama esse princípio de visão.

Domínios (ou Dimensões) representam, então, os aspectos e níveis organizacionais maiores e abstratos no qual SOA tem efeito. Nesse sentido, os domínios são os conjuntos que permitem avaliar de forma eficaz todos os aspectos da adoção de SOA, segundo as visões organizacionais (HP, 2006), e são nesses nos quais os níveis de maturidade de SOA em uma organização devem ser avaliados isoladamente, pois em cada organização cada dimensão pode estar em um nível de maturidade diferente (THE OPEN GROUP, 2011).

A partir de Vukmanovic e Kalpic (2012) e dos referenciais que declaram os modelos citados no Quadro 3.2 deste trabalho, faz-se uma compilação da inter-relação levantada entre os domínios dos frameworks estudados. 
Não obstante essa visão agregada dos domínios de capacidades, são as capacidades os reais elementos mensuráveis, pois tratam de características específicas em cada domínio e fornecem os detalhes necessários para realmente medir e orientar o progresso de uma iniciativa SOA (ORACLE, 2007). Essas capacidades se traduzem em valores discretos ao longo do eixo maior ao qual cada Dimensão pode ser medida (THE OPEN GROUP, 2011), e assim uma quantificação do estado atual da maturidade da adoção de SOA em uma organização pode ser gerado. Essas capacidades são tratadas por diversas terminologias dentro de cada framework; cabe, então, a definição de uma terminologia comum.

As partes constituintes do domínio (THE OPEN GROUP, 2011) citadas, que quando projetadas como valores tornam-se indicadores de maturidade, permitem orientar a organização sobre os controles que deve ter para que a TI cumpra seus objetivos em termos de Governança. No que se refere à Governança de TI, o framework mais comum adotado para realizar o controle necessário e orientar para escolher estratégias para integração de TI aos objetivos do negócio é o COBIT. O framework Cobit 5 - em sua última atualização lista sete categorias de controles (ISACA, 2012): 1. Princípios e Políticas e Frameworks; 2. Processos; 3. Estrutura Organizacional; 4. Cultura, Ética e Comportamento; 5. Informação; 6 Infraestrutura de Serviços e Aplicações (Capacidades de Serviços); 7. Pessoas, Habilidades e Competências.

Assim como SOA, o foco principal do COBIT é a orientação ao negócio; e os dois modelos apresentam modelos de maturidades que orientam a Governança sobre os controles que devem ser utilizados para que a TI cumpra seus objetivos (ALVES, 2012). Nesse sentido, da proximidade em diversos aspectos na terminologia e o objetivo dos frameworks, este trabalho utilizou-se da mesma terminologia Controles para designar as capacidades a serem mensuradas dentro dos domínios. Em outros trabalhos (THE OPEN GROUP, 2011; HP, 2006; ORACLE, 2007), essas capacidades também são nominadas como indicadores, indicadores-chave, características chaves ou características de maturidade.

Assim, tem-se como elementos principais de uma arquitetura para um modelo de maturidade SOA:

- Níveis de Maturidade: estabelecem os patamares atingíveis pela organização no processo de melhoria na adoção de SOA. 
- Domínios: são os grupos de elementos que representam visões significativas dos ambientes de negócio e de TI, onde a aplicação dos princípios de SOA tem maior efeito e representam um grupo de aspectos no qual a organização e sua TI podem ser medidos em seu nível de maturidade SOA. A organização pode estar em níveis diferenciados de maturidade em cada um desses domínios (THE OPEN GROUP, 2011). Domínios são mapeados, portanto, com área de conhecimento e competência organizacionais específicos.

- Controles: representam aspectos específicos pelo qual a organização pode ser medida em seu nível de maturidade SOA. Esses grupos de aspectos relacionam-se às práticas de adoção e uso de SOA e seus princípios. De forma heurística, o nível de maturidade geral de uma dimensão é agregado a partir dos níveis de maturidade individuais de seus domínios (THE OPEN GROUP, 2011).

Controles são agrupados em Domínios e assim os domínios podem ser avaliados em níveis de maturidade, sendo os controles os fatores elementares de mensuração e avaliação. Controles são assim os assuntos-chave que compreendem dado domínio do modelo; isso é, são os pontos que em conjunto estabelecem a abrangência que cada domínio se propõe a avaliar e são usados a fim de que se obtenha o nível de maturidade em um domínio em análise.

\section{3 - HISTÓRICO DA MATURIDADE NA ADOÇÃO DE SOA}

Marks e Bell (2006) reportam que SOA "é um processo distribuído espacialmente e temporalmente", sendo esse um dos fortes desafios organizacionais. Nesse sentido, a evolução da maturidade em SOA compreende séries temporais (ou séries históricas).

Séries temporais são um conjunto de observações de uma mesma variável quantitativa (discreta ou contínua) feitas ao longo do tempo. Um dos objetivos do estudo de séries temporais é conhecer o comportamento do domínio ao longo do tempo (aumento, estabilidade ou declínio dos valores).

Os domínios definidos dentro de cada situação são utilizados para a análise do nível de maturidade da organização em cada domínio dentro do tempo (YAWALKAR, 2007), já 
que o modelo de maturidade SOA suporta a ideia de que as capacidades e ativos de uma arquitetura corporativa SOA podem ser adotados em diferentes épocas e em diferentes graus (ACCENTURE, 2007).

Cada ponto de avaliação - conceito de visão do modelo ORACLE (2007) - posiciona o estágio dos domínios e de seus controles SOA em um nível determinado e discreto. Porém, é através da evolução no tempo que é possível contrapor o custo e o esforço necessários para acomodar as necessidades para atingimento de cada novo estágio em cada domínio (HP, 2006). Assim, para que um novo nível seja alcançado, é necessário que algumas mudanças pré-determinadas ocorram dentro das áreas analisadas, de modo que o grau de maturidade geral de SOA na organização seja realizado de forma visível e integrada. Além disso, para alcançar o sucesso na adoção de SOA, é importante garantir que as necessidades de cada domínio são levadas em consideração (HP, 2006), assim como deve haver harmonia de evolução entre os domínios.

Adicionalmente, é com a análise da evolução que medidas preparatórias podem ser identificadas, dada a influência dessa evolução junto a outros fatores correlatos - quanto maior o grau de maturidade atingido, mais elevado é o nível de estruturação das áreas atingidas (DIAS JR. et al., 2012) e, assim, mais coordenação é necessária visando a maximizar o retorno oriundo das práticas de orientação a serviço. 


\section{4 - PROPOSTA DE MODELO PARA AVALIAÇÃO DE MATURIDADE SOA}

Em referência aos desafios e motivação deste estudo, a solução proposta e apresentada nesta seção consiste na definição de um modelo para avaliação estruturada de maturidade em arquitetura orientada a serviços a ser realizada em ciclos de planejamento, execução e monitoramento e aferida em relação às melhores práticas de projetos $\mathrm{SOA}$, de forma a prover roteiros para conduzir a evolução da arquitetura. Desse modo, as principais características e componentes do modelo proposto podem ser assim sintetizadas:

- Avaliação quantitativa de maturidade expressa em cinco níveis de maturidade (1. Inicial, 2. Gerenciado, 3. Definido, 4. Mensurável, 5. Otimizado), em conformidade com escalas de maturidade estabelecidas na indústria - CMMI e CoBIT, por exemplo. Essa característica é ilustrada no Quadro 4.1.

- Avaliação com base em Coleta de Dados usando questionários estruturados, que abordam de maneira sistemárica itens de avaliação que permitem verificar a implementação (conformidade) de controles específicos, representando melhores práticas de SOA, agrupados, por sua vez, nos diferentes domínios (áreas de conhecimento) da organização. Essa característica é ilustrada na Figura 4.1. Domínios, Controles e Itens de Avaliação são descritos nas seções 4.1.2, 4.1.3 e 4.1.4, respectivamente.

- Heurística de avaliação quantitativa de maturidade para agregação de valores de maturidade aferidos em cada item de avaliação (questionário) em valores de maturidade por controles (seção 4.2.1), que por sua vez são agregados, também, por heurística própria do modelo, em valores de maturidade aferidos por domínio (seção 4.2.2).

- Geração de relatórios de avaliação com diferentes visualizações de resultados, permitindo uma análise rápida e uma compreensão precisa da situação avaliada. Esses modelos de resultados são apresentados e discutidos na seção 4.2.3. 
- Geração de roteiros de evolução indicando ações a serem implementadas pela organização, para se atingir um nível projetado de maturidade, usualmente o próximo nível da escala em relação ao nível da avaliação atual. Os roteiros são estruturados com base em uma análise de gaps entre a situação encontrada e a situação projetada e têm forte embasamento na base de conhecimento de avaliação de maturidade. Roteiros de evolução são discutidos na seção 4.2.4.

\section{1 - MODELO DE AVALIAÇÃO}

A Figura 4.1 apresenta a estrutura hierárquica do modelo de avaliação de maturidade SOA proposto. Nessa estrutura, identificam-se:

- Itens de avaliação: correspondem ao menor grão de avaliação do modelo e representam características ou práticas avaliáveis diretamente por aplicação de um questionário estruturado de respostas múltiplas. Assim, cada item de avaliação está associado a um conjunto de questões com múltiplas alternativas e resposta única (a que melhor descreve a situação atual), que são mapeadas diretamente com as características de cada nível de maturidade na escala de avaliação.

- Controles: representam a adoção de uma prática estabelecida no uso e adoção de SOA. Um controle agrupa diversos itens de avaliação relacionados que, conjuntamente, indicam a adoção da prática representada pelo controle. A avaliação do nível de maturidade em cada controle resulta da agregação, através de heurística própria, da maturidade de todos os itens de avaliação que o compõem.

- Domínios: correspondem a domínios de conhecimento e competência dentro da organização. Desse modo, as práticas (controles) são agrupadas em domínios, para maior efetividade da avaliação de maturidade e análise dos resultados obtidos. No modelo proposto, os perfis profissionais que fazem a avaliação de determinados controles são atribuídos no nível de domínios. Desse modo, é possível que controles pertencentes a domínios diferentes sejam avaliados por perfis profissionais diferentes dentro de uma organização. A avaliação quantitativa de maturidade por cada domínio é obtida agregando-se, através de heurística própria do modelo, a maturidade obtida em todos os controles que o compõem. 


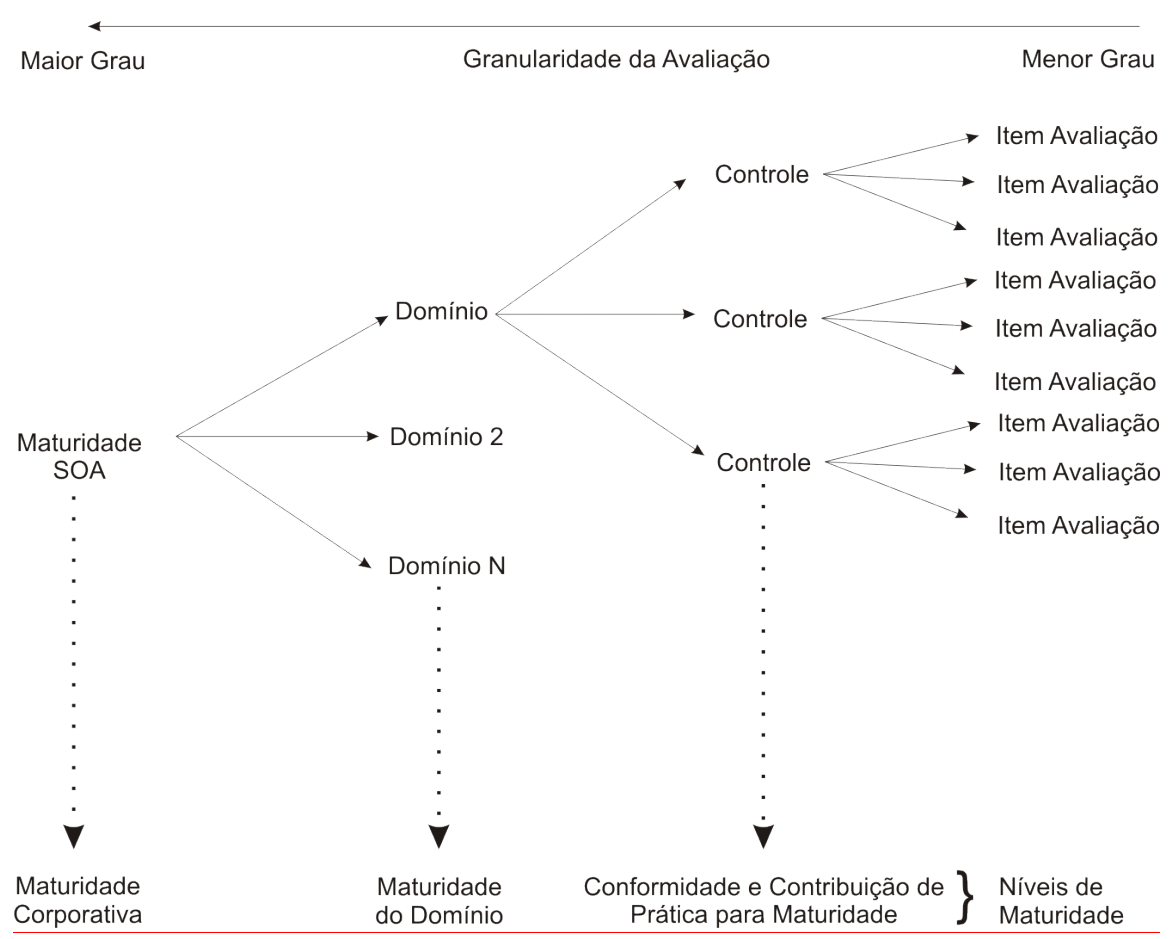

Figura 4.1 - Arquitetura do Modelo de Maturidade Proposto

A estrutura ilustrada na Figura 4.1 permite - além do estabelecimento de um nível quantitativamente definido de maturidade em cada granularidade da avaliação - uma dinâmica de acompanhamento suportada pela formação de roteiros de evolução, associando os elementos presentes e ausentes (análise de gaps) existentes na prática de SOA, em relação a uma escala evolutiva padronizada da adoção de SOA, pela observação dos valores obtidos em cada controle.

Em referência à análise apresentada na seção 3.2, que trata dos Modelos de Maturidade: CMMI, COBIT e SOA, na proposta apresentada neste trabalho, a avaliação se dá pela classificação desses controles pela conformidade de práticas SOA e suas contribuições para maturidade, e, assim, dos domínios e de forma global, por intermédio de um modelo em estágios de níveis de maturidade similar aos princípios de avaliação existentes no CMMI.

Existem, no entanto, visões díspares sobre a formação dos níveis de maturidade e como são afetos aos princípios e elementos da Governança SOA junto aos Domínios - os dois eixos principais do modelo.

De uma análise dos modelos existentes considerados relevantes, apresentados na seção 3.2 (IBM, 2005; SONIC, 2005; BEA, 2006; HP, 2006; ACCENTURE, 2007; MICROSOFT, 2007; ORACLE, 2007; GARTNER, 2009; THE OPEN GROUP, 2011; 
ITANA, 2013), observam-se focos diferenciados no estabelecimento, tanto nos domínios como nos níveis para modelos de maturidade na prática de adoção de SOA.

Como exemplo da disparidade existente, o OSIMM contempla os domínios de Negócio, Organização, Governança, Método, Aplicação, Arquitetura, Informação, e Infraestrutura e Gerenciamento. Já o modelo original da IBM contempla os domínios de Processo, Arquitetura, Aplicação e Infraestrutura, convergindo suas análises apenas nesses domínios.

\subsection{1 - Níveis de Maturidade}

Existem duas tendências ao se tratar de modelos de avaliação do nível de maturidade de SOA: o modelo do The Open Group (2009), com sete níveis de maturidade compostos por: 1. silo; 2. integrado; 3. componentizados; 4. serviços; 5. serviços compostos; 6. serviços virtualizados; e 7. serviços dinamicamente reconfiguráveis, e aqueles que apresentam associação ao modelo estabelecido pelo CMMI.

Considerando-se o critério pré-estabelecido de alinhamento dos níveis de conformidade com os princípios do modelo de maturidade do CMMI em sua versão de representação em estágios, o presente modelo ajustou a escala, conforme ilustra o Quadro 4.1.

Quadro 4.1 - Níveis de Maturidade e seus Focos

\begin{tabular}{|l|l|}
\hline \multicolumn{1}{|c|}{ Definição } & \multicolumn{1}{c|}{ Descrição/Níveis } \\
\hline 1. Inicial & $\begin{array}{l}\text { os processos e as atividades não são tipicamente documentados e tendem a ser } \\
\text { conduzidos de maneira } \text { ad hoc, isso é, de forma descontrolada e reativa por usuários ou } \\
\text { eventos. }\end{array}$ \\
\hline 2. Gerenciado & os processos e as atividades são repetitivos, possivelmente com resultados consistentes. \\
\hline 3. Definido & $\begin{array}{l}\text { os processos e as atividades são definidos, documentados e padronizados para promover } \\
\text { clara consistência. }\end{array}$ \\
\hline 4. Mensurado & $\begin{array}{l}\text { além de processos e atividades padronizadas, as métricas são coletadas e utilizadas para } \\
\text { ajudar a identificar formas de ajustar e adaptar o processo para projetos particulares, sem } \\
\text { perdas mensuráveis de qualidade ou desvios de especificações. }\end{array}$ \\
\hline 5. Otimizado & $\begin{array}{l}\text { o foco está na melhoria continuada, o desempenho do processo através de mudanças } \\
\text { tecnológicas / melhorias incrementais e inovadoras. }\end{array}$ \\
\hline
\end{tabular}

Em CMMI, tem-se as duas representações diferenciadas de níveis de maturidade analisadas na sua definição: Representação em Estágio e Representação Contínua (CARNEGIE MELLON SOFTWARE ENGINEERING INSTITUTE, 2013). No entanto, o modelo proposto neste estudo define uma revisão no conceito dessas representações a partir do que 
se observa na prática de aplicação de um ciclo contínuo de melhoria organizacional (CARNEGIE MELLON SOFTWARE ENGINEERING INSTITUTE, 2006).

No modelo proposto, reconhece-se que em um ciclo as melhorias podem ocorrer em duas situações distintas: quando uma melhoria está sendo aplicada para Evolução a um nível maior de maturidade, ou quando uma organização está empenhada na Estabilização de um nível de maturidade que foi antecipadamente planejado.

Assim, compreende-se como Estabilização as atividades necessárias para que a organização possa estar completa e reconhecidamente aderente a um nível de maturidade definido - que os controles expressem resultados para estabelecer esse nível.

Já por Evolução, compreende-se que a organização está em um estágio reconhecido como aderente, e está realizando as atividades adequadas de planejamento e execução para atingir um novo patamar de maturidade.

Nesse sentido, o modelo proposto neste estudo adota a escala de maturidade do CMMI - nas suas representações em estágio e contínua - formando um único modelo contemplando passos intercalados de estabilização (em estágios) com processos de evolução. A Figura 4.2 ilustra esse entendimento. 


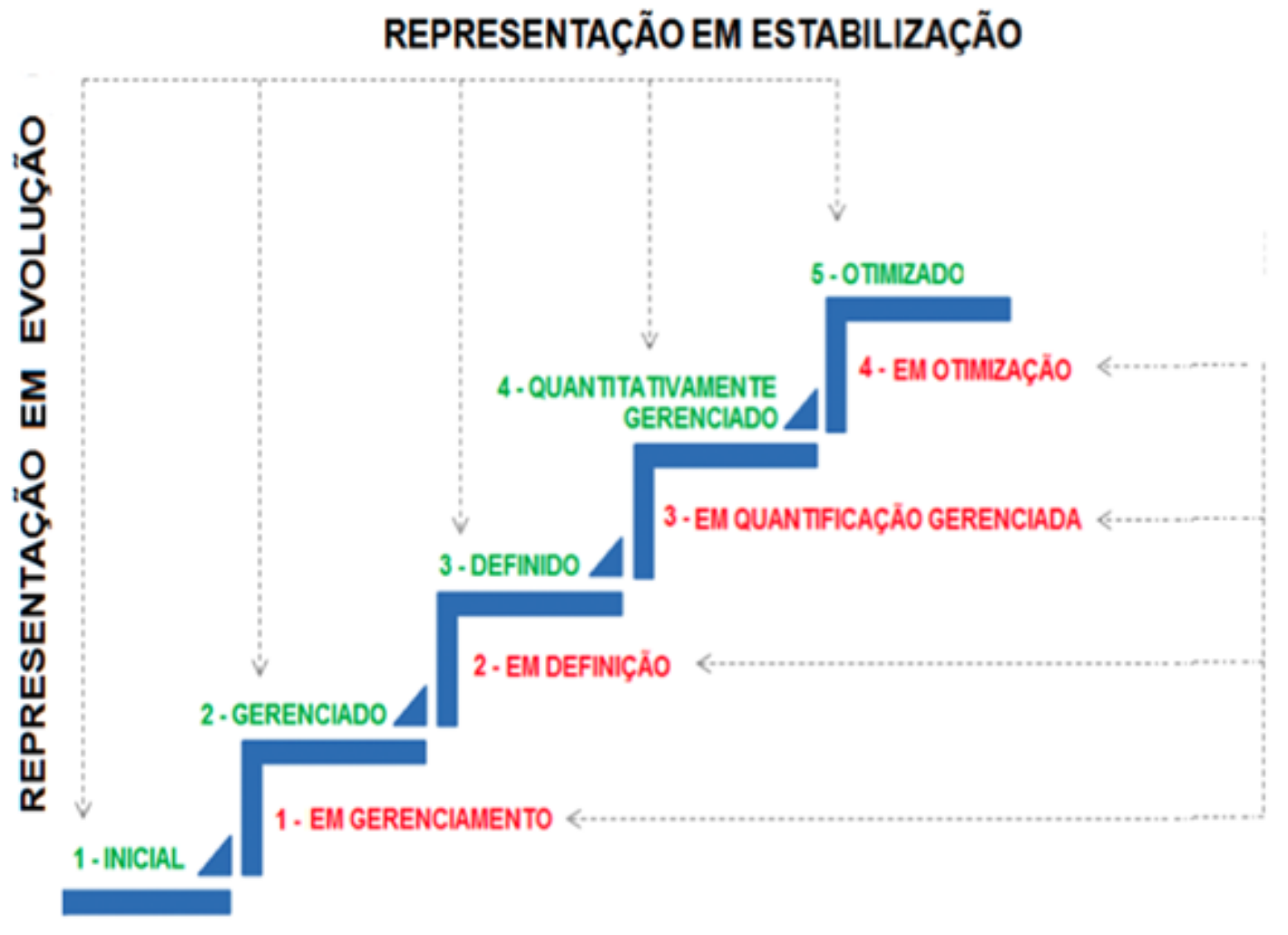

Figura 4.2 - Representação em Estágios: Estabilização e Evolução

Da Figura 4.2 observam-se duas situações especiais e distintas, no que diz respeito a sua representação contínua:

- o nível 1 , caracterizado como Inicial, que se refere às atividades necessárias para o entendimento da Arquitetura, é quando a organização deve ter uma capacitação mínima nessa arquitetura;

- não existe um nível superior correspondente à representação em estágio 5 na representação contínua, pois compreende-se que essa situação ou estágio (5) prevê que a organização já está habilitada a controlar - de forma quantitativamente gerenciada e utilizando-se de aspectos automatizados de otimização - seu processo de evolução.

Nesse sentido, o modelo proposto suporta uma indicação sequenciada de cada uma dessas situações: se a organização está preparada para promover uma Evolução ou está em um processo de Estabilização. Os princípios utilizados para avaliar esses eixos consideram que a organização em processo de Evolução esteja aderente ao mínimo necessário do estágio 
precedente de Estabilização, pois esse será o nível de maturidade a ser reportado pelo modelo. Assim sendo, o modelo proposto adaptou a declaração de níveis tal qual exposto no Quadro 4.2.

Quadro 4.2 - Níveis de Maturidade na Estabilização e na Evolução

\begin{tabular}{|c|c|}
\hline $\begin{array}{l}\text { Nível de Maturidade na } \\
\text { Situação em Estabilização }\end{array}$ & $\begin{array}{l}\text { Nível de Maturidade na } \\
\text { Situação em Evolução }\end{array}$ \\
\hline 1. Inicial & $1 \rightarrow 2$. Em Gerenciamento \\
\hline 2. Gerenciado & $2 \rightarrow 3$. Em Definição \\
\hline 3. Definido & $3 \rightarrow 4$. Em Mensuração Gerenciada. \\
\hline 4. Mensurado & $4 \rightarrow$ 5. Em Otimização \\
\hline 5. Otimizado & \\
\hline
\end{tabular}

Observa-se que tanto para o aspecto de quantificação - para qualificação do estágio de maturidade - quanto para o aspecto de aderência, os resultados obtidos devem nortear a formação de dois roteiros distintos: de Evolução ou de Estabilização. Ainda, qualquer resultado final de nível de maturidade a ser desenvolvido junto ao modelo proposto deve ser precedido da situação identificada.

Assim, levando-se em conta o critério pré-estabelecido de alinhamento dos níveis de conformidade com os princípios do modelo de maturidade do CMMI, em sua versão de representação em estágios, foi elaborado um modelo que permite a mensuração permanente do nível de maturidade e possibilita a aplicação desse critério segundo a avaliação dos domínios a serem controlados pelo modelo proposto, a saber: domínios e controles para análise.

$\mathrm{Na}$ ótica de um modelo sequenciado, alternando estágios de estabilização e em evolução (contínuo), tem-se então:

a) Inicial (nível 1): caracterizado por um planejamento intempestivo (ad hoc) de SOA.

b) Evolução de 1 para 2 - Em Gerenciamento: a organização busca abandonar seu estágio inicial e caótico pelo planejamento e estabelecimento dos requisitos iniciais para SOA.

c) Estabilização em 2 (nível 2) - Gerenciado: os processos da organização são planejados, executados, medidos e controlados, e seus requisitos são gerenciados, os projetos são executados e geridos de acordo com os planos documentados. 
d) Evolução de 2 para 3 - Em Definição: caracterizada pela expansão dos serviços pelo uso exaustivo de SOA em projetos diários, visando à construção de um portfólio de serviços, tendo como foco a reutilização desses e a aplicação dos princípios de orquestração dos mesmos.

e) Estabilização em 3 (nível 3) - Definido: nesse estágio, os serviços estão proliferados junto a processos que são bem caracterizados, compreendidos, e estão descritos em normas, procedimentos, ferramentas e métodos.

f) Evolução de 3 para 4 - Em Mensuração Gerenciada: nesse estágio, iniciam-se atividades visando à formação e ajuste de processos que permitem a mensuração efetiva dos resultados obtidos pela aplicação de SOA.

g) Estabilização em 4 (nível 4) - Mensurado: caracterizado pela medição e avaliação do impacto visível de SOA ao negócio, da extensão dos serviços para os processos de automação de negócio, com a quebra dos silos na organização.

h) Evolução de 4 para 5 - Em Otimização: é caracterizado pela forte realização da capacidade de descoberta e, assim, SOA prolifera em toda a empresa.

i) Estabilização em 5 (nível 5) - Otimizado: o foco na medição é estendido para como SOA é usado. Assim, a medição produz um processo de realimentação que suporta melhorias, que incluem medidas não só de negócios.

O modelo proposto permite, portanto, definir roteiros de estabilização em um estágio, consistindo de ações necessárias para completar as práticas requeridas por determinado nível de maturidade, bem como de evolução para novo estágio.

\subsection{2 - Domínios}

Entende-se o conceito de Domínio como elemento agregador de conhecimento e competências dentro da organização. Para se determinar a lista de domínios do modelo proposto, os diversos modelos apresentados na seção 3.2 são analisados. Em especial, verificou-se a ocorrência dos assuntos tratados nos modelos (vide APÊNDICE A), de modo 
a identificar assuntos comuns em diferentes modelos, o que foi verificado contando-se a ocorrência de determinado assunto em modelos diferentes propostos.

O resultado dessa análise é apresentado na Figura 4.3, onde os assuntos são agrupados e ordenados a partir de uma visão mais estratégica e de negócio $(\mathrm{N})$ para uma visão mais tecnológica (T). A decisão acerca dos agrupamento apresentados na Figura 4.3 e a consequente definição dos domínios escolhidos para integrar a estrutura do modelo proposto neste trabalho foi definida em oficina do Grupo Focal de especialistas.

\begin{tabular}{|c|c|c|c|}
\hline \multicolumn{2}{|r|}{ Domínio } & \multirow{2}{*}{ Ocorrência } & Domínios Propostos \\
\hline D-01 & Negócios & & Negócio e Estratégia \\
\hline \multirow{4}{*}{ D-02 } & Organização & 5 & \multirow{4}{*}{ Organização e Governança } \\
\hline & Estrutura empresarial & 2 & \\
\hline & Finanças e portfólio & 2 & \\
\hline & Governança & 7 & \\
\hline D-03 & Informação & 5 & $\begin{array}{c}\text { Informações e Modelos de } \\
\text { Dados }\end{array}$ \\
\hline \multirow{6}{*}{ D-04 } & Processos & 2 & \multirow{6}{*}{ Metódos e Práticas } \\
\hline & Execução de projetos & 1 & \\
\hline & $\begin{array}{l}\text { Gerenciamento de } \\
\text { programa }\end{array}$ & 1 & \\
\hline & Pessoas & 3 & \\
\hline & Métodos & 3 & \\
\hline & $\begin{array}{l}\text { Desenvolvimento de } \\
\text { serviço }\end{array}$ & 2 & \\
\hline \multirow{3}{*}{ D-05 } & Arquitetura & 8 & \multirow{3}{*}{ Aplicações e Arquitetura } \\
\hline & Aplicações & 4 & \\
\hline & Solução & 1 & \\
\hline \multirow{2}{*}{ D-06 } & Tecnologia & 3 & \multirow{2}{*}{ Tecnologia e Infraestrutura } \\
\hline & Infraestrutura & 5 & \\
\hline \multirow{2}{*}{ D-07 } & Suprimento e demanda & 1 & \multirow{2}{*}{$\begin{array}{c}\text { Operação e Gerenciamento } \\
\text { de TI }\end{array}$} \\
\hline & Operações & 3 & \\
\hline
\end{tabular}

Figura 4.3 - Avaliação de Maturidade SOA: Domínios

Por meio do estudo dessa tabulação - em conjunto com as observações de Dahlberg e Kivijärvi (2006) e Niemann (2008), dos frameworks de Governança SOA (seção 2.2) - e tendo como foco os objetivos estratégicos e princípios arquiteturais propostos por Erl $(2005,2008)$, dispostos na seção 2.1 para suporte à solução proposta, cabe uma revisão nos domínios, buscando definir um modelo conexo, que atenda tanto aos elementos essenciais reconhecidos como Domínios pela revisão bibliográfica, bem como permita reforçar a ótica de Erl (2005) de que SOA é uma estratégia de alinhamento das necessidades do negócio com o provimento de serviços e recursos de TI. 
Na proposição de Domínios declarada neste trabalho observa-se uma associação direta de Domínios com a arquitetura empresarial, orientados de forma a percorrer a organização a partir do nível mais estratégico; que é a área de negócios, seguida da governança, métodos e práticas, aplicações e arquitetura, informações e modelo de dados, tecnologia e infraestrutura, operações e gerenciamento; até a área de tecnologia da informação. De forma a consolidar este estudo, visualiza-se no Quadro 4.3 um resumo do modelo proposto para os Domínios, a ser usado junto às simulações e no caso de uso.

Quadro 4.3 - Domínios Propostos e seus Focos

\begin{tabular}{|c|c|}
\hline Definição & Descrição \\
\hline $\begin{array}{l}\text { Negócio e } \\
\text { Objetivos } \\
\text { Estratégicos } \\
\text { D01 }\end{array}$ & $\begin{array}{l}\text { Focado na arquitetura de negócios corporativo, ou seja, nas práticas e políticas de negócio da } \\
\text { organização; avalia como os processos de negócios são concebidos, estruturados, } \\
\text { implementados e executados. Também analisa como os custos das capacidades de TI são } \\
\text { alocados através da organização, bem como tais capacidades favorecem a flexibilidade do } \\
\text { negócio, agilidade e os indicadores do negócio. Inclui a estratégia de TI através da proposição } \\
\text { de seu valor movendo-se para um nível mais alto de maturidade. }\end{array}$ \\
\hline $\begin{array}{l}\text { Organização e } \\
\text { Governança } \\
\text { D02 }\end{array}$ & $\begin{array}{l}\text { Focado na estrutura da organização em si, analisa se estão sendo aplicadas as medidas necessárias } \\
\text { de eficácia organizacional no contexto e governança de SOA. Assim, esse aspecto está centrado na } \\
\text { estrutura organizacional, relações, funções e capacitação necessária para adotar uma estratégia } \\
\text { orientada a serviços. Isso inclui os tipos e a extensão de competências, sua formação e educação } \\
\text { que estão sendo disponibilizadas dentro da organização. A ótica de Governança é associada com o } \\
\text { gerenciamento formal de processos para manter as atividades de TI, capacidades de serviços e } \\
\text { soluções SOA alinhadas com as necessidades do negócio. }\end{array}$ \\
\hline $\begin{array}{l}\text { Métodos e } \\
\text { Práticas } \\
\text { D03 }\end{array}$ & $\begin{array}{l}\text { Focado sobre os métodos e processos empregados pela organização para a sua TI, bem como a } \\
\text { transformação de negócios e maturidade organizacional em torno do ciclo de vida de } \\
\text { desenvolvimento de software, tais como o uso de gerenciamento de requisitos, técnicas para } \\
\text { estimativas, gerenciamento de projetos, processos de garantia de qualidade, metodologias de } \\
\text { projeto e técnicas, e ferramentas para a concepção de soluções. }\end{array}$ \\
\hline $\begin{array}{l}\text { Aplicações e } \\
\text { Arquitetura } \\
\text { D04 }\end{array}$ & $\begin{array}{l}\text { Focado no estilo e estruturação da aplicação (arquitetura de aplicações) e sua } \\
\text { decomposição funcional, na reutilização, flexibilidade, confiabilidade e capacidade de } \\
\text { extensão da mesma, compreensão e uso uniforme de melhores práticas e padrões, } \\
\text { essencialmente naqueles com a mesma funcionalidade, através do uso de padrões de } \\
\text { projeto (design patterns) associados ao modelo de arquitetura de referência da organização. } \\
\text { É por meio desse domínio que é realizada a avaliação da qualidade dos serviços atuais e } \\
\text { das diversas camadas de serviços em SOA - a avaliação dos estágios de adoção de SOA, } \\
\text { tal como a eficiente decomposição de serviços (visando à reusabilidade do serviço), } \\
\text { ausência de estado em serviços e desacoplamento das regras de negócio, todos esses como } \\
\text { facilitadores da integração das aplicações organizacionais e no suporte à rápida mudança } \\
\text { nos processos informatizados. }\end{array}$ \\
\hline $\begin{array}{l}\text { Informações e } \\
\text { Modelos de } \\
\text { Dados } \\
\text { D05 }\end{array}$ & $\begin{array}{l}\text { Focado na forma como a informação é estruturada, modelada, no método de acesso aos } \\
\text { dados da empresa, na abstração do acesso de dados a partir dos aspectos funcionais, nas } \\
\text { características de dados, nas capacidades de transformação de dados, serviços e definições } \\
\text { de processo, no manuseio de identificadores, credenciais de segurança, gestão de } \\
\text { conhecimento, modelo de informações de negócios e no gerenciamento de conteúdo. }\end{array}$ \\
\hline $\begin{array}{l}\text { Tecnologia e } \\
\text { Infraestrutura } \\
\text { D06 }\end{array}$ & $\begin{array}{l}\text { Foca na tecnologia e na correspondente infraestrutura disponível para SOA, que deve dar } \\
\text { suporte às técnicas de interoperabilidade (uso de padrões interoperáveis) e de soluções de } \\
\text { mensageria necessárias para o uso de SOA. }\end{array}$ \\
\hline $\begin{array}{l}\text { Operação e } \\
\text { Gerenciamento } \\
\text { de TI } \\
\text { D07 }\end{array}$ & $\begin{array}{l}\text { Focado na capacidade dos processos de execução e gerenciamento da TI organizacional para } \\
\text { suportar SOA em destaque no gerenciamento dos seus serviços, no gerenciamento eficaz da } \\
\text { configuração dos ativos, e da implantação e operação das atividades comuns de TI, entre elas, o } \\
\text { gerenciamento de incidentes, de eventos e o monitoramento da infraestrutura. }\end{array}$ \\
\hline
\end{tabular}




\subsection{3 - Controles}

Controles representam aspectos mais específicos ao longo do qual a organização possa ser avaliada em seu nível de maturidade SOA. Esses aspectos relacionam-se aos princípios e práticas reconhecidas de SOA, que afetam sua adoção.

Como objeto real de medição, uma série de controles está associada direta ou indiretamente com os domínios previamente apontados. Esses controles são quantificados através de métricas definidas com base na valoração de itens de avaliação catalogados (assessment items). Nesse sentido, os itens de avaliação permitem a quantificação do nível de maturidade do controle específico.

Os controles catalogados no modelo propostos são classificados em controles essenciais e dispensáveis. Controles essenciais são aqueles considerados de observação obrigatória na adoção de SOA para organizações em geral, indiferente de seu negócio, porte, nacionalidade, tecnologia usada ou capacidade de recursos humanos. Controles dispensáveis são aqueles que podem ser desconsiderados em avaliações específicas, a critério da organização avaliada, pois esses controles podem não ser aplicáveis ou podem ser deliberadamente desconsiderados na estratégia de adoção de SOA, tendo caráter complementar.

Para estabelecer a lista de controles e justificar a escolha e classificação dos controles, toma-se por base os aspectos relevantes discutidos nas seções 2.1 e 3.2, o estudo de cada um dos modelos de maturidade utilizados, e, principalmente, a declaração dos domínios para enquadramento dos controles dentro de cada um desses domínios definidos.

Na seção 2.1 tem-se, principalmente, os objetivos estratégicos e os princípios de orientação a serviços de Erl (2005, 2008, 2011). Dos modelos de maturidade utilizados como referência (seção 3.2), para suporte à formação dos controles propostos, tabulou-se, no APÊNDICE A, as questões fundamentais analisadas de cada domínio/modelo. Em adição, na declaração de domínios apresentada neste Capítulo, dá-se destaque aos conceitos que estão associados aos Controles necessários. A decisão acerca dos controles escolhidos para integrar cada domínio escolhido para o modelo proposto neste trabalho é tomada em oficina do Grupo Focal de especialista, tendo como fonte de análise o APÊNDICE A. 
O Quadro 4.4 apresenta os Controles definidos, bem como dá suas interpretações. No quadro, é possível ver ainda o Peso atribuído para cada controle e a sua classificação quanto à possibilidade de Dispensa durante a avaliação.

Quadro 4.4 - Controles Estabelecidos por Domínio

\begin{tabular}{|c|c|c|c|c|}
\hline Domínio & Controles & Interpretação do Controle & Peso & Dispensa \\
\hline \multirow{12}{*}{$\begin{array}{l}\text { Negócios e } \\
\text { Objetivos } \\
\text { Estratégicos } \\
\text { D-01 }\end{array}$} & $\begin{array}{l}\text { Arquitetura } \\
\text { Corporativa }\end{array}$ & $\begin{array}{l}\text { O quanto estão formalizados os negócios, } \\
\text { documentos e diagramas na organização, } \\
\text { principalmente tendo como foco o documento } \\
\text { Arquitetura Empresarial. }\end{array}$ & 1 & $\mathrm{~N}$ \\
\hline & $\begin{array}{l}\text { Arquitetura de } \\
\text { Processo de } \\
\text { Negócio }\end{array}$ & $\begin{array}{l}\text { Quanto BPA (Business Process Architecture) se } \\
\text { encontra aplicado, governado e documentado } \\
\text { na organização. }\end{array}$ & 1 & $\mathrm{~N}$ \\
\hline & $\begin{array}{l}\text { Linhas de } \\
\text { Negócio (LOB) }\end{array}$ & $\begin{array}{l}\text { Como estão definidas e documentadas as linhas } \\
\text { de negócio organizacionais (line-of-business). }\end{array}$ & 2 & $\mathrm{~N}$ \\
\hline & $\begin{array}{l}\text { Direcionadores } \\
\text { de Negócio }\end{array}$ & $\begin{array}{l}\text { Como são documentadas e gerenciadas as } \\
\text { estruturas que conduzem a organização. }\end{array}$ & 1 & $\mathrm{~N}$ \\
\hline & $\begin{array}{l}\text { Envolvimento do } \\
\text { Negócio com SOA }\end{array}$ & $\begin{array}{l}\text { Quanto há de envolvimento empresarial frente a } \\
\text { adoção de SOA. }\end{array}$ & 1 & $\mathrm{~S}$ \\
\hline & $\begin{array}{l}\text { Alinhamento do } \\
\text { Negócio com a } \\
\text { TI }\end{array}$ & O quanto é alinhado o negócio e a TI. & 1 & $\mathrm{~N}$ \\
\hline & $\begin{array}{l}\text { Práticas } \\
\text { Financeiras } \\
(\mathrm{ROI})\end{array}$ & $\begin{array}{l}\text { Qual é a capacidade de mensuração real do } \\
\text { retorno de investimento (ROI), lucros e práticas } \\
\text { financeiras. }\end{array}$ & 1 & $\mathrm{~S}$ \\
\hline & $\begin{array}{l}\text { Financiamento da } \\
\text { Adoção de SOA }\end{array}$ & $\begin{array}{l}\text { Qual o grau de patrocínio e forma de } \\
\text { financiamento do projeto de adoção de SOA. }\end{array}$ & 1 & $\mathrm{~S}$ \\
\hline & $\begin{array}{l}\text { Conformidade } \\
\text { Legal }\end{array}$ & $\begin{array}{l}\text { Observa se a organização atua alinhada com } \\
\text { todos os aspectos legais externos a organização, } \\
\text { e oferecendo as devidas garantias auditáveis } \\
\text { desse alinhamento. }\end{array}$ & 1 & $\mathrm{~N}$ \\
\hline & $\begin{array}{l}\text { Monitoramento e } \\
\text { Mensuração }\end{array}$ & $\begin{array}{l}\text { Verifica se existe e é confiável o monitoramento } \\
\text { e mensuração dos processos de negócio. }\end{array}$ & 2 & $\mathrm{~N}$ \\
\hline & $\begin{array}{l}\text { Etapas de } \\
\text { Adoção de SOA }\end{array}$ & $\begin{array}{l}\text { Qual a visão da Governança Corporativa do } \\
\text { estágio de adoção de SOA }\end{array}$ & 1 & $\mathrm{~N}$ \\
\hline & $\begin{array}{l}\text { Tempo para } \\
\text { Entrega de } \\
\text { Soluções e } \\
\text { Satisfação }\end{array}$ & $\begin{array}{l}\text { Qual a satisfação percebida pela Governança } \\
\text { Corporativa da qualidade e confiabilidade nas } \\
\text { soluções SOA }\end{array}$ & 1 & $\mathrm{~N}$ \\
\hline
\end{tabular}




\begin{tabular}{|c|c|c|c|c|}
\hline Domínio & Controles & Interpretação do Controle & Peso & Dispensa \\
\hline \multirow{14}{*}{$\begin{array}{l}\text { Organização } \\
\text { e } \\
\text { Governança } \\
\text { D-02 }\end{array}$} & $\begin{array}{l}\text { Estratégia para } \\
\text { Adoção de SOA }\end{array}$ & $\begin{array}{l}\text { Verifica se existe uma estratégia de adoção de } \\
\text { SOA pela organização e essa é alinhada com as } \\
\text { melhores práticas. }\end{array}$ & 1 & $\mathrm{~N}$ \\
\hline & $\begin{array}{l}\text { Etapas de } \\
\text { Adoção de SOA }\end{array}$ & $\begin{array}{l}\text { Verifica qual nível a arquitetura da organização } \\
\text { se encontra é aderente aos princípios de uso de } \\
\text { SOA (oito princípios de SOA). }\end{array}$ & 1 & $\mathrm{~N}$ \\
\hline & $\begin{array}{l}\text { Governança e } \\
\text { Autoridades }\end{array}$ & $\begin{array}{l}\text { As governanças da organização e de TI estão } \\
\text { estabelecidas (papéis e perfis) e se estão bem } \\
\text { alinhadas }\end{array}$ & 2 & $\mathrm{~N}$ \\
\hline & $\begin{array}{l}\text { Fronteiras } \\
\text { Organizacionais }\end{array}$ & $\begin{array}{l}\text { As soluções implementadas / propostas pela } \\
\text { organização atravessam o limite do seu negócio, } \\
\text { abrangendo parceiros, por exemplo. }\end{array}$ & 1 & $\mathrm{~S}$ \\
\hline & $\begin{array}{l}\text { Processos e } \\
\text { Atividades }\end{array}$ & $\begin{array}{l}\text { Existe um gerenciamento de processos e } \\
\text { atividades da organização, e está automatizado. }\end{array}$ & 1 & $\mathrm{~N}$ \\
\hline & Governança SOA & $\begin{array}{l}\text { A governança SOA se encontra documentada, } \\
\text { formalizada, gerenciada e implementada. }\end{array}$ & 2 & $\mathrm{~N}$ \\
\hline & $\begin{array}{l}\text { Estrutura } \\
\text { Organizacional }\end{array}$ & $\begin{array}{l}\text { Quanto de mudança organizacional } \\
\text { correspondente foi realizada visando alinhar } \\
\text { essa estrutura com SOA }\end{array}$ & 1 & $\mathrm{~N}$ \\
\hline & $\begin{array}{l}\text { Avaliação da } \\
\text { Arquitetura SOA }\end{array}$ & $\begin{array}{l}\text { Trata o quanto a sua organização inclui } \\
\text { avaliação da arquitetura em sua metodologia de } \\
\text { projeto. }\end{array}$ & 1 & $\mathrm{~N}$ \\
\hline & Políticas & $\begin{array}{l}\text { As políticas (como práticas) estão alinhadas } \\
\text { com a Governança SOA. }\end{array}$ & 1 & $\mathrm{~N}$ \\
\hline & $\begin{array}{l}\text { Gerenciamento } \\
\text { de Riscos } \\
\text { Empresariais }\end{array}$ & $\begin{array}{l}\text { Os riscos empresarias são gerenciados em um } \\
\text { modelo de ERM }\end{array}$ & 1 & S \\
\hline & Habilidades & $\begin{array}{l}\text { Existe um controle no nível de capacidade do } \\
\text { recurso dos funcionários da organização, e se } \\
\text { esse controle permite o gerenciamento de suas } \\
\text { responsabilidades e atribuições nos papéis / } \\
\text { perfis que lhes são definidos. }\end{array}$ & 1 & $\mathrm{~N}$ \\
\hline & $\begin{array}{l}\text { Capacitação em } \\
\text { SOA }\end{array}$ & $\begin{array}{l}\text { A organização se atenta à capacitação de SOA } \\
\text { para as suas demandas. }\end{array}$ & 2 & $\mathrm{~S}$ \\
\hline & Monitoramento & $\begin{array}{l}\text { Existe e atende o monitoramento visando o } \\
\text { suporte a decisões do negócio da organização } \\
\text { com o auxílio de métricas. }\end{array}$ & 1 & $\mathrm{~N}$ \\
\hline & Valor do Serviço & $\begin{array}{l}\text { Existe uma mensuração do nível de importância } \\
\text { atribuído ao uso de serviços na organização (seu } \\
\text { valor). }\end{array}$ & 1 & $\mathrm{~N}$ \\
\hline
\end{tabular}

Continua 


\begin{tabular}{|c|c|c|c|c|}
\hline Domínio & Controles & Interpretação do Controle & Peso & Dispensa \\
\hline \multirow{11}{*}{$\begin{array}{l}\text { Métodos e } \\
\text { Práticas } \\
\text { D-03 }\end{array}$} & $\begin{array}{l}\text { Metodologia e } \\
\text { Métodos }\end{array}$ & $\begin{array}{l}\text { Metodologia e métodos existem e são compatíveis } \\
\text { com as melhores práticas de SOA. }\end{array}$ & 1 & $\mathrm{~N}$ \\
\hline & $\begin{array}{l}\text { Metodologia de } \\
\text { Implementação }\end{array}$ & $\begin{array}{l}\text { A metodologia de implementação de SOA está } \\
\text { estabelecida e gerenciada. }\end{array}$ & 1 & $\mathrm{~N}$ \\
\hline & $\begin{array}{l}\text { Melhores } \\
\text { Práticas }\end{array}$ & $\begin{array}{l}\text { Verifica se existe algum comitê ou órgão que } \\
\text { coordena e regulamenta o uso de melhores } \\
\text { práticas, principalmente com foco na reutilização } \\
\text { de ativos, e se sim, essa avalia a forma com que os } \\
\text { serviços são gerenciados no que se refere à } \\
\text { preocupação com virtualização de serviços e com } \\
\text { o uso ostensivo de BPM. }\end{array}$ & 1 & $\mathrm{~N}$ \\
\hline & $\begin{array}{l}\text { Métodos, } \\
\text { Princípios, } \\
\text { Padrões, } \\
\text { Frameworks e } \\
\text { Técnicas em } \\
\text { SOA }\end{array}$ & $\begin{array}{l}\text { Verifica a aderência aos princípios de projeto de } \\
\text { SOA (SOA como paradigma de projeto) }\end{array}$ & 2 & $\mathrm{~N}$ \\
\hline & $\begin{array}{l}\text { Gerenciamento } \\
\text { de Projetos }\end{array}$ & $\begin{array}{l}\text { Utiliza-se algum framework para gerência de } \\
\text { projetos, e se sim, esse é consolidado e sua } \\
\text { documentação é atualizada quando necessário. }\end{array}$ & 1 & $\mathrm{~N}$ \\
\hline & $\begin{array}{l}\text { Gerenciamento } \\
\text { de Riscos nos } \\
\text { Projeto }\end{array}$ & $\begin{array}{l}\text { Identifica se a organização trata o gerenciamento } \\
\text { de riscos em cada um de seus projetos e se existe } \\
\text { uma integração com o gerenciamento empresarial } \\
\text { de riscos. }\end{array}$ & 1 & $\mathrm{~N}$ \\
\hline & $\begin{array}{l}\text { Gestão de } \\
\text { Mudança em } \\
\text { SOA }\end{array}$ & $\begin{array}{l}\text { Caracteriza o uso disciplinado de práticas no } \\
\text { gerenciamento de mudanças envolvendo } \\
\text { elementos da arquitetura SOA }\end{array}$ & 1 & $\mathrm{~N}$ \\
\hline & $\begin{array}{l}\text { Conformidade } \\
\text { Normativa }\end{array}$ & $\begin{array}{l}\text { Observa se a organização realiza auditorias para } \\
\text { verificar sua conformidade normativa interna, tal } \\
\text { como a realização de um processo de ISO-9000. }\end{array}$ & 1 & $\mathrm{~N}$ \\
\hline & Práticas SOA & $\begin{array}{l}\text { Qual o nível de implantação de práticas, princípios e } \\
\text { técnicas relacionados a SOA na organização. }\end{array}$ & 1 & $\mathrm{~N}$ \\
\hline & $\begin{array}{l}\text { Práticas de } \\
\text { Desenvolvimento }\end{array}$ & $\begin{array}{l}\text { É aceitável e coerente a reutilização dos serviços } \\
\text { na organização (atenção ao princípio de } \\
\text { Reusabilidade de Serviços). }\end{array}$ & 2 & $\mathrm{~N}$ \\
\hline & Estratégia SOA & $\begin{array}{l}\text { Está sendo mensurado os benefícios que se espera } \\
\text { com a adoção de SOA dado o momento atual da } \\
\text { empresa. }\end{array}$ & 1 & $\mathrm{~N}$ \\
\hline
\end{tabular}

Continua 


\begin{tabular}{|c|c|c|c|c|}
\hline Domínio & Controles & Interpretação do Controle & Peso & Dispensa \\
\hline \multirow{11}{*}{$\begin{array}{l}\text { Aplicações e } \\
\text { Arquitetura } \\
\text { D-04 }\end{array}$} & $\begin{array}{l}\text { Arquitetura de } \\
\text { Aplicação }\end{array}$ & $\begin{array}{l}\text { Qual o grau de complexidade que a arquitetura de } \\
\text { aplicação empresarial possui em relação aos } \\
\text { modelos existentes nas melhores práticas de SOA. }\end{array}$ & 1 & $\mathrm{~N}$ \\
\hline & $\begin{array}{l}\text { Desacoplamento } \\
\text { de Regras de } \\
\text { Negócio }\end{array}$ & $\begin{array}{l}\text { É reduzido o acoplamento da lógica de negócio } \\
\text { com as funcionalidades existentes (atenção ao } \\
\text { princípio de Baixo Acoplamento). }\end{array}$ & 1 & $\mathrm{~N}$ \\
\hline & Integração & $\begin{array}{l}\text { Existe uma forte integração entre aplicações, sistemas } \\
\text { e infraestrutura, bem como no tipo de tecnologias } \\
\text { utilizadas para sua implementação (SOA). }\end{array}$ & 2 & $\mathrm{~N}$ \\
\hline & $\begin{array}{l}\text { Integração de } \\
\text { Aplicações }\end{array}$ & $\begin{array}{l}\text { Qual o nível da integração entre as aplicações } \\
\text { existentes na empresa e como é realizada. }\end{array}$ & 1 & $\mathrm{~N}$ \\
\hline & $\begin{array}{l}\text { Arquiteturas de } \\
\text { Referência }\end{array}$ & $\begin{array}{l}\text { Qual o nível de utilização da Arquitetura de } \\
\text { Referência (da organização). }\end{array}$ & 1 & $\mathrm{~N}$ \\
\hline & $\begin{array}{l}\text { Inventário de } \\
\text { Serviço }\end{array}$ & $\begin{array}{l}\text { Verifica a aderência a inventário de serviços, } \\
\text { unificados ou por domínios, e sua capacidade de } \\
\text { descoberta e interpretação. }\end{array}$ & 2 & $\mathrm{~N}$ \\
\hline & $\begin{array}{l}\text { Qualidade de } \\
\text { Serviço }\end{array}$ & $\begin{array}{l}\text { Verifica a percepção do grau de aplicação dos } \\
\text { princípios de padronização, abstração e autonomia } \\
\text { dos contratos de serviço. }\end{array}$ & 1 & $\mathrm{~N}$ \\
\hline & $\begin{array}{l}\text { Arquitetura de } \\
\text { Segurança }\end{array}$ & $\begin{array}{l}\text { Verifica o grau de aplicação dos princípios de } \\
\text { segurança junto a arquitetura/barramento corporativo }\end{array}$ & 1 & $\mathrm{~N}$ \\
\hline & $\begin{array}{l}\text { Gerenciamento } \\
\text { de Identidade e } \\
\text { de Acesso }\end{array}$ & $\begin{array}{l}\text { Verifica o uso e centralização de práticas de gestão } \\
\text { de identidade nos serviços SOA construídos, bem } \\
\text { como de propagação de identidade entre serviços. }\end{array}$ & 1 & $\mathrm{~S}$ \\
\hline & $\begin{array}{l}\text { Reusabilidade } \\
\text { de Serviço }\end{array}$ & Avalia o grau de reuso observado não organização & 1 & $\mathrm{~N}$ \\
\hline & $\begin{array}{l}\text { Ausência de } \\
\text { Estado de Serviço }\end{array}$ & $\begin{array}{l}\text { Verifica o grau de comprometimento dos projetos de } \\
\text { SOA com a aplicação e princípios de escalabilidade }\end{array}$ & 1 & $\mathrm{~N}$ \\
\hline \multirow{6}{*}{$\begin{array}{l}\text { Informações } \\
\text { e Modelos de } \\
\text { Dados } \\
\text { D-05 }\end{array}$} & $\begin{array}{l}\text { Governança de } \\
\text { Dados }\end{array}$ & $\begin{array}{l}\text { Verifica o grau de maturidade no uso de modelo } \\
\text { de dados organizacionais }\end{array}$ & 1 & $\mathrm{~N}$ \\
\hline & $\begin{array}{l}\text { Modelo de } \\
\text { Dados e } \\
\text { Metadados }\end{array}$ & $\begin{array}{l}\text { Existem modelos de dados consolidados para toda } \\
\text { organização e se sim como esses modelos auxiliam } \\
\text { o gerenciamento empresarial (tal como a existência } \\
\text { de modelos de dados canônicos corporativos). }\end{array}$ & 1 & $\mathrm{~N}$ \\
\hline & $\begin{array}{l}\text { Integração de } \\
\text { Informações do } \\
\text { Negócio }\end{array}$ & $\begin{array}{l}\text { Existe em geral uma integração das informações } \\
\text { empresariais formalizada. }\end{array}$ & 1 & $\mathrm{~N}$ \\
\hline & $\begin{array}{l}\text { Transformação } \\
\text { de Dados }\end{array}$ & $\begin{array}{l}\text { A organização ainda lida com um alto volume de } \\
\text { transformação de dados ou o princípio de } \\
\text { interoperabilidade intrínseca dos serviços está bem } \\
\text { aplicada de forma que as transformações de dados } \\
\text { foram abolidas ou fortemente minimizadas. }\end{array}$ & 1 & $\mathrm{~N}$ \\
\hline & $\begin{array}{l}\text { Padrões de } \\
\text { Integração de } \\
\text { Dados }\end{array}$ & $\begin{array}{l}\text { Verifica o uso de padrões de integração de dados e } \\
\text { sua extensão }\end{array}$ & 2 & $\mathrm{~N}$ \\
\hline & $\begin{array}{l}\text { Qualidade de } \\
\text { Dados e Métricas }\end{array}$ & $\begin{array}{l}\text { Verifica o uso de padrões de integração de dados e } \\
\text { sua extensão }\end{array}$ & 1 & $\mathrm{~N}$ \\
\hline
\end{tabular}

Continua 


\begin{tabular}{|c|c|c|c|c|}
\hline Domínio & Controles & Interpretação do Controle & Peso & Dispensa \\
\hline \multirow{6}{*}{$\begin{array}{l}\text { Tecnologia e } \\
\text { Infraestrutura } \\
\text { D-06 }\end{array}$} & $\begin{array}{l}\text { Barramento } \\
\text { Corporativo de } \\
\text { Serviços }\end{array}$ & $\begin{array}{l}\text { Verifica se a organização possui um coordenador de } \\
\text { suas aplicações, seja Enterprise Service Bus (ESB) } \\
\text { ou outra aplicação que realize esse processo. }\end{array}$ & 2 & $\mathrm{~N}$ \\
\hline & $\begin{array}{l}\text { Topologia do } \\
\text { Barramento }\end{array}$ & $\begin{array}{l}\text { Verifica a ocorrência comum de topologia na } \\
\text { construção de serviços. }\end{array}$ & 2 & $\mathrm{~N}$ \\
\hline & $\begin{array}{l}\text { Solução de } \\
\text { Mensagem }\end{array}$ & $\begin{array}{l}\text { Soluções utilizando mensageria já envolvem uma } \\
\text { alta parcela (percentual) nas soluções utilizadas } \\
\text { pela organização. }\end{array}$ & 2 & $\mathrm{~N}$ \\
\hline & $\begin{array}{l}\text { Uso de Padrões } \\
\text { Interoperáveis } \\
\text { de Dados }\end{array}$ & $\begin{array}{l}\text { A organização implementa padrões interoperáveis } \\
\text { de dados tal como XML. Se sim, qual a } \\
\text { abrangência da utilização de XML. }\end{array}$ & 1 & $\mathrm{~N}$ \\
\hline & Monitoramento & $\begin{array}{l}\text { Existe um monitoramento visando a geração de } \\
\text { métricas de atendimento da infraestrutura de } \\
\text { forma que atendam aos SLAs específicos dos } \\
\text { serviços. }\end{array}$ & 2 & $\mathrm{~N}$ \\
\hline & Segurança & $\begin{array}{l}\text { Qual o nível de segurança aplicado nos serviços } \\
\text { empresariais }\end{array}$ & 1 & $\mathrm{~N}$ \\
\hline \multirow{5}{*}{$\begin{array}{l}\text { Operação e } \\
\text { Gerenciamento } \\
\text { de TI } \\
\text { D-07 }\end{array}$} & $\begin{array}{l}\text { Gerenciamento } \\
\text { de Serviços de } \\
\text { TI }\end{array}$ & $\begin{array}{l}\text { Verifica como está o nível de integração e } \\
\text { automatização dos processos de gerenciamento } \\
\text { de infraestrutura. }\end{array}$ & 1 & $\mathrm{~N}$ \\
\hline & $\begin{array}{l}\text { Gerenciamento } \\
\text { de Configuração } \\
\text { de Ativos de TI }\end{array}$ & $\begin{array}{l}\text { Verifica se é documentado, gerenciado, versionado } \\
\text { e/ou gerido os ativos de TI na empresa e suas } \\
\text { integrações e relações. Existe uma atendimento ao } \\
\text { gerenciamento de configuração segundo as boas } \\
\text { práticas de mercado (ao exemplo, do framework } \\
\text { ITIL). }\end{array}$ & 1 & $\mathrm{~N}$ \\
\hline & $\begin{array}{l}\text { Gerenciamento } \\
\text { de Implantação }\end{array}$ & $\begin{array}{l}\text { Verifica como está o nível de integração e } \\
\text { automatização dos processos de gerenciamento } \\
\text { de implantação de serviços. }\end{array}$ & 1 & $\mathrm{~S}$ \\
\hline & $\begin{array}{l}\text { Gerenciamento } \\
\text { de Incidentes e } \\
\text { Eventos }\end{array}$ & $\begin{array}{l}\text { Verifica se existe qualquer modelo para suporte } \\
\text { ao Gerenciamento de Incidentes e Eventos e sua } \\
\text { capacidade de estar implementado como Ponto } \\
\text { de Contato Único }\end{array}$ & 1 & S \\
\hline & $\begin{array}{l}\text { Monitoramento } \\
\text { da Infraestrutura }\end{array}$ & $\begin{array}{l}\text { Avalia o grau de gerenciamento, fiscalização e } \\
\text { monitoramento da infraestrutura }\end{array}$ & 1 & $\mathrm{~N}$ \\
\hline
\end{tabular}

Fonte: dados da pesquisa.

\subsection{4 - Itens de avaliação: Questionários}

Conforme apresentado na Figura 4.1, itens de avaliação são os elementos de menor granularidade da estrutura do modelo de avaliação. Consoante com os elementos identificados na pesquisa de Racz et al. (2011), referente à lista de componentes para implementação de um framework SOA, os Itens de Avaliação deste trabalho são estruturados em um modelo baseado em questionários, atuando como instrumento para coleta de dados da análise. 
Mais especificamente, na visão proposta neste estudo, itens de avaliação são implementados como questões no questionário de avaliação. Para cada item de avaliação é associada uma questão. As questões, por sua vez, possuem múltiplas alternativas de resposta. Entretanto, a resposta é de escolha única - a resposta escolhida deve ser aquela que melhor corresponde à realidade da organização avaliada. Para cada resposta possível, é associado um valor mínimo e um valor máximo correspondente ao nível de maturidade associado ao item avaliado. Desse modo, os valores (mínimo e máximo) possíveis para cada resposta são inteiros compreendidos entre 1 e 5 (inclusive), sendo o valor mínimo sempre inferior ou igual ao valor máximo. Assim, para cada Item de Avaliação, são mapeados diretamente das respostas dadas no questionário um valor mínimo e um valor máximo para a contribuição daquele item à avaliação de maturidade.

Determinado controle pode ser detalhado em múltiplos itens de avaliação (múltiplas questões). Essa característica pretende contemplar modelos de controles que não podem ser analisados por um critério único, expresso por uma questão simples. Nesse caso, duas ou mais questões são usadas para caracterizar um controle.

O Quadro 4.5 apresenta um extrato do questionário definido para o modelo proposto. Nesse quadro é possível identificar dois controles (Arquitetura de Referência e Gerenciamento de Identidade e Aceso) que fazem parte da composiçao de um domínio (Aplicações e Arquitetura DS-04). Ambos os controles são analisados com base em múltiplos Itens de Avaliação (questões). Para cada Item de Avaliação é apresentado um conjunto de respostas possíveis, que são valoradas conforme a escala min-max discutida. $\mathrm{O}$ questionário completo é apresentado no APÊNDICE B. Por simplicidade, no Quadro 4.5 são omitidos o Peso e a Classificação (quanto à possibilidade de dispensa) dos Controles, pois essas informações já constam do Quadro 4.4. Entretanto, essas configurações são apresentadas de forma completa no APÊNDICE B. Esse questionário (APÊNDICE B) foi produzido durante a Oficina de Grupo Focal com especialistas, que elaboraram as questões conforme cada controle. Desse modo, o questionário é contribuição original deste trabalho.

Observa-se que a tabela com o questionário do APÊNDICE B é a principal parametrização do modelo. Acredita-se que outros sistemas de avaliação de maturidade podem ser usados com o mesmo modelo, utilizando-se a parametrização apropriada. 
Quadro 4.5 - Extrato do Questionário de Avaliação

\begin{tabular}{|c|c|c|c|c|}
\hline Domínio & Controle & $\begin{array}{l}\text { Interpretação } \\
\text { do Controle }\end{array}$ & $\begin{array}{c}\text { Itens de Avaliação (Questões)/Respostas } \\
\text { Possíveis }\end{array}$ & $\begin{array}{l}\text { Valor } \\
\text { Min-Max }\end{array}$ \\
\hline \multirow{27}{*}{$\begin{array}{l}\text { Aplicações e } \\
\text { Arquitetura } \\
\text { D-04 }\end{array}$} & \multirow{12}{*}{$\begin{array}{l}\text { Arquiteturas } \\
\text { de Referência }\end{array}$} & \multirow{12}{*}{$\begin{array}{l}\text { Qual o nível de } \\
\text { utilização da } \\
\text { Arquitetura de } \\
\text { Referência (da } \\
\text { organização). }\end{array}$} & $\begin{array}{l}\text { Sua organização utiliza / tem uma arquitetura de } \\
\text { referência? }\end{array}$ & \\
\hline & & & Não existe arquitetura de referência. & $1-1$ \\
\hline & & & $\begin{array}{l}\text { Arquitetura de referência utilizado por demanda ou } \\
\text { quando considerado necessário. }\end{array}$ & $2-3$ \\
\hline & & & $\begin{array}{l}\text { Arquitetura de referência é usada em toda a } \\
\text { organização. }\end{array}$ & $4-5$ \\
\hline & & & $\begin{array}{l}\text { Qual é o estado de sua arquitetura de referência } \\
\text { SOA? }\end{array}$ & \\
\hline & & & Nenhum ou não aplicável & $1-1$ \\
\hline & & & $\begin{array}{l}\text { Pesquisa e avaliação de arquiteturas SOA de } \\
\text { referência do fornecedor e da indústria. }\end{array}$ & $1-1$ \\
\hline & & & A arquitetura de referência inicial SOA foi definido. & $2-2$ \\
\hline & & & $\begin{array}{l}\text { Arquitetura de referência SOA foi revista e está } \\
\text { guiando a instalação / revisão da infraestrutura. }\end{array}$ & $3-3$ \\
\hline & & & $\begin{array}{l}\text { Os principais elementos da arquitetura de referência } \\
\text { SOA estão em produção. }\end{array}$ & $3-3$ \\
\hline & & & $\begin{array}{l}\text { Arquitetura SOA completa na produção porém com } \\
\text { refinamentos tempestivos (programados). }\end{array}$ & $4-4$ \\
\hline & & & $\begin{array}{l}\text { Arquitetura SOA completa na produção com } \\
\text { refinamentos sucessivos segundo o ciclo de melhoria } \\
\text { contínua. }\end{array}$ & $5-5$ \\
\hline & \multirow{15}{*}{$\begin{array}{l}\text { Gerenciamento } \\
\text { de Identidade } \\
\text { e de Acesso }\end{array}$} & \multirow{15}{*}{$\begin{array}{l}\text { Verifica o uso e } \\
\text { centralização de } \\
\text { práticas de } \\
\text { gestão de } \\
\text { identidade nos } \\
\text { serviços SOA } \\
\text { construídos, bem } \\
\text { como de } \\
\text { propagação de } \\
\text { identidade entre } \\
\text { serviços SOA. }\end{array}$} & $\begin{array}{l}\text { Você tem uma identidade empresarial e roteiro } \\
\text { Gerenciamento de Acesso? }\end{array}$ & \\
\hline & & & Não & $1-1$ \\
\hline & & & $\begin{array}{l}\text { A organização está no processo de criação de um } \\
\text { Gerenciamento de Identidade e de Acesso unificado. }\end{array}$ & $2-2$ \\
\hline & & & $\begin{array}{l}\text { Existe um processo de Gerenciamento de Identidade e } \\
\text { de Acesso unificado. }\end{array}$ & $3-4$ \\
\hline & & & $\begin{array}{l}\text { Existe um processo de Gerenciamento de Identidade e } \\
\text { de Acesso unificado no middleware segundo modelo } \\
\text { padrões. }\end{array}$ & $5-5$ \\
\hline & & & $\begin{array}{l}\text { Quando os aplicativos invocar serviços em nome de } \\
\text { um usuário, são pedidos representado como vindo } \\
\text { do usuário? }\end{array}$ & \\
\hline & & & Isto não é uma meta & $1-1$ \\
\hline & & & $\begin{array}{l}\text { Esta é uma meta da arquitetura, mas é só às vezes } \\
\text { implementado }\end{array}$ & $2-2$ \\
\hline & & & $\begin{array}{l}\text { Esta função é geralmente implementado para serviços } \\
\text { no domínio local }\end{array}$ & $3-3$ \\
\hline & & & $\begin{array}{l}\text { Esta função é geralmente implementado para serviços } \\
\text { através de todos os domínios existentes }\end{array}$ & $4-5$ \\
\hline & & & $\begin{array}{l}\text { Após a autenticação, existe interação entre os } \\
\text { serviços para propagar a autorização de forma a } \\
\text { gerenciar a confiança entre componentes } \\
\text { distribuídos? }\end{array}$ & \\
\hline & & & Isto não é uma meta & $1-1$ \\
\hline & & & $\begin{array}{l}\text { Esta é uma da meta arquitetura, mas é só às vezes } \\
\text { implementado }\end{array}$ & $2-2$ \\
\hline & & & $\begin{array}{l}\text { Esta função é geralmente implementado para serviços } \\
\text { no domínio local }\end{array}$ & $3-3$ \\
\hline & & & $\begin{array}{l}\text { Esta função é geralmente implementado para serviços } \\
\text { através de todos os domínios existentes }\end{array}$ & $4-5$ \\
\hline
\end{tabular}




\section{2 - HEURÍSTICA DE AVALIAÇÃO}

\subsection{1 - Avaliação de Controles}

Conforme exposto na Seção 4.1.4, após a resposta do questionário, a cada Item de Avaliação é atribuído um range de nível de maturidade (valores mínimo e máximo), que corresponde à contribuição do Item de Avaliação para a valoração da maturidade do Controle correspondente.

Nesta seção aborda-se a questão da agregação dos valores de nível de maturidade contribuídos por cada Item de Avaliação para determinar o valor do nível de maturidade para o Controle correspondente. Assim, os valores atribuídos a cada Item de Avaliação que compõe determinado Controle serão agregados para aferição do nível de maturidade desse Controle. Essa relação é expressa na Equação 4.1.

$$
C_{i}=f_{j=1, N i}\left(I_{i, j}\right)
$$

onde:

- $\quad C_{i}$ é o valor do nível de maturidade do Controle $i$;

- $\quad I_{i, j}$ é o valor do range (mínimo-máximo) (APÊNDICE B) de nível de maturidade do Item de Avaliação $j$ que compõe o Controle $i$;

- $\quad N i$ é o número de itens de avaliação que compõem o Controle $i$;

- $f$ é a função de agregação. Essa considera os valores de todos os $N i$ itens de avaliação.

A primeira preocupação na solução desse problema é a do critério de decisão a ser imposto no modelo de avaliação de cada controle, a partir das questões correlacionadas (Itens de Avaliação) que o compõem. O critério estabelecido no modelo proposto segue referencial apresentado na seção 2.4, onde aponta-se que "Em processos decisórios multiatributos, o método Minimax é comumente usado quando todos os atributos são 
comparáveis, julgados com base em um único critério" (LINKOV; RAMADAN, 2004), onde regressões Minimax ou a aplicação da regra Hurwitz com um baixo índice de otimismo são consideradas alternativas válidas.

Assim, utiliza-se o critério pessimista Minimax para cada Controle ativo (não dispensados). Desse modo, para os $N i$ Itens de Avaliação (questões) referentes ao Controle $i$, a expressão 4.1 assume a forma da Equação 4.2:

$$
C_{i}=\operatorname{MIN}\left(\operatorname{MAX}\left(I_{i, j}\right)\right)
$$

onde:

- $\operatorname{MAX}\left(I_{i, j}\right)$ refere-se ao maior valor (valor máximo) em cada questão respondida por controle;

- $\quad \mathrm{MIN}()$ refere-se ao valor mínimo dentre as questões (ou questão) que seja identificada pelo valor de $\operatorname{MAX}\left(I_{i, j}\right)$.

Como resultado, têm-se a valoração da contribuição de maturidade para cada Controle. Essa etapa de cálculo é denominada fase "MINMAX".

\subsection{2 - Avaliação de Nível de Maturidade de Domínios}

A realização de etapa anterior provê os valores de nível de maturidade correspondentes para os Controles. Nesta seção, valores atribuídos a Controles de um mesmo Domínio são agregados de forma a se obter o nível de maturidade por Domínio.

Os valores atribuídos aos controles são inteiros de 1 a 5 (inclusive), formando uma distribuição de valores discreta. Esses valores devem ainda ser ponderados pelos respectivos pesos (vide Quadro 4.4). Na proposta do modelo de maturidade deste trabalho, os valores de controles e seus pesos são utilizados na formação de uma distribuição discreta de frequência com pesos (weighted frequency distribution), utilizando a formulação descrita na Equação 4.3.

$$
L_{\text {level }}=\sum_{i}^{\text {Ci=level }} P_{i}
$$


onde:

- level: representa os níveis da escala de maturidade (level =1,2,3,4 e 5);

- $\quad L_{\text {level }}$ é a frequência de controles em cada nível;

- $\quad \mathrm{P}_{\mathrm{i}}$ é o peso de cada Controle $i$ quando $C_{i}=$ level

A equação 4.3 descreve as premissas de análise discutidas na seção 2.5 . A análise de frequência considera uma quantidade de elementos em cada frequência correspondente ao peso de cada controle. Como os valores de peso $(P)$ são variáveis discretas positivas de baixa amplitude (e.g. 1, 2 ou 3), um peso $\underline{P_{i}}$ em um controle $i$ avaliado com o nível de maturidade level representa a adição do valor $\underline{P i}$ ocorrências no histograma, para o nível de maturidade level. O Quadro 4.6 exemplifica o cálculo requerido.

Quadro 4.6 - Formação do Quadro de Distribuição de Frequências considerando seus Pesos

\begin{tabular}{|c|c|c|c|c|c|}
\hline Domínio A & $P_{i}$ & $\overline{C_{i}}$ & \multicolumn{3}{|c|}{ Distribuição de Frequência } \\
\hline Controle 01 & 2 & 2 & $\begin{array}{l}\text { Nível } \\
(\text { level })\end{array}$ & Soma Pesos & Frequência \\
\hline Controle 02 & 1 & 2 & 1 & & \\
\hline Controle 03 & 3 & 4 & 2 & $=2+1$ & 3 \\
\hline Controle 04 & 1 & 3 & 3 & $=1$ & 1 \\
\hline Controle 05 & 2 & 5 & 4 & $=3$ & 3 \\
\hline Controle 06 & 2 & 5 & 5 & $=2+2$ & 4 \\
\hline
\end{tabular}

Esse tipo de tratamento estabelece um acréscimo de situações e possibilidades típicas no espaço amostral, o que permite a definição de situações ou conglomerados possíveis, visualizados a partir da visualização gráfica dos histogramas resultantes. O Quadro 4.7, retrata essas situações nas formas que são representativas. 
Quadro 4.7 - Situações típicas reconhecidas pela heurística de avaliação de Domínios

\begin{tabular}{|c|c|c|c|c|c|c|c|}
\hline \multicolumn{5}{|c|}{ Histograma } & Situação & Descrição & Heurística \\
\hline 1 & 2 & 3 & 4 & 5 & DESORDEM & $\begin{array}{l}\text { A organização não } \\
\text { manteve nenhuma gestão } \\
\text { controlada sobre as } \\
\text { necessidades de } \\
\text { tratamento de cada } \\
\text { controle de forma } \\
\text { alinhada quanto aos } \\
\text { níveis de maturidade na } \\
\text { adoção de SOA. }\end{array}$ & $\begin{array}{l}\text { Situação significativamente } \\
\text { amodal e com elementos } \\
\text { presentes em quantidade maior } \\
\text { que um determinado número de } \\
\text { classes do histograma }(\mathrm{N}>3) \text {. } \\
\text { O valor de maturidade avaliado } \\
\text { é dado pelo menor nível de } \\
\text { maturidade encontrado. }\end{array}$ \\
\hline 1 & 2 & 3 & 4 & 5 & EXCEÇÃO & $\begin{array}{l}\text { A organização deixou de } \\
\text { considerar aspectos de } \\
\text { um mínimo de controles } \\
\text { que podem impactar na } \\
\text { efetiva adoção de SOA. } \\
\text { Esses controles devem } \\
\text { ser priorizados nas } \\
\text { atividades de } \\
\text { atingimento de níveis } \\
\text { mais elevados de } \\
\text { maturidade. }\end{array}$ & $\begin{array}{l}\text { Existem valores atípicos a } \\
\text { menor, com estes valores } \\
\text { representando um baixo } \\
\text { percentual de ocorrências } \\
\left(L_{\min }<0,2 \Sigma L_{\text {level }}\right) \text {. A maturidade } \\
\text { estabelecida é dada pelo valor } \\
\text { consecutivo ao menor nível de } \\
\text { maturidade encontrado. }\end{array}$ \\
\hline 1 & 2 & 3 & 4 & 5 & ESTÁVEL & $\begin{array}{l}\text { A situação é de um } \\
\text { equilíbrio significativo na } \\
\text { aplicação de todos os } \\
\text { princípios de SOA, } \\
\text { princípios esses que são } \\
\text { representados pelos } \\
\text { controles apurados. O } \\
\text { resultado da análise de } \\
\text { frequência é representado } \\
\text { quase na totalidade por } \\
\text { um valor único de nível } \\
\text { de maturidade. }\end{array}$ & $\begin{array}{l}\text { O histograma possui todas as } \\
\text { ocorrências na mesma classe, } \\
\text { ou ocorrências em classes } \\
\text { adjacentes mas com estes } \\
\text { valores representando um baixo } \\
\text { percentual de ocorrências } \\
\left(\Sigma L_{a d i}<0,2 \Sigma \mathrm{L}_{\text {level }}\right) \text {. A } \\
\text { maturidade estabelecida é dada } \\
\text { pelo valor da MODA. }\end{array}$ \\
\hline 1 & 2 & 3 & 4 & 5 & $\begin{array}{l}(\text { EM) } \\
\text { EVOLUÇÃO }\end{array}$ & $\begin{array}{l}\text { Dentro do ciclo de } \\
\text { melhoria contínua, a } \\
\text { organização se encontra } \\
\text { a "meio termo" de um } \\
\text { processo evolutivo de } \\
\text { maturidade na adoção de } \\
\text { SOA (representação } \\
\text { contínua). }\end{array}$ & $\begin{array}{l}\text { O histograma indica uma } \\
\text { distribuição com formato de } \\
\text { uma rampa decrescente ou de } \\
\text { uma distribuição normal } \\
\text { invertida. O valor de } \\
\text { maturidade avaliado é dado } \\
\text { pelo menor nível de maturidade } \\
\text { encontrado, indicando uma } \\
\text { evolução deste para níveis } \\
\text { maiores. }\end{array}$ \\
\hline 1 & 2 & 3 & 4 & 5 & & & \\
\hline
\end{tabular}

Continua 


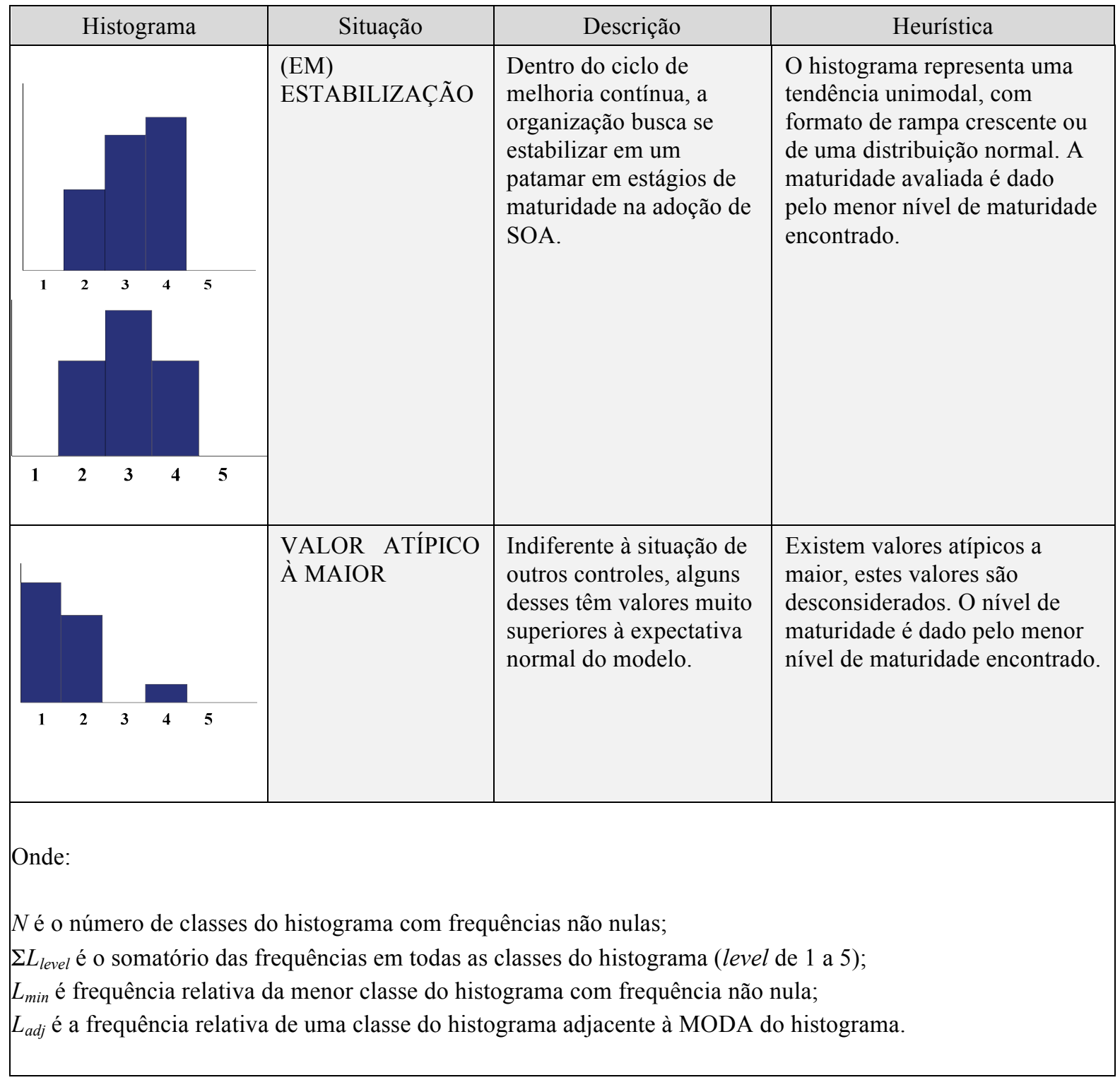

A Figura 4.4 apresenta o algoritmo projetado para reconhecer a situação de cada domínio, conforme as situações observados no Quadro 4.7. Esse algoritmo permite identificar o nível de maturidade onde o Domínio é classificado, bem como a situação em que esse se encontra (DESORDEM, EXCEÇÃO, ESTÁVEL, em EVOLUÇÃO, em ESTABILIZAÇÃO). 


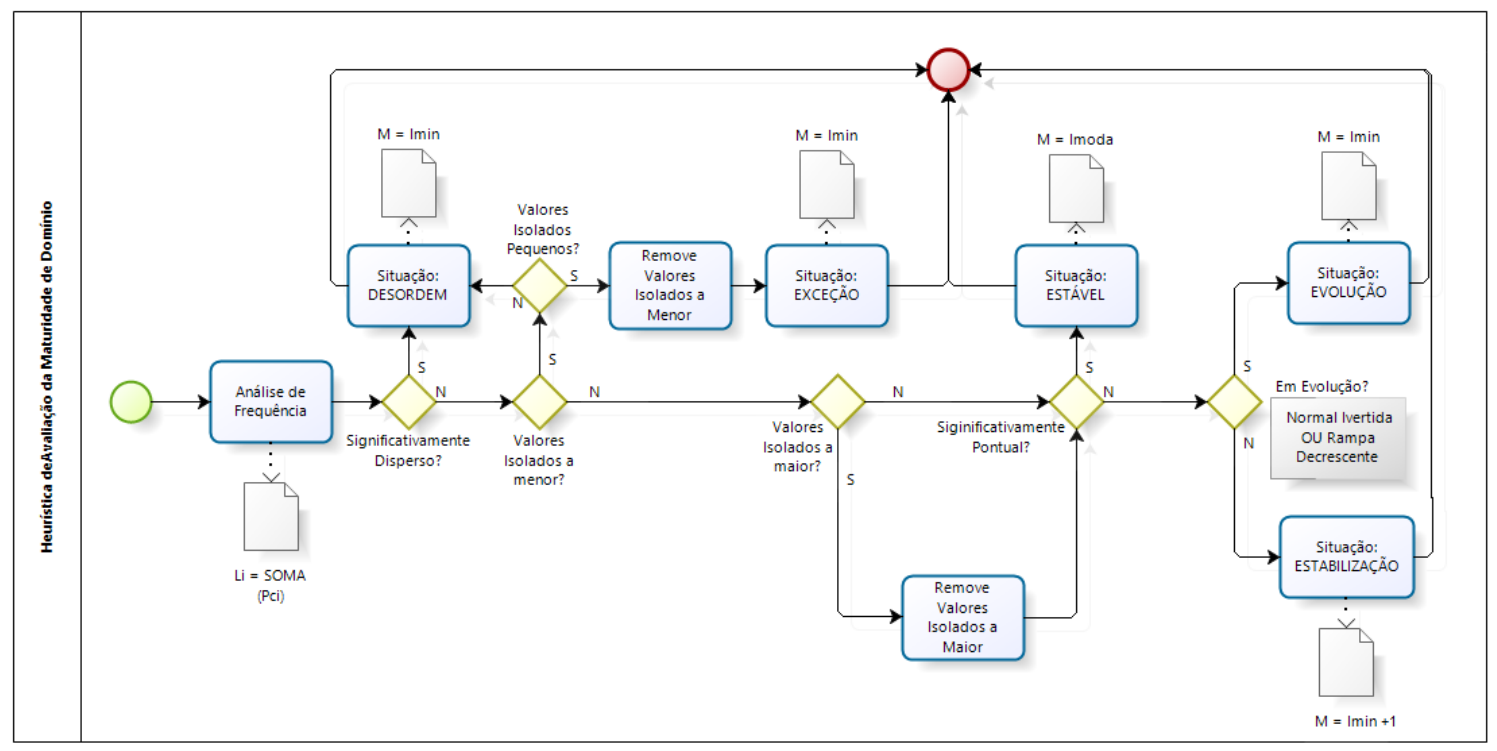

Figura 4.4 - Heurística de Avaliação da Maturidade do Domínio

Como um processo de melhoria no suporte à adoção de SOA, o modelo proposto trata então de gerar duas representações numéricas em todas as situações, que se referem ao cálculo dos seguintes níveis:

- NÍVEL DE MATURIDADE ATINGIDO: representa o nível de maturidade que pôde ser estabelecido para a situação em análise. Esse nível deve ser registrado para uso em comparações adicionais de histórico de evolução em relação aos benefícios reais obtidos subsequentes ao período de uma evolução.

- NÍVEL DE MATURIDADE ALMEJADO: conjuntamente ao cálculo de nível de maturidade atingido, o modelo proposto formula um nível de maturidade almejado, tendo por base a situação que foi encontrada. Essa formulação segue o princípio: é representado pelo valor de NÍVEL DE MATURIDADE ATINGIDO calculado para a situação de ESTABILIZAÇÃO, e pelo consecutivo ao valor de NIVEL DE MATURIDADE ATINGIDO calculado para as demais situações. O NÍVEL DE MATURIDADE ALMEJADO é usado para obtenção dos roteiros de evolução. 


\section{3 - RESULTADOS}

\subsection{1 - Dashboards}

O resultado da realização do processo de valoração dos níveis de maturidade por Domínios, discutidos na seção 4.2.2, permite gerar gráficos de "Nível de Maturidade Atingido”. Esses gráficos são a saída primária do modelo e representam o resultado geral de uma avaliação realizada em determinada época (data). Nota-se que múltiplas avaliações de uma mesma organização podem ser realizadas, em diferentes momentos, para que se possa acompanhar a evolução da maturidade ao longo do tempo. Isso normalmente é feito pela apresentação de resultados em séries históricas.

Os resultados podem ser exibidos em duas granularidades distintas: Gráficos de Barras, mostrando o nível de maturidade atingido em cada Controle de um Domínio (exemplo na Figura 4.5); e Gráfico de Radar, mostrando o nível de maturidade obtido em cada Domínio (exemplo na Figura 4.6).

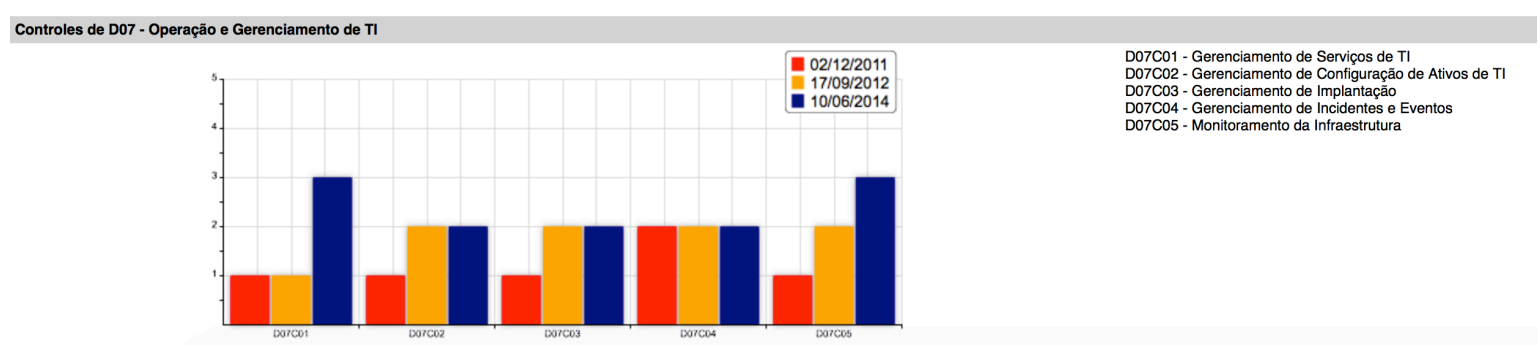

Figura 4.5 - Exemplo de Gráfico de Barras para indicar Nível de Maturidade Atingido em cada Controle de um Domínio, em três avaliações distintas (2/12/2011, $17 / 9 / 2014$ e 10/6/2014) 


\section{NIVEL ATUAL}

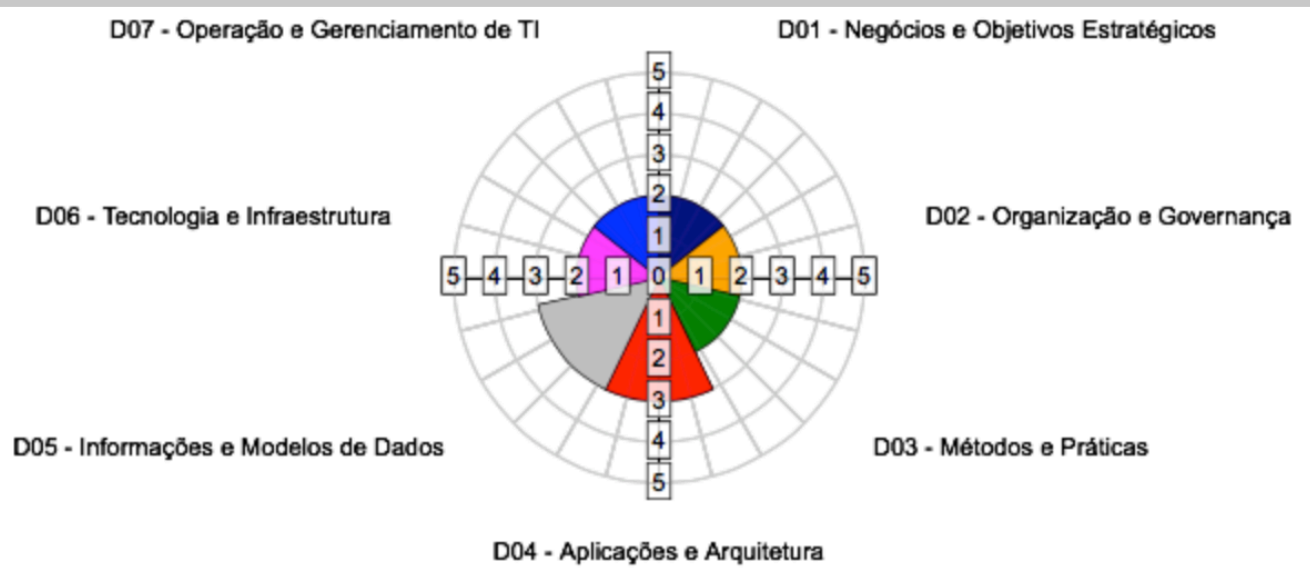

Figura 4.6 - Exemplo de Gráfico em Radar para indicar de Nível de Maturidade Atingido em cada Domínio

Assim, o valor calculado do Nível de Maturidade Atingido mostra em qual estágio a organização se encontra no momento da avaliação em relação ao modelo proposto, e suporta a observação das características percebidas na organização - quais são as forças e fraquezas, o que deve ser melhorado e o que está de acordo com as medidas aceitáveis dentro do modelo.

\section{NIVEL ALMEJADO}

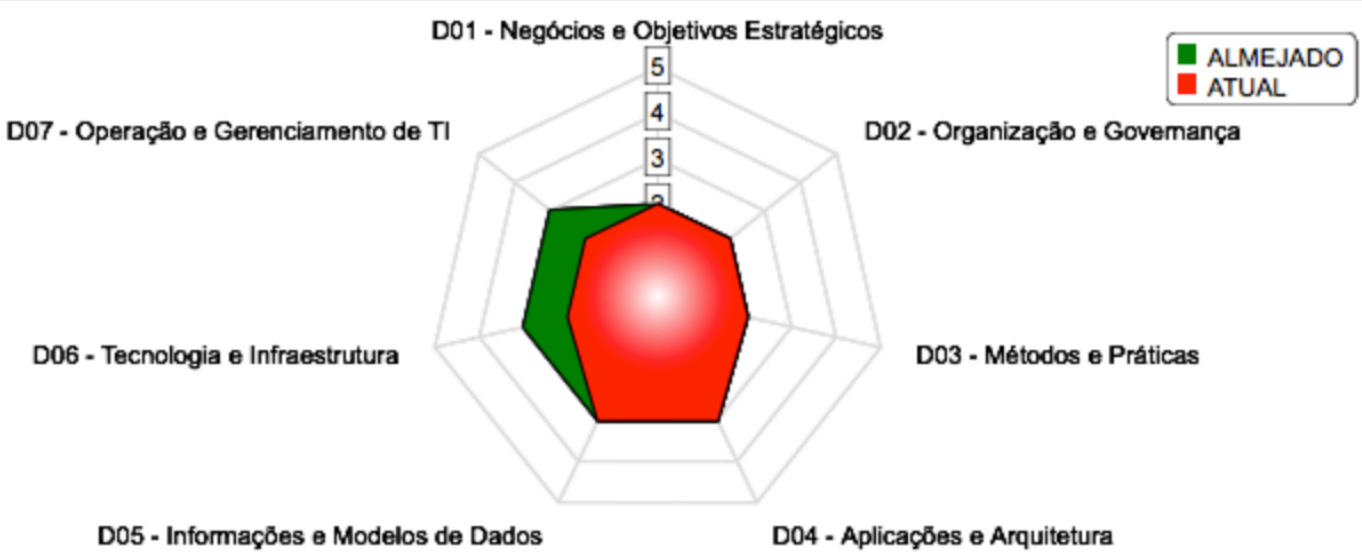

Figura 4.7 - Exemplo de Gráfico em Radar para indicar de Nível de Maturidade Atingido em comparação com o Nível de Maturidade Almejado.

Alternativamente, o resultado da avaliação por Domínios pode ser representado na forma de um Gráfico de Barras, com os domínios representados de forma ordenada (D01 a D07). Como os domínios estão ordenados indicando áreas de conhecimento que vão do nível mais estratégico do negócio (D01), seguido dos níveis de governança e de informação 
(D02 e D03), passando pelos métodos e práticas utilizados nas aplicações, e estabelecidos nos modelos arquiteturais (D04 e D05) até a ótica da TI e de sua infraestrutura subjacente e as operações necessárias para mantê-la (D06 e D07), esses últimos estão mais relacionados com aspectos operacionais. Aproveitando essa sequência lógica, esses gráficos permitem a análise de algumas situações representativas, ilustradas no Quadro 4.8.

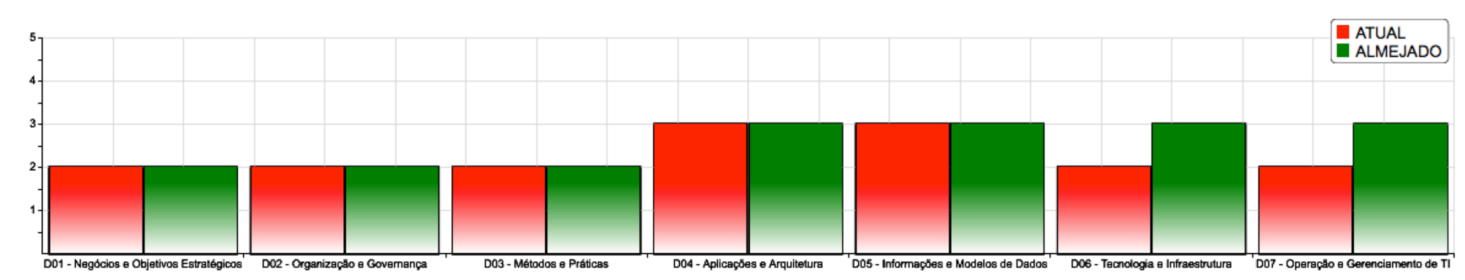

Figura 4.8 - Exemplo de Gráfico de Barras para indicar Nível de Maturidade Atingido em comparação com o Nível de Maturidade Almejado 
Quadro 4.8 - Situações representativas na valoração da maturidade entre Domínios

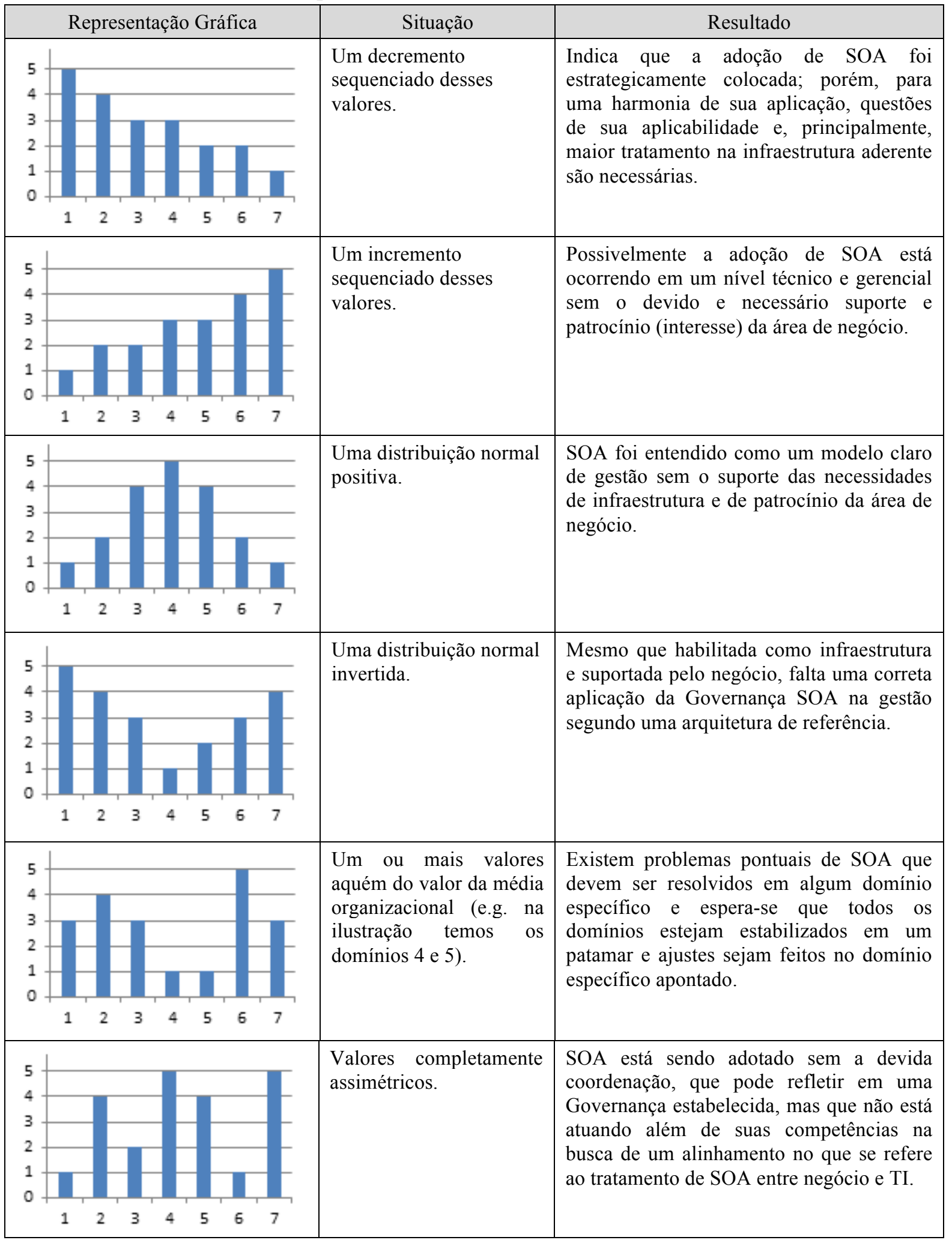




\subsection{2 - Geração de Roteiros de Evolução}

O modelo proposto permite ainda a construção de roteiros de referência (roadmaps) associado ao nível de maturidade almejado e considerando a situação encontrada para cada domínio - tipicamente em estabilização ou evolução. Esses roteiros são gerados a partir da avaliação dos controles requeridos e não implementados para o nível almejado. Desse modo, os roteiros indicam uma ação requerida para cada controle não implementado, como pode ser verificado na figura a seguir.

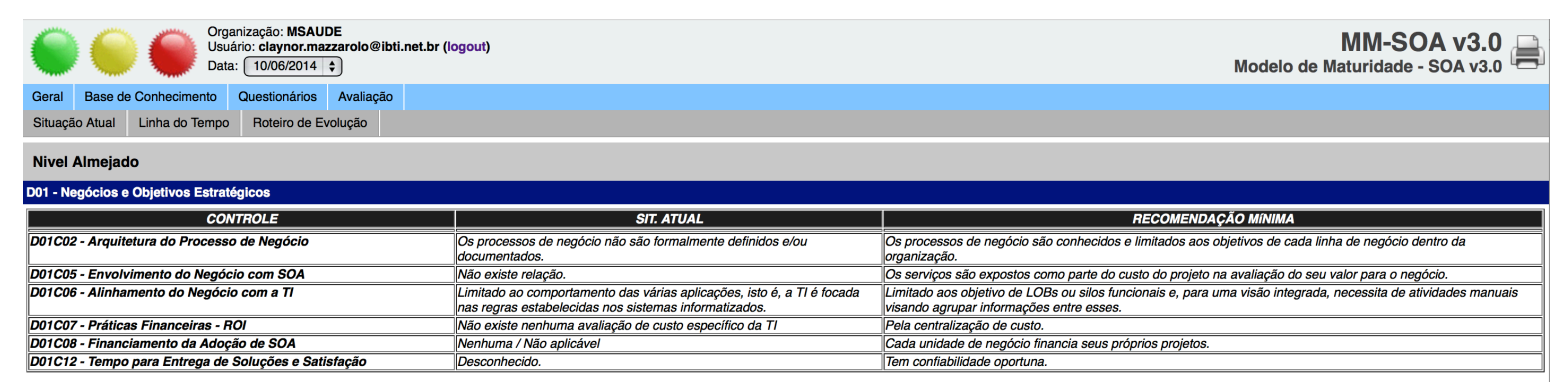

Figura 4.9 - Exemplo de Roteiro de Evolução para o Domínio

O processo de geração dos roteiros de evolução envolve a análise - controle a controle do seu valor calculado (do controle) em relação ao valor almejado. Essa análise apenas envolve os controles que estão com valor menor do que o valor do Nível de Maturidade Almejado, tendo como foco controles que possam estar com alto grau de dispersão a menor do valor estabelecido pelo domínio. Esses controles a menor apontam situações consideradas críticas para tratamento efetivo da evolução da Maturidade SOA.

Vale observar que o modelo proposto não faz inferência de uma maturidade organizacional global, agregando a maturidade obtida em cada domínio para geração de um número único para qualificação do estágio de maturidade global para a organização. Desse modo, a única alternativa que existe seria considerar como maturidade global a menor maturidade obtida entre todos os controles. Essa visão pessimista é aplicada em todo o processo de cálculo de nível de maturidade atingido. Assim, o modelo proposto suporta apenas a consideração do uso do menor valor entre esses, o que implica a priorização das necessidades de ajustes em domínios diferenciados de acordo com a escala de valores encontrados no momento.

De forma prática, valores a menor junto ao domínio de negócio apontam para urgente necessidade de atividades visando ao seu alinhamento e formação de um suporte de maior 
e mais forte patrocínio para adoção de SOA junto à alta direção. Valores a menor não alinhados no centro dessa escala indicam falta de controle na adoção do SOA. Por fim, valores a menor observados ao fim dessa escala apontam para prováveis problemas operacionais e de infraestrutura para adoção de SOA. 


\section{5 - AMBIENTE EXPERIMENTAL}

\section{1 - PROCESSO DE AVALIAÇÃO}

O processo de avaliação é associado a quatro passos com tarefas sequenciais distintas: a Coleta de Dados, a Heurística de Avaliação, a Geração de Resultados e a Geração de Roteiro de Estabilização ou Evolução. A Figura 5.1 ilustra esses aspectos e aponta as ações necessárias para a realização integral do processo como proposto, de forma a obter resultados em cada uma das camadas da arquitetura e seu equivalente roteiro de estabilização e/ou evolução, para o suporte a adoção de SOA.

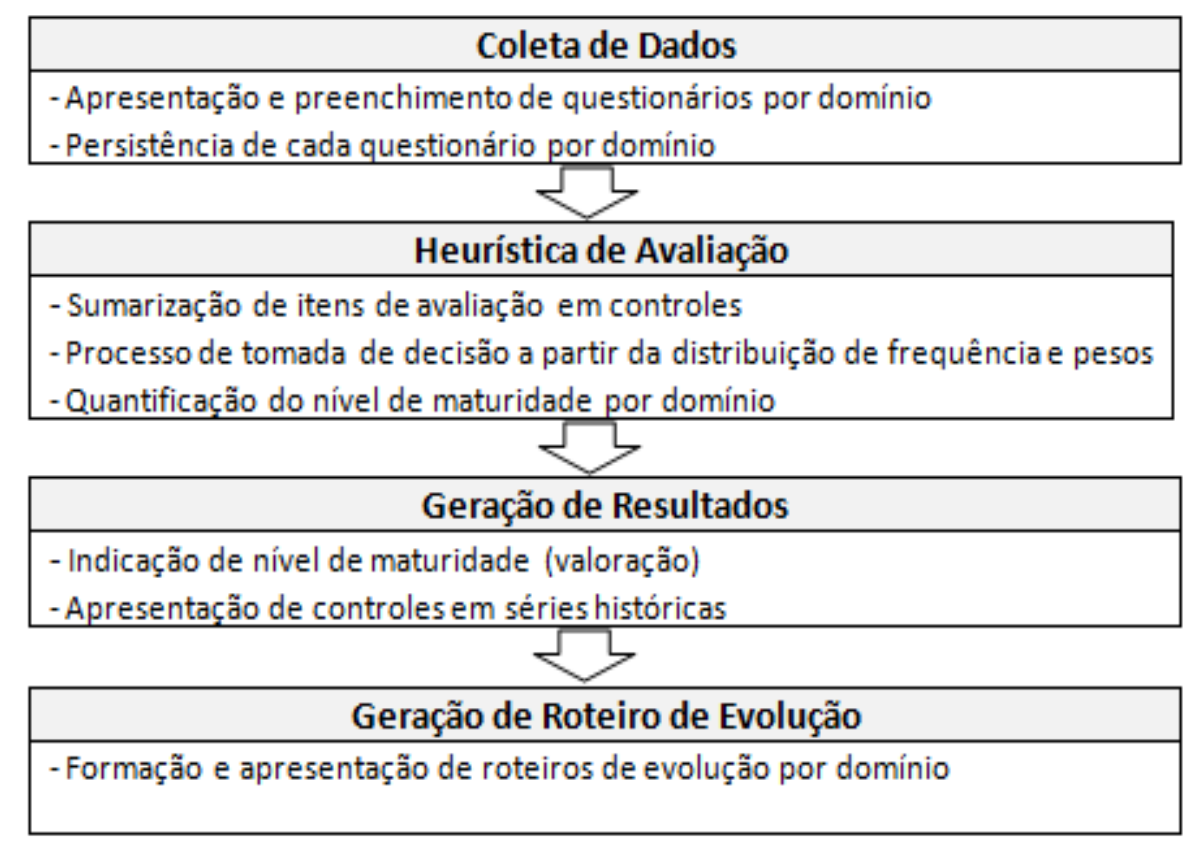

Figura 5.1 - Processo de Avaliação e Maturidade Proposto

A Figura 5.1 ilustra a sequência de atividades referentes a esses aspectos, necessárias para o processo como idealizado, tendo como resultado a definição do NÍVEL DE MATURIDADE ATINGIDO (Geração de Resultados) com a consequente geração de roteiros de referência para progressão a uma meta de NÍVEL DE MATURIDADE ALMEJADO (Geração de Roteiros de Evolução), para orientar a evolução da maturidade na adoção de SOA. 


\subsection{1 - Coleta de Dados}

O processo de Coleta de Dados trata da aplicação dos questionários associados a uma posição no tempo (data); isso é, o registro das respostas às questões, que representa a imagem da situação de cada item de avaliação, controle e domínio dentro da organização em períodos tempestivos.

A correta aplicação dos questionários garante a adequação dos resultados aferidos no processo de avaliação. A responsabilidade de respondê-los deve ser confiada a gestores das áreas de conhecimento da organização, de acordo com os princípios básicos de cada domínio e as devidas competências funcionais. O Quadro 5.1 apresenta perfis organizacionais sugeridos para preenchimento dos questionários relativos a cada domínio do modelo. Isso ilustra o ponto de vista deste estudo acerca da relação entre os domínios declarados e cargos ou atividades funcionais correlatos comuns.

Quadro 5.1 - Perfis Organizacionais sugeridos para Preenchimento nos Domínios

\begin{tabular}{|l|l|}
\hline \multicolumn{1}{|c|}{ Definição } & \multicolumn{1}{|c|}{ Descrição } \\
\hline Negócio e Objetivos Estratégicos & Alta Direção, Governança Corporativa. \\
\hline Organização e Governança & $\begin{array}{l}\text { Área de Negócios, Coordenação das Atividades Finalísticas, Governança } \\
\text { SOA. }\end{array}$ \\
\hline Métodos e Práticas & Governança SOA. \\
\hline Aplicações e Arquitetura & $\begin{array}{l}\text { Governança de TI, Coordenador de TI, Corpo Consultivo da TI, } \\
\text { Governança SOA (com restrições). }\end{array}$ \\
\hline Informações e Modelos de Dados & $\begin{array}{l}\text { Governança de TI, Coordenador de TI, Corpo Consultivo da TI, } \\
\text { Coordenador de área específica da TI que coordena as atividades de } \\
\text { Administração de Dados e/ou Modelagem Canônica de Dados. }\end{array}$ \\
\hline Tecnologia e Infraestrutura & Governança de TI, Coordenador de TI, Corpo Consultivo da TI. \\
\hline Operação e Gerenciamento de TI & Governança de TI, Coordenador de TI (de Operação de Serviços de TI). \\
\hline
\end{tabular}

\subsection{2 - Geração de Resultados e Análise}

Os dados coletados são processados pelas heurísticas definidas (seção 4.2.1 e 4.2.2), gerando os valores de maturidade nos Controles considerados e nos Domínios. Esses resultados são apresentados de forma gráfica, conforme descrito na seção 4.2.3. Finalmente, são gerados os roteiros de evolução, conforme descrito na seção 4.2.4. 
Para análise, os gráficos gerados (resultados) e roteiros de evolução são apresentados em formato navegável e podem incluir resultados de avaliações em momentos distintos, com o objetivo de permitir a análise da evolução temporal (série histórica) da maturidade de SOA. O processo de análise será explorado com maiores detalhes na avaliação do estudo de caso, contida no Capítulo 6.

\section{$5.2-S O F T W A R E$}

O processo de avaliação descrito na seção anterior pode ser sistematizado com o uso de um sistema de software que apoia a coleta de dados, a geração de resultados e sua análise. Para tanto, tal sistema foi especificado e implementado durante a elaboração desta tese. $\mathrm{O}$ software está disponível na URL http://mmsoa.dyndns.org.

Mesmo que a implementação do software seja entendida como um subproduto deste trabalho, sua relevância está em estabelecer um modelo funcional para uso comum e viabilizar o processo de validação através da realização de caso de uso. Nesse sentido, além do processo de avaliação e emissão de saídas, o software deve, adicionalmente, recomendar as atividades de evolução necessárias, direcionando a organização à implementação de melhorias no nível atual de maturidade da organização, contribuindo dessa forma com o objetivo específico deste estudo.

A estrutura do sistema é operacionalizada por um conjunto de ferramentas compostas por módulos e pelos questionários na forma de formulários, ao qual o usuário interage para que o sistema possa obter informações e realizar as avaliações. Ainda, tais avaliações são realizadas com a orientação do módulo de base de conhecimento com matrizes de Domínios $x$ Controles $x$ Itens de Avaliação parametrizadas por um modelo de pontuação ponderada (APÊNDICE B). Como resultado, as saídas são dispostas na forma de representação diagramática do tipo Gráficos de Radar e de Barras, em conjunto com o roteiro de evolução de melhorias recomendadas. A interface destinada ao usuário é apresentada em formato de abas, com o objetivo de se promover uma navegação intuitiva.

Os documentos auxiliares de Projeto de Software são apresentados no APÊNDICE D deste trabalho. Nesse apêndice, são apresentados: 
- documento de visão - que dá descrição básica da fase de iniciação na concepção do sistema, expondo as necessidades e funcionalidades gerais do mesmo;

- documento de requisitos resultante da aplicação de técnicas de engenharia de requisitos - tais como listas de requisitos funcionais e não-funcionais, bem como de sua matriz de rastreabilidade;

- documento de prototipação - no que se refere à descrição das camadas arquiteturais do modelo cliente-servidor utilizado; e

- documento de análise de dados e sua persistência - através de um Modelo de EntidadeRelacionamento Conceitual e sua devida expressão Relacional (normalizada).

\subsection{1 - Módulos do Sistema de Software}

\subsubsection{1 - Geral}

Dividido em duas abas, apresenta (na aba 'Apresentação') os conceitos gerais de orientação a serviços, bem como as peculiaridades de se trabalhar a maturidade em ambientes que suportam a adoção de SOA. Ainda, salienta-se a dificuldade de realizar tal atividade, aplicando-se modelos já padronizados na indústria. A aba 'Grupo de Trabalho' apresenta a equipe que colaborou no desenvolvimento do modelo.

\subsubsection{2 - Base de Conhecimento}

A aba base de conhecimento visa a esclarecer aos usuários do sistema quaisquer termos ou assuntos relacionados ao modelo SOA, que haja necessidade de se aprofundar sobre, sendo dividida em 7 diferentes itens (ou subabas - Conteúdo, Glossário, Princípios, Metodologia, Modelo, Domínio e Níveis).

O item inicial ('Conteúdo') introduz as informações disponíveis pelo item, enquanto que o item 'Glossário'(Figura 5.2) apresenta as definições de uma série de termos comumente utilizados durante a exposição do questionário e os resultados da avaliação. 
O item 'Princípios' expõe os princípios aplicados à elaboração dos questionários e sua análise. Já o item 'Metodologia' exibe como é definida a avaliação, bem como a heurística aplicada ao modelo desenvolvido.

O item 'Modelo' informa ao usuário sobre as referências utilizadas na elaboração da ferramenta, bem como um pouco do histórico. Como para cada domínio existem níveis comuns de maturidade, pode-se observar que os itens 'Domínios' e 'Níveis' são complementares e definem informações pertinentes sobre a classificação do estágio de maturidade da organização ao qual o respondente (ou os respondentes) atua.

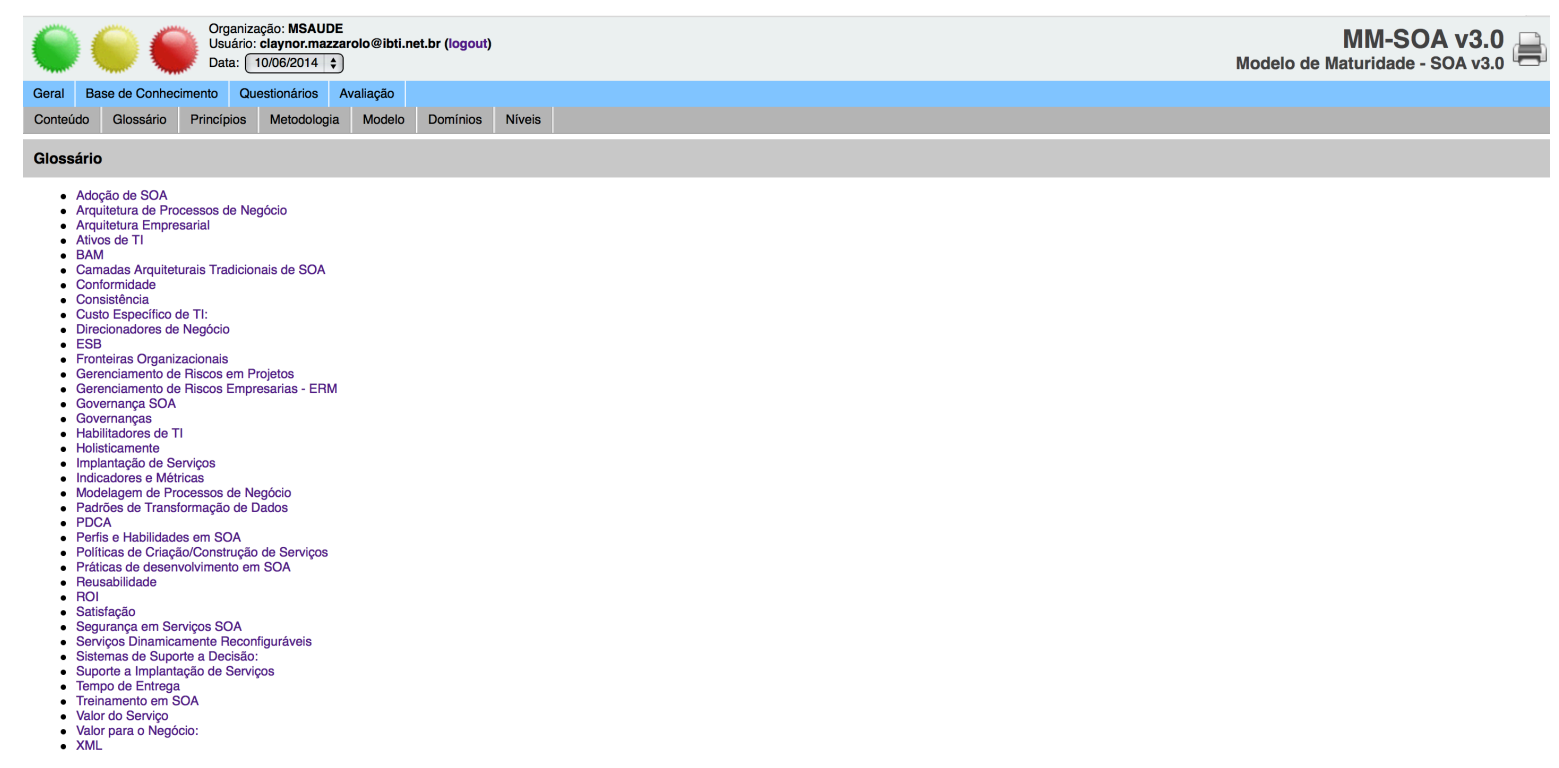

Figura 5.2 - Base de Conhecimento - Glossário

\subsubsection{3 - Questionários}

Esse item apresenta seu menu organizado por Domínios. Cada item do menu dá acesso a questionários estruturados para a avaliação dos Controles, que aparecem destacados por uma linha amarela (Figura 5.3). Nessa etapa, é possível dispensar os Controles - cuja dispensa é permitida pelo modelo.

A apresentação dos questionários em abas organizadas por Domínio permite que os perfis profissionais adequados possam avaliar o Domínio de sua área de conhecimento organizacional. Por exemplo, no Domínio 01 - Negócios e Objetivos Estratégicos - o respondente preferencialmente deve ser alguém de estratégia organizacional, enquanto no Domínio 07 - Operações de Gerenciamento de TI - o respondente precisa conhecer as 
rotinas da área de TI.

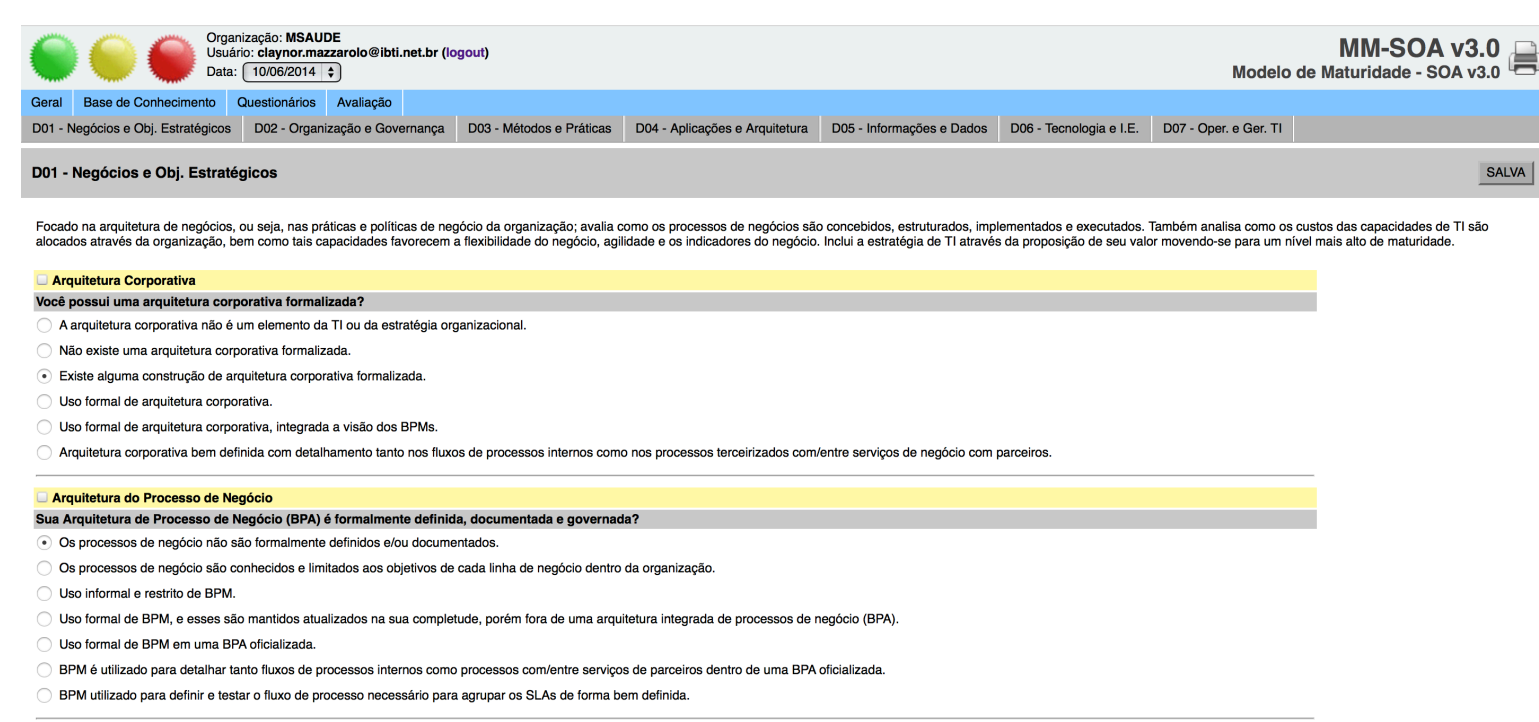

Figura 5.3 - Exemplo das Abas dos Questionários Estruturados

Após responder o questionário, é apresentada a distribuição de frequência obtida pela análise da heurística de avaliação do Domínio (Figura 5.4).

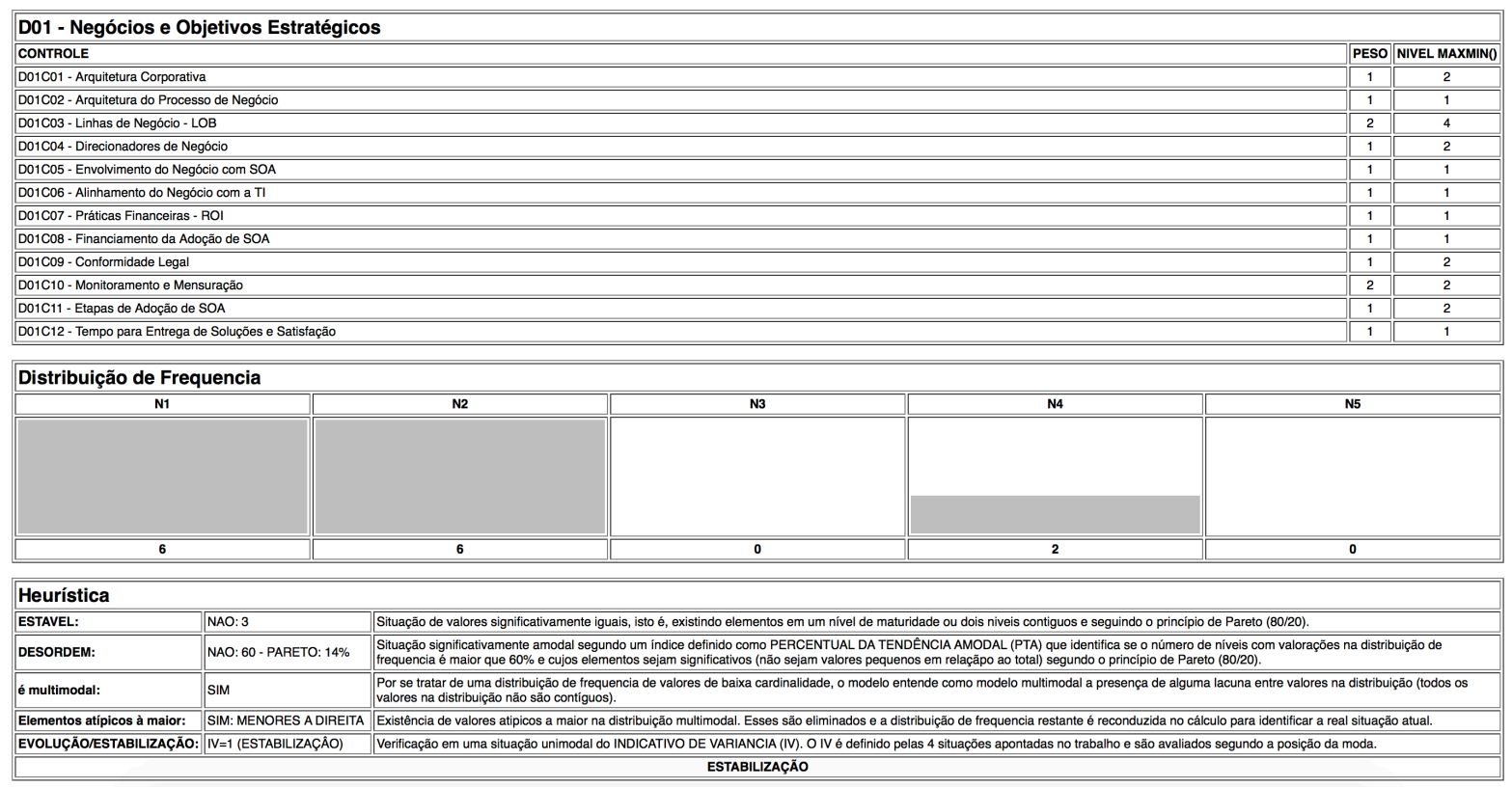

Figura 5.4 - Exemplo de Distribuição de Frequência e Heurística

\subsubsection{4 - Avaliação}

A quarta aba ('Avaliação') tem como objetivo expor a avaliação do estágio de maturidade da organização em relação às informações obtidas através dos questionários. Essa aba é apresentada com os seguintes itens: 'Situação Atual; Linha do Tempo; e Roteiro de Evolução. 
No item 'Situação Atual' é possível obter o nível atual e a comparação desse com o nível almejado de maturidade por domínio, observando-se ainda se o domínio está em estabilização ou em evolução, conforme pode-se observar na Figura 5.5.

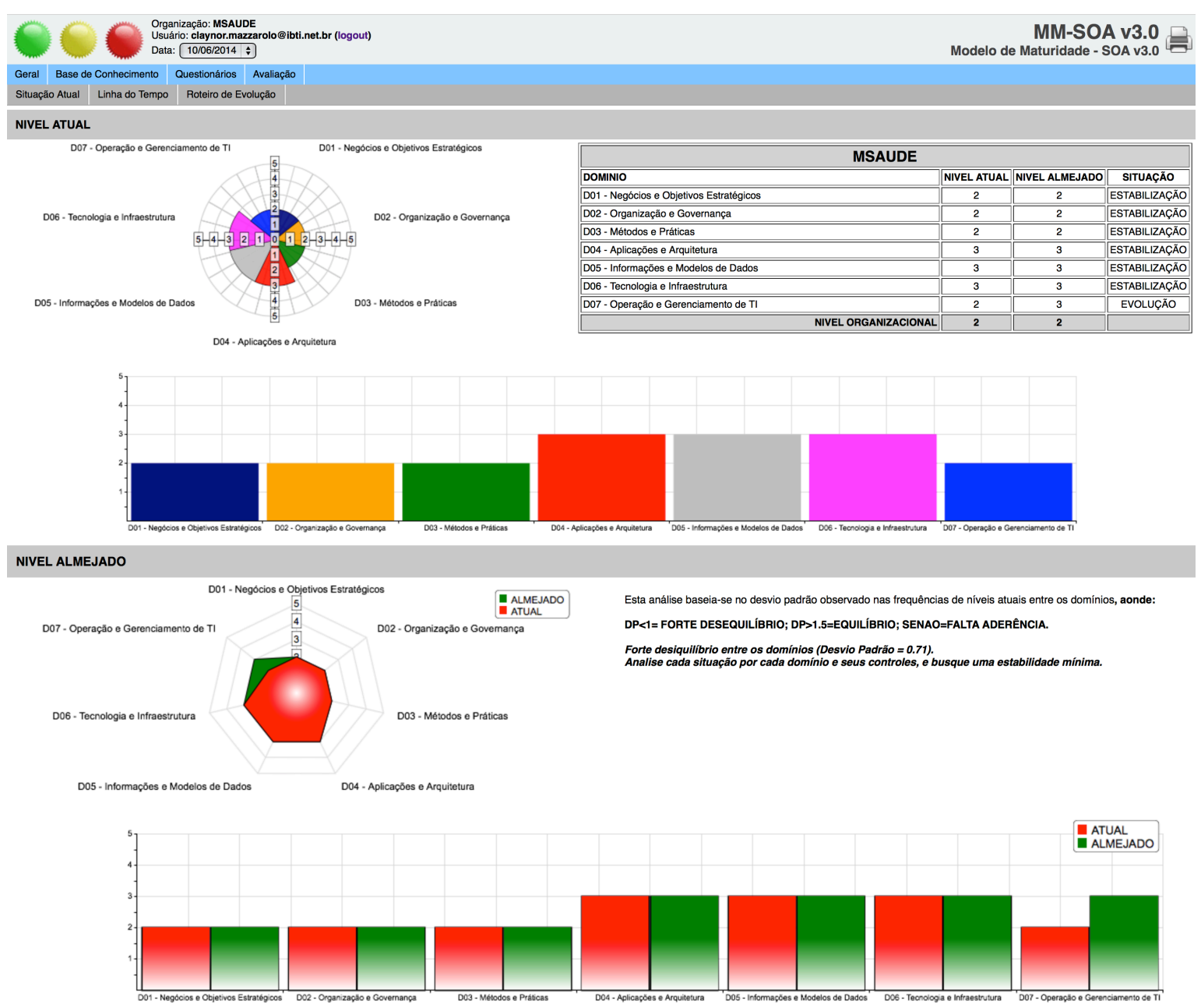

Figura 5.5 - Exemplo de Gráficos: Nível Atual e Nível Almejado

Para que haja assertividade na busca pelo equilíbrio de evolução, o sistema provê informações do nível de maturidade de menor granularidade em cada domínio, controle a controle, para que se possa visualizar os controles que precisam de prioridades de tratamento (Figura 5.6). 


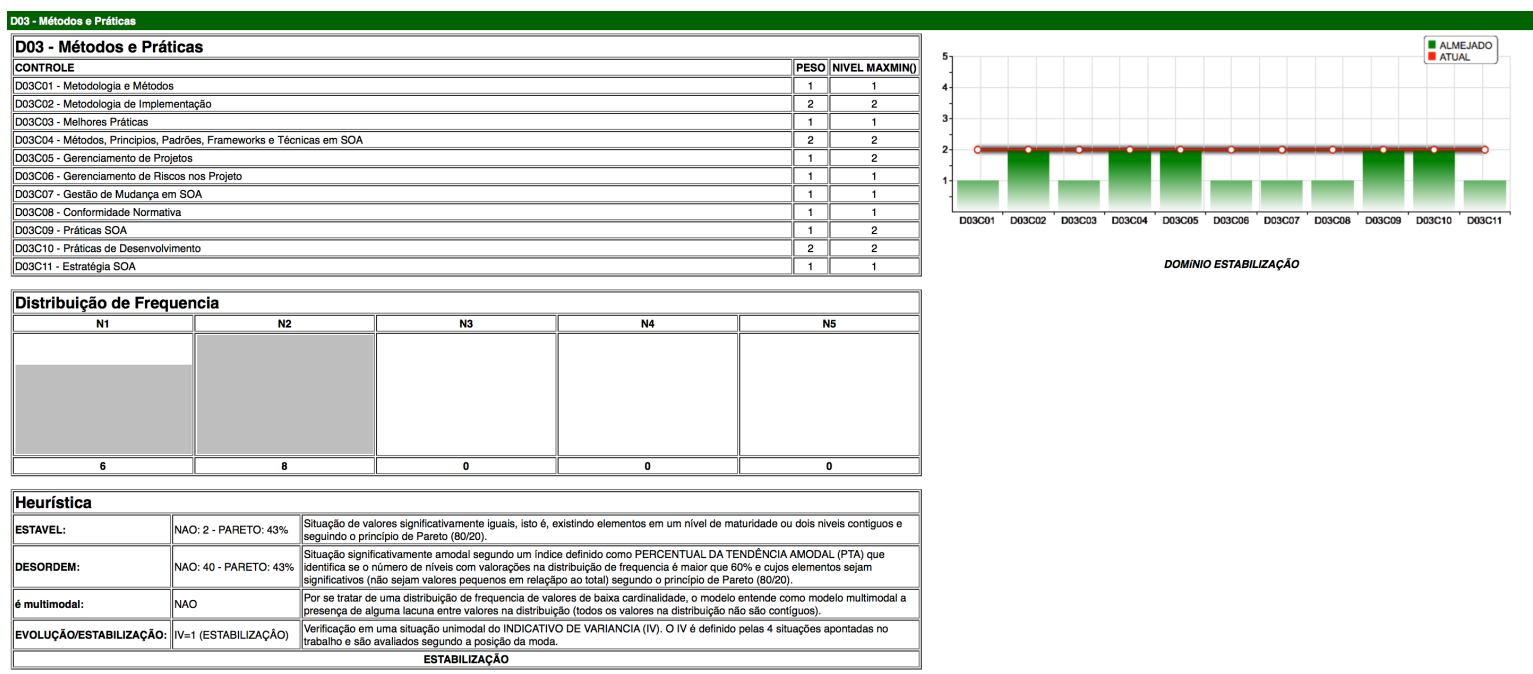

Figura 5.6 - Exemplo de Gráfico Domínios e Controles

No item 'Linha do Tempo' é possível visualizar o nível de maturidade atingido, domínio a domínio, controle a controle, em cada uma das avaliações efetuadas nas organizações ao longo do tempo (Figura 5.7).

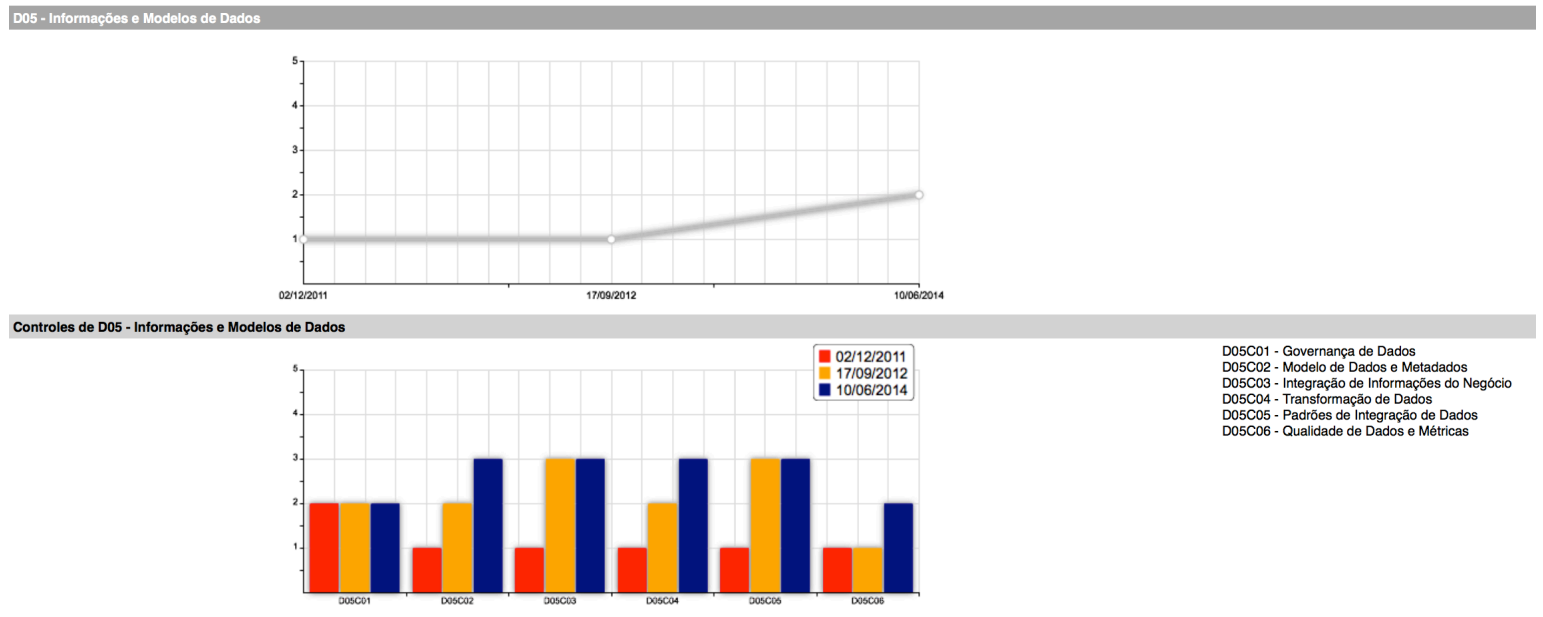

Figura 5.7 - Exemplo de Gráfico: Evolução no Tempo - Domínios

E, no item de 'Roteiro de Evolução', podem-se obter as recomendações mínimas para a evolução a níveis superiores de maturidade. Essas recomendações são organizadas por domínios e expressas individualmente para os controles que estão abaixo do nível de maturidade encontrado para o Domínio correspondente (Figura 5.8). 

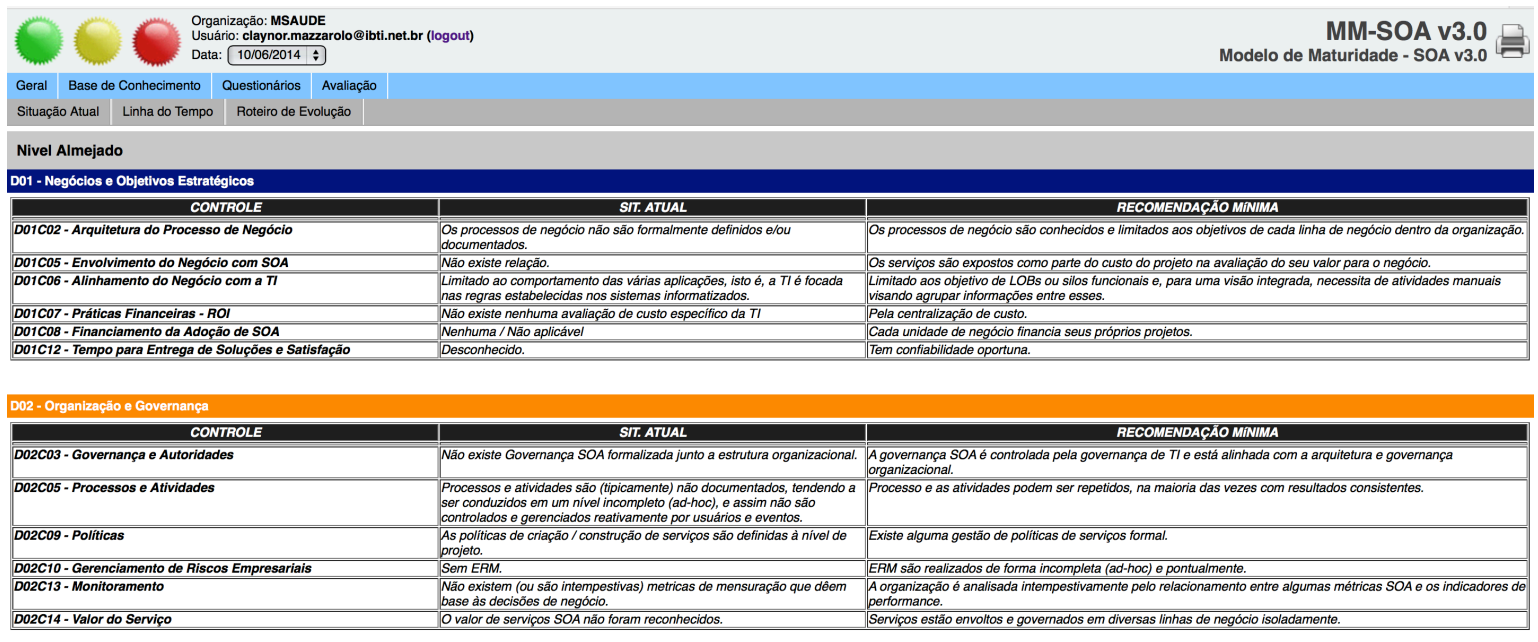

Figura 5.8 - Exemplo de Roteiro de Evolução

É possível se observar, também, a situação atual de determinado controle. Dessa forma, um planejamento de ações pode ser definido para que, por exemplo, dado um controle que está dificultando um avanço na maturidade de uma organização, possa evoluir de forma satisfatória. 


\section{6 - ESTUDO DE CASO}

Neste Capítulo é apresentada a aplicação do modelo proposto em um estudo de caso, de modo a demonstrar a aplicabilidade do modelo desenvolvido para a avaliação do nível de maturidade em projetos de arquitetura orientada a serviços.

\section{1 - DESCRIÇÃO DO ESTUDO DE CASO REALIZADO}

\subsection{1 - Caracterização do Estudo de Caso}

O estudo de caso foi realizado no Ministério da Saúde do Brasil (MS), instituição do setor público, pertencente ao Governo Federal (Poder Executivo). Trata-se de uma instituição de grande porte, incumbida de administrar políticas públicas em todo o território nacional e para toda a população. A área de atuação do MS requer grande especialização técnica.

O estudo apresentado foi possível devido à execução de Termos de Cooperação celebrados entre a Fundação Universidade de Brasília (FUB, ente jurídico mantenedor da Universidade de Brasília - UnB) e o MS, cujos objetos continham a definição e execução do Programa de Adoção de SOA do Ministério da Saúde. Esses projetos de cooperação, inicados em 2011 e em andamento até a presente data, envolvem a atuação de mais de 40 especialistas em informação em saúde - sendo que praticamente a metade desses profissionais trabalham diretamente com arquitetura orientada a serviços.

\subsubsection{1 - Situação encontrada no início da Cooperação}

O MS, por meio do Departamento de Informática do SUS (DATASUS) desenvolve e mantém o maior acervo informacional e de sistemas de informação em saúde no País. Esses sistemas dão sustentação a todo o Sistema Único de Saúde (SUS), nos mais diversos níveis. O DATASUS, unidade que desenvolve e opera os sistemas de informação do SUS, possui em seu portfólio atual mais de 200 sistemas de informação e respectivas bases de dados. Eles são acessados por um universo vasto e heterogêneo de usuários, que inclui organizações do SUS em nível federal, estadual e municipal, estabelecimentos de saúde públicos e privados, organizações internacionais, além da sociedade em geral. 
Esse acervo, construído ao longo de décadas, se formou de maneira heterogênea, tanto no que se refere a plataformas tecnológicas quanto no tocante a métodos e técnicas de engenharia de software. Como regra geral, no entanto, os diversos sistemas desse legado foram e são construídos de forma isolada, sem levar em consideração requisitos mais fortes de integração, tanto em nível de sistema quanto em relação aos dados e informações. De maneira geral, esses sistemas não estão integrados e existem bases de dados diferentes contendo dados que deveriam ser únicos. Muitos sistemas não possuem documentação alguma ou a documentação existente é claramente insuficiente. Há ainda diversos aspectos dos produtos atuais onde se observa deficiências importantes dos sistemas legados no suporte ao negócio Saúde.

O legado de sistemas de informação é, portanto, de complexa gestão e difícil manutenção e atualização. Não obstante, é um legado composto por uma rica coleção de sistemas que atualmente, bem ou mal, suportam os negócios do SUS. Assim, não é racional pensar em uma completa substituição dos sistemas legados em curto ou médio prazo. Por outro lado, há uma oportunidade de se direcionar a arquitetura de sistemas de informação buscando uma evolução continuada e que favoreça a integração. A arquitetura orientada a serviços apresenta-se como uma boa alternativa.

Avaliações recentes, realizadas pelo DATASUS/MS a partir de 2011 e por outros atores envolvidos no pensamento e definição da estratégia para o SUS e suas implicações na política nacional de informação em saúde, apontam para uma necessidade premente de se iniciar um processo gradativo, mas continuado, de integração de sistemas e de informações. Tal iniciativa visa a um aumento consistente da qualidade e da disponibilidade de informações e serviços informacionais em saúde.

Nesse cenário, o uso de tecnologia de Arquitetura Orientada a Serviços foi definido como uma alternativa estratégica para abordar essa situação sob uma perspectiva eficiente em custos para integração gradual de sistemas. Além de propiciar o melhor reaproveitamento do legado de sistemas de informação e acomodar confortavelmente a diversidade tecnológica do legado, o uso de SOA se configura como a principal tendência tecnológica para disponibilização de serviços informacionais de forma flexível e confiável, na atualidade. 
A definição acerca da adoção de SOA, como estratégia, no DATASUS/MS iniciou-se em 2011. Mais especificamente, nessa época, já se estudava, no âmbito interno do DATASUS/MS, uma arquitetura preliminar para um "barramento de serviços do SUS" que disponibilizaria gradativamente os serviços de informação gerados a partir de uma abstração do legado, com o seu reuso, sob a perspectiva de integração das informações em saúde mantidas pelos mais diversos sistemas disponíveis.

Foi exatamente nesse momento que se iniciou o Projeto "Estruturação do Programa de Adoção de Arquitetura Orientada a Serviços do SUS" (DATASUS/MS, 2011). Tal projeto, cuja execução ocorreu entre os meses de setembro de 2011 e novembro de 2012, foi executado no contexto de uma parceria entre a FUB e o MS (DATASUS/MS) e deu origem ao efetivo início da concreta adoção de SOA naquele Ministério.

\subsubsection{2 - Contexto Negocial do Programa de Adoção de SOA}

O Programa de Adoção de SOA do MS teve, desde o seu planejamento inicial, que data de março de 2012 (DATASUS/MS, 2012a), um contexto negocial bem definido. Esse contexto inclui as seguintes ações estratégicas, ainda em curso no âmbito do MS/DATASUS:

- Projeto Cartão Nacional de Saúde (CNS): visa ao desenvolvimento e implantação de sistema nacional de informação em saúde, tendo como ator central o cidadão-usuário do SUS.

- Projeto do Registro Eletrônico de Saúde (RES): sistema a ser construído com informações coletadas de diferentes sistemas de informação, a partir de um barramento de serviços que implementa a interoperabilidade dos sistemas fontes, visando a prover informações individualizadas e gerenciais acerca dos atendimentos de saúde prestados na rede SUS e seus parceiros.

Essas ações brevemente descritas estão intrinsecamente relacionadas; os projetos CNS e RES fornecem o escopo de necessidades de negócio para o Programa de Adoção de SOA, pautando inclusive suas fases e projetos. 


\subsection{2 - Plano de adoção de SOA da instituição avaliada}

O Plano do Programa de Adoção do MS (atualmente na versão 2.0, de novembro de 2012) (DATASUS/MS, 2012b) tem por finalidade estabelecer objetivos e metas para a implantação de SOA no DATASUS/MS. O uso de SOA se apresenta como uma alternativa efetiva para a estruturação continuada de uma arquitetura corporativa de interoperabilidade de sistemas de informação e de provimento de serviços de informação relacionados ao negócio Saúde, inclusive para entidades externas ao MS.

$\mathrm{Na}$ visão desse plano, considera-se que a exitosa implantação de SOA também está associada a alguns elementos estruturantes dessa tecnologia.

Entre os objetivos buscados com a adoção de SOA, destacam-se:

- entrega dos serviços relacionados ao CNS e ao RES;

- interoperabilidade entre sistemas e serviços, proporcionando facilidade na disponibilização e reuso de serviços interna e externamente, bem como no reaproveitamento do legado de sistemas de informação e na acomodação eficientemente da diversidade tecnológica existente;

- agilidade no desenvolvimento de soluções, em suporte às reais necessidades de negócio;

- redução de redundâncias e complexidade, com efetiva redução de custos de desenvolvimento, manutenção e sustentação do ambiente; e

- gestão dos riscos dos ativos de TI e, em especial, da informação utilizada para a tomada de decisão dos gestores de TI, para os gestores de saúde pública, assim como para a sociedade em geral no tocante à redução de riscos à saúde.

De uma análise rápida dos objetivos do Programa de Adoção de SOA, depreende-se que o Programa tem natureza bastante estratégica (elencando os serviços e soluções a serem entregues, bem como os benefícios desejados em interoperabilidade, agilidade e redução de custos). Entretanto, as ações e os resultados almejados e alcançados mostram forte 
direcionamento pela área técnica e bons resultados nas áreas mais operacionais. Espera-se observar esses aspectos na avaliação de maturidade a ser realizada.

\subsection{3 - Evolução da adoção de SOA e avaliações de maturidade realizadas}

Para que as ações descritas pudessem lograr êxito, identificou-se a necessidade de consolidação da sistemática de adoção de SOA no MS; processo que foi inicialmente estruturado através do projeto Estruturação do Programa de Adoção de Arquitetura Orientada a Serviços do SUS (set./2011 a nov./2012) (DATASUS/MS, 2011). Esse projeto tem entre os seus resultados os seguintes produtos:

- Plano do Programa de Adoção de SOA do MS: Planejamento de caráter estratégico, definindo as atividades e projetos relacionados à adoção de SOA (DATASUS/MS, 2012a).

- Contratação e Implantação da plataforma SOA do MS (concluído em março/2012).

- Metodologia de Desenvolvimento SOA: Metodologia adotada no MS para utilização de SOA (concluído em julho/2012) (DATASUS/MS, 2012c; PUTTINI et al. 2013).

- Arquitetura de Referência SOA: Arquitetura tecnológica de referência adotada no MS, descrevendo plataformas, inventário de serviços, arquitetura de composições e arquitetura de serviços (concluído em novembro/2012) (DATASUS/MS 2012d).

- Desenho, desenvolvimento e implantação do Cadastro Nacional de Usuários do SUS (CADSUS) usando a abordagem de orientação a serviços, referente à primeira fase do Programa de adoção de SOA (versão 4.0, concluído em maio/2012).

Mais especificamente, o subprojeto do CADSUS resultou em uma consolidação de cerca de 10 versões de sistemas, bancos de dados e interfaces programáticas Web (serviços $\mathrm{Web}$ ), em um sistema único, desenhado com arquitetura orientada a serviços. Esse resultado representa significativa otimização do ambiente legado, com benefícios imediatos e reconhecidos pelo parceiro (MS), já nessa fase preliminar do programa. A arquitetura desenvolvida provê gerenciamento de um cadastro de cerca de 150 (cento e cinquenta) 
milhões de indivíduos usuários do SUS; o novo sistema, baseado nessa arquitetura, foi lançado, em nível nacional, no dia 13 de abril de 2012.

Como se pode observar, a adoção de SOA foi estruturada de modo a permitir a incorporação continuada e estruturada de práticas de SOA, o que representa esforço claro no sentido de se estabelecer a maturidade de SOA como um processo de melhoria contínua. Obeserva-se, já na execução do primeiro projeto de cooperação, a existência de ações estruturantes, tais como o estabelecimento de uma Plataforma SOA, arquitetura de referência e metodologia de desenvolvimento SOA, sempre acompanhados de ciclos de entrega.

Esse aspecto faz com que o caso de estudo seja relevante, pois permite uma avaliação representativa dos aspectos de maturidade $\mathrm{SOA}$ em todos os domínios definidos neste trabalho.

Foi exatamente durante a realização desse projeto de "Estruturação do Programa de Adoção de SOA" que se realizou a primeira avaliação de maturidade, em dezembro de 2011. Essa avaliação foi realizada com aplicação de uma primeira versão do questionário apresentado neste trabalho, em entrevistas guiadas realizadas com os especialistas em SOA que atuavam no projeto, com a participação do Diretor do DATASUS.

Um segundo projeto, acordado via Termo de Cooperação entre a FUB e o DATASUS, executado entre julho de 2012 e dezembro de 2013, teve por objeto o Estudo e Definição da Arquitetura de Informação e de Serviços do Registro Eletrônico de Saúde (RES) do Brasil (DATASUS/MS, 2012e). Tal projeto, entendido como continuidade do primeiro (Estruturação de SOA), produziu os seguintes resultados:

- desenho, desenvolvimento e implantação de serviços do Cadastro Nacional de Estabelecimentos de Saúde (CNES), usando a abordagem de orientação a serviços, referente à segunda fase do Programa de adoção de SOA;

- construção da metodologia, arquitetura e governança de SOA, com a pesquisa e definição e aplicação de um modelo de construção de maturidade SOA e a construção de um inventário corporativo de serviços (DATASUS/MS, 2013a, MAZZAROLO et al., 2015); e 
- estudo e definição da arquitetura de informação e da arquitetura de serviços informacionais do RES (concluída em maio/2013).

Esse projeto constituiu a consolidação da adoção de SOA no MS como estratégia vinculada à entrega de soluções orientadas a serviços que atendam às necessidades de criação do RES brasileiro.

Durante a realização do segundo projeto ocorreu a segunda análise de maturidade, realizada em setembro de 2012. Essa avaliação foi realizada com a aplicação de uma versão do questionário já bastante próxima à apresentada neste trabalho, em entrevistas guiadas, realizadas pelos especialistas em SOA que atuavam no projeto, com a participação de coordenadores e gestores de TI do Ministério da Saúde.

Finalmente, um terceiro projeto, denominado "Estruturação do Centro de Excelência SOA do MS" (DATASUS/MS, 2013), em execução desde outubro de 2013 (com término previsto para maio de 2016) prevê, entre outros objetivos:

- Estruturação do Centro de Excelência em SOA - estudo, modelagem, implantação e consolidação do Centro de Excelência SOA nas dependências do DATASUS, visando criar um locus permanente de prospecção tecnológica e adoção de melhores práticas, processos de governança, bem como a evolução e inovação tecnológica em SOA, adaptado às necessidades do Ministério da Saúde, no contexto da construção do Barramento Serviços de Saúde e da estratégia de interoperabilidade do Sistema Cartão Nacional de Saúde.

Durante a realização do terceiro projeto houve a terceira avaliação de maturidade, realizada com o questionário atual da presente proposta de avaliação de maturidade SOA, em junho/2014. Participaram das entrevistas de avaliação os especialistas em SOA que atuavam no projeto.

Assim, no que se refere a esses projetos no Ministério da Saúde do Brasil, o método pôde ser aplicado analisando três momentos distintos do processo de adoção: 2011, 2012 e 2014. Desse modo, é possível analisar a evolução da maturidade na arquitetura dentro dessa organização ao longo do processo de adoção de SOA. Dessa maneira, o uso do modelo 
proposto permitiu, além da aplicação de caso de uso, a análise de séries temporais de domínios e controles.

Destaca-se que na realização do estudo não foram definidos itens de avaliação "dispensáveis" - uma possibilidade para situações de entendimento e prioridades organizacionais -, pois essa situação não afeta diretamente a heurística do modelo, apenas o seu resultado final.

Finalmente, cabe notar que as ações do Programa de Adoção de SOA não foram ainda direcionadas ou mesmo influenciadas pelas avaliações de maturidade realizadas até então. Esse processo de feedback está em curso e deve influenciar a versão 3.0 do Programa de Adoção de SOA, que deve ficar pronta no segundo semestre de 2015.

\section{2 - RESULTADOS E ANÁLISE DAS AVALIAÇÕES}

Nesta seção são apresentados os resultados e análises realizados com base na avaliação de maturidade executada com base no modelo proposto neste trabalho. O processo de avaliação consistiu-se da aplicação do modelo em três momentos diferentes: dez./2011; set./2012; jun./2014.

As respostas ao questionário estruturado de avaliação, obtidas nas avaliações realizadas, estão apresentadas no APÊNDICE C.

\subsection{1 - Coleta de dados}

Conforme apresentado na seção anterior, a coleta de dados foi realizada com suporte do questionário estruturado (vide APÊNDICE B). O preenchimento do questionário foi guiado por uma equipe de especialistas que atuam no Programa de Adoção de SOA do MS, sendo as respostas formuladas escolhidas e validadas por um ou mais gestores da organização avaliada.

De modo geral, a coleta de dados transcorreu de maneira tranquila, uma vez que a estrutura do questionário consiste de perguntas de resposta única, devendo a resposta escolhida ser a que "melhor descreve a situação da organização". Desse modo, esperava-se que mesmo havendo dúvidas na eventual resposta a uma questão particular a resolução da questão para 
uma das alternativas propostas resultasse em uma aproximação aceitável da realidade.

De fato, como os diferentes Itens de Avaliação (questões) são fortemente interrelacionados, esperava-se que as respostas estivessem igualmente correlacionadas, o que permitiria uma avaliação "pela média", que corrige eventuais desvios decorrentes de respostas aproximadas incorretamente.

Vale destacar que a coleta de dados se deu pela coleta de resposta a itens de avaliação em todos os domínios e controles do modelo. Esse processo tornou a avaliação, em si, um pouco mais complexa e trabalhosa (leva-se cerca de 12 horas para a aplicação completa do questionário). Entretanto, como estudo de caso requer essa avaliação completa, pôdese observar o comportamento do modelo de avaliação proposto em todos os controles e domínios, bem como realizar análises transversais, levando em consideração diferentes domínios.

Acredita-se que nem todas as organizações que usam SOA possam ser facilmente avaliadas em todos os domínios e controles, pois não é incomum organizações onde há fragmentação de controle e governança entre diferentes áreas de conhecimento - área de TI e área de estratégia de negócio, por exemplo -, o que pode dificultar a coleta de dados e mesmo a análise. Tal dificuldade, no entanto, não foi observada no caso de estudo em pauta, pois o Programa de Adoção de SOA é estratégia da organização e possui patrocínio executivo.

Outro fator que merece ser notado é a aplicação do questionário em diferentes momentos (2011, 2012 e 2014). As versões dos questionários aplicados em 2011 e 2012 sofreram evolução para a última versão do questionário, de 2014 (APÊNDICE B). Nesse sentido, foi necessário mapear as respostas dos questionários de versão anteriores para a versão de 2014. Esse processo foi realizado com o apoio dos pesquisadores que participaram das respostas em 2011 e 2012. Desse modo, a análise de evolução discutida a seguir já reflete o uso da última versão do questionário. Os resultados completos obtidos na coleta de dados padronizada estão apresentados no APÊNDICE C. 


\subsection{2 - Heurística de avaliação}

\subsubsection{1 - Itens de Avaliação e Controles}

Na interpretação dos questionários aplicados ao longo de todo o estudo de caso foi possível a percepção de que na maioria das respostas coletadas e tabuladas (respostas completas no APÊNDICE C) encontra-se uma relação de valoração de controles a partir de questões correlacionadas.

Em determinados casos, como, por exemplo, na questão "Relação da entrega de serviços com o negócio e sua valoração junto ao negócio?" do domínio "Negócios e Objetivos Estratégicos - D01", as respostas possíveis são:

a) Não existe relação.

(Nível 1);

b) Os serviços são expostos como parte do custo do projeto na avaliação do seu valor para o negócio.

(Nível 2);

c) Os serviços são parte da captura de requisitos.

(Nível 3);

d) A organização atua totalmente direcionada a serviços, porém, não associa formalmente seus serviços com o valor desses para o negócio.

(Nível 4);

e) A organização atua totalmente direcionada a serviços e associada ao princípio de valor do negócio.

(Nível 5).

(resposta “a” selecionada em todas as avaliações - 2011, 2012 e 2014)

Assim, para esse caso, cada resposta recebe uma pontuação unívoca e determinada (1 a 1).

Porém, em determinadas situações, fica mais claro o modelo em faixas e aplicação das técnicas de Minimax usadas na etapa de valoração dos controles a partir dos itens de avaliação - questões ou grupo de questões e suas respostas, sendo dado destaque às respostas identificadas a seguir: 
- $\quad$ Na questão "Você tem uma identidade empresarial e roteiro Gerenciamento de Acesso?" do domínio "Aplicações e Arquitetura - D04" teve-se identificada a resposta "Existe um processo de Gerenciamento de Identidade e de Acesso unificado" que atende tanto a uma maturidade no nível 3 como no 4 (resposta selecionada na avaliação de 2014). É presumido, então, para esse item de avaliação, uma maturidade de 3 a 4 .

- $\quad$ O mesmo se dá na questão "Qual a porcentagem de reutilização de serviço (número de serviços publicados/total de serviços utilizados)?" do mesmo domínio. A resposta "Não existe reutilização de serviços ou não é medido/mensurável" tanto é admissível para o nível inicial 1 como para o nível subsequente 2 (resposta selecionada na avaliação de 2011). É presumido, então, para esse item de avaliação, uma maturidade de 1 a 2.

Outra situação observada consiste em itens de avaliação que apresentam respostas com a mesma pontuação. Esse aspecto se mostrou bastante útil durante a aplicação dos questionários, pois permite facilitar a capacidade de resposta do analista. Assim, em determinadas questões, apresentam-se alternativas de respostas que são consideradas diferenciadas pela organização; porém, compreendem uma mesma situação no que se refere ao nível de maturidade a ser identificado para determinado controle.

Nesse sentido, o modelo prevê que a organização pode, eventualmente, dada a resposta da questão como definida, estar em uma situação de nível 1 a 2 . Inicialmente, de modo otimista, presume-se então que a organização esteja na valoração de 2. Porém, para a formação do controle, é então adotado o mínimo de valor entre as diversas respostas, em uma visão pessimista. Essa aproximação busca aproximar o modelo de quantificação dos controles a uma aproximação Minimax clássica (seção 2.5).

Deve-se destacar que no modelo completo do questionário (APÊNDICE B) percebe-se que a evolução do nível 1 para o 2 é fortemente estabelecida por avanços em quase todos os controles correspondentes. Esse aspecto foi observado na evolução das respostas desde a avaliação de 2011 até a de 2014. Isso se dá porque os critérios de classificação que tratam de nível 1 do modelo compreende desde a inexistência completa de conhecimento e/ou a aplicação no âmbito da organização de serviços, serviços web, mensuração de retorno de investimento, estrutura organizacional definida, entre outros, até a situação de estruturação de requisitos iniciais para adoção de SOA pela organização. 
Na Figura 6.1, a seguir, apresenta-se a agregação dos valores selecionados nas respostas de itens de avaliação que compõem o controle Gerenciamento de Identidade e de Acesso D04C09, do Domínio Aplicações e Arquitetura D04 na avaliação efetuada em 2014. Podese verificar a visão pessimista ao reconhecer o valor mínimo entre as diversas respostas, segundo a técnica Minimax.

\begin{tabular}{|c|c|c|c|c|}
\hline CONTROLE & ITENS DE AVALI AÇĀO & \begin{tabular}{|} 
VALOR MINIMODO \\
ITEM \\
SELECIONADO (EM \\
2014) \\
\end{tabular} & \begin{tabular}{|c|} 
VALOR MAXIMO \\
DO ITEM \\
SELECIONADO (EM \\
2014 \\
\end{tabular} & $\begin{array}{l}\text { QUAN TIFICACAO } \\
\text { DO CONTROLE (EM } \\
\text { 2014) CRI TÉRIO } \\
\text { MINIMAX } \\
\end{array}$ \\
\hline \multirow{3}{*}{$\begin{array}{l}\text { Gerendiame to de } \\
\text { Identidade e de Acesso } \\
\text { D04C09 }\end{array}$} & $\begin{array}{l}\text { Voc tem uma identidade empresar ial e } \\
\text { rotero Geren damen to de Acesso? }\end{array}$ & 3 & 4 & \multirow{3}{*}{3} \\
\hline & $\begin{array}{l}\text { Qu ando osaplicativos in vocar ærviços } \\
\text { em nome de um usuário, săo pedidos } \\
\text { rep resentado cmo vin do do ustário? }\end{array}$ & 3 & 3 & \\
\hline & $\begin{array}{l}\text { Após a autenticaçăo, eiste in teraçá } \\
\text { entre osser viçospar a propagar a } \\
\text { autoriz açào de forma a gøenciar a } \\
\text { confiança entre componentes }\end{array}$ & 3 & 3 & \\
\hline
\end{tabular}

Figura 6.1 - Agregação de Valores de Itens de Avaliação para o Controle

\subsubsection{2 - Domínios}

O processo de avaliação de maturidade por domínios consiste na agregação dos valores obtidos para os controles do domínio por meio de um processo de decisão multiatributos (Figura 4.4). Esse processo é iniciado pela formação de uma distribuição de frequência dos níveis de maturidade obtidos nos controles dentro de cada domínio. No caso, a distribuição de frequência é relativa, pois utiliza-se o peso para maximizar o efeito de cada controle nessa distribuição.

Nesse sentido, a primeira observação a ser feita da distribuição de frequência refere-se à identificação de que a função de densidade possa apresentar um ou mais pontos extremos apresentar um conjunto de distribuição probabilística que tem uma única moda (unimodal) ou várias modas. Assim, refere-se a interpretar se entre os valores existentes na distribuição (no caso, cinco valores de níveis) existe alguma lacuna entre valores, não permitindo uma descontinuidade da moda. Dessa forma, a presença de descontinuidade é interpretada no modelo proposto como uma distribuição multimodal.

Outra observação inicial é a presença de todos os valores concentrados em um único ponto 
de distribuição, o que aponta para uma estabilidade clara e forte do modelo, como ilustrado na Figura 6.2, a seguir. Esse caso extremo já elimina qualquer interpretação posterior.

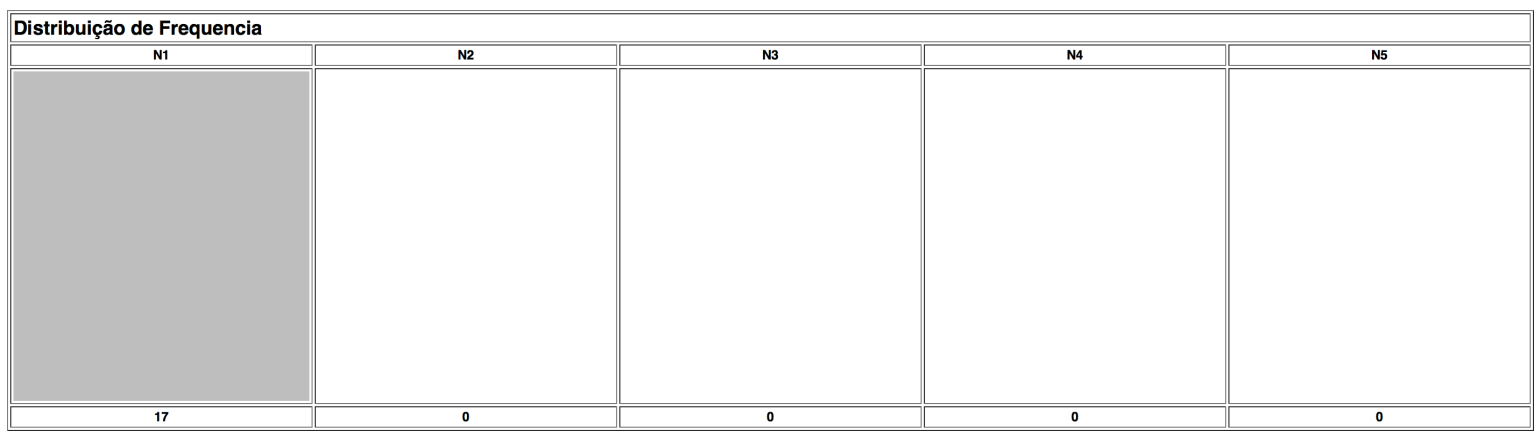

Figura 6.2 - Histograma de Frequência para uma situação ESTÁVEL

Na Figura 6.2, o Domínio Organização e Governança apresentou nível de maturidade ESTÁVEL na avaliação realizada em dezembro de 2011, situação em que se observa valores significativamente iguais - existindo elementos em um nível de maturidade ou dois níveis contíguos e seguindo o princípio de Pareto (80/20).

Em se tratando de um modelo unimodal, a presença de um modelo platicúrtico - de distribuição achatada - remete ao entendimento de que há um completo desbalanceamento no ciclo de vida no tratamento de controles afins ao mesmo domínio. A Figura 6.3 ilustra essa situação.

\begin{tabular}{|c|c|c|c|c|}
\hline \\
\hline $\mathrm{N1}$ & N2 & $\mathrm{N} 3$ & Distribuição de Frequencia & N5 \\
\hline & & & & \\
\hline 1 & 5 & 74 & 4 & 0 \\
\hline
\end{tabular}

Figura 6.3 - Histograma de Frequência para uma situação de DESORDEM

Nota: como não houve situação de DESORDEM reconhecida pela heurística no estudo de caso único em nenhuma das avaliações, a distribuição de frequência apresentada na Figura 6.3 foi simulada.

Outro ponto que deve ser destacado é o fato de o modelo proposto ser pessimista na sua essência; assim, a valoração de elementos com menor valor de nível quantificado deve ser analisada como tendência, pois causam mais forte impacto no modelo. Assim, diferenciadamente da distinção dessa distribuição de frequência da forma estatística usual, o modelo proposto tende a ignorar controles que se apresentem quantitativamente muito superiores ao conjunto de valores formados por outros elementos da distribuição. 
Nesse sentido, controles a maior são entendidos como requisitos que se apresentam cumpridos antecipadamente. $\mathrm{O}$ que significa que esses desvios representam elementos que estão acima da expectativa no momento para uma correta adoção de SOA - não sendo prioridade na situação atual da adoção de SOA pela organização -, logo sendo necessária sua eliminação na heurística geral de identificação do nível de maturidade de adoção de SOA.

A Figura 6.4 demonstra a distribuição de frequência obtida na avaliação realizada em setembro de 2012, ilustra a existência de valores atípicos a maior no Domínio Negócios e Objetivos Estratégicos. Esses valores devem ser desconsiderados, sendo o nível de maturidade dado pelo menor nível de maturidade encontrado.

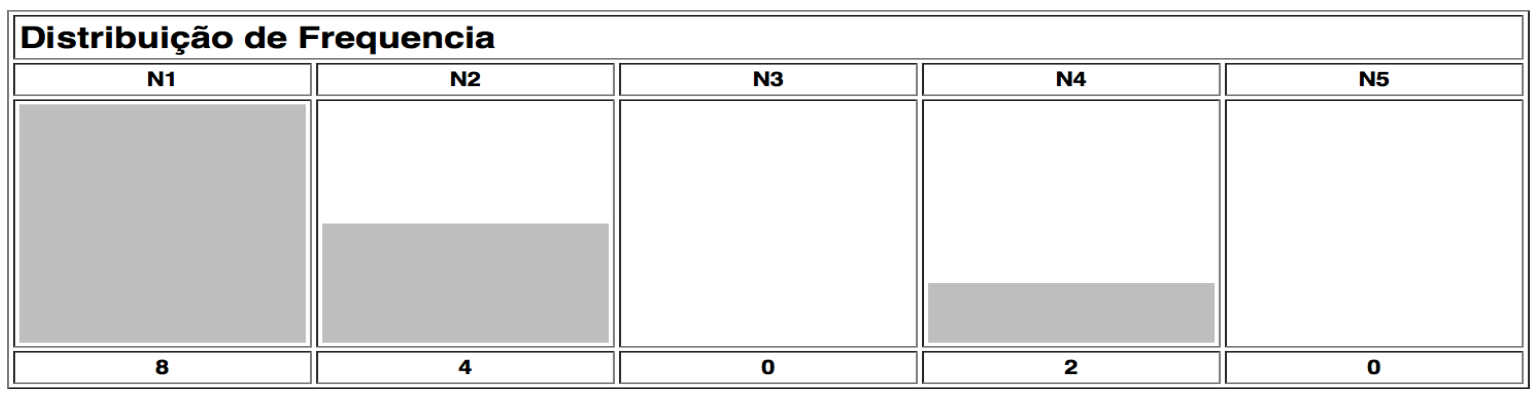

Figura 6.4 - Eliminação de valores atípicos a maior

A Figura 6.5 demonstra a situação inversa e evidencia se a organização deixou de considerar aspectos de controles que podem impactar na efetiva adoção de SOA. Esses controles devem ser priorizados nas atividades de atingimento de níveis mais elevados de maturidade. $\mathrm{Na}$ distribuição de frequência, eles são demonstrados se existirem valores atípicos a menor com esses valores, representando baixo percentual de ocorrências; nesse caso, a maturidade estabelecida é dada pelo valor consecutivo ao menor nível de maturidade encontrado.

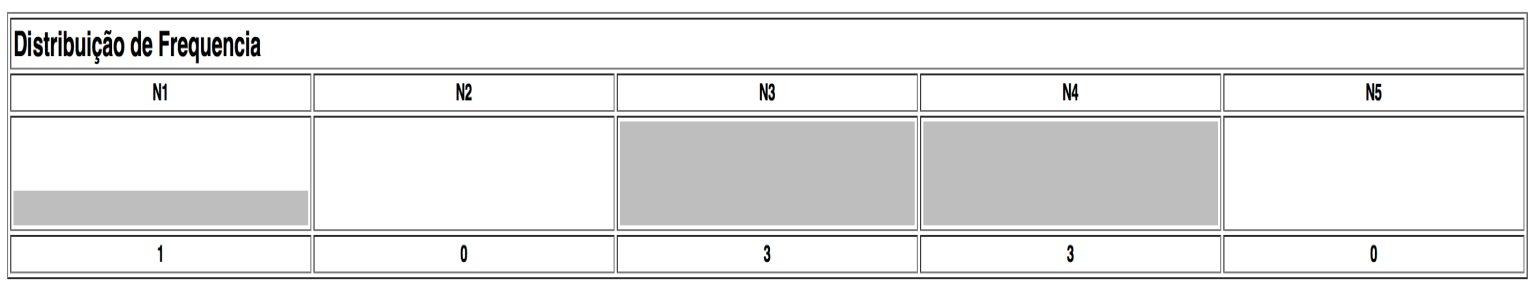

Figura 6.5 - Histograma de Frequência para uma situação de EXCEÇÃO

Nota: como não houve situação de EXCEÇÃO reconhecida pela heurística no estudo de caso único em nenhuma das avaliações, a distribuição de frequência apresentada na Figura 6.5 foi simulada. 
A Figura 6.6 apresenta a situação reconhecida pela heurística para o Domínio Tecnologia e Infraestrutura na avaliação de setembro 2012 como (EM) EVOLUÇÃO. O histograma indica uma distribuição com formato de uma rampa decrescente ou de uma distribuição normal invertida. O valor de maturidade avaliado é dado pelo menor nível de maturidade encontrado, indicando uma evolução desse para níveis maiores.

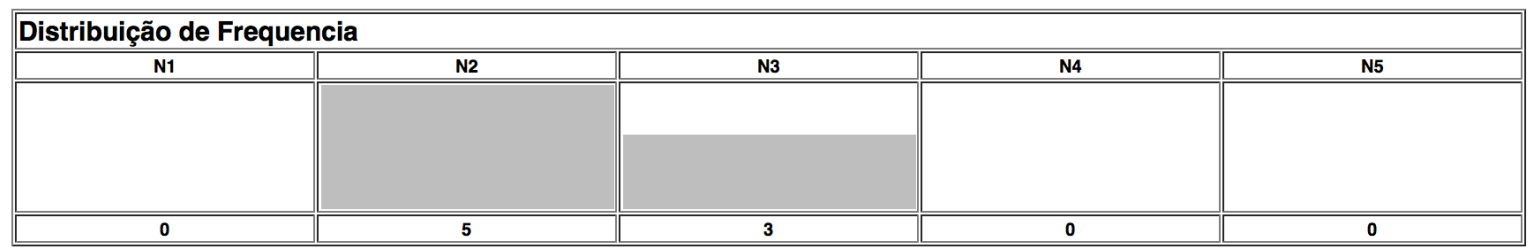

Figura 6.6 - Histograma de Frequência para uma situação (EM) EVOLUÇÃO

Outra situação importante implementada no processo de tomada de decisão é a situação encontrada na avaliação realizada em junho de 2014 no Informações e Modelos de Dados. A Figura 6.7 apresenta a situação reconhecida pela distribuição de frequência como (EM) ESTABILIZAÇÃO. Através de ciclos de melhoria contínua, a organização busca se estabilizar em um patamar em estágios de maturidade na adoção de SOA. O histograma representa uma tendência unimodal, com formato de rampa crescente ou de uma distribuição normal. A maturidade avaliada é dada pelo menor nível de maturidade encontrado.

\begin{tabular}{|c|c|c|c|c|}
\hline Distribuição de Frequencia & N3 & N4 & \\
\hline \hline $\mathrm{N} 1$ & $\mathrm{~N} 2$ & & & \\
\hline & & & & \\
& & & & \\
\hline 0 & & 5 & 0 & 0 \\
\hline \hline
\end{tabular}

Figura 6.7 - Histograma de Frequência para uma situação (EM) ESTABILIZAÇÃO

Por fim, o modelo apresenta informações de maior grau de granularidade, fornecendo os estágios de nível de maturidade atingido, com a indicação da situação do domínio, se em Estabilização ou Evolução. Obtém-se, ainda, o nível de maturidade almejado e a partir dessa etapa é possível planejar as atividades futuras baseadas nas indicações sugeridas pelo roteiro de evolução.

$\mathrm{Na}$ Figura 6.8, a seguir, é apresentada a avaliação realizada em junho de 2014, demonstrando o resultado da aplicação do modelo e seu efeito útil na gestão da adoção do 
uso de arquitetura orientada a serviços nas organizações.

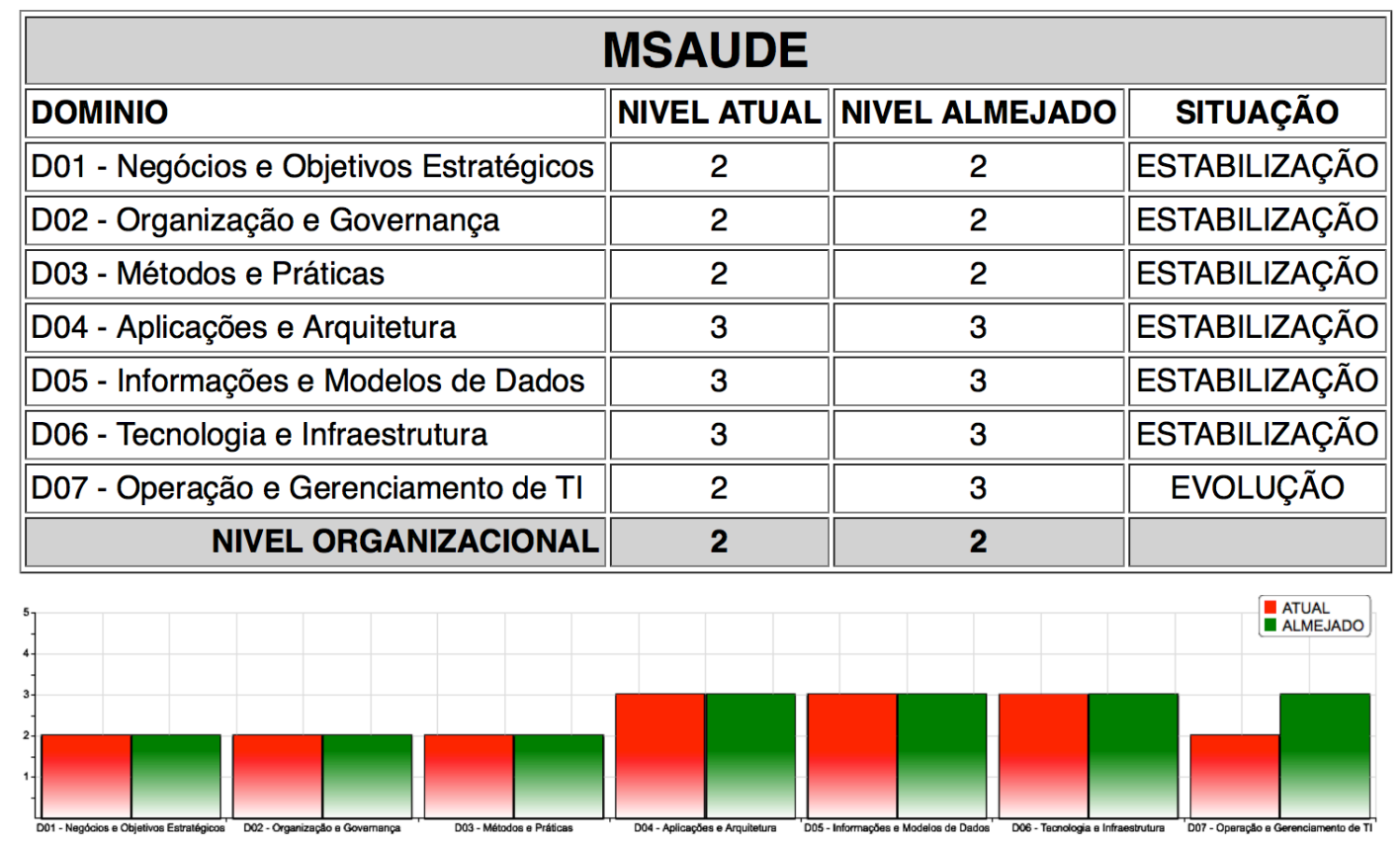

Figura 6.8 - Representação em Estágios e Nível de Maturidade Atual e Almejado

\subsection{3 - Resultados e discussões}

Nesta seção apresentam-se os resultados obtidos nas avaliações (2011, 2012 e 2014). A análise e discussão tem o objetivo de demonstrar aspectos tipicamente evidenciados com a aplicação do modelo proposto. Inicialmente, os resultados são analisados para cada domínio e, em seguida, discutem-se os resultados e observações derivados da análise dos domínios conjuntamente.

\subsubsection{1 - D01 - Negócios e Objetivos Estratégicos}

O Quadro 6.1 e a Figura 6.9, a seguir, apresentam a distribuição de frequência obtida para o domínio D01.

Quadro 6.1 - Distribuição de Frequência no Domínio D01

\begin{tabular}{|c|c|c|c|c|}
\hline \multicolumn{1}{|c|}{ Domínio } & Nível & A2011 & A2012 & A2014 \\
\hline \multirow{3}{*}{$\begin{array}{c}\text { Negócios e Objetivos Estratégicos } \\
\text { D01 }\end{array}$} & N1 & 12 & 8 & 6 \\
\cline { 2 - 5 } & N2 & 2 & 4 & 6 \\
\cline { 2 - 5 } & N3 & & & \\
\cline { 2 - 5 } & N4 & & 2 & 2 \\
\cline { 2 - 5 } & N5 & & & \\
\hline
\end{tabular}




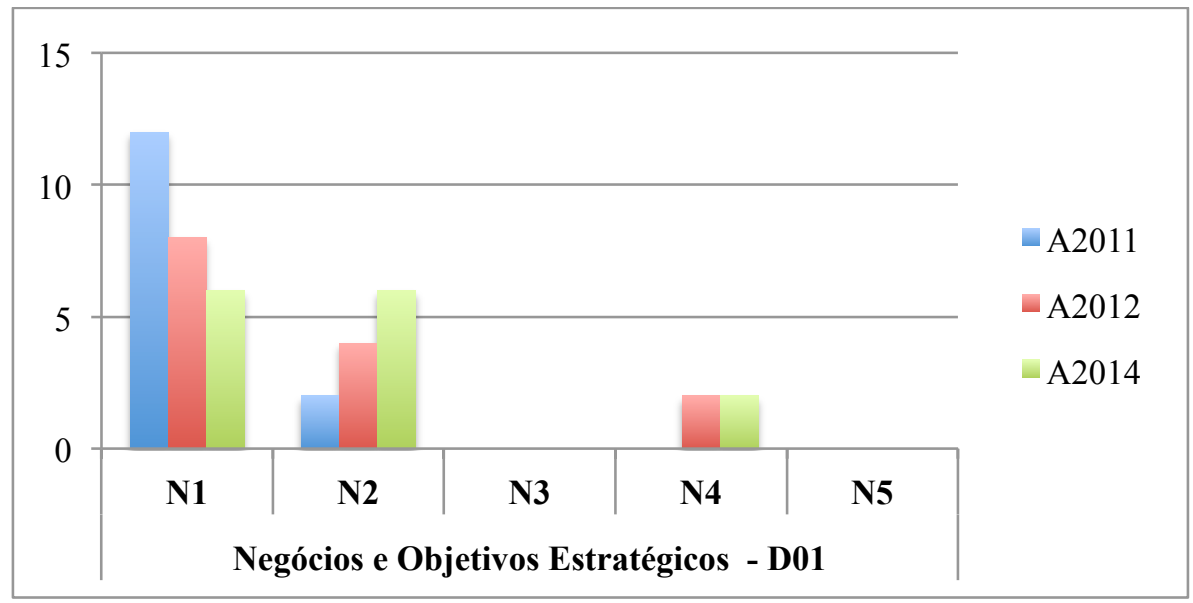

Figura 6.9 - Histograma da distribuição nos anos 2011, 2012 e 2014 para o domínio D01

Nesse domínio, observa-se nos anos de 2012 e 2014 que alguns controles foram atendidos além do ponto de estabilização, correspondente ao nível 2. Esses controles configuram a situação de VALORES ATÍPICOS A MAIOR, identificados no nível 4. Tais controles são desconsiderados na avaliação de maturidade do domínio. Observase, igualmente, evolução de controles do nível 1, predominantes em 2011, para o nível 2. Em 2014, a situação configura uma ESTABILIZAÇÃO no nível 2.

\subsubsection{2 - D02 - Organização e Governança}

O Quadro 6.2 e a Figura 6.10, a seguir, apresentam a distribuição de frequência obtida para o domínio D02.

Quadro 6.2 - Distribuição de Frequência no Domínio D02

\begin{tabular}{|c|c|c|c|c|}
\hline \multicolumn{1}{|c|}{ Domínio } & Nível & A2011 & A2012 & A2014 \\
\hline \multirow{4}{*}{ Organização e Governança - D02 } & N1 & 17 & 12 & 7 \\
\cline { 2 - 5 } & N2 & & 5 & 9 \\
\cline { 2 - 5 } & N3 & & & \\
\cline { 2 - 5 } & N4 & & & 1 \\
\cline { 2 - 5 } & N5 & & & \\
\hline
\end{tabular}




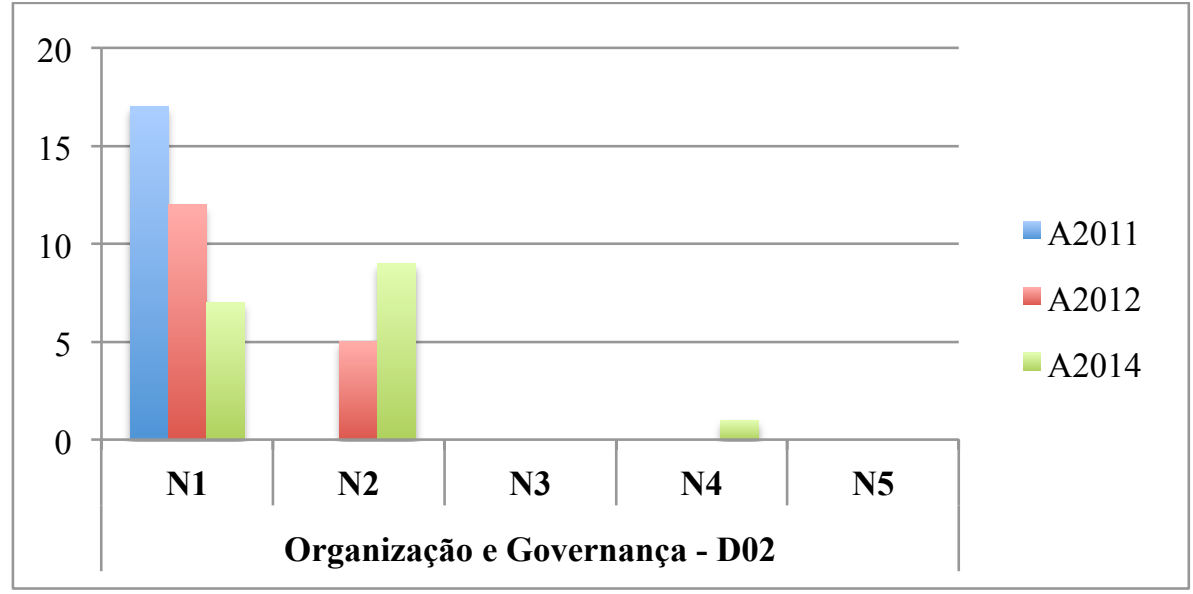

Figura 6.10 - Histograma da distribuição nos anos 2011, 2012 e 2014 para o domínio D02

No domínio em análise verifica-se que a maturidade estava claramente no nível 1 , em 2011. Nos anos seguintes, pode-se observar a evolução de alguns controles ao nível 2 e mesmo ao nível 4. Entretanto, essa evolução não é equilibrada, porquanto em 2014 ainda havia número significativo de controles avaliados com maturidade 1. Nesse sentido, esse domínio apresenta uma situação caracterizada como ESTABILIZAÇÃO no nível 2 no ano de 2014; isto é, esse seria o próximo estágio esperado, se analisada a situação do ano de 2012, que já indicava uma EVOLUÇÃO para o nível 2 na escala de maturidade.

\subsubsection{3 - D03 - Métodos e Práticas}

O Quadro 6.3 e a Figura 6.11, a seguir, apresentam a distribuição de frequência dos resultados coletados para o domínio que trata da correta aplicação de princípios, métodos e práticas para adoção de SOA.

Quadro 6.3 - Distribuição de Frequência no Domínio D03

\begin{tabular}{|c|c|r|r|r|}
\hline Domínio & Nível & \multicolumn{1}{c|}{ A2011 } & \multicolumn{1}{c|}{ A2012 } & \multicolumn{1}{c|}{ A2014 } \\
\hline \multirow{4}{*}{ Métodos e Práticas - D03 } & N1 & 13 & 11 & 6 \\
\cline { 2 - 5 } & N2 & 1 & 3 & 8 \\
\cline { 2 - 5 } & N3 & & & \\
\cline { 2 - 5 } & N4 & & & \\
\cline { 2 - 5 } & N5 & & & \\
\hline
\end{tabular}




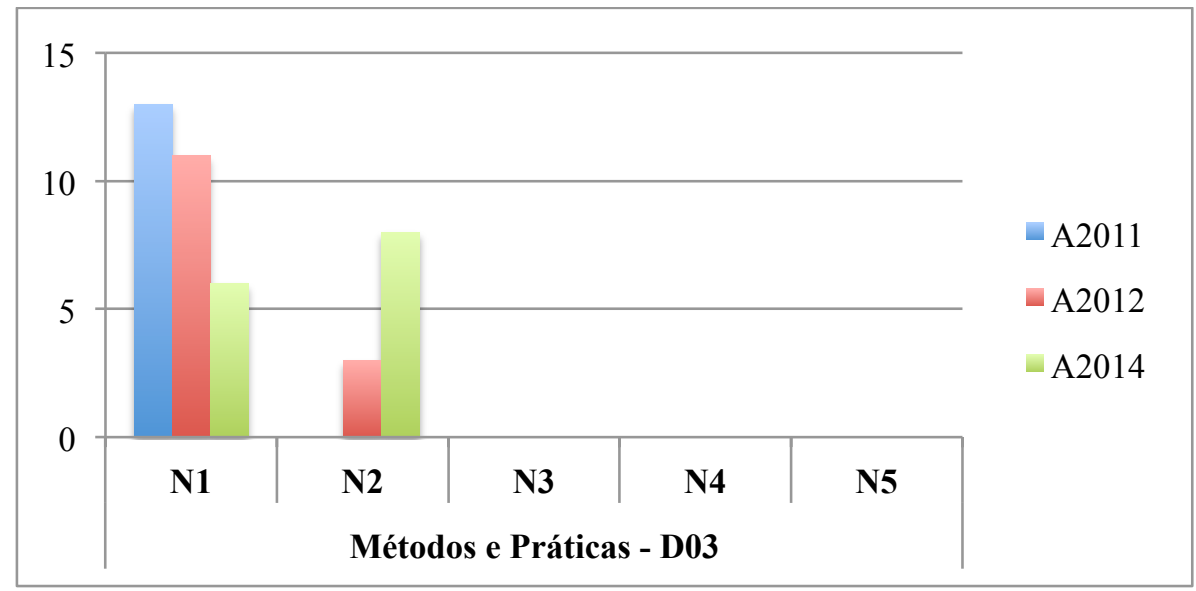

Figura 6.11 - Histograma da distribuição nos anos 2011, 2012 e 2014 para o domínio D03

Nesse modelo, observa-se clara transição, ainda em curso, do nível de maturidade 1 para o nível 2, caracterizando uma situação de ESTABILIZAÇÃO no nível 2.

\subsubsection{4 - D04 - Aplicações e Arquitetura}

Dos resultados obtidos na coleta de dados realizada nos anos de 2011, 2012 e 2014, o Quadro 6.4 e a Figura 6.12, a seguir, apresentam a distribuição de frequência no domínio de Aplicações e Arquitetura.

Quadro 6.4 - Distribuição de Frequência no Domínio D04

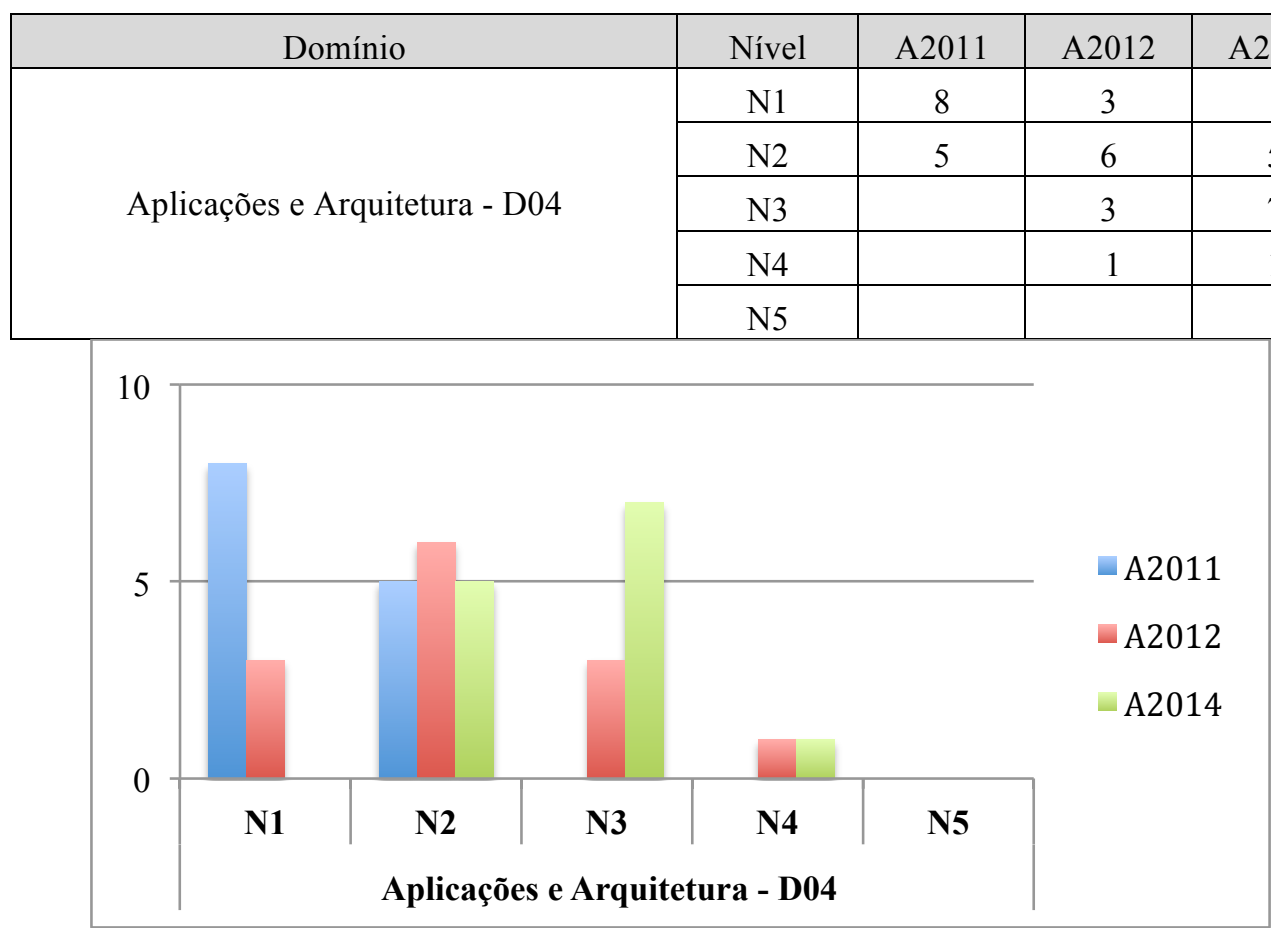

Figura 6.12 - Histograma da distribuição nos anos 2011, 2012 e 2014 para o domínio D04 
Nesse domínio, pode-se identificar clara evolução, saindo de um estágio inicial no nível 1, em 2011, para um estado de ESTABILIZAÇÃO no nível 3, em 2014. Esses resultados tornam-se evidências tangíveis do esforço de estruturação da adoção de SOA realizado pela organização nos últimos anos. Esse esforço, ressaltado no Plano de Adoção de SOA, teve grande foco na adoção de uma Arquitetura de Referência SOA e de métodos e práticas de desenvolvimento de software e de governança de serviços.

6.2.3.5 - D05 - Informação e Modelos de Dados

O Quadro 6.5 e a Figura 6.13, a seguir, apresentam a distribuição de frequência obtida nesse domínio.

Quadro 6.5 - Distribuição de Frequência no Domínio D05

\begin{tabular}{|c|c|c|c|c|}
\hline Domínio & Nível & A2011 & A2012 & A2014 \\
\hline \multirow{4}{*}{ Informações e Modelos de Dados - D05 } & N1 & 6 & 1 & \\
\cline { 2 - 5 } & N2 & 1 & 3 & 2 \\
\cline { 2 - 5 } & N3 & & 3 & 5 \\
\cline { 2 - 5 } & N4 & & & \\
\cline { 2 - 5 } & N5 & & & \\
\hline
\end{tabular}

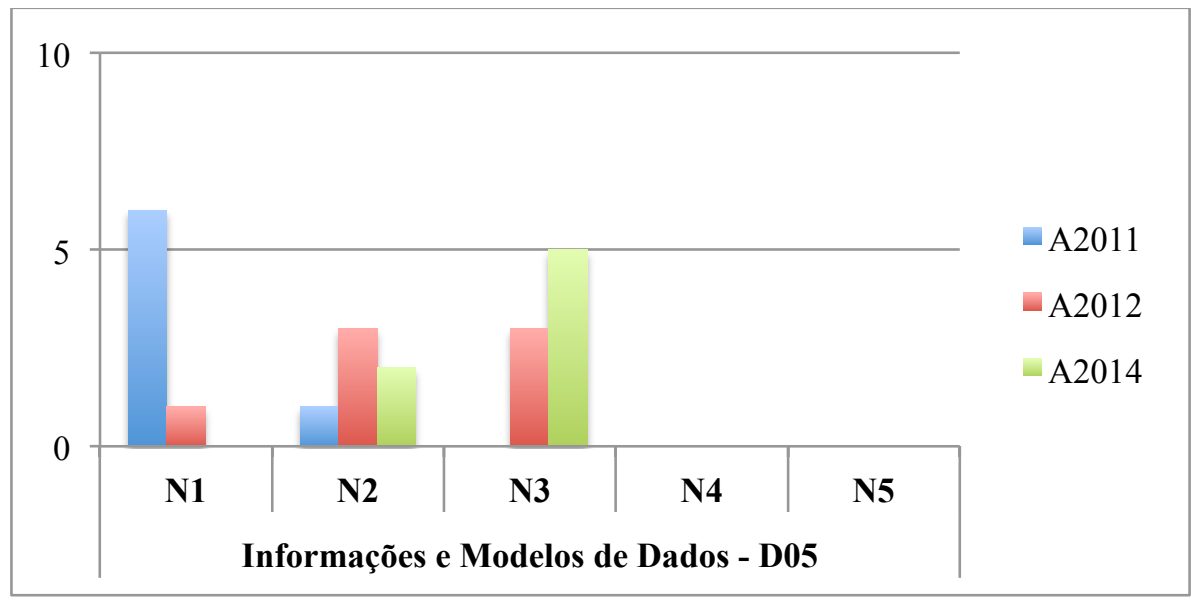

Figura 6.13 - Histograma da distribuição nos anos 2011, 2012 e 2014 para o domínio D05

A análise apontada pelo sistema indica uma transição do nível 1 (2011) para o nível 3 de maturidade (2014), onde se configura uma situação de ESTABILIZAÇÃO. De fato, a adoção de SOA na organização avaliada foi acompanhada de uma evolução sistemática da adoção de modelos de dados canônicos, bem como da construção de um repositório de 
esquemas corporativos com uma governança bem estabelecida. Isso explica o resultado obtido nesse domínio.

6.2.3.6 - D06 - Tecnologia e Infraestrutura

O Quadro 6.6 e a Figura 6.14, a seguir, mostram a distribuição de frequência resultante nesse domínio.

Quadro 6.6 - Distribuição de Frequência no Domínio D06

\begin{tabular}{|c|c|c|c|c|}
\hline Domínio & Nível & A2011 & A2012 & A2014 \\
\hline \multirow{4}{*}{ Tecnologia e Infraestrutura - D06 } & N1 & 5 & & \\
\cline { 2 - 5 } & N2 & 3 & 5 & 1 \\
\cline { 2 - 5 } & N3 & & 3 & 4 \\
\cline { 2 - 5 } & N4 & & & 3 \\
\hline & N5 & & & \\
\hline & & & & \\
\hline
\end{tabular}

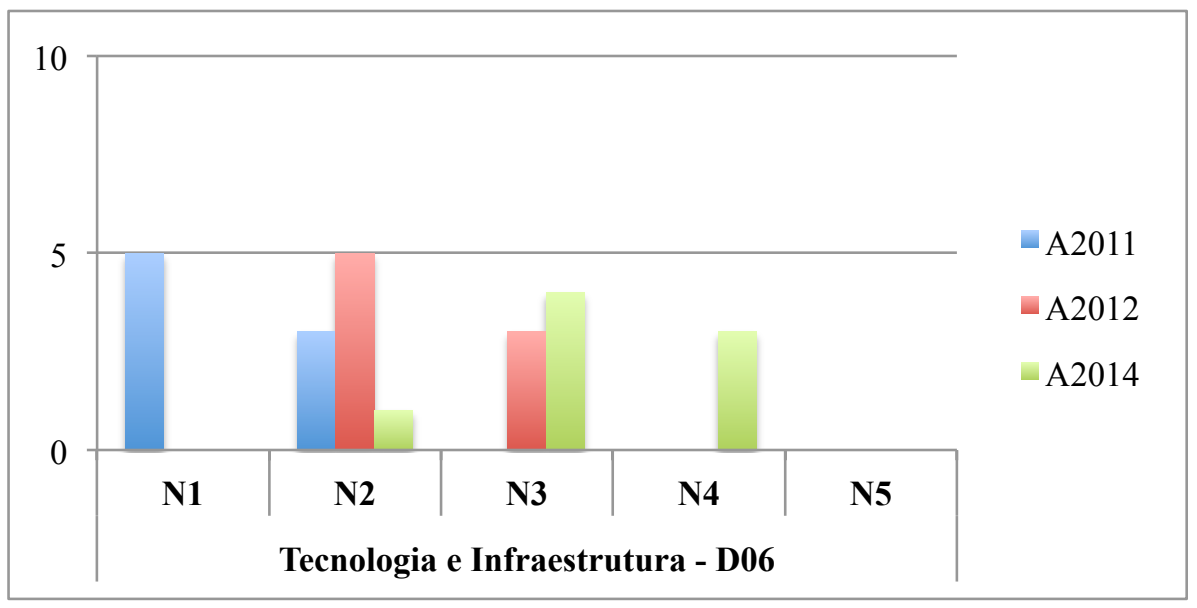

Figura 6.14 - Histograma da distribuição nos anos 2011, 2012 e 2014 para o domínio D06

Esse domínio apresenta um dos estágios de evolução mais avançados na avaliação de 2014, configurando uma ESTABILIZAÇÃO no nível 3, com alguns controles apresentando maturidade já em nível 4. Esse resultado se explica pelo forte investimento em infraestrutura de software realizado durante a execução do Programa de Adoção de SOA. 
Finalmente, o Quadro 6.7 e a Figura 6.15, a seguir, apresentam a distribuição de frequência dos resultados coletados para os controles do domínio D07.

Quadro 6.7 - Distribuição de Frequência no Domínio D07

\begin{tabular}{|c|c|c|c|c|}
\hline \multicolumn{1}{|c|}{ Domínio } & Nível & A2011 & A2012 & A2014 \\
\hline \multirow{4}{*}{$\begin{array}{c}\text { Operação e Gerenciamento de TI } \\
\text { D07 }\end{array}$} & N1 & 4 & 1 & \\
\cline { 2 - 5 } & N2 & 1 & 4 & 3 \\
\cline { 2 - 5 } & N3 & & & 2 \\
\cline { 2 - 5 } & N4 & & & \\
\cline { 2 - 5 } & N5 & & & \\
\cline { 2 - 5 } & & & & \\
\hline
\end{tabular}

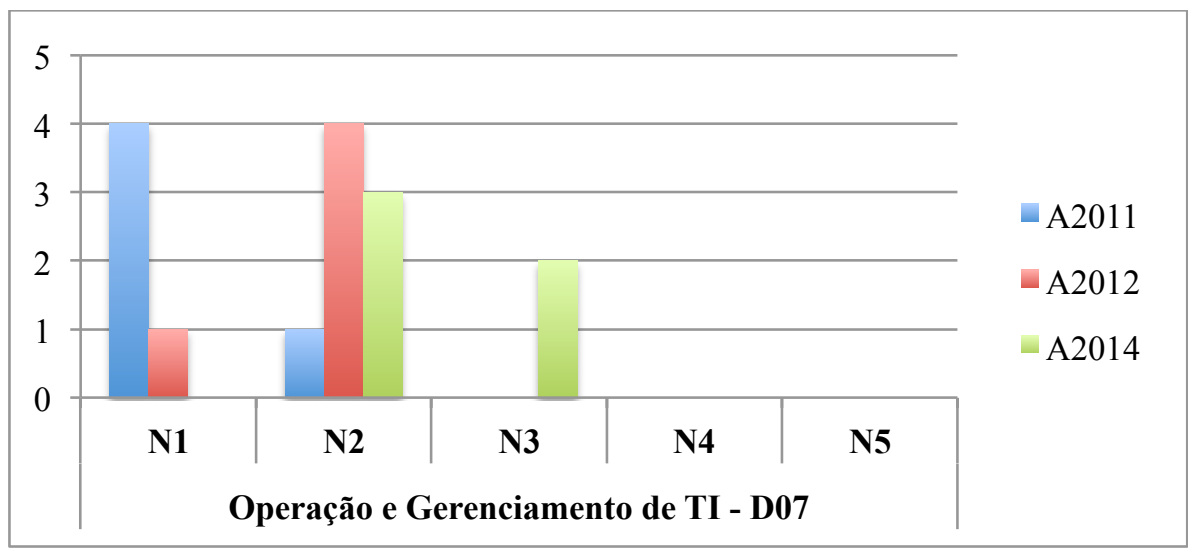

Figura 6.15 - Histograma da distribuição nos anos 2011, 2012 e 2014 para o domínio D07

Pela Figura 6.15, nesse domínio, verifica-se um ciclo de estabilização no nível 2 de maturidade entre 2011 e 2012, seguido de um novo ciclo de melhoria, observada entre os gráficos representativos da distribuição de frequência entre 2012 e 2014, apontando para o início de uma EVOLUÇÃO para o nível 3.

\subsubsection{8 - Análise Comparativa Entre Domínios}

O modelo proposto possibilita ainda a análise do nível de maturidade dos Domínios conjuntamente. Para tanto, provê informações gráficas que podem facilitar o entendimento das informações, conforme ilustrado a seguir. 
Pode-se observar a evolução do nível de maturidade dos domínios a partir dos resultados obtidos pela aplicação do modelo em ciclos de avaliação realizados no dia 2 de dezembro de 2011 (Figura 6.16), no dia 17 de setembro de 2012 (Figura 6.17) e no dia 10 de junho de 2014 (Figura 6.18).

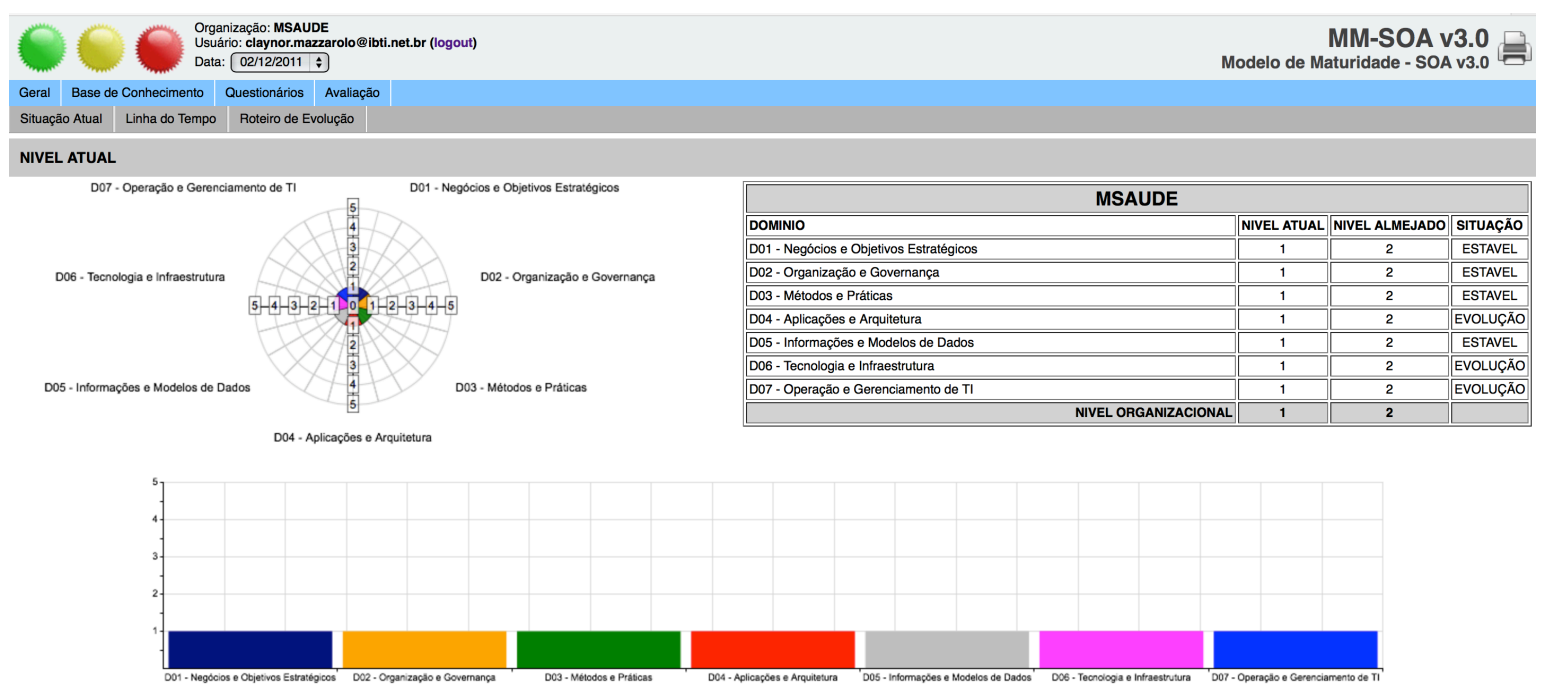

Figura 6.16 - Modelo de Maturidade - Avaliação Ciclo 2/12/2011

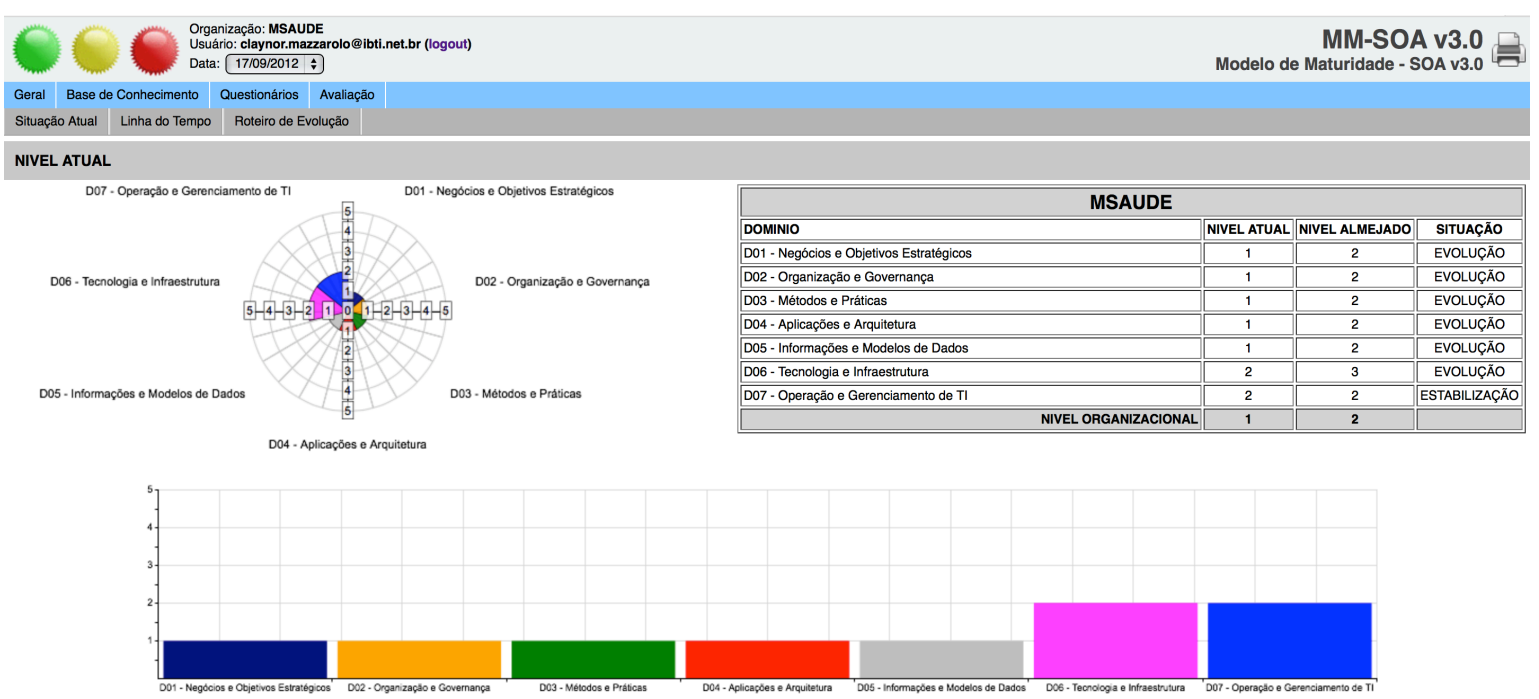

Figura 6.17 - Modelo de Maturidade - Avaliação Ciclo 17/9/2012 


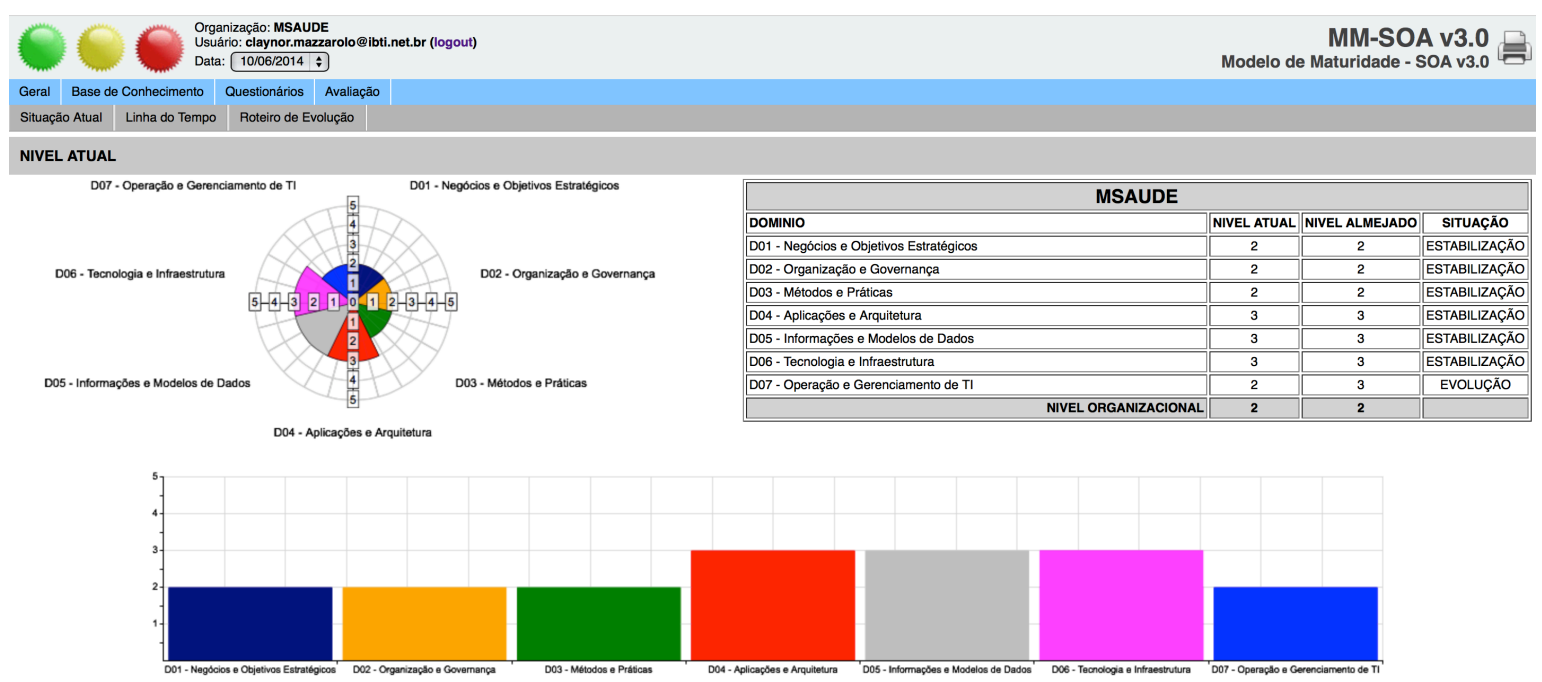

Figura 6.18 - Modelo de Maturidade - Avaliação Ciclo 10/6/2014

As Figuras 6.19 e 6.20, a seguir, apresentam resultados comparativos da avaliação de maturidade, para alguns dos domínios e seus respectivos controles avaliados. Nesse sentido, observa-se na Figura 6.19 que houve evolução continuada e consistente dos índices de maturidade em todos os Controles do Domínio Informações e Modelos de Dados. Por outro lado, da Figura 6.20, depreende-se que no domínio Métodos e Práticas a evolução de alguns controles foi inexistente em toda a série.

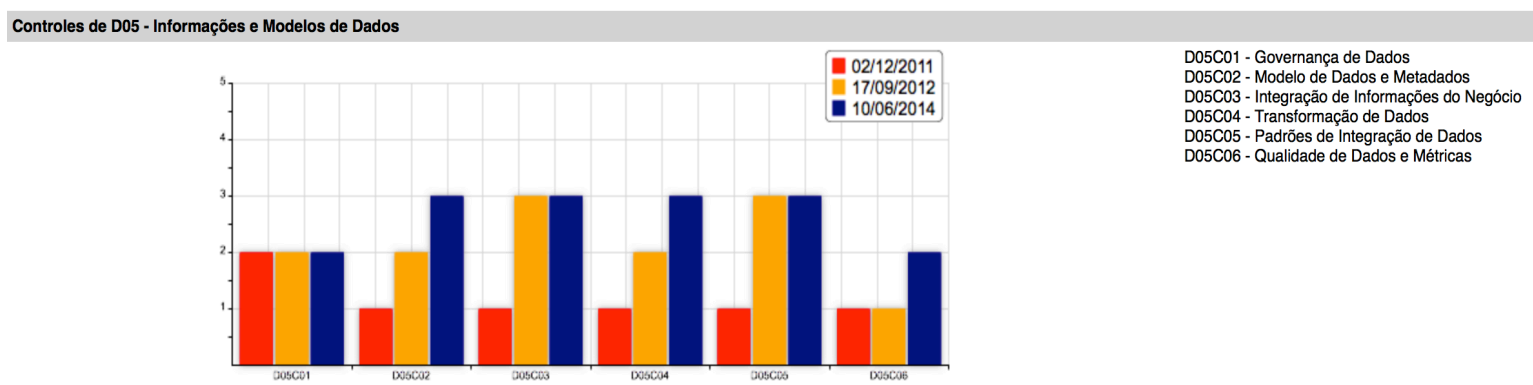

Figura 6.19 - Evolução dos Controles do Domínio Informações e Modelos de Dados D05 


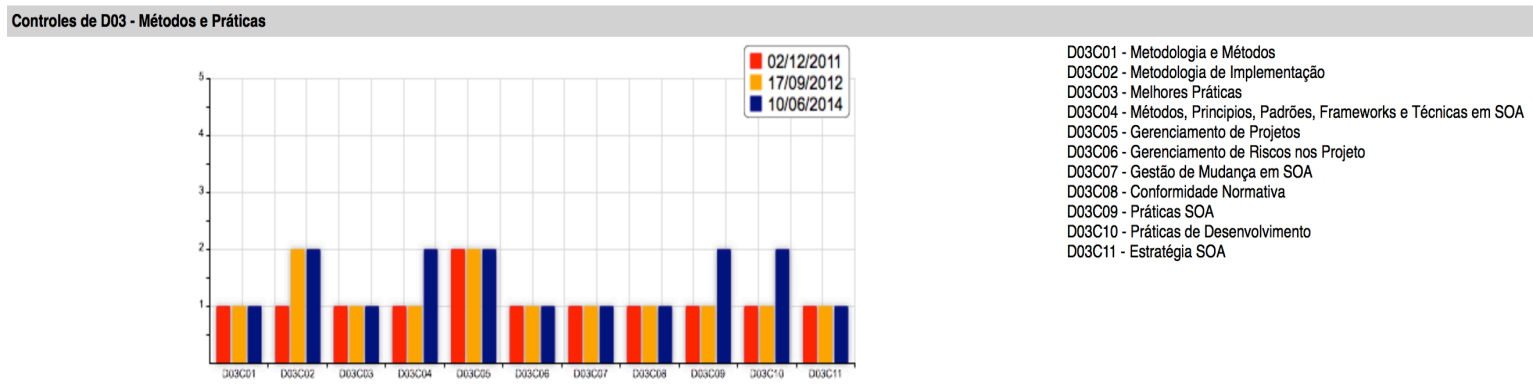

Figura 6.20 - Evolução dos Controles do Domínio Métodos e Práticas D03

A Figura 6.21 apresenta a evolução do índice de maturidade, em cada Domínio, nas avaliações realizadas.

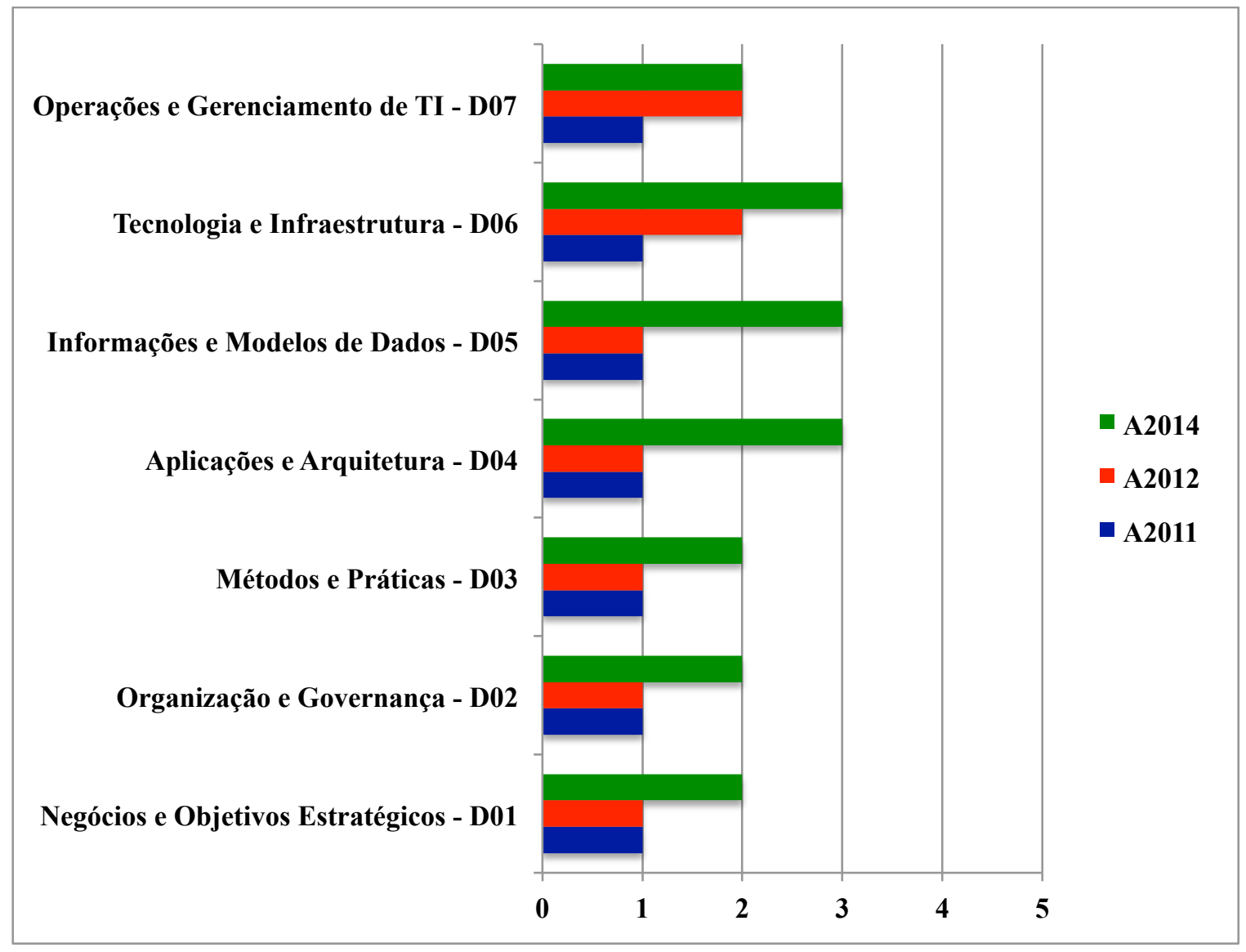

Figura 6.21 - Evolução do nível de Maturidade dos Domínios

Da Figura 6.21, uma análise possível é a observação do incremento de maturidade, ao longo do tempo, nos domínios arquiteturais e tecnológicos (D04, D05 e D06). De fato, houve investimento significativo em tecnologia e infraestrutura ao longo dos anos no Ministério da Saúde. Assim, a aplicação do modelo permitiu evidenciar os efeitos do 
investimento realizado. Entretanto, esse investimento não foi acompanhado de ações de estruturação no que se refere aos quesitos estratégicos. Pode-se classificar, portanto, o programa de adoção de SOA do MS como sendo de natureza técnica e operacional, sem o devido patrocínio do negócio. Essa percepção é válida na visão dos analistas e experts que trabalharam no projeto e pode ser demonstrada quantitativamente com o uso do método proposto.

Como avaliação final, ainda da Figura 6.21, da última situação analisada (2014), pode-se inferir que a organização está próxima a ser considerada em um patamar 2 de maturidade, pois possui apenas alguns Domínios que se apresentam em ESTABILIZAÇÃO nesse nível. Assim, se a organização der prioridade a esses domínios (Organização e Governança e de Métodos e Práticas) essa realidade pode se concretizar em curto prazo.

\subsubsection{9 - Roteiros de Evolução}

Para ilustrar os roteiros de evolução, o Quadro 6.8, a seguir, apresenta as atividades necessárias para atingir o próximo nível de maturidade almejado em cada um dos domínios avaliados, a partir da última avaliação realizada (2014, Figura 6.21). 
Quadro 6.8 - Roteiro de Evolução para os Domínios
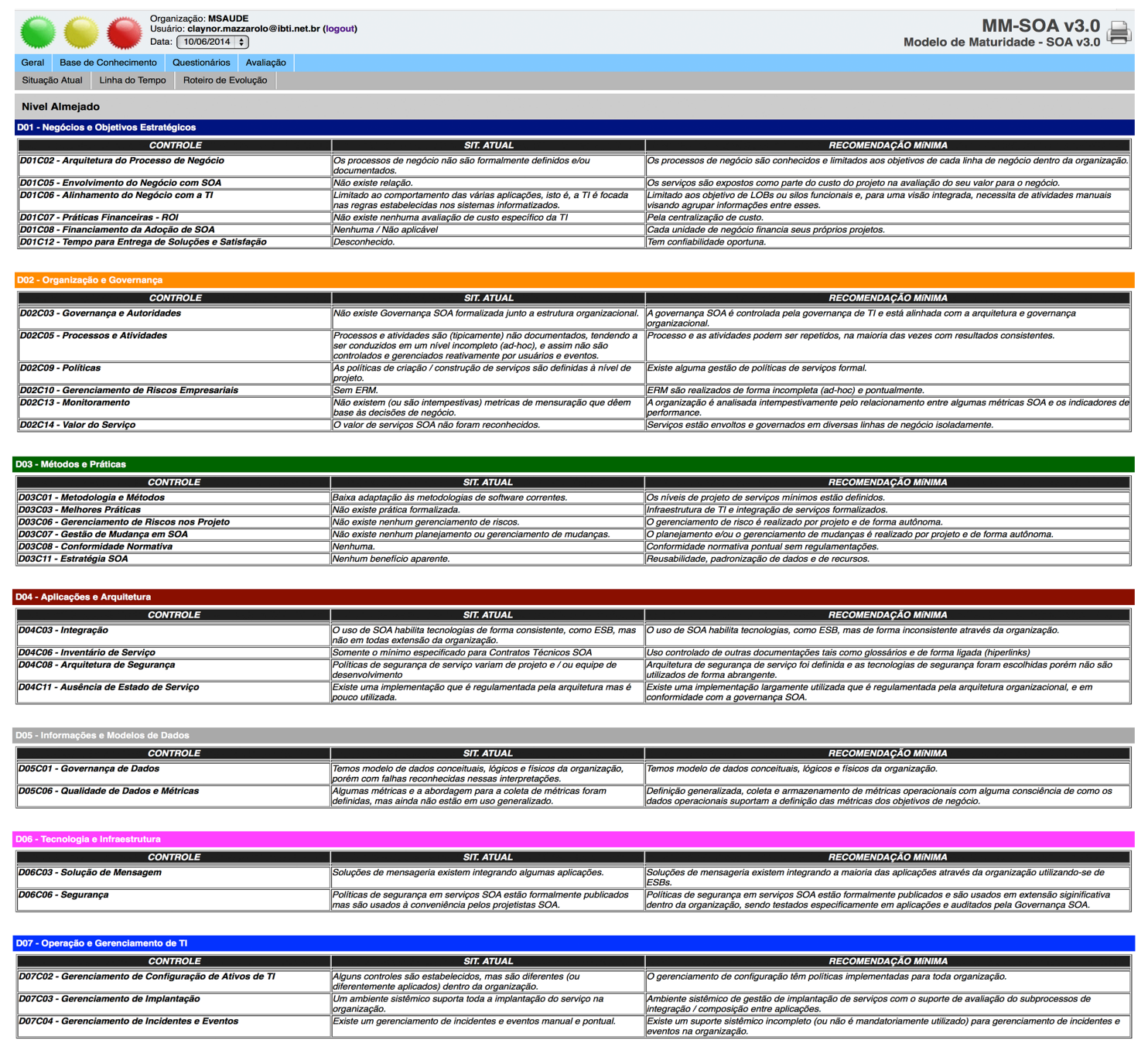

Por limitação de tempo para conclusão deste trabalho, a aplicação dos roteiros de evolução mostrados ainda não foi possível, pois começaram a ser aplicados em 2014 e não estavam disponíveis nas avaliações anteriores. Espera-se que uma nova avaliação de maturidade, prevista para o segundo semestre de 2015, possa confirmar o auxílio oferecido pelos roteiros aplicados. Entretanto, essa avaliação não é possível com os dados coletados até então. 


\section{CONCLUSÕES}

Este trabalho apresenta uma proposta de modelo de avaliação de maturidade SOA em organizações. O modelo foi construído a partir de detalhada revisão bibliográfica que gerou os insumos para, com o uso de avaliação de especialistas, se pudesse gerar uma base de conhecimento acerca de práticas, métodos e tecnologias afetos à adoção de SOA. A proposição apresentada pretende suportar a avaliação e melhoria da maturidade de SOA, efetuadas a partir da observação da conformidade de processos de planejamento, execução e monitoramento; aferida e quantificada em relação às melhores práticas em SOA.

O modelo proposto organiza esse conhecimento e, por conseguinte, o processo de avaliação de maturidade em Domínios, representando áreas de conhecimento dentro da organização, controles, representando práticas ou técnicas estabelecidas, e itens de avaliação, constituindo questões objetivas para aferir o uso dessas práticas.

O modelo utiliza uma escala de maturidade em cinco níveis ( 1 - inicial; 2 - gerenciado; 3 definido; 4 - mensurável; e 5 - otimizado), semelhante às escalas utilizadas em modelos de maturidade clássicos em TI, tais como CMMI e COBIT. A maturidade foi avaliada a partir de questionário estruturado, onde as respostas a questões objetivas (itens de avaliação) são associadas a valores de maturidade (1-5). Essas questões correspondem à granularidade mais fina da avaliação. Uma heurística de valoração, desenvolvida para o modelo proposto, foi utilizada para agregar valores atribuídos aos itens de avaliação em cada controle e, posteriormente, agregar valores atribuídos aos controles em um valor de maturidade consolidado por domínio.

Desse modo, ao final de cada processo de avaliação, pode-se observar um conjunto de valores de maturidade alcançados na organização avaliada, mapeados para cada controle e nos respectivos domínios organizacionais. Esse mapa de valores permitiu diversas análises acerca da abrangência e consolidação da adoção de SOA na organização:

- a escala de valores em níveis crescentes de maturidade permite indicar diferentes graus de consolidação da adoção de SOA. Assim, avaliações consecutivas ao longo do tempo em uma mesma organização permitem evidenciar e acompanhar a evolução concreta ocorrida no processo de adoção de SOA; 
- o uso de um modelo padronizado, que utiliza uma escala de valores predeterminada, pretende ainda permitir comparar, de maneira objetiva, o estágio da adoção de SOA em diferentes organizações;

- os índices obtidos para os controles de cada domínio permitem identificar práticas que ainda não estão em uso e que requerem atenção. Isso pode ser facilmente constatado observando a dispersão dos índices de maturidade em controles em um domínio;

- os índices obtidos para os domínios podem ainda ser avaliados conjuntamente, de modo a avaliar se os diversos aspectos da adoção de SOA estão sendo considerados de maneira equilibrada. Em especial, como os domínios são ordenados deliberadamente desde as áreas de conhecimento organizacional mais estratégicas (D01, D02) até as mais operacionais e tecnológicas (D6, D07), uma análise gráfica dos níveis de maturidade obtidos nos domínios permite caracterizar claramente a adoção de SOA como direcionada pela estratégia de negócio ou pela estratégia de TI (vide Quadro 4.7).

Roteiros de evolução a partir dos resultados obtidos foram gerados, considerando as fragilidades encontradas em relação ao nível de maturidade projetado/almejado na organização, tipicamente, indicando as ações necessárias para se alcançar o próximo nível de maturidade na escala.

Assim, a principal contribuição do trabalho é a estruturação de um arquétipo que permite estruturar os controles (práticas) requeridos em cada domínio organizacional, revendo a visão de avaliação do controle para assuntos afetos às competências distintas existentes na organização e oferecendo revisão aos objetos de controle da maturidade em SOA já apresentados em outros modelos de maturidade para essa arquitetura.

O modelo proposto observa as características típicas de um modelo de maturidade, partindo de seu ponto inicial e percorrendo um caminho guiado para atingir a maturidade. O diferencial da proposição está na criação de uma base de conhecimento especializada, voltada para maturidade em SOA. Outra característica saliente na proposição está na concepção de representação em estágios com diferenciação de situações de evolução e 
estabilização em cada nível. O modelo é ainda parametrizável, permitindo adaptar os itens a serem avaliados às particularidades e objetivos de avaliação da organização alvo.

Para suportar a validação do modelo proposto, o modelo foi aplicado e ajustado mediante uma abordagem de estudo de caso, com o objetivo de demonstrar a aplicabilidade do modelo proposto e sua contribuição para a correta utilização de arquitetura orientada a serviços nas organizações. Neste trabalho, o modelo proposto foi testado em uma instituição de grande porte, em avaliações periódicas (nos anos de 2011, 2012 e 2014). A aplicação do modelo neste estudo de caso permitiu:

- avaliar a evolução do nível de maturidade em cada ciclo de adoção e uso da Arquitetura Orientada a Serviços;

- identificar, em cada domínio, controles (práticas) que estavam sendo preteridos no processo de adoção, bem como aqueles que já se encontram conformes para um nível de maturidade projetado;

- evidenciar o tipo de estratégia de SOA, no caso avaliado, uma adoção direcionada por fatores tecnológicos, com ausência de observação de práticas importantes no alinhamento com a estratégia negocial;

- $\quad$ identificar e projetar as ações necessárias para a evolução dessa maturidade a um patamar desejado (roteiros de evolução).

Vale ressaltar que, apesar de a aplicabilidade do modelo estar sendo demonstrada em apenas um estudo de caso, nesta tese, o caso selecionado para estudo permitiu avaliação abrangente do modelo e sua base de conhecimento por um período longo de tempo, em avaliações consistentes e comparáveis entre si. Destaca-se a dificuldade de se encontrar organizações que tenham a disponibilidade e interesse em validar um modelo experimental por tanto tempo e de forma tão abrangente, o que restringiu o escopo de validação da proposição.

As avaliações realizadas, empregando a metodologia proposta nesta tese, permitiram estabelecer o estágio do nível de maturidade da organização, bem como identificar se esse nível está estabilizado ou em evolução, e, ainda, perceber a distribuição do nível de 
maturidade calculado através dos Domínios definidos. Essas avaliações são suportadas por questionários assistidos e pelo sistema de software desenvolvido para estabelecer os cenários do nível de maturidade. Esse sistema implementa completamente o modelo proposto e suporta sua aplicação de forma simples e estruturada, tanto no que se refere à coleta de dados, quanto à análise de resultados, conforme demonstrado neste estudo.

A observação dos níveis de maturidade, de sua evolução ao longo do tempo, bem como a formação de roteiro e caminhos para garantir ou melhorar as práticas na execução de projetos de SOA é o principal benefício que esta tese quer patrocinar às organizações.

Ao longo do trabalho, foi desenvolvida base de conhecimento, por meio do estudo do referencial teórico, da pesquisa das melhores práticas e de entrevistas e oficinas com especialistas da abordagem SOA. O caso de uso do MS demonstrou a aplicabilidade da base de conhecimento e permite seu reuso para mensuração do nível de maturidade SOA em organizações em geral.

\section{Resultados Principais}

Os principais resultados deste trabalho podem ser assim sintetizados conforme a seguir:

- base de conhecimento para avaliação de maturidade SOA estruturada, contendo domínios, controles e itens de avaliação organizados em questionário estruturado para condução da avaliação, de forma consistente, entre organizações distintas ou mesmo em avaliações sucessivas em uma mesma organização;

- $\quad$ sistemática de avaliação definida e suportada por sistema de software especialista; (http://mmsoa.dyndns.org/index.php).

- aplicabilidade do modelo proposto demonstrada a partir de estudo de caso único com avaliações integrais realizadas em três ciclos anuais (2011, 2012 e 2014).

Publicação dos seguintes artigos em conferências e periódicos científicos (peer reviewed) especializados: 
- MAZZAROlO, C., Martins, V.; Toffanello, A.; Puttini, R. "A Method for SOA Maturity Assessment and Improvement", in IEEE Latin America Transactions. Vol.:13, Iss.:1, Jan. 2015. ISSN: 1548-0992.

- MAZZAROLO, C.; Alves, G.; Martins, V.; Ribeiro, M.; Toffanello, A.; Puttini, R. Survey About SOA Adoption by Organizations in Brazil. X Simpósio Brasileiro de Sistemas de Informação, Maio, 2014, Londrina, Paraná.

- MAZZAROLO, C.; Toffanello, A.; Puttini, R.; Chaim, R. SOA Governance Dynamics in a Multiparadigm Approach. In: 32nd International Conference of the System Dynamics Society, 2014, Delft. Proceedings of the 32nd International Conference, 2014.

- $\quad$ PUTTINI, R.; Toffanello, A.; Vidigal, A.; Areal, J.L.; Alves, G.; Chaim, R ; Mazzarolo, C. A Service - Oriented Software Development Methodology for Outsourced Working Force. Lecture Notes in Computer Science, v. 7972(2), p. 559-573, 2013.

- CHAIM, R. ; Mazzarolo, C. ; Toffanello, A. ; Areal, J. L. ; Puttini, R. A MultiPardigm Approach For SOA Governance in it Companies. International Journal of Information Technology \& Computer Science (IJITCS), v. 9(2), p. 143-153, 2013.

- CHAIM, R.; Mazzarolo, C. ; Toffanello, A. ; Areal, J. L. ; Puttini, R. SOA Governance Dynamics for IT Organizations. In: the 31st International Conference of the System Dynamics Society, 2013, Cambridge, Massachusetts USA. Conference Proceedings, 2013.

- MazZarolo, C. ; Chaim, R. ; Toffanello, A. ; Puttini, R. A Multi Paradigm Approach for SOA Governance in IT Companies. In: International Conference on Information, Communication \& Computer Networks, 2013, Bangkok. Proceeding of ICICCN 2013, 2013. 


\section{Trabalhos Futuros}

Como continuidade do presente trabalho, identificam-se as seguintes iniciativas:

- A pesquisa teve validade estabelecida de maneira qualitativa, com avaliação de um único estudo de caso. Assim, pode-se estender a pesquisa para a avaliação de diferentes organizações, o que permitirá comparar os resultados obtidos.

- O software desenvolvido pode ainda ser disponibilizado como serviço (SaaS). Organizações interessadas podem, então, fazer uma autoavaliação da maturidade SOA. Caso obtenha-se número representativo de respondentes, tornar-se-á possível realizar uma avaliação quantitativa do uso do modelo. Entretanto, cabe ressaltar que a resposta ao questionário (coleta de dados) e a interpretação dos resultados da avaliação não é tarefa simples e pode requerer apoio de especialista.

- A validação do uso dos roteiros de evolução é outro ponto ainda em aberto. Para tanto, seria necessário acompanhar o uso dos roteiros no processo de melhoria e verificar os resultados obtidos com avaliações de maturidade realizadas após o uso dos roteiros.

- O modelo proposto possui heurísticas de avaliação e agregação de valores obtidos para itens de avaliação em controles e domínios. Esse framework base pode ser estendido para outras áreas, tais como gerenciamento de processos de negócio (BPM), adoção de computação em nuvem, adoção de modelos de apoio à decisão, adoção de modelos semânticos, entre outros, para os quais ainda não existem modelos consolidados de avaliação de maturidade. Para tanto, bastaria desenvolver a base de conhecimento apropriada, estruturando-a nos mesmos níveis granulares do modelo proposto (itens de avaliação, controles e domínios).

- O modelo proposto pode ainda ser estendido para contemplar um ciclo de melhoria continuada completo, por exemplo, com o uso de um modelo de governança, risco e conformidade (GRC). A parte de conformidade, acredita-se, está provida pelo modelo ora apresentado. 


\section{REFERÊNCIAS}

Alessio, P. Notas da Aula 07. Disponível em: <http://pessoal.utfpr.edu.br/ wilensilva/arquivos/Notas_de_aula_07.pdf $>$. Acesso em: 20 de set. 2013.

Accenture. ACCENTURE SOA Diagnostic. 2007. Disponível em: $<$ http://www.accenture.com/us-en/Pages/service-technology-soa-overview.aspx.> Acesso em: 14 mar. 2013.

Afshar, M. SOA Governance: Framework and Best Practices. Oracle. 2007. Disponível em: $\quad<$ http://www.oracle.com/us/technologies/soa/oracle-soa-governance-bestpractice-066427.pdf>. Acesso em: 9 jan. 2013.

Alves, D. R. Diretrizes para Complementação de um Modelo de Governança de TI para Atender aos Requisitos de Governança SOA.2012. 98 f. Dissertação de Mestrado. Universidade Católica de Brasília, 2012.

APQC. Service-Orientation Maturity Model (SOMM) Survey Report - APQC, Disponível em: <http://www.apqc.org/knowledge-base/documents/challenges-andopportunities-service-orientation-slides>. Acesso em: 28 mai. 2011.

Arsanjani, A. Service-Oriented Modeling and Architecture: How to Identify, Specify, and Realize Services for Your SOA. 2004. Disponível em: $<$ http://www.immagic.com/eLibrary/ARCHIVES/GENERAL/IBM/I041109A.pdf>. Acesso em: 7 jan. 2013.

. A New Service-Oriented Architecture (SOA) Maturity Model - NSOAMM. 2005. Disponível em: <http://soa.omg.org/UploadedDocs/SOA/SOA_Maturity.pdf> Acesso em: 7 jan. $2013 \mathrm{~g}$.

Bana e Costa, C.A. Structuration, Construction et Exploitation d'un Modèle Multicritère d'Aide à la Décision, Tese de Doutorado, Universidade Tec. Lisboa, Portugal, 1992.

BEA. BEA Evolution Model. 2006. Disponível em: <http://soablueprint.com /yahoo_site _admin/assets/docs/SOAEvolutionModel.291100753.pdf>. Acesso em: 9 jan. 2013.

Beasley, M., Frigo, M. L. Strategic Risk Management: Protecting and Creating Value. Strategic Finance, Maio de 2007 (cover article).

Becker, J.; Knackstedt, R. Developing Maturity Models for IT Management - A Procedure Model and its Application. In: BISE - Research Paper, Business \& Information Systems Engineering. 3 March, 2009. 
Bell, M. Service-Oriented Modeling (SOA): Service Analysis, Design, and Architecture. ISBN: 978-0-470-14111-3. Hardcover. 384 pages. February 2008.

Bieberstein, N. et al. Service Oriented Architecture (SOA) Compass Business Value, Planning, and Enterprise Roadmap. IBM Press, USA, 2005.

Biske, T. SOA Governance: The Key to Successful SOA Adoption in Your Organization. Published by Packt Publishing Ltd. Birmingham, UK. October 2008.

Brandon, J. O Desafio de Substituir Aplicativos Legados. Computer World. 2011. Disponível em: <http://computerworld.uol.com.br/tecnologia/2011/08/01/o-desafiode-substituir-aplicativos-legados/>. Acesso em: 8 jan. 2013.

Brauer, B., Kline, S. SOA Governance: a Key Ingredient of the Adaptive Enterprise. HP, $2005 . \quad$ Disponível em: $<$ http://www.managementsoftware.hp.com/products/soa/swp/soa_swp_governance.p df>. Acesso em: 9 jan. 2013.

Brown, W. A. SOA Governance Achieving and Sustaining Business and IT Agility. IBM Press, USA, 2008.

Carnegie Mellon Software Engineering Institute. CMMI for Development Version 1.2. Carnegie Mellon, August 2006. Disponível em: <CMMI for Development Version 1.2.pdf - http://repository.cmu.edu/sei/387/>. Acesso em: 9 fev. 2013.

Chaim, R. ; Mazzarolo, C. ; Toffanello, A. ; Areal, J. L. ; Puttini, R. A Multi-Pardigm Approach For SOA Governance in it Companies. International Journal of Information Technology \& Computer Science (IJTCS) 9(2), p. 143-153, 2013.

Chaim, R.; Mazzarolo, C. ; Toffanello, A. ; Areal, J. L. ; Puttini, R. SOA Governance Dynamics for IT Organizations. Proceedings of 31st International Conference of the System Dynamics Society, 2013, Cambridge, Massachusetts USA.

Chrissis, M. B., Konrad, M., Shrum, S. CMMI Guidelines for Process Integration and Product Improvement. Addison-Wesley Longman Publishing Co., Inc. 2003. Boston, MA, USA. Disponível em: <http://dl.acm.org/citation.cfm?id=773274>. Acesso em: 15 jan. 2013.

Costa, J. F. S.; Risicato, L. B.; Torres. C. A. Metodologia Multicritério na Avaliação de Custos na Segurança do Trabalho. Sistemas \& Gestão, v. 1, n. 2, p. 104-115, maio a agosto de 2006 .

Crawford, G., Williams, C. The Analysis of Subjective Judgment Matrices. The Rand Corporation R- 2572-1-AF, USA, 1985.

Dahlberg, T.; Kivijarvi, H. An Integrated Framework for IT Governance and the 
Development and Validation of an Assessment Instrument. 2006.

.DATASUS/MS. Estruturação do Programa de Adoção de Arquitetura

Orientada a Serviços do SUS - Plano de Trabalho. 2011

. Plano do Programa de Adoção de SOA do Ministério da Saúde v1.0. 2012(a)

. Plano do Programa de Adoção de SOA do Ministério da Saúde v2.0. 2012(b)

. Metodologia de Desenvolvimento SOA do Ministério da Saúde v1.0. 2012(c)

. Arquitetura de Referência SOA do Ministério da Saúde v1.0. 2012(d)

. Estudo e Definição da Arquitetura de Informação e de Serviços do Registro

Eletrônico de Saúde (RES) do Brasil - Plano de Trabalho. 2012(e)

. Governança SOA do Ministério da Saúde. 2013(a)

. Estruturação do Centro de Excelência SOA do MS - Plano de Trabalho. 2013(b)

De Bruin, T. Freeze, R. Kaulkarni, U., Rosemann, M. Understanding the Main Phases of

Developing a Maturity Assessment Model. In Campbell, B, Underwood, J, \& Bunker, D (Eds.) Australasian Conference on Information Systems (ACIS), November 30 - December 2 2005, Australia, New South Wales, Sydney. This file was downloaded from: <http://eprints.qut.edu.au/25152/>. Acesso em: 10 jan. 2013.

De Haes, S.; Van Grembergen, W. IT Governance and its Mechanisms. Information Systems Control Journal. Information Systems Audit and Control Association. ISACA. VOLUME 1. 2004.

Derler, P., Weinreich, R. Models and Tools for SOA Governance. Trends in Enterprise Application Architecture. Lecture Notes in Computer Science Volume 4473, 2007, pp 112-126. Disponível em: <http://link.springer.com/chapter/10.1007\%2F978-3540-75912-6_9?LI=true. Acesso em: 7 jan. 2013.

Dias JR., J. J. L., Oliveira, J. A. P., Meira, S. R. L. Pontos Chaves para Adoção de uma Arquitetura Orientada a Serviços: uma análise comparativa de modelos de maturidade SOA da indústria. Centro de Ciências Aplicadas e Educação Universidade Federal da Paraíba (UFPB). In: VIII Simpósio Brasileiro de Sistemas de Informação (SBSI 2012) - Trilhas Técnicas.

Erl, T. Service-Oriented Architecture: Concepts, Technology, and Design. Prentice Hall, USA, 2005.

. SOA: Design Patterns. Prentice Hall, USA, 2008.

. SOA Governance: Governing Shared Services On-Premise and the Cloud. Prentice Hall, USA, 2011. 
Ferreira, P. L. Estatística Descritiva e Inferencial. Apostila da Faculdade de Economia da Faculdade de Coimbra. Disponível em: $<$ https://estudogeral.sib.uc.pt/bitstream/10316/9961/1/AP200501.pdf $>$. Acesso em: 10 de jan. 2013.

Frigo, M. L. When Strategy and MTC Meet. Strategic Finance. Janeiro de 2008.

Frigo, M. L.; Anderson, R. J. A Strategic Framework for Governance, Risk, and Compliance. IMA's Annual Conference, June 6-10, 2009, in Denver, Colorado.

Gartner. GARTNER's Roadmap to SOA. 2009. Disponível em: $<$ https://www.gartner.com/doc/1405618>. Acesso em: 8 jan. 2013.

Gil, A. C. Métodos e Técnicas de Pesquisa Social. 5 ed. São Paulo: Atlas, 1999.

Günther, H. Como Elaborar um Questionário. Publicação do Laboratório de Pesquisa Ambiental, Universidade de Brasília. Série: Planejamento de Pesquisas em Ciências Sociais, n.. 1. 2003. Disponível em: $<$ http://beco-dobosque.net/XTextos/01Questionario.pdf>. Acesso em: 9 jan. 2013.

Gupta, P. K., Hira, D. S. Problems in Operations Research: Principles and Solutions. S. Chand \& Company Ltda. 2009.

Haimes, Y. Risk Modeling, Assessment and Management. John Wiley \& Sons, Inc., New York, 1998.

HP. HP SOA Maturity Model. 2006. Disponível em: $<$ http://people.ischool. berkeley.edu/ glushko/SSME-Lectures-Fall2006/Assess-SOA.pdf $>$. Acesso em: 9 jan. 2013.

IBM. IBM SOA Service Integration Maturity Model - SIMM. 2005. Disponível em: $<$ http://www.ibm.com/developerworks/webservices/library/ws-soa-simm/>. Acesso em: 18 fev. 2013.

IBM. Effective Governance Through the IBM SOA Governance Management Method Approach. 2006.

IBM. Introduction to SOA Governance and Service Lifecycle Management. Best practices for development and deployment. 2009. Disponível em: $<\mathrm{ftp}$ ://ftp.software.ibm.com/software/soa/pdf/IBMSGMMOverview.pdf $>$. Acesso em: 9 jan. 2013.

Isaca. Cobit 5 Laminate. 2012. Disponível em: $<$ http://www.isaca.org/COBIT/Documents/COBIT5-Laminate.pdf $>$. Acesso em: 7 fev. 2013. 
Itana. SOA WORKING GROUP. Disponível em: < https://spaces.internet2.edu/ display /itana/SOA+Working+Group>. Acesso em: 20 fev. 2013.

Janiesch, C., Korthaus, A., Rosemann, M. Conceptualisation and Facilitation of SOA Governance. In: Proceedings of ACIS 2009: 20th Australasian Conference on Information Systems, 2-4 December 2009, Monash University, Melbourne.

Josuttis, Nicolai M. SOA in Practice. 1.ed. Sebastopol: O'Reilly Media, 2007.

Kassou, M.; Kjiri, L. A Maturity Metric Based Approach for Eliciting SOA Security Requirements. 2012 National Days of Network Security and Systems (JNS2), 20-21 April 2012. Pags. 7-11.

Kreger, H; Carrato, T.; Arsanjani, A.; Szakal, A.; Diaz, J.; Holley, K. IBM Advantage for Service Maturity Model Standards. Disponível em: $<\mathrm{http}: / / w w w . i b m . c o m /$ developerworks/webservices/library/ws-OSIMM/index.html>. Acesso em: 9 fev. 2013.

Kruskal, J.B., Wish, M. Multidimensional Scaling. Sage University Press. Beverly Hills. USA. 1973.

Laville, C.; Dionne, J. A Construção do Saber: Manual de Metodologia da Pesquisa em Ciências Humanas. Belo Horizonte: UFMG, 1999.

Linkov, I.; Ramadan, A. B. Comparative Risk Assessment and Environmental Decision Making, Kluwer Academic Publishers. 2004. Netherlands. Págs. 15-54.

Lisboa, E. Pesquisa Operacional. Cap. 9 - Risco e incerteza. RJ. 2002.

Lopes, M. Apontamentos de Estatística Aplicada, Jun 15, 2011. Disponível em: $<$ http://pt.scribd.com/doc/57948870/Apontamentos-de-a-Aplicada>. Acesso em: 14 jan, 2013.

Luftman, J. Assessing Business - IT Alignment Maturity - Strategies for Information Technology Governance - Chapter IV. Disponível em: <http://books.google.com.br /books?hl=en\&lr=\&id=IleHOs41iIMC\&oi=fnd\&pg=PA99\&dq=luftman+2004\&ots= wV3CFK1BN\&sig=mvs4YgDNex-NFfpDfoQ35qbjCRA\#v=onepage\&q=luftman $\% 20$ $2004 \& \mathrm{f}=$ false $>$. Acesso em: 7 jan. 2013.

Manes, A. T., Handouts of a Talk at OOP 2007. SIG Datacom.

Marconi, M. A; Lakatos, E. V. Metodologia do Trabalho Científico. 4.ed. São Paulo: Atlas, 1992.

Martínez, E. Evaluacion y Decision Multicriterio: Una perspectiva. In: Martinez, E. e Escudey, M. Evaluacion y Decision Multicriterio. Universidad de Santiago, Chile. 1998. 
Marks, E. Service-Oriented Architecture Governance for the Services Driven Enterprise. John Wiley \& Sons, Inc. New Jersey, USA, 2008.

Marks, E., Bell, M. SOA: A Planning and Implementation Guide for Business and Technology. John Wiley \& Sons, Inc. New Jersey, USA, 2006.

Mazzarolo, C., Martins, V.; Toffanello, A.; Puttini, R. A Method for SOA Maturity Assessment and Improvement. IEEE Latin America Transactions 13(1), Jan. 2015. ISSN: 1548-0992.

Mazzarolo, C.; Alves, G.; Martins, V.; Ribeiro, M.; Toffanello, A.; Puttini, R. Survey About SOA Adoption by Organizations in Brazil. Anais do X Simpósio Brasileiro de Sistemas de Informação, Maio, 2014, Londrina, Paraná.

Mazzarolo, C.; Toffanello, A.; Puttini, R.; Chaim, R. SOA Governance Dynamics in a Multiparadigm Approach. Proceedings of 32nd International Conference of the System Dynamics Society, 2014, Delft.

Mazzarolo, C. ; Chaim, R. ; Toffanello, A. ; Puttini, R. A Multi Paradigm Approach for SOA Governance in IT Companies. Proceedings of International Conference on Information, Communication \& Computer Networks, 2013, Bangkok..

Microsoft. MICROSOFT Services Assessment and Roadmap for Service Oriented Architecture. 2007. Disponível em: <http://www.microsoft.com/en-us/download /details.aspx?id=10486>. Acesso em: 23 jan. 2013.

Mitra, Tilak. A Case for SOA Governance. IBM Developer Works Technical Library. August. 2005.

Natis, Y. SSA Research Note SPA-401-068 , 12 April 1996, 'Service Oriented' Architectures, Part 1" and SSA Research Note SPA-401-069 , 12 April 1996, "'Service Oriented' Architectures, Part 2". Gartner.

Niemann, M. Towards a Generic Governance Model for Service-Oriented Architectures. In Proceeding of the fourteenth Americas Conference on Information Systems. Toronto, Canada, 2008. Disponível em: $<$ http://www.jointresearch.org/wp-content/uploads/2011/07/NER+08.pdf>. Acesso em: 8 jan. 2013.

Niemann, M.; Miede, A., Johannsen, W.; Repp, N.; Steinmetz, R. Structuring SOA Governance. 58 International Journal on IT/Business Alignment and Governance, 1(1), 58-75, January-March 2010. IGI Global.

Oasis. Reference Model for Service Oriented Architecture 1.0. 2006. Disponível em: $<$ http://docs.oasis-open.org/soa-rm/v1.0/soa-rm.pdf $>$. Acesso em: 7 jan. 2013. 
OECD. Organisation for Economic Co-Operation and Development, OECD Principles of Corporate Governance. Paris: OECD, 2004.

Oliveira, E. C. Comparação das Diferentes Técnicas para a Exclusão de "Outliers". ENQUALAB-2008 - Congresso da Qualidade em Metrologia, Rede Metrológica do Estado de São Paulo - REMESP. São Paulo, Brasil. Junho de 2008.

Oracle. Oracle SOA Maturity Model. 2007. Disponível em: $<$ http://www.oracle.com/us/technologies/soa/oracle-soa-governance-best-practice066427.pdf >. Acesso em: 10 fev. 2013.

Papazoglou, M. P.; Georgakopoulos, D. Introduction: Service-Oriented Computing. 2003.

Magazine Communications of the ACM - Service-Oriented Computing. Vol. 46, Issue 10, October 2003, p. 24-28.

Papazoglou, M. P. Service Oriented Architectures: Approaches, Technologies and

Research Issues. 2007. Disponível em: <http://link.springer.com/article/10. 1007\%2Fs00778-007-0044-3?LI=true\#page-1>. Acesso em: 14 jan. 2013.

Papazoglou, M. P.; Heuvel, W. J. V. D. Service-Oriented Design and Development

Methodology. 2006. Disponível em: <http://arno.uvt.nl/show.cgi?fid=106517>. Acesso em: 14 jan. 2013.

Papazoglou, M. P.; Traverso, P.; Dustdar, S.; Leymann, F. Service-Oriented Computing:

State of the Art and Research Challenges. Computing \& Processing (Hardware/Software). Volume 40, Issue: 11. IEEE Computer Society. Nov. 2007.

Puttini, R.; Toffanello, A.; Vidigal, A.; Areal, J.L.; Alves, G.; Chaim, R ; Mazzarolo, C. A Service - Oriented Software Development Methodology for Outsourced

Working Force. Lecture Notes in Computer Science, 7972(2), p. 559-573, 2013.

Racz, N.; Weippl, E.; Seufert, A. Governance, Risk \& Compliance (GRC) Software - an Exploratory Study of Software Vendor and Market Research Perspectives. In: Proceedings of the 44th Hawaii International Conference on System Sciences 2011. Págs. 1530-1605. IEEE.

Raines, G. Leveraging Federal IT Investment Using SOA. Service-Oriented Architecture (SOA) Series. The MITRE Corporation. 2009.

Renken, J. "Developing an IS/ICT Management Capability Maturity Framework". 2004. Publish in SAICSIT '04 Proceedings of the 2004 annual research Conference of the South African Institute of Computer Scientists and Information Technologists on IT Research in Developing Countries. Págs. 53-62.

Ribbers, P. M. A.; Peterson, R. R.; Parker, M. M. Designing Information Technology 
Governance Processes: Diagnosing Contemporary Practices and Competing Theories; 2002.

Rosen, M.; Lublinsky, B.; Smith, K. T. Applied SOA: Service Oriented Architecture and Design Strategies. 1 ed. - Indianapolis, Indiana, 2008.

Roy, B.; Vanderpooten, D. The European School of MCDA: Emergence, Basic Features and Current Works. J. of Multicriteria Decision Analysis, vol.5, 22-38, 1996.

Saltelli, A. The Critique of Modeling and Sensitivity Analysis in the Scientific Discourse: An Overview of Good Practices. Transatlantic Uncertainty Colloquium (TAUC) Washington, October 2006. 10-11.

Saltelli, A., Chan, K., Scott, E. M. Sensitivity Analysis, Wiley Paperback Series in Probability and Statistics. 2000. New York: John Wiley and Sons.

Schropfer, C.; Schonherr, M. Introducing a Method to Derive an Enterprise-Specific SOA Operating Model. IEEE.2008.

Site Tutorials Point. Disponível em: $<\mathrm{http}: / \mathrm{www}$.tutorialspoint.com/cmmi/cmmimaturity-levels.htm>. Acesso em: 14 set. 2012.

Sonkar, G. Operation Research - Decision Making Criterion. Apresentação do Departamento Business Administration. 2013. Disponível em: $<$ http://www.docstoc.com/docs/144209641/Operation-Research-Decision-MakingCriterion>. Acesso em: 20 jan. 2013.

Spiegel, M. R. Estatística. São Paulo. Mc Graw-Hill do Brasil. 1976.

Tarantino, A. Governance, Risk, and Compliance Handbook: Technology, Finance, Environmental and International Guidance and Best Practices. 2008.

The Open Group. SOA Governance Framework Technical Standard. ISBN: 1-9316242-8. Documento C093. Publicado pelo The Open Group, Agosto de 2009.

The Open Group. Open Group Service Integration Maturity Model - OSIMM. 2009.

Disponível em: <https://collaboration.opengroup.org/projects/osimm/>. Acesso em: 31 jan. 2013.

The Open Group. SOA Source Book - Current Edition. Documento G102. Publicado pelo The Open Group, Agosto de 2011. Disponível em: $<$ http://www.opengroup.org/soa/source-book/intro/index.htm>. Acesso em: 18 out. 2012.

The Open Group. THE OPEN GROUP SERVICE INTEGRATION MATURITY MODEL - OSIMM. Technical Standard Version 2. ISBN: 1-931624-99-2. Documento C117. Publicado pelo The Open Group, Outubro 2011. 
Triantaphyllou, E. Multi-Criteria Decision Making: A Comparative Study. SpringerVerlag. 2000. p. 320. ISBN 0-7923-6607-7.

Triantaphyllou, E., Sanchez, A. A Sensitivity Analysis Approach for Some Deterministic Multi-Criteria Decision-Making Methods. Decision Sciences 28 (1): 151-194. 1997.

Tribunal de Contas da União. Levantamento de Governança de TI de 2010. Sumários Executivos. Brasília, 2010.

Van Grembergen, W. Strategies for Information Technology Governance. 2004.

Vismara, L.S., Karam, D., Morita, L. H. M. Aplicação das Inferências Clássica e Bayesiana na Estimação dos Parâmetros do Modelo de Densidade Populacional de Plantas Daninhas. SBCPD. Viçosa-MG, v. 25, n. 4, p. 661-669, 2007.

Vom Brocke, J., Rosemann, M. Handbook on Business Process Management. Springer, 2010.

Vukmanovic, D., Kalpic, D. Key Practices for SOA Adoption. In: Proceedings of the 5th WSEAS Congress on Applied Computing Conference, and Proceedings of the 1st International Conference on Biologically Inspired Computation (BICA'12). World Scientific and Engineering Academy and Society (WSEAS) Stevens Point, Wisconsin, USA. 2012. ISBN: 978-1-61804-089-3.

Webmethods. SOA Governance - Enabling Sustainable Success with SOA. 2006. Disponível em: <http:/www.cioindex.com/channels/enterprise_architecture /article /articleid/1091/enabling-sustainable-success-with-soa.aspx>. Acesso em: 9 jan. 2013.

Weill, P.; Ross, J. W. IT Governance - How Top Performers Manage IT Decision Rights for Superior Results. Cambridge. Harvard Business School Press, 2004.

Welke, R.; Hirschheim, R.; Schwarz, A. Service-Oriented Architecture Maturity. Revista Computing Now. IEEE Computer Society. Feb. 2011.

Yawalkar, S. HP Service-Oriented Architecture Maturity Self-Assessment Report. CTS by Hewlett-Packard Company. September 18, 2007. Disponível em: $<$ http://www.nyu.edu/classes/jcf/g22.3033-003_fa09/handouts/HP-SOA-Assessment Report.pdf>. Acesso em: 12 jan. 2013.

Yin, R. K. Estudo de Caso: Planejamento e Métodos. 2. Ed. Porto Alegre: Bookman, 2001. Zeleny, M. Six Concepts of Optimality. TIM/ORSA Joint Meeting. USA. 1994. 


\section{APÊNDICES}




\section{APÊNDICE A - COMPILAÇÃO DOS ASSUNTOS FUNDAMENTAIS}

\section{ANALISADOS EM CADA MODELO DE MATURIDADE DE SOA.}

\begin{tabular}{|c|c|c|}
\hline Referencial & Dimensão & Assunto \\
\hline \multicolumn{3}{|c|}{ RISCOS } \\
\hline $\begin{array}{l}\text { Weill e Ross (2004); Dahlberg e } \\
\text { 'Kivijãrvi (2006) }\end{array}$ & Governança & $\begin{array}{l}\text { Balanceamento e controle de riscos e } \\
\text { oportunidades em ambientes } \\
\text { dinâmicos }\end{array}$ \\
\hline Frigo e Anderson (2009) & Conformiade legal e interna & Estratégia de gerenciamento de riscos \\
\hline $\begin{array}{l}\text { Weill e Ross (2004); Dahlberg e } \\
\text { Kivijãrvi (2006) }\end{array}$ & Governança & $\begin{array}{l}\text { Balanceamento e controle de riscos e } \\
\text { oportunidades em ambientes } \\
\text { dinâmicos }\end{array}$ \\
\hline $\begin{array}{l}\text { Weill e Ross (2004); Dahlberg e } \\
\text { Kivijãrvi (2006) }\end{array}$ & Governança & Riscos e Gestão \\
\hline $\begin{array}{l}\text { Weill e Ross (2004); Dahlberg e } \\
\text { Kivijãrvi (2006) }\end{array}$ & Governança & $\begin{array}{llrl}\text { Avaliação } & \text { de } & \text { oportunidades } & \text { de } \\
\text { negócios (oportunidades e riscos) }\end{array}$ \\
\hline Marks (2008) e Raz et al. (2011) & Governança & Gestão de Risco Empresarial \\
\hline Marks (2008) e Raz et al. (2011) & Governança & Gestão de Risco por Projeto \\
\hline Rosemann and Von Brocke, 2010 & Governança & $\begin{array}{l}\text { Riscos no ciclo de vida de adoção de } \\
\text { SOA }\end{array}$ \\
\hline The Open Group & Organização e Gover & Gerenciamento de riscos empresariais \\
\hline The Open Group & Métodos e Práticas & Gerenciamento de riscos no projeto \\
\hline Microsoft & Administração/Gerenciamento & $\begin{array}{l}\text { Segurança (do básico passando pelo } \\
\text { empresarial e análise de risco) }\end{array}$ \\
\hline \multicolumn{3}{|c|}{ ROI } \\
\hline BPTrends & Organização & $\begin{array}{l}\text { Acompanhamento da efetividade de } \\
\text { custos e viabilidade de SOA }\end{array}$ \\
\hline BPTrends & Organização & ROI e SOA \\
\hline The Open Group & Negócios e objetivos estratégicos & Práticas financeiras - ROI \\
\hline CSDI & Serviços & Gerenciamento do ROI \\
\hline $\begin{array}{l}\text { Weill e Ross (2004); Dahlberg e } \\
\text { Kivijãrvi (2006) }\end{array}$ & Governança & $\begin{array}{l}\text { Equilíbrio de custos } \\
\text { acompanhamento do ROI (nas suas } \\
\text { múltiplas funções e unidades de } \\
\text { negócio) }\end{array}$ \\
\hline $\begin{array}{l}\text { Weill e Ross (2004); Dahlberg e } \\
\text { Kivijãrvi (2006) }\end{array}$ & Governança & $\begin{array}{l}\text { Avaliação de entrega de valor de } \\
\text { negócio (benefícios-custos) }\end{array}$ \\
\hline Oracle & Financeiro & Modelos de financiamento de projetos \\
\hline Oracle & Financeiro & Taxas de utilização de serviços \\
\hline Oracle & Financeiro & $\begin{array}{l}\text { Plataforma de cobrança no uso de } \\
\text { serviços }\end{array}$ \\
\hline
\end{tabular}

Continua 


\begin{tabular}{|c|c|c|}
\hline Referencial & Dimensão & Assunto \\
\hline \multicolumn{3}{|c|}{ GOVERNANÇA } \\
\hline $\begin{array}{l}\text { Weill e Ross (2004); Dahlberg e } \\
\text { Kivijãrvi (2006) }\end{array}$ & Governança & $\begin{array}{l}\text { Suporte a tomadores de decisão } \\
\text { (disponibilização de informações de } \\
\text { Governança SOA) }\end{array}$ \\
\hline $\begin{array}{l}\text { Weill e Ross, 2004; Dahlberg e } \\
\text { Kivijãrvi, } 2006\end{array}$ & Governança & $\begin{array}{l}\text { Desenvolvimento de Governança de } \\
\text { TI }\end{array}$ \\
\hline Racz et al. (2011) & Frameworks & Suporte à Governança Corporativa \\
\hline Microsoft & Administração/Gerenciamento & $\begin{array}{l}\text { Governança (básica até à Governança } \\
\text { com suporte analítico e de resultados) }\end{array}$ \\
\hline The Open Group & Organização e Governança & Governança no Negócio \\
\hline $\begin{array}{l}\text { Oracle (2007); Niemann et al. } \\
(2008)\end{array}$ & Padrões e políticas metodológicas & $\begin{array}{l}\text { Governança de TI, segundo Práticas } \\
\text { de Mercado (ITIL, ISSO, Cobit) }\end{array}$ \\
\hline The Open Group & Organização e Governança & Governança e autoridades \\
\hline The Open Group & Organização e Governança & Governança SOA \\
\hline Oracle & Execução de Projetos & $\begin{array}{l}\text { Governança do ciclo de vida de } \\
\text { serviços }\end{array}$ \\
\hline The Open Group & Tecnologia e Infraestrutura & Governança \\
\hline Oracle & Tecnologia & 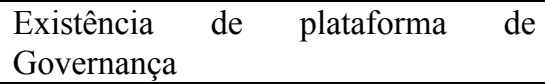 \\
\hline \multicolumn{3}{|c|}{ ADOÇÃO/TREINAMENTO } \\
\hline $\begin{array}{l}\text { Weill e Ross (2004); Dahlberg e } \\
\text { Kivijãrvi (2006) }\end{array}$ & Governança & $\begin{array}{l}\text { Suporte a tomadores de decisão } \\
\text { (estágio de adoção de SOA) }\end{array}$ \\
\hline BPTrends & Governança & Escopo de adoção de SOA \\
\hline The Open Group & Negócio e objetivos estratégicos & Etapas de adoção de SOA \\
\hline The Open Group & Organização e Governança & Treinamento SOA \\
\hline The Open Group & Organização e Governança & Estratégia para adoção de SOA \\
\hline The Open Group & Tecnologia e Infraestrutura & Etapas de adoção de SOA \\
\hline Oracle & Pessoas & $\begin{array}{l}\text { Treinamento SOA (inclusive para } \\
\text { gerentes de alta direção) }\end{array}$ \\
\hline
\end{tabular}

Continua 


\begin{tabular}{|c|c|c|}
\hline Referencial & Dimensão & Assunto \\
\hline \multicolumn{3}{|c|}{ NEGÓCIOS } \\
\hline The Open Group & Negócio e Objetivos Estratégicos & Direcionadores de negócio \\
\hline The Open Group & Negócio e Objetivos Estratégicos & Envolvimento do negócio com SOA \\
\hline The Open Group & Negócio e Objetivos Estratégicos & Arquitetura e processo de negócio \\
\hline The Open Group & Negócio e Objetivos Estratégicos & $\begin{array}{l}\text { Visão e objetivos do negócio, e seu } \\
\text { alinhamento com TI }\end{array}$ \\
\hline The Open Group & Negócio e Objetivos Estratégicos & Linhas de negócio (LOB) \\
\hline The Open Group & Tecnologia e Infraestrutura & Integração de informação de negócio \\
\hline Oracle & Arquitetura & $\begin{array}{l}\text { Arquitetura de referência (para } \\
\text { alinhamento das linhas de negócio) }\end{array}$ \\
\hline CSDI & Negócios & Ontologia de negócios \\
\hline CSDI & Negócios & Modelos de maturidade de negócios \\
\hline CSDI & Negócios & Políticas de regras de negócio \\
\hline CSDI & Negócios & Fluxo de negócios \\
\hline CSDI & Negócios & Negócio como componentes \\
\hline CSDI & Serviços & Semântica do negócio (ontologia) \\
\hline Microsoft & Implementação & $\begin{array}{l}\text { Serviços criados com o suporte de } \\
\text { modelagem de processos de negócio }\end{array}$ \\
\hline CSDI & Negócios & Business inteligente \\
\hline CSDI & Negócios & $\begin{array}{l}\text { Modelo de colaboração na realização } \\
\text { do negócio }\end{array}$ \\
\hline CSDI & Negócios & $\begin{array}{llll}\begin{array}{l}\text { Cumprimento das obrigações do } \\
\text { negócio }\end{array} & & \\
\end{array}$ \\
\hline \multicolumn{3}{|c|}{ POLÍTICAS } \\
\hline The Open Group & Organização e Governança & Políticas \\
\hline Oracle & Operacional & Imposição e políticas \\
\hline Oracle & Informações e dados & $\begin{array}{l}\text { Políticas de segurança no nível de } \\
\text { dados }\end{array}$ \\
\hline CSDI & Serviços & Política de uso dos serviços \\
\hline CSDI & Serviços & $\begin{array}{l}\begin{array}{l}\text { Políticas de provisionamento dos } \\
\text { serviços }\end{array} \\
\end{array}$ \\
\hline Microsoft & Implementação & $\begin{array}{l}\text { Suporte de inventário de serviços com } \\
\text { versionamento e políticas de execução }\end{array}$ \\
\hline Oracle & Pessoas & Perfis e responsabilidades \\
\hline Racle & Pessoas & Proprietários de serviços e processos \\
\hline Oracle & Informações e dados & Proprietário de dados \\
\hline Oracle & Execução de projetos & Proprietário de serviços \\
\hline
\end{tabular}

Continua 


\begin{tabular}{|c|c|c|}
\hline Referencial & Dimensão & Assunto \\
\hline \multicolumn{3}{|c|}{ ARQUITETURA } \\
\hline The Open Group & Tecnologia e Infraestrutura & Arquitetura de referência \\
\hline Oracle & Arquitetura & Padrões arquiteturais centralizados \\
\hline CSDI & Tecnologia & $\begin{array}{l}\text { Arquitetura de referência (protocolos } \\
\text { e formatos de mensagens) }\end{array}$ \\
\hline The Open Group & Organização e Governança & Arquitetura empresarial \\
\hline BPTrends & Governança & $\begin{array}{l}\text { Arquitetura com capacidade de } \\
\text { avaliação dos níveis de maturidade } \\
\text { SOA }\end{array}$ \\
\hline The Open Group & Negócios e objetos estratégicos & Arquitetura empresarial \\
\hline The Open Group & Aplicações e Arquitetura & Arquitetura de aplicação \\
\hline \multicolumn{3}{|c|}{ GESTÃO } \\
\hline CSDI & Negócios & Gestão nas entregas do negócio \\
\hline CSDI & Serviços & $\begin{array}{l}\text { Gestão e planejamento de portfólio de } \\
\text { serviços }\end{array}$ \\
\hline CSDI & Serviços & $\begin{array}{l}\text { Gestão de composição e colaboração } \\
\text { dos serviços }\end{array}$ \\
\hline $\begin{array}{l}\text { Dahlberg e Kivijãrvi (2006); } \\
\text { Niemann et al. (2008) }\end{array}$ & Governança & $\begin{array}{l}\text { Gestão (do contexto) do ciclo de vida } \\
\text { do negócio }\end{array}$ \\
\hline Racz et al (2011) & Frameworks & Gestão operacional \\
\hline Racz et al (2011) & Frameworks & $\begin{array}{l}\text { Gerenciamento de conformidade e } \\
\text { auditoria }\end{array}$ \\
\hline Racz et al (2011) & Frameworks & $\begin{array}{l}\text { Gerenciamento e testos de controles } \\
\text { financeiros }\end{array}$ \\
\hline Racz et al (2011) & Frameworks & $\begin{array}{l}\text { Gerenciamento de fluxo de processos, } \\
\text { atividades e tarefas }\end{array}$ \\
\hline Microsoft & Administração/Gerenciamento & $\begin{array}{l}\text { Gestão de eficiência até o } \\
\text { monitoramento avançado }\end{array}$ \\
\hline \multicolumn{3}{|c|}{ MONITORAMENTO/ACOMPANHAMENTO } \\
\hline The Open Group & Operação e Gerenciamento de TI & Monitoramento \\
\hline $\begin{array}{l}\text { Weill e Ross (2004); Dahlberg e } \\
\text { Kivijãrvi (2006) }\end{array}$ & Governança & Monitoramento de recursos de TI \\
\hline $\begin{array}{l}\text { Weill e Ross (2004); Dahlberg e } \\
\text { Kivijãrvi (2006) }\end{array}$ & Governança & $\begin{array}{l}\begin{array}{l}\text { Acompanhamento de medição de } \\
\text { desempenho de TI }\end{array} \\
\end{array}$ \\
\hline The Open Group & Negócio e objetos estratégicos & Monitoramento e mensuração \\
\hline He Open Group & Organização e Governança & Monitoramento \\
\hline Microsoft & Implementação & $\begin{array}{l}\text { Eficiência nas integrações (com } \\
\text { monitoramento e recomposições) }\end{array}$ \\
\hline CSDI & Tecnologia & Modelos de mediação de serviços \\
\hline CSDI & Tecnologia & Gerenciamento de status dos serviços \\
\hline
\end{tabular}

Continua 


\begin{tabular}{|c|c|c|}
\hline Referencial & Dimensão & Assunto \\
\hline \multicolumn{3}{|c|}{ XM/DADOS } \\
\hline The Open Group & Aplicações e Arquitetura & Uso do XML \\
\hline The Open Group & Informações e modelos de dados & Modelo de dados \\
\hline The Open Group & Informações e modelos de dados & Transformações de dados \\
\hline The Open Group & Informações de modelos de dados & Informação \\
\hline The Open Group & Informações de modelos de dados & Metadados \\
\hline Oracle & Informações e dados & Padronização de dados \\
\hline Oracle & Informações e dados & Qualidade de dados \\
\hline \multicolumn{3}{|c|}{ PADRONIZAÇÃO DE CONTRATO } \\
\hline ERL & Boas práticas & Contrato de serviço padronizado \\
\hline Microsoft & Uso & $\begin{array}{l}\text { Contratos explícitos e padronizados } \\
\text { até o suporte de serviços de semântica }\end{array}$ \\
\hline \multicolumn{3}{|c|}{ ACOPLAMENTO } \\
\hline ERL & Boas práticas & Baixo acoplamento \\
\hline The Open Group & Aplicações e Arquitetura & Acoplamento de lógica de negócio \\
\hline Microsoft & implementação & $\begin{array}{l}\text { Boas práticas de adoção (baixo } \\
\text { acoplamento, } \\
\text { progressivas, padrões de projeto) }\end{array}$ \\
\hline \multicolumn{3}{|c|}{ ALINHAMENTO } \\
\hline ERL & Objetivos & Maior alinhamento entre Negócio e TI \\
\hline $\begin{array}{l}\text { Weill e Ross (2004); Dahlberg e } \\
\text { Kivijãrvi (2006) }\end{array}$ & Governança & Alinhamento de negócios e TI \\
\hline $\begin{array}{l}\text { Dahlberg e Kivijãrvi (2006) e } \\
\text { Niemann et al. (2008) }\end{array}$ & Governança & $\begin{array}{l}\text { Estratégicas de TI direcionadas pelas } \\
\text { estratégias de negócio }\end{array}$ \\
\hline CSDI & Negócios & $\begin{array}{l}\text { Modelo de respostas a eventos de } \\
\text { negócio }\end{array}$ \\
\hline \multicolumn{3}{|c|}{ INTEGRAÇÃO } \\
\hline The Open Group & Aplicações e Arquitetura & Integração \\
\hline The Open Group & Tecnologia e Infraestrutura & Integração de aplicações empresariais \\
\hline 'The Open Group & Operação e Gerenciamento de TI & Integração \\
\hline CSDI & Serviços & Serviços integrados \\
\hline \multicolumn{3}{|c|}{ REUSABILIDADE } \\
\hline ERL & Boas práticas & Reusabilidade \\
\hline Microsoft & Implementação & Reuso de serviços de entidade comuns \\
\hline Oracle & Tecnologia & $\begin{array}{l}\text { Serviços básicos compartilhados } \\
\text { (junto à IE SOA) }\end{array}$ \\
\hline Oracle & Execução de projetos & Compartilhamento de artefatos \\
\hline
\end{tabular}

Continua 


\begin{tabular}{|c|c|c|}
\hline Referencial & Dimensão & Assunto \\
\hline \multicolumn{3}{|c|}{ CONFORMIDADE } \\
\hline Niemann (2008) & Conformidade legal e interna & $\begin{array}{l}\text { Controle efetivo da conformidade às } \\
\text { regulações legais técnicas normativas } \\
\text { internas }\end{array}$ \\
\hline The Open Group & Negócio e objetos estratégicos & Conformidade legal \\
\hline The Open Group & Métodos e práticas & Conformidade normativa \\
\hline Oracle (2007) & Conformidade legal e interna & $\begin{array}{l}\text { Atendimento de pontos internos e } \\
\text { externos de regulação }\end{array}$ \\
\hline \multicolumn{3}{|c|}{ ATIVOS } \\
\hline The Open Group & Organização e Governança & Habilidades \\
\hline The Open Group & Operação e Gerenciamento de TI & Ativos de TI \\
\hline \multicolumn{3}{|c|}{ DESCOBERTA } \\
\hline Microsoft & Uso & $\begin{array}{l}\text { Identificação, descoberta } \\
\text { interpretação de serviços }\end{array}$ \\
\hline CSDI & Serviços & $\begin{array}{l}\text { Fácil descoberta e interpretação dos } \\
\text { serviços }\end{array}$ \\
\hline Oracle & Portfólios & Inventário de sérvios \\
\hline ERL & Boas práticas & $\begin{array}{l}\text { Fácil descoberta (e interpretação de } \\
\text { serviços) }\end{array}$ \\
\hline \multicolumn{3}{|c|}{ VERSIONAMENTO } \\
\hline The Open Group & Operação e Gerenciamento de TI & Controle de versão \\
\hline CSDI & Negócios & Planejamento e controle de mudanças \\
\hline \multicolumn{3}{|c|}{ AVALIAÇÃO } \\
\hline Racz et al. (2011) & Frameworks & Pesquisas e questionários avaliativos \\
\hline Oracle & Arquitetura & $\begin{array}{l}\text { Processos estabelecidos de avaliações } \\
\text { (com comentários e revisões) }\end{array}$ \\
\hline \multicolumn{3}{|c|}{ PORTFÓLIO } \\
\hline Oracle & Portfólios & Portfólio de aplicação de legado \\
\hline Oracle & Portfólios & Portfólio de projetos \\
\hline \multicolumn{3}{|c|}{ COMPONENTIZAÇÃO } \\
\hline CSDI & Serviços & Componentização \\
\hline ERL & Boas práticas & Maximização da composabilidade \\
\hline The Open Group & Métodos e práticas & Melhores práticas \\
\hline The Open Group & Métodos e práticas & Metodologia e implementação \\
\hline The Open Group & Métodos e práticas & Metodologia e métodos \\
\hline The Open Group & Métodos e práticas & Práticas SOA \\
\hline The Open Group & Aplicações e Arquitetura & Práticas de desenvolvimento \\
\hline The Open Group & Tecnologia e Infraestrutura & $\begin{array}{l}\text { Métodos, princípios, padrões, } \\
\text { framewors e técnicas em SOA }\end{array}$ \\
\hline ERL & Boas práticas & Abstração \\
\hline ERL & Boas práticas & $\begin{array}{l}\text { Autonomia (habilidade } \\
\text { autogoverno dos serviços) }\end{array}$ \\
\hline
\end{tabular}

Continua 


\begin{tabular}{|c|c|c|}
\hline Referencial & Dimensão & Assunto \\
\hline ERL & Boas práticas & $\begin{array}{l}\text { Independência/diferimento de estado } \\
\text { em serviços }\end{array}$ \\
\hline \multicolumn{3}{|c|}{ OUTROS } \\
\hline ERL & Objetivos & Maior interoperabilidade \\
\hline ERL & Objetivos & $\begin{array}{l}\text { Maior federação (recursos e apli-cativos } \\
\text { trabalham de forma conjunta) }\end{array}$ \\
\hline ERL & Objetivos & $\begin{array}{l}\text { Maiores opções de diversificação de } \\
\text { fornecedores (uso de padrões no } \\
\text { projeto) }\end{array}$ \\
\hline Weill e Ross (2004) & Organização e Governança & $\begin{array}{l}\text { Especificação clara de estrutura de } \\
\text { responsabilidades e direitos }\end{array}$ \\
\hline BPTrends & Governança & $\begin{array}{lllll}\begin{array}{l}\text { Estágios de } \\
\text { planejados }\end{array} & \text { expansão de } & \text { SOA } \\
\end{array}$ \\
\hline The Open Group & Organização e Governança & Fronteiras organizacionais \\
\hline The Open Group & Organização e Governança & Processos e atividades \\
\hline The Open Group & Organização e Governança & Valor do serviço \\
\hline The Open Group & Métodos e práticas & Gerenciamento de projeto \\
\hline The Open Group & Aplicações e Arquitetura & Fonte de serviço primário \\
\hline The Open Group & Aplicações e Arquitetura & Tempo de mercado e confiança \\
\hline The Open Group & Tecnologia e Infraestrutura & Estratégia SOA \\
\hline The Open Group & Operação e gerenciamento de TI & Gerenciamento de configuração \\
\hline The Open Group & Operação e gerenciamento de TI & Gerenciamento de TI \\
\hline The Open Group & Operação e gerenciamento de TI & Orientação a mensagens \\
\hline The Open Group & Operação e gerenciamento de TI & Serviços SOA \\
\hline Oracle & Pessoas & Grupos de EA \\
\hline Oracle & Operacional & Planejamento da capacidade \\
\hline Oracle & Operacional & Imposição de níveis de serviços \\
\hline Oracle & Arquitetura & Templates e padrões de projeto \\
\hline Oracle & Tecnologia & Plataforma aderente a SOA \\
\hline Oracle & Tecnologia & $\begin{array}{llll}\begin{array}{l}\text { Imposição } \\
\text { plataformas }\end{array} & \text { nas } & \text { decisões } & \text { de } \\
\end{array}$ \\
\hline CSDI & Negócios & Orquestração \\
\hline CSDI & Negócios & Modelo de cadeia de valor \\
\hline CSDI & Serviços & Definição clara de contextos \\
\hline CSDI & Serviços & $\begin{array}{l}\text { Formalização de modelos de dados } \\
\text { corporativos }\end{array}$ \\
\hline CSDI & Serviços & $\begin{array}{l}\text { Detalhamento da especificação dos } \\
\text { serviços }\end{array}$ \\
\hline CSDI & Serviços & $\begin{array}{l}\text { Gerenciamento dos modelos de } \\
\text { implementação de serviços }\end{array}$ \\
\hline CSDI & Serviços & Serviços no modelo de informação \\
\hline CSDI & Serviços & Modelos de processo \\
\hline CSDI & Serviços & $\begin{array}{l}\text { Modelo de fluxo de atividades nas } \\
\text { aplicações }\end{array}$ \\
\hline CSDI & Serviços & QoS \\
\hline Microsoft & Uso & $\begin{array}{l}\text { Suporte de testes extremos com SLA } \\
\text { até canais de serviços extensíveis }\end{array}$ \\
\hline
\end{tabular}




\section{APÊNDICE B - MODELO DOS QUESTIONÁRIOS PROPOSTOS POR DOMÍNIOS}

\begin{tabular}{|c|c|c|c|c|c|}
\hline Domínio & Controle & Interpretação do controle & Dispensável & \begin{tabular}{|c|} 
Peso/ \\
ponto \\
Min - $\max$ \\
\end{tabular} & Itens de avaliação (questões)/ \\
\hline \multirow[t]{8}{*}{$\begin{array}{l}\text { Negócios e } \\
\text { Objetivos } \\
\text { Estratégicos } \\
\text { D-01 }\end{array}$} & $\begin{array}{l}\text { Arquitetura } \\
\text { Corporativa }\end{array}$ & $\begin{array}{l}\text { O quanto estão } \\
\text { formalizados os negócios, } \\
\text { documentos e diagramas } \\
\text { na organização, } \\
\text { principalmente tendo } \\
\text { como foco o documento } \\
\text { Arquitetura Empresarial. }\end{array}$ & $\mathbf{N}$ & 1 & \\
\hline & & & & $1-1$ & $\begin{array}{l}\text { A arquitetura corporativa não é um elemento da TI ou da estratégia } \\
\text { organizacional. }\end{array}$ \\
\hline & & & & $1-1$ & Não existe uma arquitetura corporativa formalizada. \\
\hline & & & & $2-2$ & Existe alguma construção de arquitetura corporativa formalizada. \\
\hline & & & & $3-4$ & Uso formal de arquitetura corporativa. \\
\hline & & & & $3-4$ & Uso formal de arquitetura corporativa, integrada a visão dos BPMs. \\
\hline & & & & $5-5$ & $\begin{array}{l}\text { Arquitetura corporativa bem definida detalhando tanto fluxos de processos } \\
\text { internos como processos terceirizados com/entre serviços de negócio com } \\
\text { parceiros. }\end{array}$ \\
\hline & $\begin{array}{l}\text { Arquitetura de } \\
\text { Processo de } \\
\text { Negócio }\end{array}$ & $\begin{array}{l}\text { Quanto BPA (Business } \\
\text { Process Architecture) se } \\
\text { encontra aplicado, } \\
\text { governado e } \\
\text { documentado na } \\
\text { organização. }\end{array}$ & $\mathbf{N}$ & 1 & \\
\hline
\end{tabular}




\begin{tabular}{|c|c|c|c|c|c|}
\hline Domínio & Controle & Interpretação do controle & Dispensável & $\begin{array}{c}\text { Peso/ } \\
\text { ponto } \\
\text { Min - } \max \\
\end{array}$ & Itens de avaliação (questões)/ \\
\hline \multirow[t]{15}{*}{$\begin{array}{l}\text { Negócios e } \\
\text { Objetivos } \\
\text { Estratégicos } \\
\text { D-01 }\end{array}$} & & & & & $\begin{array}{l}\text { Sua Arquitetura de Processo de Negócio (BPA) é formalmente } \\
\text { definida, documentada e governada? }\end{array}$ \\
\hline & & & & $1-1$ & Os processos de negócio não são formalmente definidos e/ou documentados. \\
\hline & & & & $2-2$ & $\begin{array}{l}\text { Os processos de negócio são conhecidos e limitados aos objetivos de } \\
\text { cada linha de negócio dentro da organização. }\end{array}$ \\
\hline & & & & $2-2$ & Uso informal e restrito de BPM. \\
\hline & & & & $3-3$ & $\begin{array}{l}\text { Uso formal de BPM, e esses são mantidos atualizados na sua } \\
\text { completude porém fora de uma arquitetura integrada de processos de } \\
\text { negócio (BPA). }\end{array}$ \\
\hline & & & & $4-4$ & Uso formal de BPM em uma BPA oficializada. \\
\hline & & & & $5-5$ & $\begin{array}{l}\text { BPM é utilizado para detalhar tanto fluxos de processos internos como } \\
\text { processos com/entre serviços de parceiros dentro de uma BPA oficializada. }\end{array}$ \\
\hline & & & & $5-5$ & $\begin{array}{l}\text { BPM utilizado para definir e testar o fluxo de processo necessário para } \\
\text { agrupar os SLAs de forma bem definida. }\end{array}$ \\
\hline & $\begin{array}{l}\text { Linhas de Negócio } \\
\text { (LOB) }\end{array}$ & $\begin{array}{l}\text { Como estão definidas e } \\
\text { documentadas as linhas de } \\
\text { negócio organizacionais } \\
\text { (line-of-business). }\end{array}$ & $\mathbf{N}$ & 2 & \\
\hline & & & & & Suas Linhas de Negócio (LOB) são claras e específicas? \\
\hline & & & & $1-1$ & As LOB não são claramente observadas. \\
\hline & & & & $2-4$ & As LOB são claras e detalhadas. \\
\hline & & & & $5-5$ & $\begin{array}{l}\text { As LOB são claras e detalhadas, bem como suas relações com clientes, } \\
\text { fornecedores e parceiros. }\end{array}$ \\
\hline & & & & $5-5$ & Definição formal dos fluxos de processo de negócio. \\
\hline & & & & $5-5$ & $\begin{array}{l}\text { Definição formal dos fluxos de processo de negócio através do uso de } \\
\text { redistribuição de serviços dinâmicos. }\end{array}$ \\
\hline
\end{tabular}

Continua 


\begin{tabular}{|c|c|c|c|c|c|}
\hline Domínio & Controle & Interpretação do controle & Dispensável & $\begin{array}{c}\text { Peso/ } \\
\text { ponto } \\
\text { Min - max }\end{array}$ & \multirow[t]{2}{*}{ Itens de avaliação (questões)/ } \\
\hline $\begin{array}{l}\text { Negócios e } \\
\text { Objetivos } \\
\text { Estratégicos } \\
\text { D-01 }\end{array}$ & $\begin{array}{l}\text { Direcionadores de } \\
\text { Negócio }\end{array}$ & $\begin{array}{l}\text { Como são documentadas e } \\
\text { gerenciadas as estruturas } \\
\text { que conduzem a } \\
\text { organização. }\end{array}$ & $\mathbf{N}$ & 1 & \\
\hline & & & & & $\begin{array}{l}\text { Em que nível os direcionadores de negócio de sua organização são } \\
\text { documentados? }\end{array}$ \\
\hline & & & & $1-1$ & Os direcionadores de negócio não são documentados. \\
\hline & & & & $2-2$ & $\begin{array}{l}\text { Os direcionadores de negócio são documentados como objetivos de } \\
\text { negócio através da organização. }\end{array}$ \\
\hline & & & & $3-4$ & $\begin{array}{l}\text { Os direcionadores de negócio são documentados como elementos da } \\
\text { missão organizacional e arquitetura de negócio. }\end{array}$ \\
\hline & & & & $5-5$ & $\begin{array}{l}\text { Os direcionadores de negócio são documentados como elementos da } \\
\text { missão organizacional, arquitetura de negócio e com todos elementos } \\
\text { significativos de parceiros e fornecedores. }\end{array}$ \\
\hline & $\begin{array}{l}\text { Envolvimento do } \\
\text { Negócio com SOA }\end{array}$ & $\begin{array}{l}\text { Quanto há de envolvimento } \\
\text { empresarial frente a adoção } \\
\text { de SOA. }\end{array}$ & $\mathbf{S}$ & 1 & \\
\hline & & & & & $\begin{array}{l}\text { Relação da entrega de serviços com o negócio e sua valoração junto } \\
\text { ao negócio? }\end{array}$ \\
\hline & & & & $1-1$ & Não existe relação. \\
\hline & & & & $2-2$ & $\begin{array}{l}\text { Os serviços são expostos como parte do custo do projeto na avaliação } \\
\text { do seu valor para o negócio. }\end{array}$ \\
\hline & & & & $3-3$ & Os serviços são parte da captura de requisitos. \\
\hline & & & & $4-4$ & A organização atua totalmente direcionada a serviços. \\
\hline & & & & $5-5$ & $\begin{array}{l}\text { A organização atua totalmente direcionada a serviços e associada ao } \\
\text { princípio de valor do negócio }\end{array}$ \\
\hline
\end{tabular}

Continua 


\begin{tabular}{|c|c|c|c|c|c|}
\hline Domínio & Controle & Interpretação do controle & Dispensável & $\begin{array}{c}\text { Peso/ } \\
\text { ponto } \\
\text { Min - max }\end{array}$ & Itens de avaliação (questões)/ \\
\hline \multirow{7}{*}{$\begin{array}{l}\text { Negócios e } \\
\text { Objetivos } \\
\text { Estratégicos } \\
\text { D-01 }\end{array}$} & $\begin{array}{l}\text { Alinhamento do } \\
\text { Negócio com a TI }\end{array}$ & $\begin{array}{l}\text { O quanto é alinhado o } \\
\text { negócio e a TI. }\end{array}$ & $\mathbf{N}$ & 1 & \\
\hline & & & & & $\begin{array}{l}\text { Qual o nível de alinhamento entre as visões e objetivos de Negócio e } \\
\text { da TI? }\end{array}$ \\
\hline & & & & $1-1$ & $\begin{array}{l}\text { Limitado ao comportamento das várias aplicações, isto é, a TI é focado } \\
\text { na em aspectos de regras em sistemas informatizados. }\end{array}$ \\
\hline & & & & $2-2$ & $\begin{array}{l}\text { Limitado aos objetivo de LOBs ou silos funcionais e, para uma visão } \\
\text { integrada, necessita de atividades manuais visando agrupar informações } \\
\text { entre esses. }\end{array}$ \\
\hline & & & & $3-3$ & $\begin{array}{l}\text { SLAs de negócio e TI alinhados, porém mensurados e gerados } \\
\text { manualmente. }\end{array}$ \\
\hline & & & & $4-4$ & $\begin{array}{l}\text { SLAs de negócio e TI alinhados, mensurados e gerados } \\
\text { automaticamente, associados aos fluxos de processos em BPM. }\end{array}$ \\
\hline & & & & $5-5$ & $\begin{array}{l}\text { SLAs de negócio e TI alinhados, mensurados e gerados } \\
\text { automaticamente, associados aos fluxos de processos em BPM, e } \\
\text { utilizados para produzir novos planos estratégicos organizacionais em } \\
\text { ciclos de melhoria. }\end{array}$ \\
\hline
\end{tabular}

Continua 


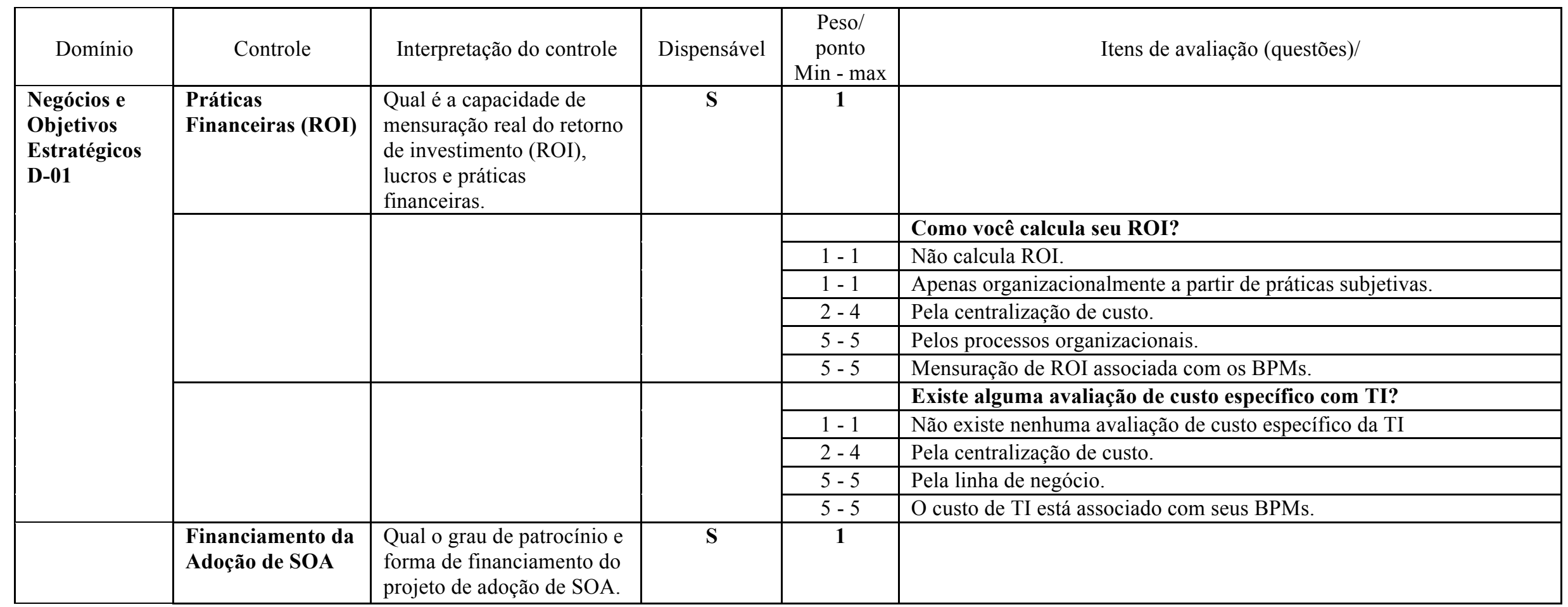




\begin{tabular}{|c|c|c|c|c|c|}
\hline Domínio & Controle & Interpretação do controle & Dispensável & $\begin{array}{c}\text { Peso/ } \\
\text { ponto } \\
\text { Min - max } \\
\end{array}$ & Itens de avaliação (questões)/ \\
\hline \multirow[t]{14}{*}{$\begin{array}{l}\text { Negócios e } \\
\text { Objetivos } \\
\text { Estratégicos } \\
\text { D-01 }\end{array}$} & & & & & Qual é o nível de patrocínio de negócios para SOA? \\
\hline & & & & $1-1$ & SOA é apenas um projeto em estudo. \\
\hline & & & & $2-2$ & SOA é uma prioridade para o CIO. \\
\hline & & & & $2-2$ & Existe algum suporte das áreas de negócio \\
\hline & & & & $3-4$ & O negócio não espera benefícios além da redução dos custos de TI. \\
\hline & & & & $5-5$ & Agilidade de SOA é reconhecida como estratégica para negócios e TI \\
\hline & & & & & Como é financiada a iniciativa SOA? \\
\hline & & & & $1-1$ & Nenhuma / Não aplicável \\
\hline & & & & $2-2$ & Cada unidade de negócio financia seus próprios projetos. \\
\hline & & & & $3-3$ & $\begin{array}{l}\text { Um plano explícito de financiamento existe mas está nos estágios } \\
\text { iniciais }\end{array}$ \\
\hline & & & & $3-3$ & $\begin{array}{l}\text { Financiamento centralizado para os programas de SOA (ex: Centro de } \\
\text { Excelência) é parte do orçamento. }\end{array}$ \\
\hline & & & & $4-4$ & $\begin{array}{l}\text { Procedimentos definidos, é determinado a proporção do projeto } \\
\text { financiado pelo programa SOA vs na linha de nível empresarial. }\end{array}$ \\
\hline & & & & $5-5$ & $\begin{array}{l}\text { SOA tem financiamento pleno. O financiamento adicional é } \\
\text { determinado pelo benefício do negócio real }\end{array}$ \\
\hline & $\begin{array}{l}\text { Conformidade } \\
\text { Legal }\end{array}$ & $\begin{array}{l}\text { Observa se a organização } \\
\text { atua alinhada com todos os } \\
\text { aspectos legais externos a } \\
\text { organização, e oferecendo } \\
\text { as devidas garantias } \\
\text { auditáveis desse } \\
\text { alinhamento. }\end{array}$ & $\mathbf{N}$ & 1 & \\
\hline
\end{tabular}

Continua 


\begin{tabular}{|c|c|c|c|c|c|}
\hline Domínio & Controle & Interpretação do controle & Dispensável & $\begin{array}{c}\text { Peso/ } \\
\text { ponto } \\
\text { Min - max }\end{array}$ & Itens de avaliação (questões)/ \\
\hline \multirow[t]{13}{*}{$\begin{array}{l}\text { Negócios e } \\
\text { Objetivos } \\
\text { Estratégicos } \\
\text { D-01 }\end{array}$} & & & & & Como a conformidade legal é garantida (se existir alguma)? \\
\hline & & & & $1-1$ & A conformidade legal não existe ou não é observada. \\
\hline & & & & $2-2$ & A conformidade legal existe, mas não é garantida. \\
\hline & & & & $3-4$ & $\begin{array}{l}\text { A conformidade legal é garantida dentro de serviços formalizados nos } \\
\text { seus BPMs. }\end{array}$ \\
\hline & & & & $5-5$ & $\begin{array}{l}\text { A conformidade legal é garantida dentro de serviços formalizados nos } \\
\text { seus BPMs e é declarada junto a um serviços de centralização de regras } \\
\text { de negócio. }\end{array}$ \\
\hline & $\begin{array}{l}\text { Monitoramento e } \\
\text { Mensuração }\end{array}$ & $\begin{array}{l}\text { Verifica se existe e é } \\
\text { confiável o monitoramento } \\
\text { e mensuração dos } \\
\text { processos de negócio. }\end{array}$ & $\mathbf{N}$ & 2 & \\
\hline & & & & & Como seus processo de negócio são mensurados e monitorados? \\
\hline & & & & $1-1$ & Não existe monitoramento de processos de negócio. \\
\hline & & & & $2-2$ & Mensurados usando-se aspectos financeiros. \\
\hline & & & & $3-3$ & Mensurados usando-se ferramentas manuais. \\
\hline & & & & $3-3$ & Uso baixo/ pontual de monitoramento. \\
\hline & & & & $4-4$ & $\begin{array}{l}\text { Forte utilização de BAM mas sem prática formal de reavaliação de } \\
\text { processos de negócio. }\end{array}$ \\
\hline & & & & $5-5$ & $\begin{array}{l}\text { Forte utilização de BAM, o que gera um retorno na reavaliação de } \\
\text { processos de negócio. }\end{array}$ \\
\hline
\end{tabular}

Continua 


\begin{tabular}{|c|c|c|c|c|c|}
\hline Domínio & Controle & Interpretação do controle & Dispensável & $\begin{array}{c}\text { Peso/ } \\
\text { ponto } \\
\text { Min - max }\end{array}$ & Itens de avaliação (questões)/ \\
\hline \multirow[t]{6}{*}{$\begin{array}{l}\text { Negócios e } \\
\text { Objetivos } \\
\text { Estratégicos } \\
\text { D-01 }\end{array}$} & & & & & Como as informações de sistemas de suporte a decisão são geradas? \\
\hline & & & & $1-1$ & Incompletas (ad-hoc). \\
\hline & & & & $2-2$ & Geradas usando-se aspectos financeiros e organizacionais. \\
\hline & & & & $3-3$ & $\begin{array}{l}\text { Mensuradas usando-se ferramentas manuais a partir de aspectos de } \\
\text { recursos / infraestrutura. }\end{array}$ \\
\hline & & & & $4-4$ & $\begin{array}{l}\text { Diretamente e automaticamente associada com cada nível hierárquico } \\
\text { da organização e suportado pro sistemas informatizados. }\end{array}$ \\
\hline & & & & $5-5$ & $\begin{array}{l}\text { Diretamente e automaticamente associada com todos os níveis que são } \\
\text { suportados pela TI (provindas de métricas de serviço organizacionais e } \\
\text { da TI). }\end{array}$ \\
\hline
\end{tabular}

Continua 


\begin{tabular}{|c|c|c|c|c|c|}
\hline Domínio & Controle & Interpretação do controle & Dispensável & $\begin{array}{c}\text { Peso/ } \\
\text { ponto } \\
\text { Min - max }\end{array}$ & Itens de avaliação (questões)/ \\
\hline \multirow{7}{*}{$\begin{array}{l}\text { Negócios e } \\
\text { Objetivos } \\
\text { Estratégicos } \\
\text { D-01 }\end{array}$} & $\begin{array}{l}\text { Etapas de Adoção } \\
\text { de SOA }\end{array}$ & $\begin{array}{l}\text { Qual a visão da } \\
\text { Governança Corporativa do } \\
\text { estágio de adoção de SOA }\end{array}$ & $\mathbf{N}$ & 1 & \\
\hline & & & & & Em que etapa de adoção de SOA sua organização se encontra? \\
\hline & & & & $1-1$ & $\begin{array}{l}\text { SOA não é buscada ou está em fase experimental, i.e., através do } \\
\text { aprendizado de alguns conceitos de SOA. }\end{array}$ \\
\hline & & & & $3-3$ & $\begin{array}{l}\text { Os conceitos de SOA são aplicados de forma consistente, facilitando o } \\
\text { compartilhamento e a reutilização. }\end{array}$ \\
\hline & & & & $4-4$ & $\begin{array}{l}\text { Processos e procedimentos são gerenciados quantitativamente } \\
\text { associados aos valor definidos junto aos direcionadores de negócio. }\end{array}$ \\
\hline & & & & $5-5$ & $\begin{array}{l}\text { Capaz de suportar iniciativas de negócio de uma forma oportuna e com } \\
\text { custo efetivo dinamicamente (serviços dinamicamente reconfiguráveis) }\end{array}$ \\
\hline & $\begin{array}{l}\text { Tempo para } \\
\text { Entrega de } \\
\text { Soluções e } \\
\text { Satisfação }\end{array}$ & $\begin{array}{l}\text { Qual a satisfação percebida } \\
\text { pela Governança } \\
\text { Corporativa da qualidade e } \\
\text { confiabilidade nas soluções } \\
\text { SOA }\end{array}$ & $\mathbf{N}$ & 1 & \\
\hline
\end{tabular}

Continua 


\begin{tabular}{|c|c|c|c|c|c|}
\hline Domínio & Controle & Interpretação do controle & Dispensável & $\begin{array}{c}\text { Peso/ } \\
\text { ponto } \\
\text { Min - max }\end{array}$ & Itens de avaliação (questões)/ \\
\hline \multirow[t]{12}{*}{$\begin{array}{l}\text { Negócios e } \\
\text { Objetivos } \\
\text { Estratégicos } \\
\text { D-01 }\end{array}$} & & & & & $\begin{array}{l}\text { Qual é a satisfação dos clientes de TI com o tempo de entrega de } \\
\text { suas aplicações atuais? }\end{array}$ \\
\hline & & & & $1-1$ & Clientes de aplicações com alta taxa de insatisfação. \\
\hline & & & & $2-2$ & Clientes de aplicações com satisfação pontual. \\
\hline & & & & $3-4$ & Clientes de aplicações com moderada taxa de satisfação. \\
\hline & & & & $5-5$ & Clientes de aplicações com alta taxa de satisfação. \\
\hline & & & & & $\begin{array}{l}\text { Quão confiáveis são as aplicações críticas de negócio em sua } \\
\text { organização? }\end{array}$ \\
\hline & & & & $1-1$ & Desconhecido. \\
\hline & & & & $1-1$ & Não confiáveis. \\
\hline & & & & $2-2$ & Tem confiabilidade oportuna. \\
\hline & & & & $3-3$ & Confiabilidade satisfatória. \\
\hline & & & & $4-4$ & Confiabilidade satisfatória, controlada e mensurada. \\
\hline & & & & $5-5$ & $\begin{array}{l}\text { Confiabilidade satisfatória, controlada e mensurada e sob ciclo de } \\
\text { melhoria contínua. }\end{array}$ \\
\hline
\end{tabular}

Continua 


\begin{tabular}{|c|c|c|c|c|c|}
\hline Domínio & Controle & Interpretação do controle & Dispensável & $\begin{array}{c}\text { Peso/ } \\
\text { ponto } \\
\text { Min - max } \\
\end{array}$ & Itens de avaliação (questões)/ \\
\hline \multirow[t]{9}{*}{$\begin{array}{l}\text { Organização } \\
\text { e Governança } \\
\text { D-02 }\end{array}$} & $\begin{array}{l}\text { Estratégia para } \\
\text { Adoção de SOA }\end{array}$ & $\begin{array}{l}\text { Verifica se existe uma } \\
\text { estratégia de adoção de } \\
\text { SOA pela organização e } \\
\text { essa é alinhada com as } \\
\text { melhores práticas de SOA. }\end{array}$ & $\mathbf{N}$ & 1 & \\
\hline & & & & & $\begin{array}{l}\text { Como sua organização trata a Arquitetura Orientada a Serviços e } \\
\text { seus elementos? }\end{array}$ \\
\hline & & & & $1-1$ & O valor de SOA não é reconhecido. \\
\hline & & & & $2-2$ & $\begin{array}{l}\text { O valor de SOA tem sido reconhecido, mas não é de forma holística } \\
\text { adotada pela empresa. }\end{array}$ \\
\hline & & & & $2-2$ & $\begin{array}{l}\text { SOA como serviços está em evolução e são governados, em uma ou } \\
\text { mais linhas de negócio. }\end{array}$ \\
\hline & & & & $3-3$ & $\begin{array}{l}\text { O uso de serviços SOA e seu compartilhamento são um elemento aceito } \\
\text { por parte da estratégia da organização e dos modelos de TI. }\end{array}$ \\
\hline & & & & $3-3$ & $\begin{array}{l}\text { O uso de serviços SOA e seu compartilhamento são um elemento aceito } \\
\text { em toda estratégia da organização e em todos os modelos de TI }\end{array}$ \\
\hline & & & & $4-4$ & A organização trata serviços SOA como ativos organizacionais. \\
\hline & & & & $5-5$ & $\begin{array}{l}\text { Os serviços SOA são modelados, avaliados e gerenciados como elementos da } \\
\text { estratégia de negócios, e assim, estão sempre em evolução. }\end{array}$ \\
\hline
\end{tabular}

Continua 


\begin{tabular}{|c|c|c|c|c|c|}
\hline Domínio & Controle & Interpretação do controle & Dispensável & $\begin{array}{c}\text { Peso/ } \\
\text { ponto } \\
\text { Min - max }\end{array}$ & Itens de avaliação (questões)/ \\
\hline \multirow[t]{5}{*}{$\begin{array}{l}\text { Organização } \\
\text { e Governança } \\
\text { D-02 }\end{array}$} & & & & & Em que estágio de adoção de SOA sua organização se encontra? \\
\hline & & & & $1-1$ & $\begin{array}{l}\text { Não existe uma visão ou estratégia para a adoção de SOA. Não há } \\
\text { reconhecimento da governança de serviços e não existe governança } \\
\text { associada aos processos de negócio. }\end{array}$ \\
\hline & & & & $2-3$ & $\begin{array}{l}\text { Existe algum envolvimento estratégico de SOA formalmente, com } \\
\text { alguma coordenação através da organização. }\end{array}$ \\
\hline & & & & $4-4$ & $\begin{array}{l}\text { Uma estratégia e visão de SOA foi definida formalmente em toda } \\
\text { organização, esta se encontra publicada e atravessa todas as unidades da } \\
\text { organização. }\end{array}$ \\
\hline & & & & $5-5$ & $\begin{array}{l}\text { O uso de SOA e de serviços compartilhados são utilizados em toda a } \\
\text { empresa. }\end{array}$ \\
\hline
\end{tabular}

Continua 


\begin{tabular}{|c|c|c|c|c|c|}
\hline Domínio & Controle & Interpretação do controle & Dispensável & $\begin{array}{l}\text { Peso/ } \\
\text { ponto } \\
\text { Min - max }\end{array}$ & Itens de avaliação (questões)/ \\
\hline & $\begin{array}{l}\text { Etapas de Adoção } \\
\text { de SOA }\end{array}$ & $\begin{array}{l}\text { Verifica qual nível a } \\
\text { arquitetura da organização } \\
\text { se encontra é aderente aos } \\
\text { princípios de uso de SOA } \\
\text { (oito princípios de SOA). }\end{array}$ & $\mathbf{N}$ & 1 & \\
\hline & & & & & Em que fase de arquitetura SOA você se encontra? \\
\hline & & & & $1-1$ & Baseada em componentes de software. \\
\hline & & & & $2-2$ & Arquitetura SOA emergente. \\
\hline & & & & $3-3$ & Suporte de processos de negócio. \\
\hline & & & & $4-5$ & Arquitetura corporativa de serviços. \\
\hline & $\begin{array}{l}\text { Governança e } \\
\text { Autoridades }\end{array}$ & $\begin{array}{l}\text { As governanças da } \\
\text { organização e de TI estão } \\
\text { estabelecidas (papéis e } \\
\text { perfis) e se estão bem } \\
\text { alinhadas }\end{array}$ & $\mathbf{N}$ & 2 & \\
\hline & & & & & $\begin{array}{l}\text { Como a governança de TI se relaciona ou está alinhada com sua } \\
\text { governança SOA? }\end{array}$ \\
\hline & & & & $1-1$ & $\begin{array}{l}\text { Não existe Governança SOA formalizada junto a estrutura } \\
\text { organizacional. }\end{array}$ \\
\hline & & & & $2-2$ & $\begin{array}{l}\text { A governança SOA é controlada pela governança de TI e está alinhada } \\
\text { com a arquitetura e governança organizacional. }\end{array}$ \\
\hline & & & & $3-4$ & $\begin{array}{l}\text { A governança de TI é estabelecida pela governança organizacional, } \\
\text { organizada pela arquitetura organizacional e dirigida pela governança } \\
\text { SOA. }\end{array}$ \\
\hline & & & & $3-4$ & $\begin{array}{l}\text { A governança de TI e de SOA são administradas pela governança } \\
\text { organizacional dentro da cadeia de comando da estrutura } \\
\text { organizacional. }\end{array}$ \\
\hline & & & & $5-5$ & $\begin{array}{l}\text { A governança de TI e de SOA são administradas pela governança } \\
\text { organizacional dentro da cadeia de comando da estrutura } \\
\text { organizacional, e suas métricas estão alinhadas (são usadas) junto aos } \\
\text { indicadores estratégicos estabelecidos pela organização. }\end{array}$ \\
\hline
\end{tabular}

Continua 


\begin{tabular}{|c|c|c|c|c|c|}
\hline Domínio & Controle & Interpretação do controle & Dispensável & $\begin{array}{c}\text { Peso/ } \\
\text { ponto } \\
\text { Min - max }\end{array}$ & Itens de avaliação (questões)/ \\
\hline & $\begin{array}{l}\text { Fronteiras } \\
\text { Organizacionais }\end{array}$ & $\begin{array}{l}\text { As soluções implementadas } \\
\text { / propostas pela } \\
\text { organização atravessam o } \\
\text { limite do seu negócio, } \\
\text { abrangendo parceiros, por } \\
\text { exemplo. }\end{array}$ & $\mathbf{S}$ & 1 & \\
\hline & & & & & Suas soluções SOA atravessam as fronteiras organizacionais? \\
\hline & & & & $1-1$ & $\begin{array}{l}\text { Não existem soluções SOA que cruzem as fronteiras organizacionais de } \\
\text { forma significativa. }\end{array}$ \\
\hline & & & & $2-2$ & $\begin{array}{l}\text { Existem uma poucas soluções SOA que atravessam as fronteiras } \\
\text { organizacionais. }\end{array}$ \\
\hline & & & & $3-3$ & Sim, existem porém com um número limitados de parceiros. \\
\hline & & & & $4-4$ & Sim, existem com um número significativos de parceiros. \\
\hline & & & & $5-5$ & $\begin{array}{l}\text { Sim, existem com um número significativos de parceiros e com a } \\
\text { utilização de serviços dinamicamente reconfiguráveis. }\end{array}$ \\
\hline
\end{tabular}

Continua 


\begin{tabular}{|c|c|c|c|c|c|}
\hline Domínio & Controle & Interpretação do controle & Dispensável & $\begin{array}{c}\text { Peso/ } \\
\text { ponto } \\
\text { Min - max }\end{array}$ & Itens de avaliação (questões)/ \\
\hline & $\begin{array}{l}\text { Processos e } \\
\text { Atividades }\end{array}$ & $\begin{array}{l}\text { Existe um gerenciamento } \\
\text { de processos e atividades } \\
\text { da organização, e está } \\
\text { automatizado. }\end{array}$ & $\mathbf{N}$ & 1 & \\
\hline & & & & & Como são seus desenvolvimento de processos e atividades? \\
\hline & & & & $1-1$ & $\begin{array}{l}\text { Processos e atividades são (tipicamente) não documentados, tendendo a } \\
\text { ser conduzidos em um nível incompleto (ad-hoc), e assim não são } \\
\text { controlados e gerenciados reativamente por usuários e eventos. }\end{array}$ \\
\hline & & & & $2-2$ & $\begin{array}{l}\text { Processo e as atividades podem ser repetidos, na maioria das vezes com } \\
\text { resultados consistentes. }\end{array}$ \\
\hline & & & & $3-3$ & $\begin{array}{l}\text { Processos e atividades são definidos, documentados e padronizados com } \\
\text { completa consistência. }\end{array}$ \\
\hline & & & & $4-4$ & $\begin{array}{l}\text { Além da padronização de processos e atividades, métricas são coletadas } \\
\text { e usadas para ajudar a identificar maneiras de ajustar e adaptar o } \\
\text { processo para projetos particulares sem perdas mensuráveis de } \\
\text { qualidade ou desvios das especificações. }\end{array}$ \\
\hline
\end{tabular}

Continua 


\begin{tabular}{|c|c|c|c|c|c|}
\hline Domínio & Controle & Interpretação do controle & Dispensável & $\begin{array}{c}\text { Peso/ } \\
\text { ponto } \\
\text { Min - max }\end{array}$ & Itens de avaliação (questões)/ \\
\hline & Governança SOA & $\begin{array}{l}\text { A governança SOA se } \\
\text { encontra documentada, } \\
\text { formalizada, gerenciada e } \\
\text { implementada. }\end{array}$ & $\mathbf{N}$ & 2 & \\
\hline & & & & & $\begin{array}{l}\text { Existe algum processo de governança SOA, eles são documentados, } \\
\text { e, se sim, eles são formalizados? }\end{array}$ \\
\hline & & & & $1-1$ & Não existe governança SOA de forma significativa. \\
\hline & & & & $2-2$ & $\begin{array}{l}\text { Existe uma governança informal dentro da arquitetura organizacional, e } \\
\text { é vagamente definida, sendo suportada por ferramentas limitadas e por } \\
\text { práticas de governança. }\end{array}$ \\
\hline & & & & $3-3$ & A Governança SOA existe e é totalmente documentada e formalizada. \\
\hline & & & & $4-4$ & $\begin{array}{l}\text { A Governança SOA existe e é totalmente documentada e formalizada e } \\
\text { estabelece e implementa a qualidade de seus serviços através de } \\
\text { mensurações baseadas em métodos e regras. }\end{array}$ \\
\hline & & & & $5-5$ & $\begin{array}{l}\text { Métodos formais de SOA e práticas são empregadas em toda a } \\
\text { organização apoiada por um processo formal de governança. } \\
\text { Adicionalmente, a Governança SOA é revisitada antes de todo ciclo de } \\
\text { processo de forma contínua. }\end{array}$ \\
\hline & & & & & $\begin{array}{l}\text { Quais são as funcionalidades e responsabilidades da Governança } \\
\text { SOA? }\end{array}$ \\
\hline & & & & $1-1$ & Não existe funcionalidade e responsabilidade na Governança SOA. \\
\hline & & & & $2-2$ & $\begin{array}{l}\text { As funcionalidades e responsabilidades da Governança SOA estão em } \\
\text { fase de definição. }\end{array}$ \\
\hline & & & & $3-3$ & $\begin{array}{l}\text { As funcionalidades e responsabilidades de Governança SOA são } \\
\text { definidas e documentadas. }\end{array}$ \\
\hline & & & & $4-4$ & A Governança SOA se encontra completamente formalizada. \\
\hline & & & & $5-5$ & $\begin{array}{l}\text { A Governança SOA se encontra completamente formalizada e sofre } \\
\text { adaptações contínuas através de ciclos de melhoria de seus processos } \\
\text { (em geral associado à um replanejamento da estratégia organizacional } \\
\text { ou de requisitos adicionais de conformidade dessa). }\end{array}$ \\
\hline
\end{tabular}

Continua 


\begin{tabular}{|c|c|c|c|c|c|}
\hline Domínio & Controle & Interpretação do controle & Dispensável & $\begin{array}{c}\text { Peso/ } \\
\text { ponto } \\
\text { Min - max }\end{array}$ & Itens de avaliação (questões)/ \\
\hline & & & & & Como a governança SOA está implementada? \\
\hline & & & & $1-1$ & $\begin{array}{l}\text { Não existe coordenação dos serviços SOA através da organização (e ou } \\
\text { de suas linhas de negócio - LOBs). }\end{array}$ \\
\hline & & & & $2-2$ & $\begin{array}{l}\text { O valor do serviço e da governança SOA foram reconhecidos, mas não } \\
\text { foram holisticamente adotados pela organização. }\end{array}$ \\
\hline & & & & $2-2$ & $\begin{array}{l}\text { A governança SOA foi estabelecida, mas não é adotada holisticamente } \\
\text { pela organização. }\end{array}$ \\
\hline & & & & $3-3$ & $\begin{array}{l}\text { Existe governança formal SOA, aonde processos e estruturas são } \\
\text { documentada, e esta está funcionando na maior parte das linhas de } \\
\text { negócio (LOBs). }\end{array}$ \\
\hline & & & & $4-4$ & $\begin{array}{l}\text { A governança SOA foi adotada através da organização pela maior parte } \\
\text { da mesma e tem poderes para gerenciar os serviços e soluções SOA. }\end{array}$ \\
\hline & & & & $4-4$ & A governança SOA é parte da cultura organizacional. \\
\hline & & & & $4-4$ & $\begin{array}{l}\text { A partir da implementação formal de SOA, os SLAs de negócio e TI } \\
\text { são alinhados, mensurados e gerados por fluxos de processos em BPM. }\end{array}$ \\
\hline & & & & $5-5$ & $\begin{array}{l}\text { A partir da implementação formal de SOA, os SLAs de negócio e TI } \\
\text { são alinhados, mensurados e gerados por fluxos de processos em BPM, } \\
\text { e são utilizados para gerar novos planos estratégicos empresariais em } \\
\text { um ciclo de melhoria contínua }\end{array}$ \\
\hline & $\begin{array}{c}\text { Estrutura } \\
\text { Organizacional }\end{array}$ & $\begin{array}{l}\text { Quanto de mudança } \\
\text { organizacional } \\
\text { correspondente foi } \\
\text { realizada visando alinhar } \\
\text { essa estrutura com SOA }\end{array}$ & $\mathbf{N}$ & 1 & \\
\hline & & & & & Suas soluções SOA atravessam as fronteiras organizacionais? \\
\hline & & & & $1-1$ & Não. \\
\hline & & & & $2-2$ & Não ou não significativamente. \\
\hline & & & & $3-4$ & Sim, com poucos parceiros. \\
\hline & & & & $5-5$ & Sim, com os parceiros significativos. \\
\hline & & & & $5-5$ & $\begin{array}{l}\text { Sim, com todos os parceiros usando reconfiguração dinâmica de } \\
\text { serviços. }\end{array}$ \\
\hline
\end{tabular}

Continua 


\begin{tabular}{|c|c|c|c|c|c|}
\hline Domínio & Controle & Interpretação do controle & Dispensável & $\begin{array}{c}\text { Peso/ } \\
\text { ponto } \\
\text { Min - max }\end{array}$ & Itens de avaliação (questões)/ \\
\hline & $\begin{array}{l}\text { Avaliação da } \\
\text { Arquitetura SOA }\end{array}$ & $\begin{array}{l}\text { Trata o quanto a sua } \\
\text { organização inclui } \\
\text { avaliação da arquitetura em } \\
\text { sua metodologia de projeto. }\end{array}$ & $\mathbf{N}$ & 1 & \\
\hline & & & & & $\begin{array}{l}\text { A sua organização inclui avaliação da arquitetura em sua } \\
\text { metodologia de projeto? }\end{array}$ \\
\hline & & & & $1-1$ & Não ou não significativamente. \\
\hline & & & & $2-2$ & $\begin{array}{l}\text { Sim, porém sem nenhuma revisão de como os princípios de SOA são } \\
\text { aplicados }\end{array}$ \\
\hline & & & & $3-4$ & $\begin{array}{l}\text { Sim, e os princípios de SOA são aplicados e revistos na completude } \\
\text { durante a avaliação da arquitetura em alguns projetos }\end{array}$ \\
\hline & & & & $5-5$ & $\begin{array}{l}\text { Sim, e os princípios de SOA são aplicados e revistos na completude } \\
\text { durante a avaliação da arquitetura em todos os projetos }\end{array}$ \\
\hline & Políticas & $\begin{array}{l}\text { As políticas (como } \\
\text { práticas) estão alinhadas } \\
\text { com a Governança SOA. }\end{array}$ & $\mathbf{N}$ & 1 & \\
\hline & & & & & $\begin{array}{l}\text { Como as políticas de criação / construção de serviços estão } \\
\text { alinhadas com sua governança? }\end{array}$ \\
\hline & & & & $1-1$ & $\begin{array}{l}\text { As políticas de criação / construção de serviços são definidas à nível de } \\
\text { projeto. }\end{array}$ \\
\hline & & & & $2-2$ & Existe alguma gestão de políticas de serviços formal. \\
\hline & & & & $3-3$ & $\begin{array}{l}\text { Conjunto formal e completo de políticas de serviços com métricas } \\
\text { associadas em vigor. }\end{array}$ \\
\hline & & & & $4-4$ & Alinhada com as métricas da Governança Corporativa e de TI. \\
\hline & & & & $5-5$ & $\begin{array}{l}\text { As políticas são revistas continuamente (retorno nas políticas utilizadas) } \\
\text { a fim de se ajustar a entrega. }\end{array}$ \\
\hline
\end{tabular}

Continua 


\begin{tabular}{|c|c|c|c|c|c|}
\hline Domínio & Controle & Interpretação do controle & Dispensável & $\begin{array}{c}\text { Peso/ } \\
\text { ponto } \\
\text { Min - max }\end{array}$ & Itens de avaliação (questões)/ \\
\hline & $\begin{array}{l}\text { Gerenciamento de } \\
\text { Riscos } \\
\text { Empresariais }\end{array}$ & $\begin{array}{l}\text { Os riscos empresarias são } \\
\text { gerenciados em um modelo } \\
\text { de ERM }\end{array}$ & $\mathbf{S}$ & 1 & \\
\hline & & & & & $\begin{array}{l}\text { Existem atividades de Gerenciamento de Risco Organizacional } \\
\text { (ERM)? }\end{array}$ \\
\hline & & & & $1-1$ & Sem ERM. \\
\hline & & & & $2-3$ & ERM são realizados de forma incompleta (ad-hoc) e pontualmente. \\
\hline & & & & $4-4$ & ERM são utilizados em um modelo que atende a toda organização. \\
\hline & & & & $4-4$ & ERM são integrados com a arquitetura organizacional. \\
\hline & & & & $5-5$ & $\begin{array}{l}\text { ERM são integrados com a arquitetura organizacional e se encontra } \\
\text { fortemente vinculado à utilização de SOA. }\end{array}$ \\
\hline & Habilidades & $\begin{array}{l}\text { Existe um controle no nível } \\
\text { de capacidade do recurso } \\
\text { dos funcionários da } \\
\text { organização, e se esse } \\
\text { controle permite o } \\
\text { gerenciamento de suas } \\
\text { responsabilidades e } \\
\text { atribuições nos papéis / } \\
\text { perfis que lhes são } \\
\text { definidos. }\end{array}$ & $\mathbf{N}$ & 1 & \\
\hline & & & & & Que tipo de habilidades SOA são comuns em sua equipe de TI? \\
\hline & & & & $1-1$ & Equipe sem conhecimento em SOA. \\
\hline & & & & $2-2$ & $\begin{array}{l}\text { Conhecimentos em SOA estão presentes mas de forma limitada à alguns } \\
\text { membros de TI. }\end{array}$ \\
\hline & & & & $3-4$ & $\begin{array}{l}\text { Treinamentos de habilidades SOA em formação com os perfis } \\
\text { necessários. }\end{array}$ \\
\hline & & & & $5-5$ & $\begin{array}{l}\text { Conhecimentos em SOA existem seguindo padrões de conformidade } \\
\text { existentes. }\end{array}$ \\
\hline
\end{tabular}

Continua 


\begin{tabular}{|c|c|c|c|c|c|}
\hline Domínio & Controle & Interpretação do controle & Dispensável & $\begin{array}{c}\text { Peso/ } \\
\text { ponto } \\
\text { Min - max }\end{array}$ & Itens de avaliação (questões)/ \\
\hline & & & & & $\begin{array}{l}\text { Qual afirmação melhor descreve as avaliações de habilidades e } \\
\text { planos de capacitação? }\end{array}$ \\
\hline & & & & $1-1$ & $\begin{array}{l}\text { Há uma necessidade de se realizar uma avaliação formal de } \\
\text { conhecimentos e habilidades SOA. }\end{array}$ \\
\hline & & & & $2-2$ & $\begin{array}{l}\text { Temos um programa de treinamento para os conceitos de SOA e } \\
\text { tecnologias com base nas lacunas identificadas de avaliações de } \\
\text { habilidades. }\end{array}$ \\
\hline & & & & $3-3$ & $\begin{array}{l}\text { Em processo de definição de uma linha padrão de habilidades SOA } \\
\text { necessárias para todas as funções afetadas. }\end{array}$ \\
\hline & & & & $4-4$ & $\begin{array}{l}\text { Participação ativa da gestão para garantir as habilidades SOA } \\
\text { necessárias estão em curso em toda a organização. }\end{array}$ \\
\hline & & & & $5-5$ & $\begin{array}{l}\text { Estão em curso avaliações de habilidades e formação adequada } \\
\text { disponível para todos os funcionários. }\end{array}$ \\
\hline & $\begin{array}{l}\text { Capacitação em } \\
\text { SOA }\end{array}$ & $\begin{array}{l}\text { A organização se atenta à } \\
\text { capacitação de SOA para as } \\
\text { suas demandas. }\end{array}$ & $\mathbf{S}$ & 2 & \\
\hline & & & & & $\begin{array}{l}\text { Que tipos de treinamento SOA estão disponíveis em sua } \\
\text { organização? }\end{array}$ \\
\hline & & & & $1-1$ & A organização não possui treinamento em SOA. \\
\hline & & & & $2-2$ & A organização possui poucos treinamento em SOA. \\
\hline & & & & $3-4$ & $\begin{array}{l}\text { O treinamento em SOA está presente em todos setores da TI envolvidos } \\
\text { com o assunto. }\end{array}$ \\
\hline & & & & $5-5$ & $\begin{array}{l}\text { Treinamentos em SOA foram aplicados tanto nas áreas de negócio } \\
\text { quanto nas áreas de TI. }\end{array}$ \\
\hline & Monitoramento & $\begin{array}{l}\text { Existe e atende o } \\
\text { monitoramento visando o } \\
\text { suporte a decisões do } \\
\text { negócio da organização } \\
\text { com o auxílio de métricas. }\end{array}$ & $\mathbf{N}$ & 1 & \\
\hline
\end{tabular}




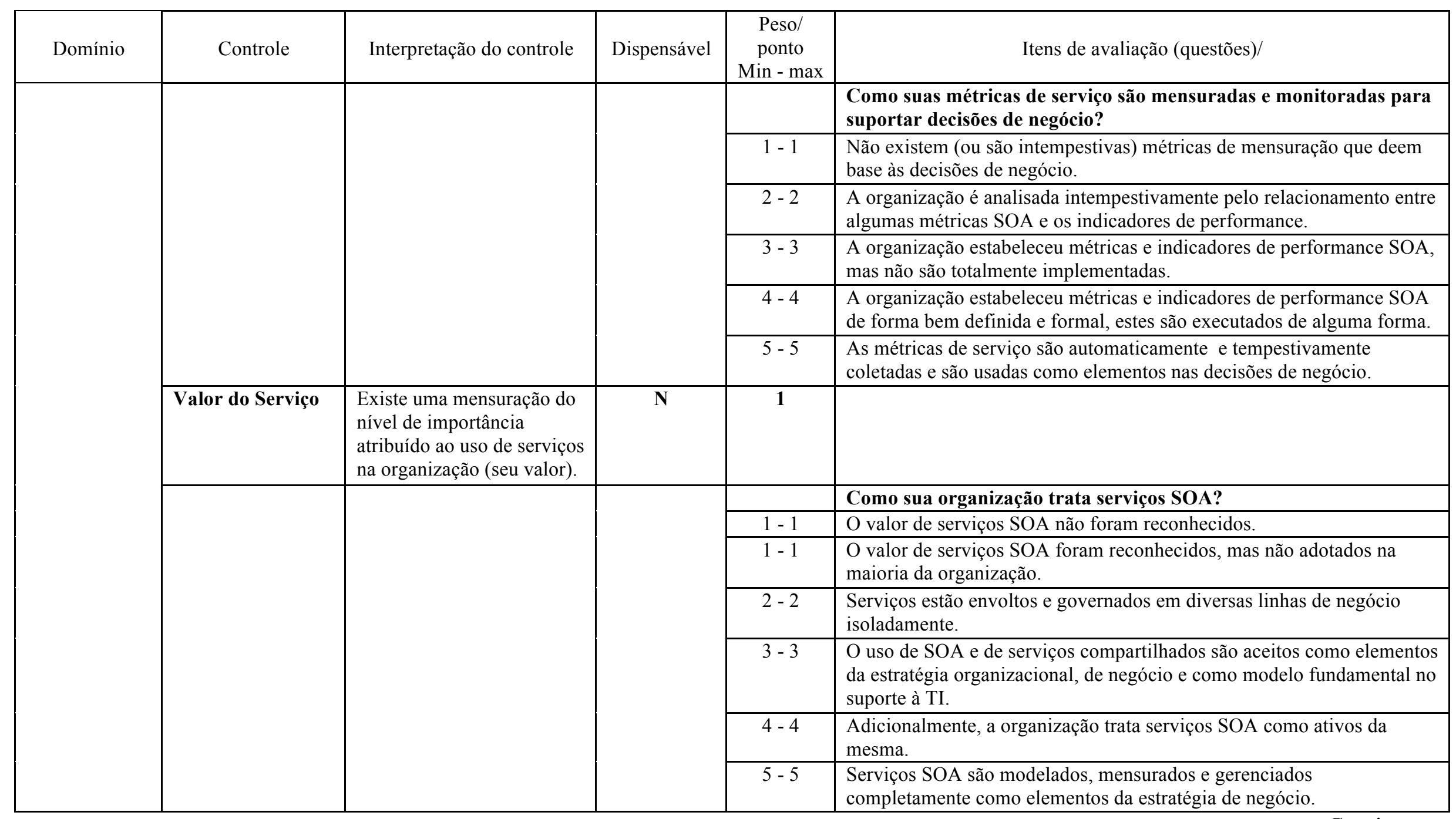




\begin{tabular}{|c|c|c|c|c|c|}
\hline Domínio & Controle & Interpretação do controle & Dispensável & $\begin{array}{c}\text { Peso/ } \\
\text { ponto } \\
\text { Min - max }\end{array}$ & Itens de avaliação (questões)/ \\
\hline \multirow[t]{13}{*}{$\begin{array}{l}\text { Métodos e } \\
\text { Práticas } \\
\text { D-03 }\end{array}$} & $\begin{array}{l}\text { Metodologia e } \\
\text { Métodos }\end{array}$ & $\begin{array}{l}\text { Metodologia e métodos } \\
\text { existem e são compatíveis } \\
\text { com as melhores práticas } \\
\text { de SOA. }\end{array}$ & $\mathbf{N}$ & 1 & \\
\hline & & & & & Como os métodos são desenvolvidos em sua metodologia? \\
\hline & & & & $1-1$ & Baixa adaptação às metodologias de software correntes. \\
\hline & & & & $2-2$ & Os níveis de projeto de serviços mínimos estão definidos. \\
\hline & & & & $3-3$ & $\begin{array}{l}\text { Níveis de projeto estão claramente definidos, até mesmo de serviços de } \\
\text { negócio. }\end{array}$ \\
\hline & & & & $4-4$ & $\begin{array}{l}\text { Existe a definição de serviços colaborativos e cooperativos além dos } \\
\text { limites organizacionais. }\end{array}$ \\
\hline & & & & $5-5$ & $\begin{array}{l}\text { A metodologia estabelece (e é executada corretamente) a medição e } \\
\text { avaliação de fatores para otimização do valor de serviço. }\end{array}$ \\
\hline & $\begin{array}{l}\text { Metodologia de } \\
\text { Implementação }\end{array}$ & $\begin{array}{l}\text { A metodologia de } \\
\text { implementação de SOA } \\
\text { está estabelecida e } \\
\text { gerenciada. }\end{array}$ & $\mathbf{N}$ & 2 & \\
\hline & & & & & Como sua metodologia é estabelecida? \\
\hline & & & & $1-1$ & Não existe uso formal de projeto ou metodologia SOA. \\
\hline & & & & $2-3$ & $\begin{array}{l}\text { A metodologia é largamente focada na implementação da infraestrutura } \\
\text { de TI e integração de serviços. }\end{array}$ \\
\hline & & & & $4-4$ & $\begin{array}{l}\text { Uma metodologia formalizada e reconhecida para criação, } \\
\text { desenvolvimento e implementação, e é amplamente (quase na } \\
\text { totalidade) aplicada na prática. }\end{array}$ \\
\hline & & & & $5-5$ & $\begin{array}{l}\text { Uma metodologia formalizada e reconhecida para criação, } \\
\text { desenvolvimento e implementação, e é revista em ciclos contínuos } \\
\text { derivados de melhorias nos habilitadores de TI ou revisões apontadas } \\
\text { pelos direcionadores de negócios. }\end{array}$ \\
\hline
\end{tabular}

Continua 


\begin{tabular}{|c|c|c|c|c|c|}
\hline Domínio & Controle & Interpretação do controle & Dispensável & $\begin{array}{c}\text { Peso/ } \\
\text { ponto } \\
\text { Min - max }\end{array}$ & Itens de avaliação (questões)/ \\
\hline & Melhores Práticas & $\begin{array}{l}\text { Há algum comitê ou órgão } \\
\text { que coordena e } \\
\text { regulamenta o uso de } \\
\text { melhores práticas, } \\
\text { principalmente com foco na } \\
\text { reutilização de ativos, e se } \\
\text { sim, essa avalia a forma } \\
\text { com que os serviços são } \\
\text { gerenciados no que se } \\
\text { refere à preocupação com } \\
\text { virtualização de serviços e } \\
\text { com o uso ostensivo de } \\
\text { BPM. }\end{array}$ & $\mathbf{N}$ & 1 & \\
\hline & & & & & $\begin{array}{l}\text { Você possui algum tipo de equipe que tem como objetivo } \\
\text { desenvolver métodos e práticas SOA? }\end{array}$ \\
\hline & & & & $1-1$ & Não existe tal tipo de equipe. \\
\hline & & & & $2-3$ & $\begin{array}{l}\text { Existe uma equipe reconhecida para treinar e atualizar os métodos e } \\
\text { práticas de SOA em TI. }\end{array}$ \\
\hline & & & & $4-5$ & $\begin{array}{l}\text { Existe uma equipe reconhecida que tem o poder de gerenciar, treinar e } \\
\text { atualizar os métodos e práticas SOA na organização, sendo ela proativa } \\
\text { na percepção de avanços tecnológicos com atualização nos } \\
\text { treinamentos. }\end{array}$ \\
\hline & & & & & Sua organização estabelece repositórios para melhores práticas? \\
\hline & & & & $1-1$ & Não existe base de conhecimento de melhores práticas. \\
\hline & & & & $2-2$ & $\begin{array}{l}\text { Existe base de conhecimento de melhores práticas de forma pontual } \\
\text { dentro da organização. }\end{array}$ \\
\hline & & & & $3-4$ & $\begin{array}{l}\text { Repositórios de melhores práticas estáticos alimentado manualmente e } \\
\text { intempestivamente. }\end{array}$ \\
\hline & & & & $5-5$ & $\begin{array}{l}\text { Repositórios de melhores práticas dinamicamente alimentados por } \\
\text { outros processos sistêmicos. }\end{array}$ \\
\hline
\end{tabular}

Continua 


\begin{tabular}{|c|c|c|c|c|c|}
\hline Domínio & Controle & Interpretação do controle & Dispensável & $\begin{array}{c}\text { Peso/ } \\
\text { ponto } \\
\text { Min - } \max \\
\end{array}$ & Itens de avaliação (questões)/ \\
\hline & & & & & $\begin{array}{l}\text { Qual a prática corrente para o desenvolvimento e gerenciamento de } \\
\text { serviços? }\end{array}$ \\
\hline & & & & $1-1$ & Não existe prática formalizada. \\
\hline & & & & $2-3$ & Infraestrutura de TI e integração de serviços formalizados. \\
\hline & & & & $4-4$ & $\begin{array}{l}\text { Melhores práticas de orientação foram desenvolvidas para facilitar a } \\
\text { consistência da adoção de SOA, como por exemplo, o uso de ESB e } \\
\text { inventários com fácil descoberta e interpretação. A virtualização é o } \\
\text { elemento chave das operações de serviços de TI e é utilizada para } \\
\text { facilitar serviços. }\end{array}$ \\
\hline & & & & $5-5$ & $\begin{array}{l}\text { Adicionalmente, uma metodologia formal conduz a uma construção } \\
\text { arquitetural e ao suporte a virtualização de ativos e serviços dinâmicos, } \\
\text { bem como modelagem de processos de negócio. }\end{array}$ \\
\hline & $\begin{array}{l}\text { Métodos, } \\
\text { Princípios, } \\
\text { Padrões, } \\
\text { Frameworks e } \\
\text { Técnicas em SOA }\end{array}$ & $\begin{array}{l}\text { Verifica a aderência aos } \\
\text { princípios de projeto de } \\
\text { SOA (SOA como } \\
\text { paradigma de projeto) }\end{array}$ & $\mathbf{N}$ & 2 & \\
\hline & & & & & SOA é parte do ciclo de vida de desenvolvimento de software? \\
\hline & & & & $1-1$ & Em estudo ou não é meta da organização \\
\hline & & & & $2-3$ & As vezes, ou em uma parcela insignificante de projetos. \\
\hline & & & & $4-5$ & Em uma parcela significativa de projetos. \\
\hline & & & & & $\begin{array}{l}\text { Quão extensivo e sofisticado é a utilização em sua organização de } \\
\text { frameworks em sua arquitetura? }\end{array}$ \\
\hline & & & & $1-1$ & Sem frameworks. \\
\hline & & & & $2-2$ & Alguns frameworks são usados dentro de vários grupos na organização. \\
\hline & & & & $3-4$ & Frameworks unificadas são usados em toda a organização. \\
\hline & & & & $5-5$ & SOA é totalmente governada com o apoio de frameworks. \\
\hline
\end{tabular}

Continua 


\begin{tabular}{|c|c|c|c|c|c|}
\hline Domínio & Controle & Interpretação do controle & Dispensável & $\begin{array}{c}\text { Peso/ } \\
\text { ponto } \\
\text { Min - max }\end{array}$ & Itens de avaliação (questões)/ \\
\hline & & & & & $\begin{array}{l}\text { Quão extensiva é a utilização de métodos, princípios, padrões, } \\
\text { frameworks e técnicas SOA? }\end{array}$ \\
\hline & & & & $1-1$ & Nenhum uso é evidente. \\
\hline & & & & $2-2$ & Uso limitado de métodos formais de SOA e práticas básicas. \\
\hline & & & & $3-3$ & $\begin{array}{l}\text { Métodos e práticas formais de SOA são empregadas por vários grupos } \\
\text { dentro da organização. }\end{array}$ \\
\hline & & & & $4-4$ & $\begin{array}{l}\text { Aplicações e serviços são projetados pelo uso formal e regulado de } \\
\text { princípios e padrões SOA. }\end{array}$ \\
\hline & & & & $4-4$ & $\begin{array}{l}\text { Frameworks e práticas organizacionais são suportadas pelo uso formal } \\
\text { de métodos e arquiteturas de referência SOA pela da organização. }\end{array}$ \\
\hline & & & & $5-5$ & $\begin{array}{l}\text { Os componentes de serviço são projetados para uso formal de métodos, } \\
\text { práticas e frameworks para promover a reutilização de ativos. }\end{array}$ \\
\hline & $\begin{array}{l}\text { Gerenciamento de } \\
\text { Projetos }\end{array}$ & $\begin{array}{l}\text { Utiliza-se algum } \\
\text { framework para gerência de } \\
\text { projetos, e se sim, esse é } \\
\text { consolidado e sua } \\
\text { documentação é atualizada } \\
\text { quando necessário. }\end{array}$ & $\mathbf{N}$ & 1 & \\
\hline & & & & & Como está o seu framework de Gerenciamento de Projetos? \\
\hline & & & & $1-1$ & Sem frameworks. \\
\hline & & & & $2-2$ & O framework está definido mas não é significativamente utilizado. \\
\hline & & & & $3-3$ & $\begin{array}{l}\text { Framework significativamente utilizado mas é gerido } \\
\text { descentralizadamente. }\end{array}$ \\
\hline & & & & $4-4$ & Framework formalmente utilizado e é gerido centralizadamente \\
\hline & & & & $5-5$ & $\begin{array}{l}\text { Framework centralizado que é revisitado antes de cada ciclo de } \\
\text { melhoria contínua na organização. }\end{array}$ \\
\hline
\end{tabular}

Continua 


\begin{tabular}{|c|c|c|c|c|c|}
\hline Domínio & Controle & Interpretação do controle & Dispensável & $\begin{array}{c}\text { Peso/ } \\
\text { ponto } \\
\text { Min - max }\end{array}$ & Itens de avaliação (questões)/ \\
\hline & $\begin{array}{l}\text { Gerenciamento de } \\
\text { Riscos nos Projeto }\end{array}$ & $\begin{array}{l}\text { Identifica se a organização } \\
\text { trata o gerenciamento de } \\
\text { riscos em cada um de seus } \\
\text { projetos e se existe uma } \\
\text { integração com o } \\
\text { gerenciamento empresarial } \\
\text { de riscos. }\end{array}$ & $\mathbf{N}$ & 1 & \\
\hline & & & & & $\begin{array}{l}\text { Existe algum gerenciador de riscos dentro das atividades de } \\
\text { gerenciamento de projetos? }\end{array}$ \\
\hline & & & & $1-1$ & Não existe nenhum gerenciamento de riscos. \\
\hline & & & & $2-2$ & O gerenciamento de risco é realizado por projeto e de forma autônoma. \\
\hline & & & & $3-4$ & Gerenciamento de risco formal e completo. \\
\hline & & & & $5-5$ & $\begin{array}{l}\text { Práticas de gerenciamento de risco integradas com o modelo de ERM } \\
\text { da organização. }\end{array}$ \\
\hline & $\begin{array}{l}\text { Gestão de } \\
\text { Mudança em SOA }\end{array}$ & $\begin{array}{l}\text { Caracteriza o uso } \\
\text { disciplinado de práticas no } \\
\text { gerenciamento de } \\
\text { mudanças envolvendo } \\
\text { elementos da arquitetura } \\
\text { SOA }\end{array}$ & $\mathbf{N}$ & 1 & \\
\hline & & & & & $\begin{array}{l}\text { Existe algum processo de planejamento e gestão controlada de } \\
\text { mudança dentro das atividades de gerenciamento de projetos? }\end{array}$ \\
\hline & & & & $1-1$ & Não existe nenhum planejamento ou gerenciamento de mudanças. \\
\hline & & & & $2-2$ & $\begin{array}{l}\text { O planejamento e/ou o gerenciamento de mudanças é realizado por } \\
\text { projeto e de forma autônoma. }\end{array}$ \\
\hline & & & & $3-4$ & $\begin{array}{l}\text { O planejamento e/ou o gerenciamento de mudanças é formal, } \\
\text { disciplinado e completo. }\end{array}$ \\
\hline & & & & $5-5$ & $\begin{array}{l}\text { Práticas de planejamento e gerenciamento de mudanças estão integradas } \\
\text { com o modelo de ERM da organização. }\end{array}$ \\
\hline
\end{tabular}

Continua 


\begin{tabular}{|c|c|c|c|c|c|}
\hline Domínio & Controle & Interpretação do controle & Dispensável & $\begin{array}{c}\text { Peso/ } \\
\text { ponto } \\
\text { Min - max }\end{array}$ & Itens de avaliação (questões)/ \\
\hline & $\begin{array}{l}\text { Conformidade } \\
\text { Normativa }\end{array}$ & $\begin{array}{l}\text { Observa se a organização } \\
\text { realiza auditorias para } \\
\text { verificar sua conformidade } \\
\text { normativa interna, tal como } \\
\text { a realização de um processo } \\
\text { de ISO-9000. }\end{array}$ & $\mathbf{N}$ & 1 & \\
\hline & & & & & $\begin{array}{l}\text { Existe alguma conformidade normativa no que envolve o uso de } \\
\text { SOA e das suas melhores práticas? }\end{array}$ \\
\hline & & & & $1-1$ & Nenhuma. \\
\hline & & & & $2-2$ & Conformidade normativa pontual sem regulamentações. \\
\hline & & & & $3-4$ & Conformidade normativa de práticas SOA centralizada estabelecida. \\
\hline & & & & $5-5$ & $\begin{array}{l}\text { SOA e as melhores práticas estão em conformidade em toda a } \\
\text { organização e são regulamentadas pela governança SOA. }\end{array}$ \\
\hline & Práticas SOA & $\begin{array}{l}\text { Qual o nível de } \\
\text { implantação de práticas, } \\
\text { princípios e técnicas } \\
\text { relacionados a SOA na } \\
\text { organização } \\
\end{array}$ & $\mathbf{N}$ & 1 & \\
\hline & & & & & Como os métodos e práticas SOA foram implementados? \\
\hline & & & & $1-1$ & $\begin{array}{l}\text { Os funcionários de TI e de negócio possuem pouco entendimento ou } \\
\text { pouco valorizam as implementação de serviços. }\end{array}$ \\
\hline & & & & $2-2$ & $\begin{array}{l}\text { Os métodos e práticas SOA são limitados à times de desenvolvimento } \\
\text { específicos da TI e não foram formalizados com as demais equipes. }\end{array}$ \\
\hline & & & & $3-3$ & $\begin{array}{l}\text { Os métodos e práticas SOA atingem uma parte significativa da } \\
\text { organização e estão adaptados para o tratamento de criação, } \\
\text { implementação e implantação de serviços. }\end{array}$ \\
\hline & & & & $4-4$ & $\begin{array}{l}\text { Métodos e práticas foram implementadas na organização, e toda } \\
\text { organização segue tal abordagem unificada }\end{array}$ \\
\hline & & & & $5-5$ & $\begin{array}{l}\text { Métodos e práticas foram implementadas na organização com uma } \\
\text { abordagem unificada regulamentada pela governança SOA e otimizada } \\
\text { ou adaptada a novas realidades através de processos de melhoria } \\
\text { contínua. }\end{array}$ \\
\hline
\end{tabular}

Continua 


\begin{tabular}{|c|c|c|c|c|c|}
\hline Domínio & Controle & Interpretação do controle & Dispensável & $\begin{array}{c}\text { Peso/ } \\
\text { ponto } \\
\text { Min - max } \\
\end{array}$ & Itens de avaliação (questões)/ \\
\hline & $\begin{array}{l}\text { Práticas de } \\
\text { Desenvolvimento }\end{array}$ & $\begin{array}{l}\text { É aceitável e coerente a } \\
\text { reutilização dos serviços na } \\
\text { organização (atenção ao } \\
\text { princípio de Reusabilidade } \\
\text { de Serviços). }\end{array}$ & $\mathbf{N}$ & 2 & \\
\hline & & & & & Como são suas práticas de desenvolvimento baseadas em SOA? \\
\hline & & & & $1-1$ & $\begin{array}{l}\text { Não existem práticas de desenvolvimento SOA ou as mesmas não são } \\
\text { documentadas. }\end{array}$ \\
\hline & & & & $2-2$ & $\begin{array}{l}\text { Desenvolvimento com Web Services é largamente utilizado, mas não } \\
\text { segue consistentemente as práticas de SOA. }\end{array}$ \\
\hline & & & & $3-3$ & $\begin{array}{l}\text { Práticas de desenvolvimento SOA são aplicadas consistentemente em } \\
\text { toda a organização. }\end{array}$ \\
\hline & & & & $4-4$ & $\begin{array}{l}\text { Práticas de desenvolvimento SOA são governadas e aplicadas em uma } \\
\text { extensão significativa da organização. }\end{array}$ \\
\hline & & & & $5-5$ & $\begin{array}{l}\text { Práticas de desenvolvimento SOA são formalmente aplicadas e } \\
\text { aprimoradas por ações da Governança SOA. }\end{array}$ \\
\hline & & & & & Quão comum é a reutilização em sua organização? \\
\hline & & & & $1-1$ & Não avaliado. \\
\hline & & & & $1-1$ & Baixa ou inexistente. \\
\hline & & & & $2-2$ & $\begin{array}{l}\text { Reusabilidade tática (o esforço de reusabilidade tem foco na imediata } \\
\text { entrega de requisitos funcionais de rápida entrega) }\end{array}$ \\
\hline & & & & $2-2$ & $\begin{array}{l}\text { Reusabilidade direcionada (o esforço de reusabilidade não é focado em } \\
\text { funcionalidades imediatas, mas em funcionalidades que serão utilizadas } \\
\text { em breve). }\end{array}$ \\
\hline & & & & $3-3$ & $\begin{array}{l}\text { Reusabilidade completa e governada (entregando todas as } \\
\text { funcionalidades de serviço). }\end{array}$ \\
\hline & & & & $4-4$ & Reusabilidade completa, governada e mensurada. \\
\hline & & & & $5-5$ & $\begin{array}{l}\text { Reusabilidade completa, governada, mensurada e os inventários são } \\
\text { revistos continuamente em busca de melhorias de desempenho e de } \\
\text { decomposições funcionais de interesse. }\end{array}$ \\
\hline
\end{tabular}

Continua 


\begin{tabular}{|c|c|c|c|c|c|}
\hline Domínio & Controle & Interpretação do controle & Dispensável & $\begin{array}{c}\text { Peso/ } \\
\text { ponto } \\
\text { Min - max }\end{array}$ & Itens de avaliação (questões)/ \\
\hline & Estratégia SOA & $\begin{array}{l}\text { Está sendo mensurado os } \\
\text { benefícios que se espera } \\
\text { com a adoção de SOA dado } \\
\text { o momento atual da } \\
\text { empresa. }\end{array}$ & $\mathbf{N}$ & 1 & \\
\hline & & & & & Quais benefícios são encontrados atualmente com SOA? \\
\hline & & & & $1-1$ & Nenhum benefício aparente. \\
\hline & & & & $2-2$ & Reusabilidade, padronização de dados e de recursos. \\
\hline & & & & $3-4$ & Reformulação de processos de negócio. \\
\hline & & & & $5-5$ & Agilidade e flexibilidade. \\
\hline \multirow[t]{6}{*}{$\begin{array}{l}\text { Aplicações e } \\
\text { Arquitetura } \\
\text { D-04 }\end{array}$} & $\begin{array}{l}\text { Arquitetura de } \\
\text { Aplicação }\end{array}$ & $\begin{array}{l}\text { Qual o grau de } \\
\text { complexidade que a } \\
\text { arquitetura de aplicação } \\
\text { empresarial possui em } \\
\text { relação aos modelos } \\
\text { existentes nas melhores } \\
\text { práticas de SOA. }\end{array}$ & $\mathbf{N}$ & 1 & \\
\hline & & & & & Quão complexa são suas arquiteturas de aplicações? \\
\hline & & & & $1-1$ & $\begin{array}{l}\text { As arquiteturas de aplicações e suas topologias são monolíticas, e ainda } \\
\text { possuem necessidade de integração manuais entre sistemas dentro } \\
\text { organização. }\end{array}$ \\
\hline & & & & $2-2$ & $\begin{array}{l}\text { As arquiteturas de aplicações e topologias são em parte monolíticas } \\
\text { porém com mínima análise da separação de interesses entre as camadas } \\
\text { arquiteturais ou de aplicação. }\end{array}$ \\
\hline & & & & $3-3$ & $\begin{array}{l}\text { A maioria das topologias arquiteturais de aplicação possuem separação } \\
\text { de interesses, tanto fisicamente quanto logicamente, nas camadas de } \\
\text { apresentação, lógica de negócio e camada de dados. }\end{array}$ \\
\hline & & & & $3-3$ & $\begin{array}{l}\text { Os componentes de serviço da arquitetura de aplicação utilizam padrões } \\
\text { SOA, tais como separação de interesses entre as camadas físicas e } \\
\text { lógicas das lógicas de apresentação e negócio. }\end{array}$ \\
\hline
\end{tabular}

Continua 


\begin{tabular}{|c|c|c|c|c|c|}
\hline Domínio & Controle & Interpretação do controle & Dispensável & $\begin{array}{c}\text { Peso/ } \\
\text { ponto } \\
\text { Min - max }\end{array}$ & Itens de avaliação (questões)/ \\
\hline & & & & $3-3$ & $\begin{array}{l}\text { Arquitetura de aplicação são desenhadas utilizando-se a separação de } \\
\text { interesses segundo as camadas arquiteturais convencionais de SOA. }\end{array}$ \\
\hline & & & & $4-4$ & $\begin{array}{l}\text { A arquitetura de aplicação é desacoplada dos componentes de } \\
\text { infraestrutura. }\end{array}$ \\
\hline & & & & $4-4$ & $\begin{array}{l}\text { A arquitetura de aplicação suporta reconfiguração dinâmica dos } \\
\text { serviços de negócio e infraestrutura, e é aplicada usando SOA também } \\
\text { para atender tanto consumidores e parceiros internos como externos. }\end{array}$ \\
\hline & & & & $5-5$ & $\begin{array}{l}\text { A arquitetura de aplicação é desacoplada dos componentes de } \\
\text { infraestrutura e é constantemente aperfeiçoada em ciclos de melhoria } \\
\text { contínua. }\end{array}$ \\
\hline & $\begin{array}{l}\text { Desacoplamento } \\
\text { de Regras de } \\
\text { Negócio }\end{array}$ & $\begin{array}{l}\text { É reduzido o acoplamento } \\
\text { da lógica de negócio com } \\
\text { as funcionalidades } \\
\text { existentes (atenção ao } \\
\text { princípio de Baixo } \\
\text { Acoplamento). }\end{array}$ & $\mathbf{N}$ & 1 & \\
\hline & & & & & $\begin{array}{l}\text { Como é a representação da lógica de negócio em suas aplicações } \\
\text { organizacionais? }\end{array}$ \\
\hline & & & & $1-1$ & Interna à cada código. \\
\hline & & & & $2-3$ & Isolada por código em bibliotecas. \\
\hline & & & & $4-4$ & Por mecanismos de regras. \\
\hline & & & & $5-5$ & $\begin{array}{l}\text { Por mecanismos de regras com reconfiguração dinâmica de modelos } \\
\text { utilizando-se fatores mensurados sistemicamente. }\end{array}$ \\
\hline & Integração & $\begin{array}{l}\text { Existe uma forte integração } \\
\text { entre aplicações, sistemas e } \\
\text { infraestrutura, bem como } \\
\text { no tipo de tecnologias } \\
\text { utilizadas para sua } \\
\text { implementação (SOA). }\end{array}$ & $\mathbf{N}$ & 2 & \\
\hline
\end{tabular}




\begin{tabular}{|c|c|c|c|c|c|}
\hline Domínio & Controle & Interpretação do controle & Dispensável & $\begin{array}{c}\text { Peso/ } \\
\text { ponto } \\
\text { Min - max }\end{array}$ & Itens de avaliação (questões)/ \\
\hline & & & & & Como é a integração de aplicações e sistemas em sua organização? \\
\hline & & & & $1-1$ & $\begin{array}{l}\text { A utilização de Web Service ou de outro modelo tecnológico suportado por } \\
\text { SOA é inexistente ou reduzido em integração de aplicações e sistemas. }\end{array}$ \\
\hline & & & & $1-1$ & $\begin{array}{l}\text { As aplicações utilizam o mínimo de integração entre outros sistemas, e } \\
\text { geralmente a integração é implementada usando-se técnicas de ponto-a- } \\
\text { ponto. }\end{array}$ \\
\hline & & & & $2-2$ & $\begin{array}{l}\text { O uso de SOA habilita tecnologias, como ESB, mas de forma } \\
\text { inconsistente através da organização. }\end{array}$ \\
\hline & & & & $3-3$ & $\begin{array}{l}\text { O uso de SOA habilita tecnologias, como ESB, mas não em todas } \\
\text { extensão da organização. }\end{array}$ \\
\hline & & & & $4-4$ & $\begin{array}{l}\text { Padrões de integração ESB são usados para dar suporte a integração de } \\
\text { aplicações e processos para o alcance de compartilhamento de serviços. }\end{array}$ \\
\hline & & & & $4-4$ & $\begin{array}{l}\text { Uso extensivo de padrões arquiteturais de ESB para dar suporte a } \\
\text { processos de negócios definidos em BPMs. }\end{array}$ \\
\hline & & & & $5-5$ & $\begin{array}{l}\text { Padrões arquiteturas de ESB dão suporte a todos os LOBs, usando-se BPM e } \\
\text { com refatoração automática de serviços de negócio através de seus BPMs. }\end{array}$ \\
\hline & $\begin{array}{l}\text { Integração de } \\
\text { Aplicação }\end{array}$ & $\begin{array}{l}\text { Qual o nível da integração } \\
\text { entre as aplicações } \\
\text { existentes na empresa e } \\
\text { como é realizada. }\end{array}$ & $\mathbf{N}$ & 1 & \\
\hline & & & & & Quão extensivo é a integração de suas aplicações? \\
\hline & & & & $1-1$ & $\begin{array}{l}\text { A integração entre aplicações ou sistemas não é significativa mas é } \\
\text { necessária. }\end{array}$ \\
\hline & & & & $2-2$ & $\begin{array}{l}\text { Métodos e práticas são limitadas à integração entre todas as aplicações } \\
\text { ou sistemas. }\end{array}$ \\
\hline & & & & $3-3$ & $\begin{array}{l}\text { Métodos e práticas são significativamente utilizado para integrar } \\
\text { aplicações ou sistemas. }\end{array}$ \\
\hline & & & & $4-5$ & $\begin{array}{l}\text { Os processos de integração foram substituidos totalmente pelo princípio } \\
\text { da interoperabilidade intrínseca. }\end{array}$ \\
\hline & $\begin{array}{l}\text { Arquiteturas de } \\
\text { Referência }\end{array}$ & $\begin{array}{l}\text { Qual o nível de utilização } \\
\text { da Arquitetura de } \\
\text { Referência (da } \\
\text { organização). }\end{array}$ & $\mathbf{N}$ & 1 & \\
\hline
\end{tabular}

Continua 


\begin{tabular}{|c|c|c|c|c|c|}
\hline Domínio & Controle & Interpretação do controle & Dispensável & $\begin{array}{c}\text { Peso/ } \\
\text { ponto } \\
\text { Min - max } \\
\end{array}$ & Itens de avaliação (questões)/ \\
\hline & & & & & Sua organização utiliza / tem uma arquitetura de referência? \\
\hline & & & & $1-1$ & Não existe arquitetura de referência. \\
\hline & & & & $2-3$ & $\begin{array}{l}\text { Arquitetura de referência utilizado por demanda ou quando considerado } \\
\text { necessário. }\end{array}$ \\
\hline & & & & $4-5$ & Arquitetura de referência é usada em toda a organização. \\
\hline & & & & & Qual é o estado de sua arquitetura de referência SOA? \\
\hline & & & & $1-1$ & Nenhum ou não aplicável \\
\hline & & & & $1-1$ & $\begin{array}{l}\text { Pesquisa e avaliação de arquiteturas SOA de referência do fornecedor e } \\
\text { da indústria. }\end{array}$ \\
\hline & & & & $2-2$ & A arquitetura de referência inicial SOA foi definido. \\
\hline & & & & $3-3$ & $\begin{array}{l}\text { Arquitetura de referência SOA foi revista e está guiando a instalação / } \\
\text { revisão da infraestrutura. }\end{array}$ \\
\hline & & & & $3-3$ & $\begin{array}{l}\text { Os principais elementos da arquitetura de referência SOA estão em } \\
\text { produção. }\end{array}$ \\
\hline & & & & $4-4$ & $\begin{array}{l}\text { Arquitetura SOA completa na produção porém com refinamentos } \\
\text { tempestivos (programados). }\end{array}$ \\
\hline & & & & $5-5$ & $\begin{array}{l}\text { Arquitetura SOA completa na produção com refinamentos sucessivos } \\
\text { segundo o ciclo de melhoria contínua. }\end{array}$ \\
\hline & $\begin{array}{l}\text { Inventário de } \\
\text { Serviço }\end{array}$ & $\begin{array}{l}\text { Verifica a aderência a } \\
\text { inventário de serviços, } \\
\text { unificados ou por } \\
\text { domínios, e sua capacidade } \\
\text { de descoberta e } \\
\text { interpretação. }\end{array}$ & $\mathbf{N}$ & 2 & \\
\hline & & & & & Existe um repositório central ou por domínios para os serviços? \\
\hline & & & & $1-1$ & Não há suporte sistêmico a inventários de serviços. \\
\hline & & & & $2-3$ & $\begin{array}{l}\text { Por domínios porém associados a estrutura funcional da organização } \\
\text { (silo) }\end{array}$ \\
\hline & & & & $4-5$ & $\begin{array}{l}\text { Sim, existe um repositório central, seja ele único ou por domínios de } \\
\text { negócio }\end{array}$ \\
\hline
\end{tabular}

Continua 


\begin{tabular}{|c|c|c|c|c|c|}
\hline \multirow[t]{4}{*}{ Domínio } & \multirow[t]{4}{*}{ Controle } & \multirow[t]{4}{*}{ Interpretação do controle } & \multirow[t]{4}{*}{ Dispensável } & $\begin{array}{c}\text { Peso/ } \\
\text { ponto } \\
\text { Min - } \max \\
\end{array}$ & \multirow[t]{2}{*}{ Itens de avaliação (questões)/ } \\
\hline & & & & & \\
\hline & & & & $1-1$ & Não há suporte sistêmico a inventários de serviços. \\
\hline & & & & $2-2$ & $\begin{array}{l}\text { Há um suporte sistêmico emergente a inventários de serviços, ainda } \\
\text { com problemas de descoberta e interpretação, causando } \\
\text { desnormalização no(s) inventário(s) }\end{array}$ \\
\hline & & & & $3-3$ & $\begin{array}{l}\text { Os inventários são automatizados, mas possuem uma larga serviços com } \\
\text { o mesmo contexto funcional (desnormalização de inventário), o que } \\
\text { favorece que o(s) mesmo(s) seja }(\mathrm{m}) \text { revisados muitas vezes. }\end{array}$ \\
\hline & & & & $4-4$ & $\begin{array}{l}\text { Algumas vezes algumas recomposições e intervenções são necessárias } \\
\text { para revisão de contratos visando possíveis reusos observados } \\
\text { tardiamente. }\end{array}$ \\
\hline & & & & $5-5$ & Nenhuma recomposição ou intervenção é necessária. \\
\hline & & & & & Como você documenta seus contratos de serviços? \\
\hline & & & & $1-1$ & $\begin{array}{l}\text { Descrições textuais em documentos (não disponível para acesso } \\
\text { comum) }\end{array}$ \\
\hline & & & & $2-2$ & Descrições textuais em ambiente de disponibilização por perfis \\
\hline & & & & $3-5$ & $\begin{array}{l}\text { Descrições em XML nos contratos em ambiente de disponibilização por } \\
\text { perfis }\end{array}$ \\
\hline & & & & & Que tipos de metadados você mantém sobre seus serviços? \\
\hline & & & & $1-1$ & Nenhum \\
\hline & & & & $2-3$ & Somente o mínimo especificado para Contratos Técnicos SOA \\
\hline & & & & $2-3$ & Contratos Técnicos e Operacionais (SLA) \\
\hline & & & & $4-4$ & $\begin{array}{l}\text { Uso controlado de outras documentações tais como glossários e de } \\
\text { forma ligada (hiperlinks) }\end{array}$ \\
\hline & & & & $5-5$ & $\begin{array}{l}\text { Uso controlado de outras documentações tais como glossários e de } \\
\text { forma ligada (hiperlinks) com princípios de gestão versionada. }\end{array}$ \\
\hline
\end{tabular}




\begin{tabular}{|c|c|c|c|c|c|}
\hline Domínio & Controle & Interpretação do controle & Dispensável & $\begin{array}{c}\text { Peso/ } \\
\text { ponto } \\
\text { Min - max }\end{array}$ & Itens de avaliação (questões)/ \\
\hline & $\begin{array}{l}\text { Qualidade de } \\
\text { Serviço }\end{array}$ & $\begin{array}{l}\text { Verifica a percepção do } \\
\text { grau de aplicação dos } \\
\text { princípios de padronização, } \\
\text { abstração e autonomia dos } \\
\text { contratos de serviço. }\end{array}$ & $\mathbf{N}$ & 1 & \\
\hline & & & & & $\begin{array}{l}\text { Se for possível mensurar, qual é o grau de aplicação dos princípios } \\
\text { de padronização, abstração e autonomia dos contratos de serviço? }\end{array}$ \\
\hline & & & & $1-1$ & Não existe conhecimento sobre esse assunto. \\
\hline & & & & $2-2$ & Muitas vezes esses princípios não são aplicados. \\
\hline & & & & $3-3$ & $\begin{array}{l}\text { Esses princípios não são aplicados largamente, aonde a sua não- } \\
\text { aplicabilidade se dá por erro de projeto e não por falta de suporte } \\
\text { metodológico }\end{array}$ \\
\hline & & & & $4-4$ & $\begin{array}{l}\text { A aplicação desses princípios se dá em uma extensão significativa mas a } \\
\text { não aplicação não é completamente documentada. }\end{array}$ \\
\hline & & & & $5-5$ & $\begin{array}{l}\text { A aplicação desses princípios se dá em toda a extensão julgada } \\
\text { necessária, e a sua não aplicação e'; completamente documentada. }\end{array}$ \\
\hline
\end{tabular}

Continua 


\begin{tabular}{|c|c|c|c|c|c|}
\hline Domínio & Controle & Interpretação do controle & Dispensável & $\begin{array}{c}\text { Peso/ } \\
\text { ponto } \\
\text { Min - max }\end{array}$ & Itens de avaliação (questões)/ \\
\hline & $\begin{array}{l}\text { Arquitetura de } \\
\text { Segurança }\end{array}$ & $\begin{array}{l}\text { Verifica o grau de } \\
\text { aplicação dos princípios de } \\
\text { segurança junto a } \\
\text { arquitetura / barramento } \\
\text { corporativo } \\
\end{array}$ & $\mathbf{N}$ & 1 & \\
\hline & & & & & Qual é o estado de sua arquitetura de segurança de serviço? \\
\hline & & & & $1-1$ & Nenhum ou não é aplicável \\
\hline & & & & $3-3$ & $\begin{array}{l}\text { Arquitetura de segurança de serviço foi definida e as tecnologias de } \\
\text { segurança foram escolhidas porém não são utilizados de forma } \\
\text { abrangente. }\end{array}$ \\
\hline & & & & $4-4$ & $\begin{array}{l}\text { Arquitetura de segurança de serviço foi definida e as tecnologias de } \\
\text { segurança foram escolhidas dentro de um projeto único de segurança } \\
\text { aplicado de forma significativa. }\end{array}$ \\
\hline & & & & $4-4$ & $\begin{array}{l}\text { Segurança de grão fino na produção, permitindo delegação de segurança } \\
\text { para componentes individuais. }\end{array}$ \\
\hline
\end{tabular}

Continua 


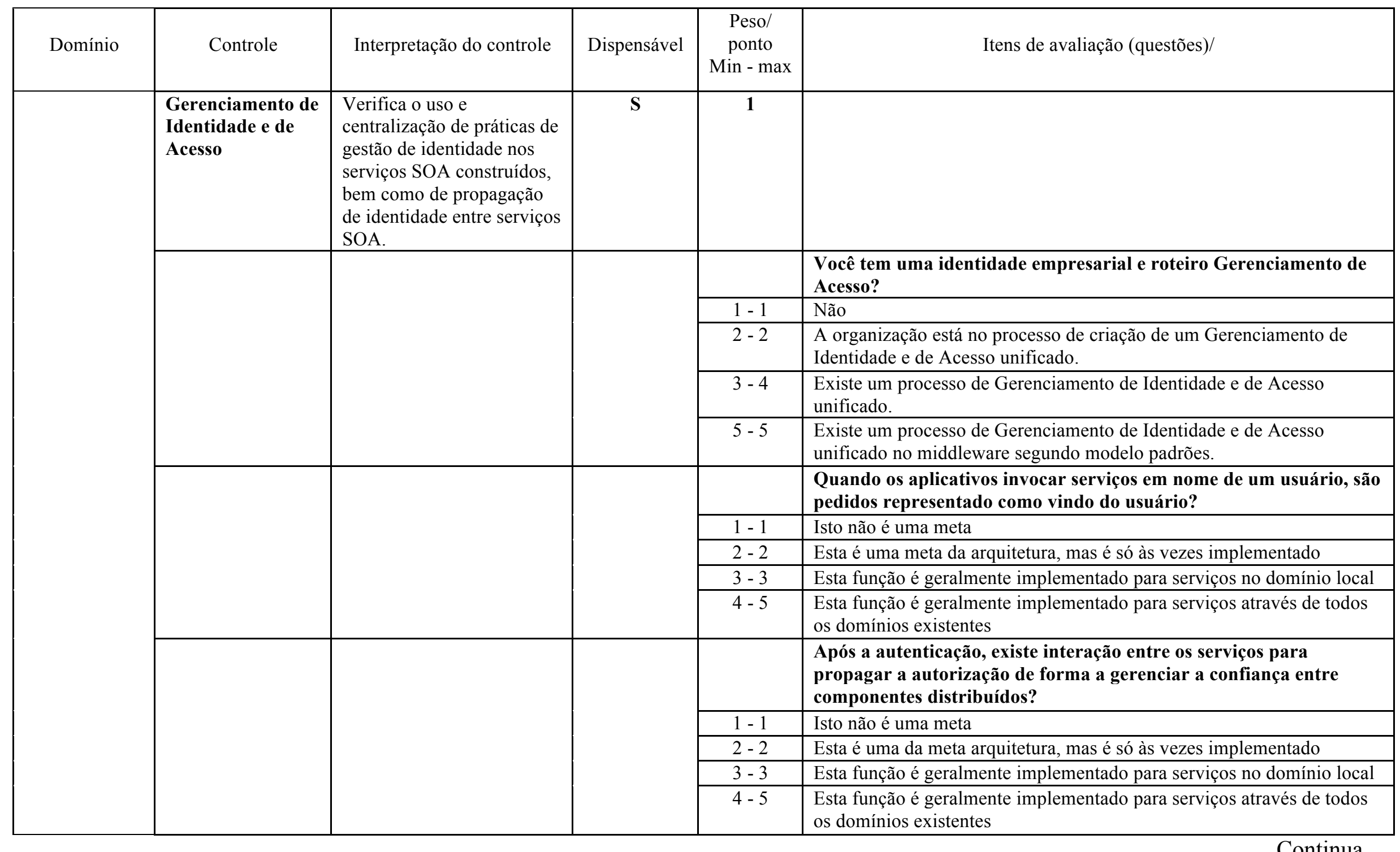

Continua 


\begin{tabular}{|c|c|c|c|c|c|}
\hline Domínio & Controle & Interpretação do controle & Dispensável & $\begin{array}{c}\text { Peso/ } \\
\text { ponto } \\
\text { Min - max }\end{array}$ & Itens de avaliação (questões)/ \\
\hline & $\begin{array}{l}\text { Reusabilidade de } \\
\text { Serviço }\end{array}$ & $\begin{array}{l}\text { Avalia o grau de reuso } \\
\text { observado não organização }\end{array}$ & $\mathbf{N}$ & 2 & \\
\hline & & & & & $\begin{array}{l}\text { Qual a porcentagem de reutilização de serviço (número de serviços } \\
\text { publicados / total de serviços utilizados)? }\end{array}$ \\
\hline & & & & $1-2$ & Não existe reutilização de serviços ou não é medido / mensurável. \\
\hline & & & & $3-3$ & Mais do que $5 \%$. \\
\hline & & & & $4-4$ & Mais do que $15 \%$. \\
\hline & & & & $5-5$ & Mais do que $40 \%$. \\
\hline & $\begin{array}{l}\text { Ausência de } \\
\text { Estado de Serviço }\end{array}$ & $\begin{array}{l}\text { Verifica o grau de } \\
\text { comprometimento dos } \\
\text { projetos de SOA com a } \\
\text { aplicação e princípios de } \\
\text { escalabilidade }\end{array}$ & $\mathbf{N}$ & 1 & \\
\hline & & & & & $\begin{array}{l}\text { Existe alguma prática de implementação que favoreça a ausência de } \\
\text { estados nos serviços? }\end{array}$ \\
\hline & & & & $1-1$ & Nenhuma. \\
\hline & & & & $2-2$ & $\begin{array}{l}\text { Existe uma implementação que é regulamentada pela arquitetura mas é } \\
\text { pouco utilizada. }\end{array}$ \\
\hline & & & & $3-5$ & $\begin{array}{l}\text { Existe uma implementação largamente utilizada que é regulamentada pela } \\
\text { arquitetura organizacional, e em conformidade com a governança SOA. }\end{array}$ \\
\hline \multirow[t]{6}{*}{$\begin{array}{l}\text { Informações e } \\
\text { Modelos de } \\
\text { Dados } \\
\text { D-05 }\end{array}$} & $\begin{array}{l}\text { Governança de } \\
\text { Dados }\end{array}$ & $\begin{array}{l}\text { Verifica o grau de } \\
\text { maturidade no uso de } \\
\text { modelo de dados } \\
\text { organizacionais }\end{array}$ & $\mathbf{N}$ & 1 & \\
\hline & & & & & $\begin{array}{l}\text { Você tem um modelo de dados conceituais, lógicos e físicos da } \\
\text { organização? }\end{array}$ \\
\hline & & & & $1-1$ & Não ou não tenho todos \\
\hline & & & & $2-2$ & $\begin{array}{l}\text { Temos modelo de dados conceituais, lógicos e físicos da organização, } \\
\text { porém com falhas reconhecidas nessas interpretações. }\end{array}$ \\
\hline & & & & $3-4$ & Temos modelo de dados conceituais, lógicos e físicos da organização. \\
\hline & & & & $5-5$ & $\begin{array}{l}\text { Temos modelo de dados conceituais, lógicos e físicos da organização e } \\
\text { que abrange toda organização. }\end{array}$ \\
\hline
\end{tabular}

Continua 


\begin{tabular}{|c|c|c|c|c|c|}
\hline Domínio & Controle & Interpretação do controle & Dispensável & $\begin{array}{c}\text { Peso/ } \\
\text { ponto } \\
\text { Min - max }\end{array}$ & Itens de avaliação (questões)/ \\
\hline & $\begin{array}{l}\text { Modelo de Dados } \\
\text { e Metadados }\end{array}$ & $\begin{array}{l}\text { Existem modelos de dados } \\
\text { consolidados para toda } \\
\text { organização e se sim como } \\
\text { esses modelos auxiliam o } \\
\text { gerenciamento empresarial } \\
\text { (tal como a existência de } \\
\text { 'modelos de dados mestres" } \\
\text { / modelos corporativos). }\end{array}$ & $\mathbf{N}$ & 1 & \\
\hline & & & & & $\begin{array}{l}\text { Como o modelo de dados pode ajudar no gerenciamento de } \\
\text { informação? }\end{array}$ \\
\hline & & & & $1-1$ & Modelo de informação conceitual organizacional é ausente. \\
\hline & & & & $2-2$ & Vocábulos iniciais de dados estão começando a emergir. \\
\hline & & & & $3-3$ & $\begin{array}{l}\text { Modelos de informação de negócio formal emergiram, frequentemente } \\
\text { definidos através de interfaces no estilos de esquemas XML. }\end{array}$ \\
\hline & & & & $3-3$ & $\begin{array}{l}\text { Vocabulários de dados de negócio são unificados e padronizados em } \\
\text { uma extensão significativa da organização, todos definidos através de } \\
\text { interfaces no estilos de esquemas XML (centralização de esquemas). }\end{array}$ \\
\hline & & & & $4-4$ & $\begin{array}{l}\text { Um modelo de informação de negócio foi desenvolvido e implantado } \\
\text { para suporte a toda organização, principalmente no desenvolvimento de } \\
\text { serviços. }\end{array}$ \\
\hline & & & & $5-5$ & $\begin{array}{l}\text { Um modelo de informação de negócio foi usado para melhorar os } \\
\text { serviços, e seu monitoramento se dá em tempo real, a fim de prover um } \\
\text { retorno aos parâmetros de entrada e melhorar o modelo de dados de } \\
\text { negócio global. }\end{array}$ \\
\hline & & & & $5-5$ & $\begin{array}{l}\text { Um modelo de informação de negócio foi projetado e implementado, o } \\
\text { que inclui tanto a organização quanto o relacionamento externo com } \\
\text { outras entidades. }\end{array}$ \\
\hline & $\begin{array}{l}\text { Integração de } \\
\text { Informações do } \\
\text { Negócio }\end{array}$ & $\begin{array}{l}\text { Existe em geral uma } \\
\text { integração das informações } \\
\text { empresariais formalizada. }\end{array}$ & $\mathbf{N}$ & 1 & \\
\hline
\end{tabular}

Continua 


\begin{tabular}{|c|c|c|c|c|c|}
\hline Domínio & Controle & Interpretação do controle & Dispensável & $\begin{array}{c}\text { Peso/ } \\
\text { ponto } \\
\text { Min - max }\end{array}$ & Itens de avaliação (questões)/ \\
\hline & & & & & Existe algum modelo de informação de negócio? \\
\hline & & & & $1-1$ & Não existem informações de negócio organizacional. \\
\hline & & & & $2-3$ & O modelo formal da empresa está evoluindo (quase concluindo). \\
\hline & & & & $4-4$ & $\begin{array}{l}\text { Serviços de informação de negócio foram formalizados em toda } \\
\text { organização e foram utilizados no desenvolvimento e implementação. }\end{array}$ \\
\hline & & & & $5-5$ & $\begin{array}{l}\text { Serviços de informação de negócio foram formalizados em toda } \\
\text { organização e foram utilizados no desenvolvimento e implementação, } \\
\text { incluindo também o relacionamento organizacional com entidades } \\
\text { externas, e são continuamente revisitados quando da melhoria de } \\
\text { processos. }\end{array}$ \\
\hline & $\begin{array}{l}\text { Transformação de } \\
\text { Dados }\end{array}$ & $\begin{array}{l}\text { A organização ainda lida } \\
\text { com um alto volume de } \\
\text { transformação de dados ou } \\
\text { o princípio de } \\
\text { interoperabilidade } \\
\text { intrínseca dos serviços está } \\
\text { bem aplicada de forma que } \\
\text { as transformações de dados } \\
\text { foram abolidas ou } \\
\text { fortemente minimizadas. }\end{array}$ & $\mathbf{N}$ & 1 & \\
\hline & & & & & Como a transformação de dados é utilizada por sua organização? \\
\hline & & & & $1-1$ & Transformação de dados são realizadas em código. \\
\hline & & & & $1-1$ & Transformação de dados se realizam pelo uso de APIs. \\
\hline & & & & $2-2$ & $\begin{array}{l}\text { Transformação de dados se realizam diretamente junto à chamada de } \\
\text { serviços. }\end{array}$ \\
\hline & & & & $3-3$ & Transformação de dados são alcançados por adaptadores. \\
\hline & & & & $3-3$ & ESB é utilizado para realizar transformações. \\
\hline & & & & $4-4$ & $\begin{array}{l}\text { ESB é utilizado para realizar transformações, e é monitorado de forma a } \\
\text { dar suporte a melhoria / unificação do modelo de dados de negócio. }\end{array}$ \\
\hline & & & & $5-5$ & $\begin{array}{l}\text { Nenhuma transformação de dados é necessária porque todos os serviços } \\
\text { são projetados garantindo a interoperabilidade intrínseca de dados, pois } \\
\text { os modelos são padronizados através de toda organização. }\end{array}$ \\
\hline
\end{tabular}




\begin{tabular}{|c|c|c|c|c|c|}
\hline Domínio & Controle & Interpretação do controle & Dispensável & $\begin{array}{l}\text { Peso/ } \\
\text { ponto } \\
\text { Min - max }\end{array}$ & Itens de avaliação (questões)/ \\
\hline & $\begin{array}{l}\text { Padrões de } \\
\text { Integração de } \\
\text { Dados }\end{array}$ & $\begin{array}{l}\text { Verifica o uso de padrões } \\
\text { de integração de dados e } \\
\text { sua extensão }\end{array}$ & $\mathbf{N}$ & 2 & \\
\hline & & & & & Como metadados são utilizados para integrar sua organização? \\
\hline & & & & $1-1$ & Metadados são utilizados apenas em aplicações silo. \\
\hline & & & & $2-2$ & $\begin{array}{l}\text { Múltiplas unidades de negócio estão utilizando relacionamentos de } \\
\text { metadados. }\end{array}$ \\
\hline & & & & $3-3$ & $\begin{array}{l}\text { Serviços de dados mestre estão em vigor e são utilizados através da } \\
\text { organização. }\end{array}$ \\
\hline & & & & $4-4$ & $\begin{array}{l}\text { Um registro com metadados é usado para gerenciar os ativos de serviços } \\
\text { organizacionais. }\end{array}$ \\
\hline & & & & $5-5$ & $\begin{array}{l}\text { Um registro com metadados é usado para gerenciar os ativos de serviços } \\
\text { organizacionais, e o serviço de metadados é constantemente revisado } \\
\text { para melhorar o modelo de dados de negócio global. }\end{array}$ \\
\hline & & & & $5-5$ & $\begin{array}{l}\text { Um registro com metadados é usado para gerenciar os ativos de serviços } \\
\text { organizacionais, e o serviço de metadados é constantemente revisado } \\
\text { usando conceitos de web semântica / ontologias. }\end{array}$ \\
\hline & & & & & Como a infraestrutura de sua organização é integrada? \\
\hline & & & & $1-1$ & Não existe uma política de integração. \\
\hline & & & & $2-2$ & $\begin{array}{l}\text { Existe integração, mas não usa padrões formalizados, sendo } \\
\text { implementado na forma de complexos problemas de conversão e/ou } \\
\text { migração de dados. }\end{array}$ \\
\hline & & & & $3-3$ & $\begin{array}{l}\text { Padrões de integração foram formalizados nos frameworks de } \\
\text { arquitetura (suportados por modelos de dados integrados em uma } \\
\text { extensão significativa). }\end{array}$ \\
\hline & & & & $4-4$ & $\begin{array}{l}\text { Padrões de integração foram formalizados nos frameworks de } \\
\text { arquitetura e são mensurados visando melhorias de processo (isto é, se } \\
\text { possível, sua eliminação). }\end{array}$ \\
\hline & & & & $5-5$ & $\begin{array}{l}\text { Políticas de integração foram formalizadas entre parceiros de negócio e } \\
\text { são mensuradas para ajudar em processos de melhoria na relação } \\
\text { com/entre serviços externos a organização. }\end{array}$ \\
\hline
\end{tabular}




\begin{tabular}{|c|c|c|c|c|c|}
\hline Domínio & Controle & Interpretação do controle & Dispensável & $\begin{array}{l}\text { Peso/ } \\
\text { ponto } \\
\text { Min - max }\end{array}$ & Itens de avaliação (questões)/ \\
\hline & $\begin{array}{l}\text { Qualidade de } \\
\text { Dados e Métricas }\end{array}$ & $\begin{array}{l}\text { Verifica o uso de padrões } \\
\text { de integração de dados e } \\
\text { sua extensão }\end{array}$ & $\mathbf{N}$ & 1 & \\
\hline & & & & & $\begin{array}{l}\text { Como você descreveria a qualidade dos dados críticos da sua } \\
\text { organização? }\end{array}$ \\
\hline & & & & $1-1$ & Nenhum ou não aplicável. \\
\hline & & & & $2-2$ & Dados de baixa qualidade sem abordagem sistemática para a melhoria. \\
\hline & & & & $3-3$ & $\begin{array}{l}\text { Informações de referência arquitetural inclui recursos para qualidade de } \\
\text { dados e auditoria. }\end{array}$ \\
\hline & & & & $4-4$ & $\begin{array}{l}\text { Padrões de qualidade de dados, melhores práticas e métricas estão em } \\
\text { uso. }\end{array}$ \\
\hline & & & & $4-4$ & $\begin{array}{l}\text { Serviços de gestão de qualidade de dados permitem a empresa de } \\
\text { automação de qualidade de dados na camada de serviços de dados. }\end{array}$ \\
\hline & & & & $5-5$ & $\begin{array}{l}\text { Estratégia de governança de dados abrangente no lugar junto com } \\
\text { adoção corporativa da qualidade dos dados }\end{array}$ \\
\hline & & & & & $\begin{array}{l}\text { Como você descreveria a coleta e uso de métricas operacionais } \\
\text { existentes? }\end{array}$ \\
\hline & & & & $1-1$ & Coleta esporádica de métricas sem qualquer plano abrangente. \\
\hline & & & & $2-2$ & $\begin{array}{l}\text { As métricas e a abordagem para a coleta de métricas foram definidas, } \\
\text { mas ainda não estão em uso generalizado. }\end{array}$ \\
\hline & & & & $3-3$ & $\begin{array}{l}\text { Definição generalizada, coleta e armazenamento de métricas } \\
\text { operacionais com alguma consciência de como os dados operacionais } \\
\text { suportam a definição das métricas dos objetivos de negócio. }\end{array}$ \\
\hline & & & & $4-4$ & $\begin{array}{l}\text { Métricas padronizadas e definidas e sua coleta é requerida para todos os } \\
\text { processos operacionais, e alguns serviços de apoio automatizado para } \\
\text { relatórios de métricas objetivas de negócios. }\end{array}$ \\
\hline & & & & $5-5$ & $\begin{array}{l}\text { Métricas são rotineiramente coletadas, armazenadas e prontamente } \\
\text { disponíveis para relatórios e análise, incluindo métricas dos objetivos de } \\
\text { negócio quando aplicável. }\end{array}$ \\
\hline
\end{tabular}

Continua 


\begin{tabular}{|c|c|c|c|c|c|}
\hline Domínio & Controle & Interpretação do controle & Dispensável & $\begin{array}{c}\text { Peso/ } \\
\text { ponto } \\
\text { Min - max }\end{array}$ & Itens de avaliação (questões)/ \\
\hline \multirow[t]{15}{*}{$\begin{array}{l}\text { Tecnologia e } \\
\text { Infraestrutura } \\
\text { D-06 }\end{array}$} & $\begin{array}{l}\text { Barramento } \\
\text { Corporativo de } \\
\text { Serviços }\end{array}$ & $\begin{array}{l}\text { Verifica se a organização } \\
\text { possui um coordenador de } \\
\text { suas aplicações, seja } \\
\text { Enterprise Service Bus } \\
\text { (ESB) ou outra aplicação } \\
\text { que realize esse processo. }\end{array}$ & $\mathbf{N}$ & 2 & \\
\hline & & & & & Como está o uso de barramento de serviços? \\
\hline & & & & $1-1$ & Não ou explorando produtos \\
\hline & & & & $2-2$ & Em fase final de estudo ou aplicação em projeto piloto. \\
\hline & & & & $3-4$ & Existe uma implementação corporativa única. \\
\hline & & & & $5-5$ & $\begin{array}{l}\text { Existe uma implementação corporativa única, com alta disponibilidade } \\
\text { e aplica princípios de escalabilidade. }\end{array}$ \\
\hline & $\begin{array}{l}\text { Topologia do } \\
\text { Barramento }\end{array}$ & $\begin{array}{l}\text { Verifica a ocorrência } \\
\text { comum de topologia na } \\
\text { construção de serviços. }\end{array}$ & $\mathbf{N}$ & 1 & \\
\hline & & & & & $\begin{array}{l}\text { Como em sua organização você descreveria a topologia lógica de } \\
\text { suas aplicações SOA (no seu maior uso)? }\end{array}$ \\
\hline & & & & $1-1$ & $\begin{array}{l}\text { Desconhece ou os serviços são pontuais (serviços web diretos, sem } \\
\text { composição ou processos) }\end{array}$ \\
\hline & & & & $1-1$ & Ponto-a-Ponto \\
\hline & & & & $2-2$ & Barramento (todos os terminais estão conectados ao barramento) \\
\hline & & & & $3-3$ & Centralizado (Hub and spoke) ou Composições \\
\hline & & & & $4-4$ & Composições com acesso federado \\
\hline & & & & $5-5$ & $\begin{array}{l}\text { Modelo híbrido criado segundo um projeto adequado e plenamente } \\
\text { governado }\end{array}$ \\
\hline & $\begin{array}{l}\text { Solução de } \\
\text { Mensagem }\end{array}$ & $\begin{array}{l}\text { Soluções utilizando } \\
\text { mensageria já envolvem } \\
\text { uma alta parcela } \\
\text { (percentual) nas soluções } \\
\text { utilizadas pela organização. }\end{array}$ & $\mathbf{N}$ & 1 & \\
\hline
\end{tabular}




\begin{tabular}{|c|c|c|c|c|c|}
\hline Domínio & Controle & Interpretação do controle & Dispensável & $\begin{array}{c}\text { Peso/ } \\
\text { ponto } \\
\text { Min - } \max \\
\end{array}$ & Itens de avaliação (questões)/ \\
\hline & & & & & Você possui alguma solução de mensageria implementada formalmente? \\
\hline & & & & $1-1$ & Não há nenhuma solução de mensagens formalmente implementada. \\
\hline & & & & $2-2$ & Soluções de mensageria existem integrando algumas aplicações. \\
\hline & & & & $2-2$ & $\begin{array}{l}\text { Soluções de mensageria existem integrando a maioria das aplicações } \\
\text { através da organização, mas ainda não se utiliza de padrões de } \\
\text { infraestrutura SOA tal como ESBs. }\end{array}$ \\
\hline & & & & $3-3$ & $\begin{array}{l}\text { Soluções de mensageria existem integrando a maioria das aplicações } \\
\text { através da organização utilizando-se de ESBs. }\end{array}$ \\
\hline & & & & $4-4$ & $\begin{array}{l}\text { Soluções de mensageria existem integrando aplicações até mesmo fora } \\
\text { dos limites organizacionais (sendo que dentro da organização essa } \\
\text { aplicação é regida pelo ESB). }\end{array}$ \\
\hline & & & & $5-5$ & $\begin{array}{l}\text { Adicionalmente, toda solução de mensageria (interna ou externa) } \\
\text { envolve mensurações para geração de indicadores a serem utilizados } \\
\text { para melhorar a performance de serviços. }\end{array}$ \\
\hline & $\begin{array}{l}\text { Uso de Padrões } \\
\text { Interoperáveis de } \\
\text { Dados }\end{array}$ & $\begin{array}{l}\text { A organização implementa } \\
\text { padrões interoperáveis de } \\
\text { dados tal como XML. Se } \\
\text { sim, qual a abrangência da } \\
\text { utilização de XML. }\end{array}$ & $\mathbf{N}$ & 2 & \\
\hline & & & & & Sua estrutura de mensagens usa padrões interoperáveis de dados? \\
\hline & & & & $1-1$ & Não \\
\hline & & & & $2-2$ & Diversos modelos interoperáveis integrados. \\
\hline & & & & $3-3$ & $\begin{array}{l}\text { Diversos modelos interoperáveis integrados reconhecidos de mercado } \\
\text { (SOAP, REST, POX - Plain Old XML, etc). }\end{array}$ \\
\hline & & & & $4-4$ & $\begin{array}{l}\text { Modelos interoperáveis integrados utilizando-se unicamente de padrões } \\
\text { de mercado (SOAP, REST) em quantidade significativa de aplicações. }\end{array}$ \\
\hline & & & & $5-5$ & $\begin{array}{l}\text { Modelos interoperáveis integrados utilizando-se unicamente de padrões } \\
\text { de mercado (SOAP, REST) em todas as aplicações. }\end{array}$ \\
\hline
\end{tabular}

Continua 


\begin{tabular}{|c|c|c|c|c|c|}
\hline \multirow[t]{2}{*}{ Domínio } & Controle & Interpretação do controle & Dispensável & $\begin{array}{c}\text { Peso/ } \\
\text { ponto } \\
\text { Min - max } \\
\end{array}$ & Itens de avaliação (questões)/ \\
\hline & Monitoramento & $\begin{array}{l}\text { Existe um monitoramento } \\
\text { visando a geração de } \\
\text { métricas de atendimento da } \\
\text { infraestrutura de forma que } \\
\text { atendam aos SLAs } \\
\text { específicos dos serviços. }\end{array}$ & $\mathbf{N}$ & 1 & \\
\hline & & & & & Como é a política de monitoramento de em sua infraestrutura? \\
\hline & & & & $1-1$ & $\begin{array}{l}\text { Não possuímos políticas de monitoramento da infraestrutura } \\
\text { formalizado, quando feita é de forma adhoc por interesses } \\
\text { intempestivos. }\end{array}$ \\
\hline & & & & $2-2$ & $\begin{array}{l}\text { Políticas de monitoramento de infraestrutura (e seus recursos) } \\
\text { parcialmente implementado apenas com alguns requisitos básicos. }\end{array}$ \\
\hline & & & & $3-3$ & $\begin{array}{l}\text { Políticas de monitoramento de infraestrutura em conformidade está } \\
\text { implementado em escala significativa sobre a maioria dos ativos de } \\
\text { infraestrutura usando práticas modernas de mercado (desempenho, } \\
\text { confiabilidade e outros), mas ainda não apresenta real interesse. }\end{array}$ \\
\hline & & & & $4-4$ & $\begin{array}{l}\text { O monitoramento é completamente implementado centralizadamente e } \\
\text { seus resultados são efetivamente mensurados, muito desses oriundos de } \\
\text { uma solução de BAM. }\end{array}$ \\
\hline & & & & $4-4$ & Os níveis de política são dinâmicos e gerenciados. \\
\hline & & & & $5-5$ & $\begin{array}{l}\text { Os níveis de política são dinâmicos e gerenciados e os feedbacks são } \\
\text { usados para melhorias dos mesmos. }\end{array}$ \\
\hline
\end{tabular}

Continua 


\begin{tabular}{|c|c|c|c|c|c|}
\hline Domínio & Controle & Interpretação do controle & Dispensável & $\begin{array}{c}\text { Peso/ } \\
\text { ponto } \\
\text { Min - max }\end{array}$ & Itens de avaliação (questões)/ \\
\hline & Segurança & $\begin{array}{l}\text { Qual o nível de segurança } \\
\text { aplicado nos serviços } \\
\text { empresariais. }\end{array}$ & $\mathbf{N}$ & 1 & \\
\hline & & & & & $\begin{array}{l}\text { Políticas de segurança em serviços SOA estão implementados e/ou } \\
\text { gerenciados? }\end{array}$ \\
\hline & & & & $1-1$ & Não há nenhuma políticas formal de segurança em serviços SOA \\
\hline & & & & $2-2$ & $\begin{array}{l}\text { Políticas de segurança em serviços SOA estão formalmente publicados } \\
\text { mas são usados à conveniência pelos projetistas SOA. }\end{array}$ \\
\hline & & & & $3-4$ & $\begin{array}{l}\text { Políticas de segurança em serviços SOA estão formalmente publicados } \\
\text { e são usados em extensão significativa dentro da organização, sendo } \\
\text { testados especificamente em aplicações e auditados pela Governança } \\
\text { SOA. }\end{array}$ \\
\hline & & & & $5-5$ & $\begin{array}{l}\text { Políticas de segurança de serviços são dinâmicos e gerenciados em } \\
\text { tempo real, sendo utilizadas para a melhoria do processo de feedback. }\end{array}$ \\
\hline
\end{tabular}

Continua 


\begin{tabular}{|c|c|c|c|c|c|}
\hline Domínio & Controle & Interpretação do controle & Dispensável & $\begin{array}{c}\text { Peso/ } \\
\text { ponto } \\
\text { Min - max }\end{array}$ & Itens de avaliação (questões)/ \\
\hline \multirow[t]{11}{*}{$\begin{array}{l}\text { Operação e } \\
\text { Gerenciament } \\
\text { o de TI } \\
\text { D-07 }\end{array}$} & $\begin{array}{l}\text { Gerenciamento de } \\
\text { Serviços de TI }\end{array}$ & $\begin{array}{l}\text { Verifica como está o nível } \\
\text { de integração e } \\
\text { automatização dos } \\
\text { processos de gerenciamento } \\
\text { de infraestrutura. }\end{array}$ & $\mathbf{N}$ & 1 & \\
\hline & & & & & $\begin{array}{l}\text { Os processos de gerenciamento de TI se encontram integrados e } \\
\text { automatizados? }\end{array}$ \\
\hline & & & & $3-3$ & Fraca integração com processos semi-automatizados. \\
\hline & & & & $4-5$ & Alta integração com processos automatizados. \\
\hline & $\begin{array}{l}\text { Gerenciamento de } \\
\text { Configuração de } \\
\text { Ativos de TI }\end{array}$ & $\begin{array}{l}\text { Verifica se é documentado, } \\
\text { gerenciado, versionado e/ou } \\
\text { gerido os ativos de TI na } \\
\text { empresa e suas integrações e } \\
\text { relações. Existe uma } \\
\text { atendimento ao gerenciamento } \\
\text { de configuração segundo as } \\
\text { boas práticas de mercado (a } \\
\text { exemplo do framework ITIL). }\end{array}$ & $\mathbf{N}$ & 1 & \\
\hline & & & & & Os ativos de TI são controlados (gerenciados) em sua organização? \\
\hline & & & & $1-1$ & Não existe esse tipo de controle centralizado definido na organização. \\
\hline & & & & $2-2$ & $\begin{array}{l}\text { A organização possui gestão de ativos de hardware e software } \\
\text { centralizada. }\end{array}$ \\
\hline & & & & $3-3$ & $\begin{array}{l}\text { Adicionalmente, temos a gestão de serviços (webservices e SOA) junto } \\
\text { a gestão de ativos. }\end{array}$ \\
\hline & & & & $4-4$ & $\begin{array}{l}\text { Todos ativos da organização (incluindo serviços SOA) são classificados } \\
\text { mesmo que em soluções distintas de ativos de TI e inventário de } \\
\text { serviços. }\end{array}$ \\
\hline & & & & $5-5$ & $\begin{array}{l}\text { Todos ativos da organização são classificados, e essa gestão é } \\
\text { automaticamente atualizada por todos os processos de gerenciamento de } \\
\text { serviços de TI, inclusive de implantação de soluções SOA. }\end{array}$ \\
\hline
\end{tabular}




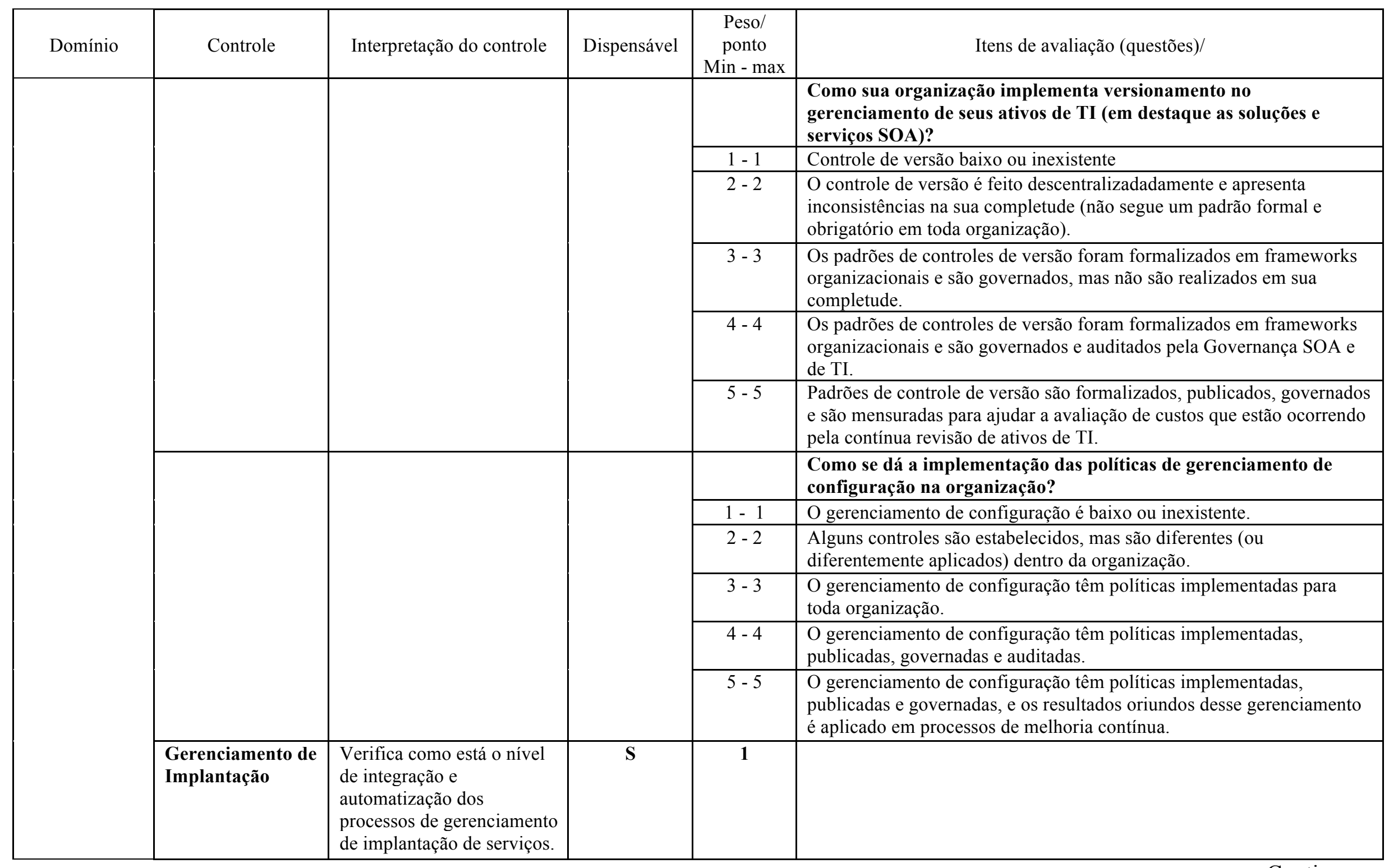




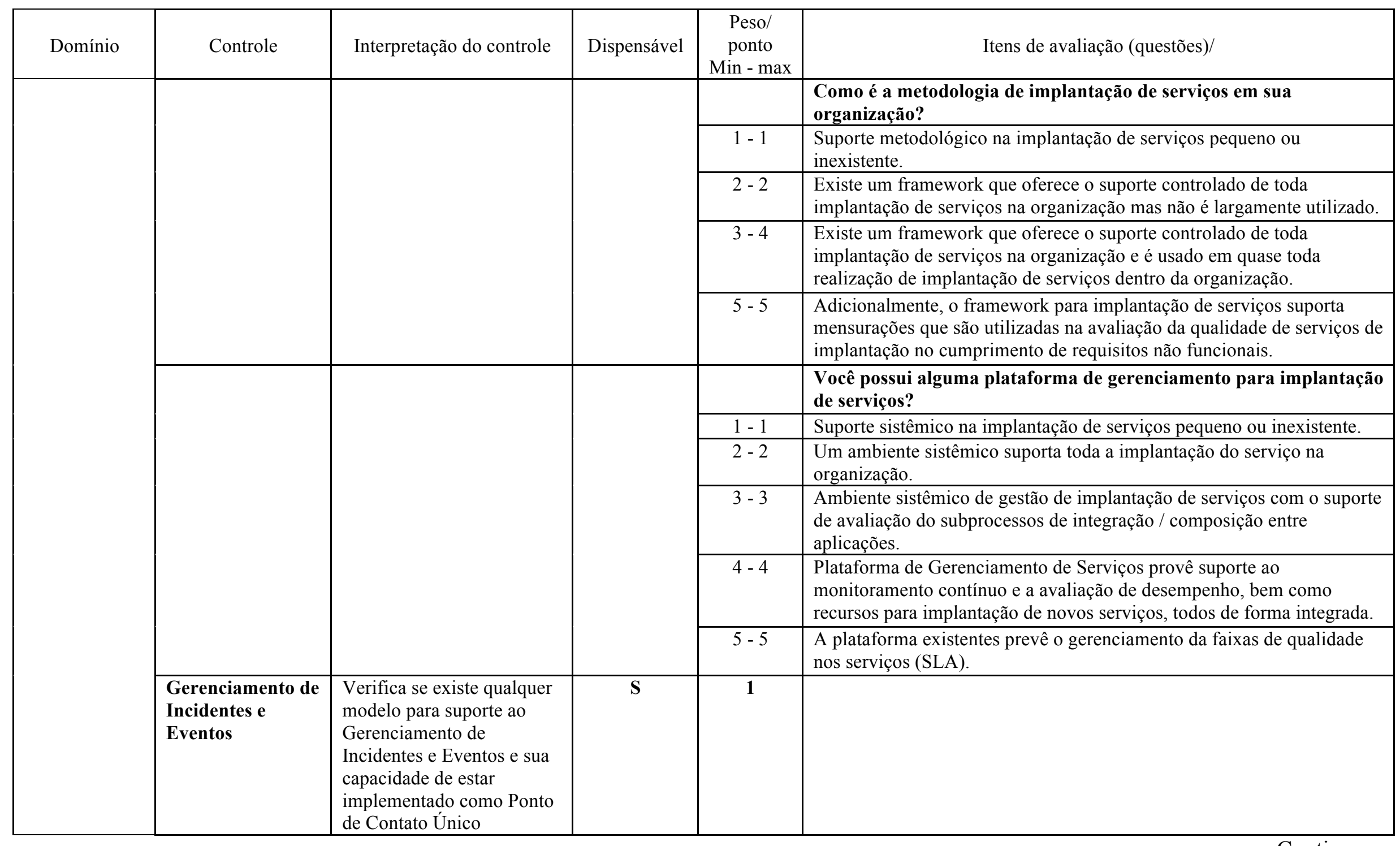




\begin{tabular}{|c|c|c|c|c|c|}
\hline Domínio & Controle & Interpretação do controle & Dispensável & $\begin{array}{c}\text { Peso/ } \\
\text { ponto } \\
\text { Min - max }\end{array}$ & Itens de avaliação (questões)/ \\
\hline & & & & & Como sua organização implementa o gerenciamento de incidentes e eventos? \\
\hline & & & & $1-1$ & Não existe gerenciamento de incidentes e eventos. \\
\hline & & & & $2-2$ & Existe um gerenciamento de incidentes e eventos manual e pontual. \\
\hline & & & & $3-4$ & $\begin{array}{l}\text { Existe um suporte sistêmico incompleto (ou não é mandatoriamente } \\
\text { utilizado) para gerenciamento de incidentes e eventos na organização. }\end{array}$ \\
\hline & & & & $5-5$ & $\begin{array}{l}\text { Existe um suporte sistêmico completo para gerenciamento de incidentes } \\
\text { e eventos na organização com a geração de informações estratégicas no } \\
\text { suporte ao replanejamento de atividades. }\end{array}$ \\
\hline & $\begin{array}{l}\text { Monitoramento } \\
\text { da Infraestrutura }\end{array}$ & $\begin{array}{l}\text { Avalia o grau de } \\
\text { gerenciamento, fiscalização } \\
\text { e monitoramento da } \\
\text { infraestrutura }\end{array}$ & $\mathbf{N}$ & 1 & \\
\hline & & & & & Como é a política de fiscalização de sua infraestrutura? \\
\hline & & & & $1-1$ & $\begin{array}{l}\text { Não existe e/ou não é controlada e/ou não é formalizada uma política de } \\
\text { monitoramento. }\end{array}$ \\
\hline & & & & $2-2$ & Está parcialmente implementada em alguns requisitos \\
\hline & & & & $3-3$ & $\begin{array}{l}\text { O monitoramento é implementado (desempenho, confiabilidade e } \\
\text { outros), mas não são medidos. }\end{array}$ \\
\hline & & & & $4-4$ & O monitoramento é totalmente implementados e monitorados (ex. usando BAM) \\
\hline & & & & $4-4$ & Os níveis de políticas são dinâmicos e gerenciados. \\
\hline & & & & $5-5$ & $\begin{array}{l}\text { Os níveis de políticas são dinâmicos e gerenciados, sendo diretamente } \\
\text { utilizados em um processo de melhoria contínua. }\end{array}$ \\
\hline & & & & & Você tem uma plataforma de gestão para implantar seus serviços? \\
\hline & & & & $1-1$ & O suporte operacional para a implantação de serviços é pouco ou inexistente. \\
\hline & & & & $2-2$ & $\begin{array}{l}\text { O ambiente operacional em toda a organização apoia a implantação dos } \\
\text { serviços. }\end{array}$ \\
\hline & & & & $3-3$ & $\begin{array}{l}\text { O gerenciamento de serviços de suporte de qualidade de serviço e } \\
\text { aplicações é integrado. }\end{array}$ \\
\hline & & & & $4-4$ & $\begin{array}{l}\text { O monitoramento de serviços e gestão de desempenho oferecem suporte } \\
\text { à implantação de novos serviços. }\end{array}$ \\
\hline & & & & $5-5$ & $\begin{array}{l}\text { A gestão de serviços verifica e prevê as mudanças nos serviços } \\
\text { necessários para otimizar a qualidade dos serviços. }\end{array}$ \\
\hline
\end{tabular}




\section{APÊNDICE C - RESULTADO DO ESTUDO DE USO DA ORGANIZAÇÃO AVALIADA}

LEGENDA:

[1] VALOR MÍNIMO DO ÍTEM SELECIONADO (EM 2011)

[2] VALOR MAXIMO DO ÍTEM SELECIONADO (EM 2011)

[3] QUANTIFICAÇÂO DO CONTROLE (EM 2011)

[4] VALOR MÍNIMO DO ÍTEM SELECIONADO (EM 2012)

[5] VALOR MAXIMO DO ÍTEM SELECIONADO (EM 2012)

[6] QUANTIFICAÇÂO DO CONTROLE (EM 2012)

[7] VALOR MÍNIMO DO ÍTEM SELECIONADO (EM 2014)

[8] VALOR MAXIMO DO ÍTEM SELECIONADO (EM 2014)

[9] QUANTIFICAÇÂO DO CONTROLE (EM 2014)

\begin{tabular}{|c|c|c|c|c|c|c|c|c|c|c|c|}
\hline Domínio & Controle & Questão (item de avaliaçâo) & [1] & [2] & {$[3]$} & [4] & [5] & [6] & [7] & [8] & [9] \\
\hline \multirow{6}{*}{$\begin{array}{c}\text { Negócios e } \\
\text { Objetivos } \\
\text { Estratégicos - D01 }\end{array}$} & Arquitetura Corporativa (1) & & & & 1 & & & 2 & & & 2 \\
\hline & & Você possui uma arquitetura corporativa formalizada? & 1 & 1 & & 2 & 2 & & 2 & 2 & \\
\hline & Arquitetura Corporativa (1) & & & & 1 & & & 1 & & & 1 \\
\hline & & $\begin{array}{l}\text { Sua Arquitetura de Processo de Negócio (BPA) é formalmente } \\
\text { definida, documentada e governada? }\end{array}$ & 1 & 1 & & 1 & 1 & & 1 & 1 & \\
\hline & Linhas de Negócio (LOB) (2) & & & & 1 & & & 4 & & & 4 \\
\hline & & $\begin{array}{l}\text { Suas Linhas de Negócio (LOB) são estáveis, claras e } \\
\text { específicas? }\end{array}$ & 1 & 1 & & 2 & 4 & & 2 & 4 & \\
\hline
\end{tabular}

Continua 


\begin{tabular}{|c|c|c|c|c|c|c|c|c|c|c|c|}
\hline Domínio & Controle & Questão (item de avaliaçâ) & [1] & [2] & [3] & [4] & {$[5]$} & {$[6]$} & [7] & {$[8]$} & [9] \\
\hline & Direcionadores de Negócio (1) & & & & 2 & & & 2 & & & 2 \\
\hline & & $\begin{array}{l}\text { Em que nível os direcionadores de negócio de sua organização } \\
\text { são documentados? }\end{array}$ & 2 & 2 & & 2 & 2 & & 2 & 2 & \\
\hline & Envolvimento do Negócio com SOA (1) & & & & 1 & & & 1 & & & 1 \\
\hline & & $\begin{array}{l}\text { Qual a relação da entrega de serviços com o negócio e sua } \\
\text { valoração junto ao negócio? }\end{array}$ & 1 & 1 & & 1 & 1 & & 1 & 1 & \\
\hline & Alinhamento do Negócio com a TI (1) & & & & 1 & & & 1 & & & 1 \\
\hline & & $\begin{array}{l}\text { Qual o nível de alinhamento entre as visões e objetivos de } \\
\text { Negócio e da TI? }\end{array}$ & 1 & 1 & & 1 & 1 & & 1 & 1 & \\
\hline & Práticas Financeiras (ROI) (1) & & & & 1 & & & 1 & & & 1 \\
\hline & & Como você calcula seu ROI? & 1 & 1 & & 1 & 1 & & 1 & 1 & \\
\hline & Financiamento da Adoção de SOA (1) & & & & 1 & & & 1 & & & 1 \\
\hline & & Qual é o nível de patrocínio de negócios para SOA? & 1 & 1 & & 1 & 1 & & 2 & 2 & \\
\hline & & Como é financiada a iniciativa SOA? & 1 & 1 & & 1 & 1 & & 1 & 1 & \\
\hline & Conformidade Legal (1) & & & & 2 & & & 2 & & & 2 \\
\hline & & Como a conformidade legal é garantida (se existir alguma)? & 2 & 2 & & 2 & 2 & & 2 & 2 & \\
\hline
\end{tabular}

Continua 


\begin{tabular}{|c|c|c|c|c|c|c|c|c|c|c|c|}
\hline Domínio & Controle & Questão (item de avaliaçâo) & {$[1]$} & {$[2]$} & [3] & [4] & [5] & {$[6]$} & {$[7]$} & {$[8]$} & [9] \\
\hline & Monitoramento e Mensuração (2) & & & & 1 & & & 1 & & & 2 \\
\hline & & $\begin{array}{l}\text { Como seus processo de negócio são mensurados e } \\
\text { monitorados? }\end{array}$ & 1 & 1 & & 1 & 1 & & 2 & 2 & \\
\hline & & $\begin{array}{l}\text { Como as informações de sistemas de suporte a decisão são } \\
\text { geradas? }\end{array}$ & 3 & 3 & & 3 & 3 & & 3 & 3 & \\
\hline & Etapas de Adoção de SOA (1) & & & & 1 & & & 2 & & & 2 \\
\hline & & Em que etapa da adoção de SOA sua organização se encontra? & 1 & 1 & & 2 & 2 & & 2 & 2 & \\
\hline & $\begin{array}{l}\text { Tempo para Entrega de Soluções e } \\
\text { Satisfação (1) }\end{array}$ & & & & 1 & & & 1 & & & 1 \\
\hline & & $\begin{array}{l}\text { Qual é a satisfação dos consumidores/usuários de TI com o } \\
\text { tempo de entrega de suas aplicações atuais? }\end{array}$ & 1 & 1 & & 1 & 1 & & 1 & 1 & \\
\hline & & $\begin{array}{l}\text { Quão confiáveis são as aplicações críticas de negócio em sua } \\
\text { organização? }\end{array}$ & 1 & 1 & & 1 & 1 & & 1 & 1 & \\
\hline \multirow{7}{*}{$\begin{array}{c}\text { Organização e } \\
\text { Governança - D02 }\end{array}$} & Estratégia para Adoção de SOA (1) & & & & 1 & & & 2 & & & 2 \\
\hline & & $\begin{array}{l}\text { Como sua organização trata a Arquitetura Orientada a Serviços } \\
\text { e seus elementos? }\end{array}$ & 2 & 2 & & 2 & 2 & & 2 & 2 & \\
\hline & & $\begin{array}{l}\text { Em que estágio de adoção de SOA sua organização se } \\
\text { encontra? }\end{array}$ & 1 & 1 & & 2 & 3 & & 2 & 3 & \\
\hline & Etapas de Adoção de SOA (1) & & & & 1 & & & 2 & & & 2 \\
\hline & & Em que fase de arquitetura SOA você se encontra? & 1 & 1 & & 2 & 2 & & 2 & 2 & \\
\hline & Governança e Autoridades (2) & & & & 1 & & & 1 & & & 1 \\
\hline & & $\begin{array}{l}\text { Como a governança de TI se relaciona ou está alinhada com sua } \\
\text { governança SOA? }\end{array}$ & 1 & 1 & & 1 & 1 & & 1 & 1 & \\
\hline
\end{tabular}

Continua 


\begin{tabular}{|c|c|c|c|c|c|c|c|c|c|c|c|}
\hline Domínio & Controle & Questão (item de avaliaçâo) & {$[1]$} & [2] & [3] & [4] & {$[5]$} & {$[6]$} & [7] & [8] & [9] \\
\hline & Fronteiras Organizacionais (1) & & & & 1 & & & 1 & & & 2 \\
\hline & & Suas soluções SOA atravessam as fronteiras organizacionais? & 1 & 1 & & 1 & 1 & & 2 & 2 & \\
\hline & Processos e Atividades (1) & & & & 1 & & & 1 & & & 1 \\
\hline & & Como são seus desenvolvimento de processos e atividades? & 1 & 1 & & 1 & 1 & & 1 & 1 & \\
\hline & Governança SOA (2) & & & & 1 & & & 2 & & & 2 \\
\hline & & $\begin{array}{l}\text { Existe algum processo de governança SOA, eles são } \\
\text { documentados, e, se sim, eles são formalizados? }\end{array}$ & 1 & 1 & & 2 & 2 & & 3 & 3 & \\
\hline & & $\begin{array}{l}\text { Quais são as funcionalidades e responsabilidades da } \\
\text { Governança SOA? }\end{array}$ & 1 & 1 & & 2 & 2 & & 3 & 3 & \\
\hline & & Como a governança SOA está implementada? & 1 & 1 & & 2 & 2 & & 2 & 2 & \\
\hline & Estrutura Organizacional (1) & & & & 1 & & & 1 & & & 2 \\
\hline & & Suas soluções SOA atravessam as fronteiras organizacionais? & 1 & 1 & & 1 & 1 & & 2 & 2 & \\
\hline & Avaliação da Arquitetura SOA (1) & & & & 1 & & & 2 & & & 4 \\
\hline & & $\begin{array}{l}\text { A sua organização inclui avaliação da arquitetura em sua } \\
\text { metodologia de projeto? }\end{array}$ & 1 & 1 & & 2 & 2 & & 3 & 4 & \\
\hline & Políticas (1) & & & & 1 & & & 1 & & & 1 \\
\hline & & $\begin{array}{l}\text { Como as políticas de criação / construção de serviços estão } \\
\text { alinhadas com sua governança? }\end{array}$ & 1 & 1 & & 1 & 1 & & 1 & 1 & \\
\hline & $\begin{array}{l}\text { Gerenciamento de Riscos Empresariais } \\
\text { (1) }\end{array}$ & & & & 1 & & & 1 & & & 1 \\
\hline & & $\begin{array}{l}\text { Existem atividades de Gerenciamento de Risco Organizacional } \\
\text { (ERM)? }\end{array}$ & 1 & 1 & & 1 & 1 & & 1 & 1 & \\
\hline
\end{tabular}

Continua 


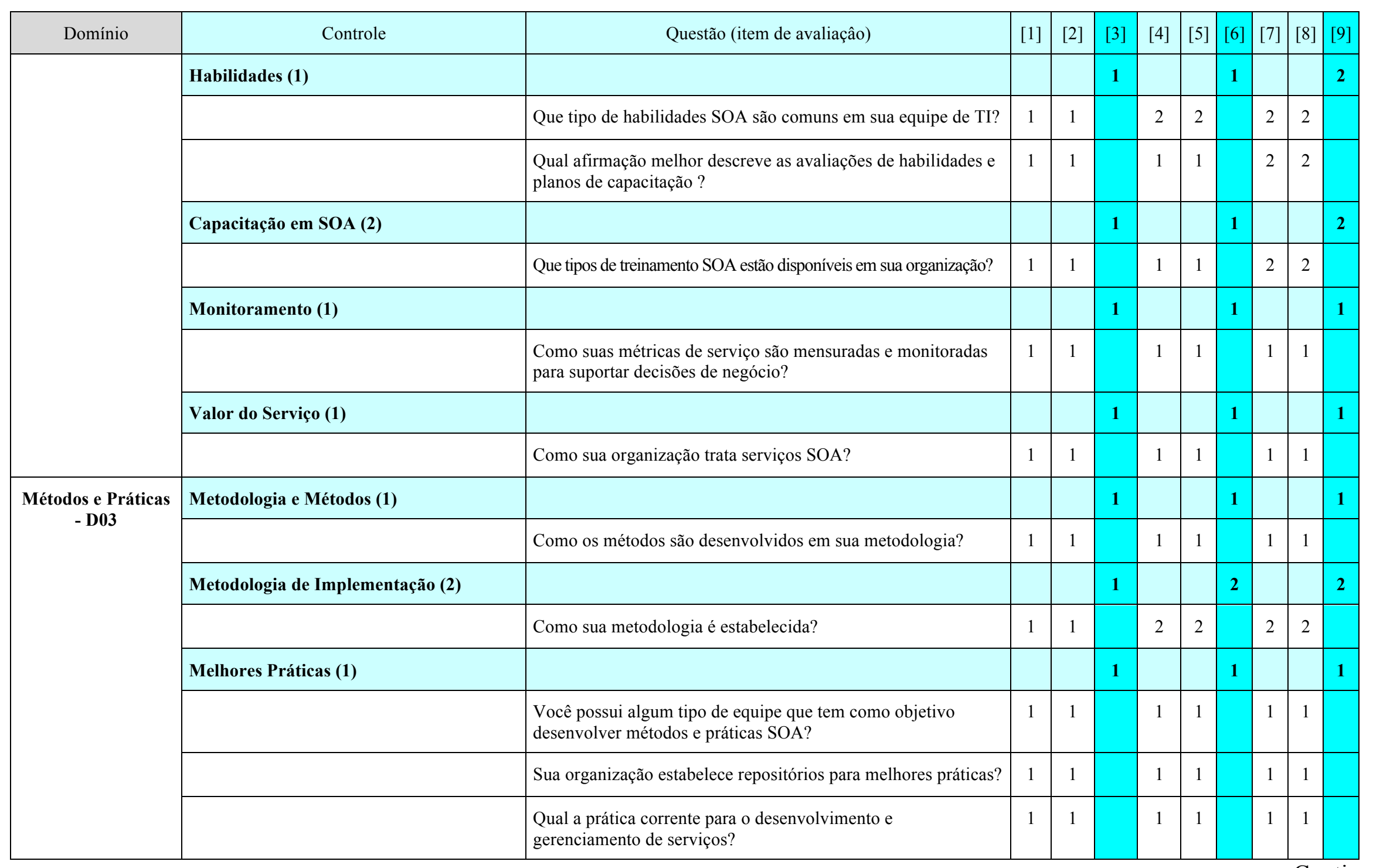

Continua 


\begin{tabular}{|c|c|c|c|c|c|c|c|c|c|c|c|}
\hline Domínio & Controle & Questão (item de avaliaçâo) & {$[1]$} & [2] & [3] & [4] & [5] & {$[6]$} & {$[7]$} & [8] & [9] \\
\hline & $\begin{array}{l}\text { Métodos, Princípios, Padrões, Frameworks e } \\
\text { Técnicas em SOA (2) }\end{array}$ & & & & 1 & & & 1 & & & 2 \\
\hline & & SOA é parte do ciclo de vida de desenvolvimento de software? & 1 & 1 & & 1 & 1 & & 2 & 3 & \\
\hline & & $\begin{array}{l}\text { Quão extensivo e sofisticado é a utilização em sua organização } \\
\text { de frameworks em sua arquitetura? }\end{array}$ & 1 & 1 & & 1 & 1 & & 2 & 2 & \\
\hline & & $\begin{array}{l}\text { Quão extensiva é a utilização de métodos, princípios, padrões, } \\
\text { frameworks e técnicas SOA? }\end{array}$ & 1 & 1 & & 1 & 1 & & 2 & 2 & \\
\hline & Gerenciamento de Projetos (1) & & & & 2 & & & 2 & & & 2 \\
\hline & & Como está o seu framework de Gerenciamento de Projetos? & 2 & 2 & & 2 & 2 & & 2 & 2 & \\
\hline & Gerenciamento de Riscos nos Projeto (1) & & & & 1 & & & 1 & & & 1 \\
\hline & & $\begin{array}{l}\text { Existe algum gerenciador de riscos dentro das atividades de } \\
\text { gerenciamento de projetos? }\end{array}$ & 1 & 1 & & 1 & 1 & & 1 & 1 & \\
\hline & Gestão de Mudança em SOA (1) & & & & 1 & & & 1 & & & 1 \\
\hline & & $\begin{array}{l}\text { Existe algum processo de planejamento e gestão controlada de } \\
\text { mudança dentro das atividades de gerenciamento de projetos? }\end{array}$ & 1 & 1 & & 1 & 1 & & 1 & 1 & \\
\hline & Conformidade Normativa (1) & & & & 1 & & & 1 & & & 1 \\
\hline & & $\begin{array}{l}\text { Existe alguma conformidade normativa no que envolve o uso } \\
\text { de SOA e das suas melhores práticas? }\end{array}$ & 1 & 1 & & 1 & 1 & & 1 & 1 & \\
\hline & Práticas SOA (1) & & & & 1 & & & 1 & & & 2 \\
\hline & & Como os métodos e práticas SOA foram implementados? & 1 & 1 & & 1 & 1 & & 2 & 2 & \\
\hline
\end{tabular}




\begin{tabular}{|c|c|c|c|c|c|c|c|c|c|c|c|}
\hline Domínio & Controle & Questão (item de avaliaçâo) & {$[1]$} & {$[2]$} & [3] & [4] & {$[5]$} & {$[6]$} & {$[7]$} & {$[8]$} & [9] \\
\hline & Práticas de Desenvolvimento (2) & & & & 1 & & & 1 & & & 2 \\
\hline & & Como são suas práticas de desenvolvimento baseadas em SOA? & 1 & 1 & & 1 & 1 & & 2 & 2 & \\
\hline & & Quão comum é a reutilização em sua organização? & 1 & 1 & & 1 & 1 & & 2 & 2 & \\
\hline & Estratégia SOA (1) & & & & 1 & & & 1 & & & 1 \\
\hline & & Quais benefícios são encontrados atualmente com SOA? & 1 & 1 & & 1 & 1 & & 1 & 1 & \\
\hline \multirow{11}{*}{$\begin{array}{c}\text { Aplicações e } \\
\text { Arquitetura - D04 }\end{array}$} & Arquitetura de Aplicação (1) & & & & 1 & & & 2 & & & 3 \\
\hline & & Quão complexa são suas arquiteturas de aplicações? & 1 & 1 & & 2 & 2 & & 3 & 3 & \\
\hline & Desacoplamento de Regras de Negócio (1) & & & & 1 & & & 1 & & & 3 \\
\hline & & $\begin{array}{l}\text { Como é a representação da lógica de negócio em suas } \\
\text { aplicações organizacionais? }\end{array}$ & 1 & 1 & & 1 & 1 & & 2 & 3 & \\
\hline & Integração (1) & & & & 1 & & & 2 & & & 2 \\
\hline & & $\begin{array}{l}\text { Como é a integração de aplicações e sistemas em sua } \\
\text { organização? }\end{array}$ & 1 & 1 & & 2 & 2 & & 2 & 2 & \\
\hline & Integração de Aplicação (1) & & & & 2 & & & 2 & & & 3 \\
\hline & & Quão extensivo é a integração de suas aplicações? & 2 & 2 & & 2 & 2 & & 3 & 3 & \\
\hline & Arquiteturas de Referência (1) & & & & 1 & & & 2 & & & 3 \\
\hline & & Sua organização utiliza / tem uma arquitetura de referência? & 1 & 1 & & 2 & 3 & & 2 & 3 & \\
\hline & & Qual é o estado de sua arquitetura de referência SOA? & 1 & 1 & & 2 & 2 & & 3 & 3 & \\
\hline
\end{tabular}




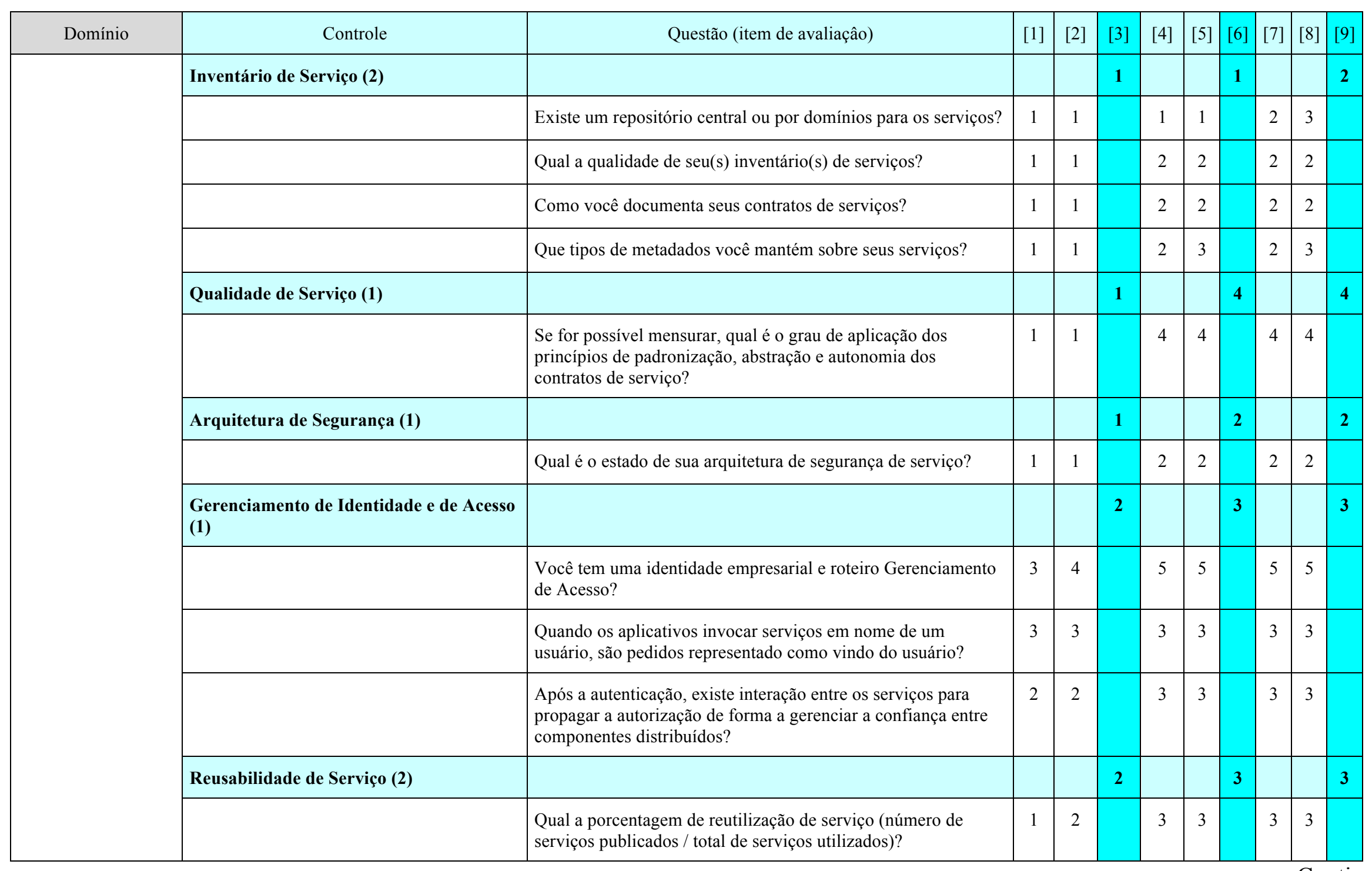

Continua 


\begin{tabular}{|c|c|c|c|c|c|c|c|c|c|c|c|}
\hline Domínio & Controle & Questão (item de avaliaçâo) & {$[1]$} & [2] & [3] & {$[4]$} & {$[5]$} & {$[6]$} & [7] & {$[8]$} & [9] \\
\hline & Ausência de Estado de Serviço (1) & & & & 2 & & & 2 & & & 2 \\
\hline & & $\begin{array}{l}\text { Existe alguma prática de implementação que favoreça a } \\
\text { ausência de estados nos serviços? }\end{array}$ & 2 & 2 & & 2 & 2 & & 2 & 2 & \\
\hline \multirow{13}{*}{$\begin{array}{c}\text { Informações e } \\
\text { Modelos de Dados - } \\
\text { D05 }\end{array}$} & Governança de Dados (1) & & & & 2 & & & 2 & & & 2 \\
\hline & & $\begin{array}{l}\text { Você tem um modelo de dados conceituais, lógicos e físicos da } \\
\text { organização? }\end{array}$ & 2 & 2 & & 2 & 2 & & 2 & 2 & \\
\hline & Modelo de Dados e Metadados (1) & & & & 1 & & & 2 & & & 3 \\
\hline & & $\begin{array}{l}\text { Como o modelo de dados pode ajudar no gerenciamento de } \\
\text { informação? }\end{array}$ & 1 & 1 & & 2 & 2 & & 3 & 3 & \\
\hline & Integração de Informações do Negócio (1) & & & & 1 & & & 3 & & & 3 \\
\hline & & Existe algum modelo de informação de negócio? & 1 & 1 & & 2 & 3 & & 2 & 3 & \\
\hline & & $\begin{array}{l}\text { Como a transformação de dados é utilizada por sua } \\
\text { organização? }\end{array}$ & 1 & 1 & & 2 & 2 & & 3 & 3 & \\
\hline & Padrões de Integração de Dados (2) & & & & 1 & & & 3 & & & 3 \\
\hline & & Como metadados são utilizados para integrar sua organização? & 1 & 1 & & 3 & 3 & & 4 & 4 & \\
\hline & & Como a infraestrutura de sua organização é integrada? & 2 & 2 & & 3 & 3 & & 3 & 3 & \\
\hline & Qualidade de Dados e Métricas (1) & & & & 1 & & & 1 & & & 2 \\
\hline & & $\begin{array}{l}\text { Como você descreveria a qualidade dos dados críticos da sua } \\
\text { organização? }\end{array}$ & 2 & 2 & & 2 & 2 & & 2 & 2 & \\
\hline & & $\begin{array}{l}\text { Como você descreveria a coleta e uso de métricas operacionais } \\
\text { existentes? }\end{array}$ & 1 & 1 & & 1 & 1 & & 2 & 2 & \\
\hline
\end{tabular}

Continua 


\begin{tabular}{|c|c|c|c|c|c|c|c|c|c|c|c|}
\hline Domínio & Controle & Questão (item de avaliaçâo) & {$[1]$} & {$[2]$} & {$[3]$} & {$[4]$} & {$[5]$} & {$[6]$} & [7] & [8] & [9] \\
\hline \multirow{12}{*}{$\begin{array}{c}\text { Tecnologia e } \\
\text { Infraestrutura - } \\
\text { D06 }\end{array}$} & Barramento Corporativo de Serviços (2) & & & & 1 & & & 2 & & & 4 \\
\hline & & Como está o uso de barramento de serviços? & 1 & 1 & & 2 & 2 & & 3 & 4 & \\
\hline & Topologia do Barramento (1) & & & & 1 & & & 2 & & & 3 \\
\hline & & $\begin{array}{l}\text { Como em sua organização você descreveria a topologia lógica } \\
\text { de suas aplicações SOA (no seu maior uso)? }\end{array}$ & 1 & 1 & & 2 & 2 & & 3 & 3 & \\
\hline & Solução de Mensagem (1) & & & & 1 & & & 2 & & & 3 \\
\hline & & $\begin{array}{l}\text { Você possui alguma solução de mensageria implementada } \\
\text { formalmente? }\end{array}$ & 1 & 1 & & 2 & 2 & & 3 & 3 & \\
\hline & $\begin{array}{l}\text { Uso de Padrões Interoperáveis de Dados } \\
\text { (2) }\end{array}$ & & & & 2 & & & 3 & & & 3 \\
\hline & & $\begin{array}{l}\text { Sua estrutura de mensagens usa padrões interoperáveis de } \\
\text { dados? }\end{array}$ & 2 & 2 & & 3 & 3 & & 3 & 3 & \\
\hline & Monitoramento (1) & & & & 2 & & & 3 & & & 4 \\
\hline & & Como é a política de monitoramento de em sua infraestrutura? & 2 & 2 & & 3 & 3 & & 4 & 4 & \\
\hline & Segurança (1) & & & & 1 & & & 2 & & & 2 \\
\hline & & $\begin{array}{l}\text { Políticas de segurança em serviços SOA estão implementados } \\
\text { e/ou gerenciados? }\end{array}$ & 1 & 1 & & 2 & 2 & & 2 & 2 & \\
\hline
\end{tabular}

Continua 


\begin{tabular}{|c|c|c|c|c|c|c|c|c|c|c|c|}
\hline Domínio & Controle & Questão (item de avaliaçâo) & {$[1]$} & {$[2]$} & {$[3]$} & {$[4]$} & {$[5]$} & {$[6]$} & [7] & {$[8]$} & [9] \\
\hline \multirow{13}{*}{$\begin{array}{l}\text { Operação e } \\
\text { Gerenciamento de } \\
\text { TI - D07 }\end{array}$} & Gerenciamento de Serviços de TI (1) & & & & 1 & & & 1 & & & 3 \\
\hline & & $\begin{array}{l}\text { Os processos do Gerenciamento de Serviços de TI se encontram } \\
\text { integrados e automatizados? }\end{array}$ & 1 & 1 & & 1 & 1 & & 3 & 3 & \\
\hline & $\begin{array}{l}\text { Gerenciamento de Configuração de } \\
\text { Ativos de TI (1) }\end{array}$ & & & & 1 & & & 2 & & & 2 \\
\hline & & $\begin{array}{l}\text { Como sua organização implementa versionamento no } \\
\text { gerenciamento de seus ativos de TI (em destaque as soluções e } \\
\text { serviços SOA)? }\end{array}$ & 1 & 1 & & 2 & 2 & & 2 & 2 & \\
\hline & & $\begin{array}{l}\text { Como se dá a implementação das políticas de gerenciamento de } \\
\text { configuração na organização? }\end{array}$ & 1 & 1 & & 2 & 2 & & 2 & 2 & \\
\hline & Gerenciamento de Implantação (1) & & & & 1 & & & 2 & & & 2 \\
\hline & & $\begin{array}{l}\text { Como é a metodologia de implantação de serviços em sua } \\
\text { organização? }\end{array}$ & 1 & 1 & & 2 & 2 & & 2 & 2 & \\
\hline & & $\begin{array}{l}\text { Você possui alguma plataforma de gerenciamento para } \\
\text { implantação de serviços? }\end{array}$ & 2 & 2 & & 3 & 3 & & 3 & 3 & \\
\hline & $\begin{array}{l}\text { Gerenciamento de Incidentes e Eventos } \\
\text { (1) }\end{array}$ & & & & 2 & & & 2 & & & 2 \\
\hline & & $\begin{array}{l}\text { Como sua organização implementa o gerenciamento de } \\
\text { incidentes e eventos? }\end{array}$ & 2 & 2 & & 2 & 2 & & 2 & 2 & \\
\hline & Monitoramento da Infraestrutura (1) & & & & 1 & & & 2 & & & 3 \\
\hline & & Como é a política de fiscalização de sua infraestrutura? & 1 & 1 & & 2 & 2 & & 3 & 3 & \\
\hline & & $\begin{array}{l}\text { Você tem uma plataforma de gestão para implantar seus } \\
\text { serviços? }\end{array}$ & 1 & 1 & & 2 & 2 & & 3 & 3 & \\
\hline
\end{tabular}




\section{APÊNDICE D - DOCUMENTAÇÃO DO PROJETO E DESENVOLVIMENTO DO SOFTWARE}

Neste apêndice, é apresentada a documentação referente aos processos de projeto e desenvolvimento do sistema, composta por:

- documento de visão - que dá descrição básica da fase de iniciação na concepção do sistema;

- documento de requisitos - resultante da aplicação de técnicas de engenharia de requisitos, tais como listas de requisitos funcionais e não-funcionais, bem como de sua matriz de rastreabilidade;

- documento de prototipação - no que se refere à descrição das camadas arquiteturais do modelo cliente-servidor utilizado; e

- documento de análise de dados e sua persistência - através de um Modelo de Entidade-Relacionamento Conceitual e sua devida expressão Relacional (normalizada). 
Modelo para Avaliação de Maturidade SOA

Visão do Negócio

Modelo para Avaliação de Maturidade SOA - Documento de Visão do Negócio 
Modelo para Avaliação de Maturidade SOA

Visão do Negócio

\section{HISTÓRICO DAS REVISÕES}

\begin{tabular}{|c|c|l|l|}
\hline Data & Versão & \multicolumn{1}{|c|}{ Descrição } & \multicolumn{1}{|c|}{ Autor } \\
\hline $01 / 12 / 2011$ & 0.1 & Versão Inicial & André Toffanello \\
\hline $13 / 11 / 2012$ & 0,2 & Inserção dos Itens de Gerenciamento de Projeto & Felipe Magalhães \\
\hline $01 / 12 / 2013$ & 0.3 & $\begin{array}{l}\text { Revisão do Escopo com a retirado do item de Gestão } \\
\text { de Riscos }\end{array}$ & Claynor Mazzarolo \\
\hline $10 / 10 / 2014$ & 1.0 & $\begin{array}{l}\text { Nome do Sistema alterado para } \\
\text { "Modelo para Avaliação de Maturidade SOA" }\end{array}$ & Claynor Mazzarolo \\
\hline
\end{tabular}




\section{CONTEÚDO}

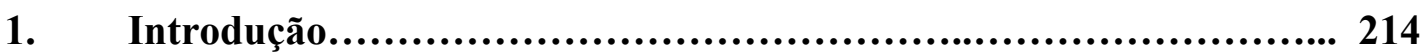

2. Concepção e Evolução da Idéia......................................... 214

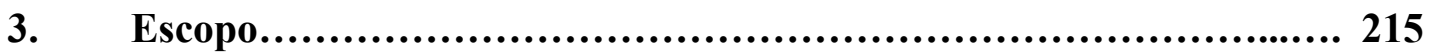

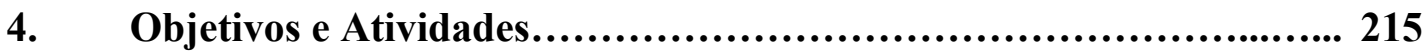

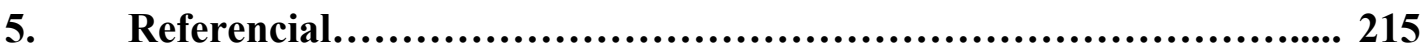

6. Descrições dos Envolvidos e Usuários...................................... 215

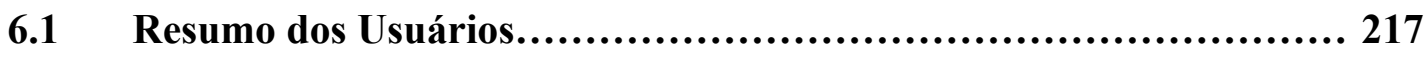

7. Visão Geral do Produto..................................................... 218

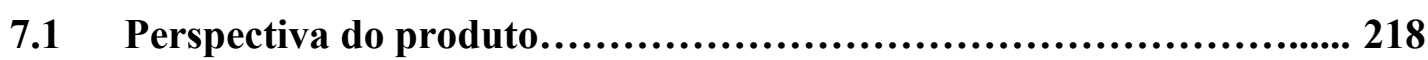

7.2 Suposições e dependências / Análise Estratégica............................ 218

7.3 Macro-Processos do Produto GRC........................................ 219

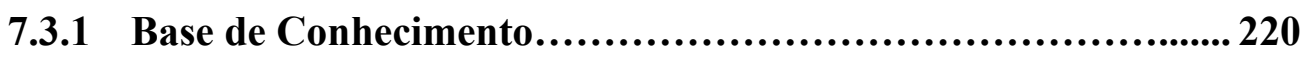

7.3.2 Gerenciamento de Riscos.......................................... 220

7.3.3 Avaliação de Conformidade........................................... 221

7.4 Resultados Esperados......................................................... 221 


\section{Introdução}

O objetivo deste documento é apresentar aa primeiras observações definidas a partir de uma especificação definida para a elaboração de uma ferramenta sistêmica que suporte a avaliação dos impactos e necessidades de um ciclo contínuo de maturidade para adoção de uma arquitetura orientada a serviços - SOA.

\section{Concepção e Evolução da Ideia}

Nos dias 27 e 28 de abril de 2011, em Brasília, DF, ocorreu, pela primeira vez na América Latina, o $4^{\text {th }}$ International SOA Symposium e o $3^{\text {rd }}$ International Cloud Symposium, que contou com a presença de Thomas Erl, da SOA Systems, Anne Mann Thomas, do Gartner, e outros nomes importantes no cenário mundial da computação orientada a serviço. A promoção do simpósio proporcionou o estabelecimento de uma rede de relacionamento, que permitiu o contato e o desenvolvimento de ideias com os especialistas reconhecidos internacionalmente da Computação Orientada a Serviço e Cloud Computing. A concepção da ideia surgiu aproximadamente 12 meses antes do simpósio, em março de 2010, com tempo de planejamento para o simpósio. Vislumbrou-se a possibilidade de desenvolver um produto capaz de:

- $\quad$ ornecer de uma base de conhecimento, na forma de documentos estruturados, sobre adoção de SOA e suas implicações de Governança, Riscos e Conformidade.

- Fornecer de um Modelo de Avaliação e Monitoração, estruturado por Área de Conhecimento/Processos/Disciplinas, Processos, Listas de Verificação (check lists) e Métricas, conforme Modelo de Maturidade de Orientação a Serviço (SOMM).

- Fornecer um produto de Software que implemente o Modelo de Avaliação e Monitoração Continuada.

A proposta foi motivada a evoluir para o patamar de Projeto quando considerando o caráter inovador catalisada pelo $4^{\text {th }}$ International SOA Symposium e o $3^{\text {rd }}$ International Cloud 
Symposium, com o lançamento do livro inédito sobre Governança em SOA por Thomas Erl e ainda as diretrizes para desenvolvimento do SOMM [APQC - "Service-Orientation Maturity Model - SOMM", 2011].

\section{Escopo}

O projeto tem o foco na produção, análise e gerenciamento de requisitos ao longo do desenvolvimento dos projeto de uma plataforma sistêmica para suporte a adoção de SOA. Do escopo inicial está prevista a disponibilização de recursos de:

- uma Base de Conhecimento estruturada e navegável, disponibilizada em formato HTML e integrada com os demais componentes do produto;

- um Modelo para Avaliação e Monitoração da Maturidade em SOA.

\section{Objetivos e Atividades}

O documento deve ser utilizado para uma melhor avaliação no desenvolvimento do software, possibilitando melhor noção das necessidades e características que serão descritas no documento de requisitos, para a posterior implementação. Dessa forma, o documento visa a esclarecer os objetivos e decisões a serem tomadas na construção do sistema.

\section{Referencial}

SOA Governance Tutorial.

Disponível em: $<$ http://searchsoa.techtarget.com/tutorial/SOA-Governance-Tutorial $>$. Acesso em: 2011-08-01.

\section{Descrições dos Envolvidos e Usuários}

Os principais envolvidos neste projeto estão descritos abaixo. 
Modelo para Avaliação de Maturidade SOA

Visão do Negócio

\begin{tabular}{|c|c|c|c|c|c|}
\hline \multirow{2}{*}{ Área } & Função & RACI & $\begin{array}{c}\text { Interesse no } \\
\text { projeto }\end{array}$ & Influência no projeto & Impacto \\
\hline Presidente IBTI & Coordenador/ Gestor & R/A & 5-Muito Alto & 5-Muito Alta & 5-Muito Alto \\
\hline Coordenador Técnico & Coordenador & R & 5-Muito Alto & 5-Muito Alta & 5-Muito Alto \\
\hline Coordenador Negócio & Coordenador & R & 5-Muito Alto & 5-Muito Alta & 5-Muito Alto \\
\hline Bolsista IBTI & Consultora/ Analista & C/I & 4-Alto & 4-Alto & 4-Alto \\
\hline Bolsista IBTI & Consultor & C/I & 4-Alto & 4-Alto & 4-Alto \\
\hline Bolsista UnB & Consultor SOA & C/I & 3-Médio & 4-Alta & 5-Muito Alto \\
\hline Bolsista IBTI & Analista & I & 3-Médio & 4-Alta & 3-Média \\
\hline Bolsista IBTI & Analista & I & 3-Médio & 3-Média & 3-Média \\
\hline Bolsista IBTI & Projetista/ Prog & I & 3-Médio & 3-Média & 3-Média \\
\hline Bolsista IBTI & Projetista/ Prog & I & 3-Médio & 3-Média & 3-Média \\
\hline
\end{tabular}

\begin{tabular}{|c|c|c|c|}
\hline Parte interessada & Interesse & Influência & Impacto \\
\hline \multirow[t]{5}{*}{$\begin{array}{l}\text { Pessoa, comunidade ou organização envolvida cujos } \\
\text { interesses podem ser afetados pelo projeto. Exercem } \\
\text { influência sobre o projeto, suas entregas e sua equipe }\end{array}$} & $\begin{array}{lr}\text { Nível } & \text { de } \\
\text { preocupação } & \text { em } \\
\text { relação } & \text { aos } \\
\text { resultados } & \text { do } \\
\text { projeto } & \end{array}$ & $\begin{array}{l}\text { Envolvimento } \\
\text { ativo no projeto. }\end{array}$ & $\begin{array}{l}\text { Habilidade } \\
\text { para efetuar } \\
\text { mudanças no } \\
\text { planejamento } \\
\text { ou na } \\
\text { execução do } \\
\text { projeto }\end{array}$ \\
\hline & 1-Muito baixo & 1-Muito baixa & $\begin{array}{l}\text { 1-Muito } \\
\text { baixo }\end{array}$ \\
\hline & 2-Baixo & 2-Baixa & 2-Baixo \\
\hline & 3-Médio & 3-Média & 3-Médio \\
\hline & 4-Alto & 4-Alta & 4-Alto \\
\hline
\end{tabular}

O perfil inicial da equipe envolvida para a execução do projeto é basicamente descrita a seguir:

- nível superior completo nas áreas de ciência da computação e informação.

- $\quad$ pós-graduação desejável;

- $\quad$ apresentar fluência em língua inglesa para leitura, escrita e conversação;

- apresentar conhecimentos relacionados ao processo de desenvolvimento de softwares com base em metodologias RUP/UML; 
- apresentar conhecimentos relacionados ao Modelo de Maturidade de Software CMMI - Capability Maturity Model;

- apresentar conhecimentos relacionados à Arquitetura da Informação com foco em definições de metadados da informação;

- apresentar conhecimentos relacionados à Arquitetura Orientada a Serviço para o desenvolvimento de sistemas de informação;

- apresentar conhecimentos relacionados ao mapeamento de processo de negócio através das técnicas de modelagem e notação BPMN - Business Process Medeling Notation.

- apresentar aptidão para o desenvolvimento de Base de Conhecimento através das técnicas da Arquitetura da Informação.

- apresentar aptidão para, através das técnicas empregadas pela Metodologia Científica, realizar pesquisas relacionadas à Computação Orientada a Serviço, Métodos de Análise de Governança, Métodos de Análise de Riscos e Métodos para Análise de Conformidade.

A estrutura de responsabilidade inicia com a gestão do projeto sendo executada por um Coordenador de Projeto, responsável pela equipe - na pessoa do Coordenador Claynor Mazzarolo e pela entrega dos produtos, pela elaboração de um cronograma inicial de atividades, pelo alinhamento de escopo, pela alocação inicial de recursos como elencado anteriormente, e ainda pela geração, coleta, distribuição, armazenamento, recuperação e destinação final das informações sobre o projeto de forma oportuna e adequada.

Para a gestão de Projeto deverá ser utilizada metodologia de gerenciamento de projetos baseada no PMBook do Project Management Institute - PMI, através de artefatos gerados em comum acordo com as especificidades do Projeto no âmbito do IBTI.

\subsection{Resumo dos Usuários}

Segue uma lista resumida dos usuários inicialmente identificados para o sistema. 


\begin{tabular}{|c|c|c|}
\hline Nome & Descrição & Responsabilidades \\
\hline Administrador & $\begin{array}{l}\text { Administrador do } \begin{array}{r}\text { Sistema. } \\
\text { Gerenciamento } \\
\text { ilimitada). }\end{array} \\
\text { (permissão }\end{array}$ & $\begin{array}{l}\text { - Inclusão e exclusão no sistema- } \\
\text { Fazer backup }\end{array}$ \\
\hline Usuário de Registro & $\begin{array}{l}\text { Funcionário que tenha permissão } \\
\text { (senha) limitada (restrição) para a } \\
\text { utilização do sistema. }\end{array}$ & $\begin{array}{l}\text { - Realiza o preenchimento dos } \\
\text { formulários } \\
\text { - Realiza as atividades de Usuário } \\
\text { Analista }\end{array}$ \\
\hline Usuário Analista & $\begin{array}{l}\text { Consulta relatórios gerados pelo } \\
\text { sistema. }\end{array}$ & $\begin{array}{l}\text { - Não possui responsabilidades de } \\
\text { cadastramento }\end{array}$ \\
\hline Usuário de Estudo & $\begin{array}{l}\text { Consulta informações / } \\
\text { conhecimentos sobre SOA }\end{array}$ & $\begin{array}{l}\text { - Acessa os módulos de } \\
\text { disponibilização de informações } \\
\text { do sistema }\end{array}$ \\
\hline
\end{tabular}

\section{Visão Geral do Produto}

Esta seção oferece uma visão de nível superior dos recursos do produto.

\subsection{Perspectiva do produto}

A nossa perspectiva é que o modelo sistêmico atenda não só a perspectiva de uso dos consultores SOA no suporte a projeto de consultoria em SOA bem como a recursos humanos previamente qualificados na realização de suas avaliações locais nas práticas de adoção de SOA.

\subsection{Suposições e dependências / Análise Estratégica}

Com a indicação inovadora do conceito GRC aplicado para a Computação Orientada a Serviço apresentado no objetivo do projeto, é apresentada preliminarmente na forma de análise estratégica simplificada o seguinte: 


\begin{tabular}{|l|l|}
\hline \multicolumn{1}{|c|}{ Perspectiva } & \multicolumn{1}{c|}{ Ambiente Interno } \\
\hline Oportunidade & $\begin{array}{l}\text { Desenvolver Capital Humano com proficiência para execução de modelos para } \\
\text { planejamento, implementação e governança de projetos em SOA. } \\
\text { Desenvolver capital humano para emprego de técnicas para governança, análise } \\
\text { de riscos e análise de conformidade em projetos em SOA }\end{array}$ \\
\hline Ameaças & $\begin{array}{l}\text { Disponibilidade de perfis profissionais conforme perfil definido para equipe. } \\
\text { Mudança de políticas de gestão do projeto. } \\
\text { Atrasos na execução do projeto por indisponibilidade de equipe. }\end{array}$ \\
\hline Pontos Fortes & $\begin{array}{l}\text { Acesso privilegiado a informações e bases de conhecimentos restritas sobre } \\
\text { Computação Orientada. } \\
\text { Corpo técnico dedicado ao projeto com larga experiência na execução de } \\
\text { projetos em SOA. } \\
\text { Rede de relacionamentos com instituições internacionais como SOA Systems } \\
\text { Gartner. } \\
\text { Proficiência na modelagem de processos pelas melhores práticas e notação } \\
\text { BPMN. }\end{array}$ \\
\hline Peunir equipe focada $100 \%$ da disponibilidade para o projeto. \\
Proficiência nas técnicas de Governança, Análise de Riscos e Análise de \\
Conformidade em $100 \%$ da equipe.
\end{tabular}

\begin{tabular}{|l|l|}
\hline \multicolumn{1}{|c|}{ Perspectiva } & \multicolumn{1}{|c|}{ Ambiente Externo } \\
\hline Oportunidade & $\begin{array}{l}\text { Desenvolver Framework automatizado em ferramenta de software para a } \\
\text { Governança, Análise de Riscos e Análise de Conformidade para projetos em } \\
\text { SOA. }\end{array}$ \\
\hline Ameaças & $\begin{array}{l}\text { Indisponibilidade de recursos financeiros e humanos. } \\
\text { Surgimento de produtos concorrentes antes da conclusão do produto de software. }\end{array}$ \\
\hline Pontos Fortes & $\begin{array}{l}\text { Projeto inovador de nível internacional. } \\
\text { Capacidade de apresentação e utilização dos modelos desenvolvidos para GRC- } \\
\text { SOA para o mercado. } \\
\text { Capacidade de captação de recursos financeiros para o projeto através } \\
\text { instituições de fomento a pesquisa e inovação. } \\
\text { Necessidade de mercado de um framework bem definido para o desenvolvimento } \\
\text { de projetos em SOA. }\end{array}$ \\
\hline Pontos Fracos & $\begin{array}{l}\text { Prazos e recursos financeiros escassos para lançamento de um produto comercial } \\
\text { em tempo de ineditismo. }\end{array}$ \\
\hline
\end{tabular}

\subsection{Macro-Processos do Produto GRC}

Processo de integração entre Governança, Conformidade e Risco baseado na metodologia SOA. 


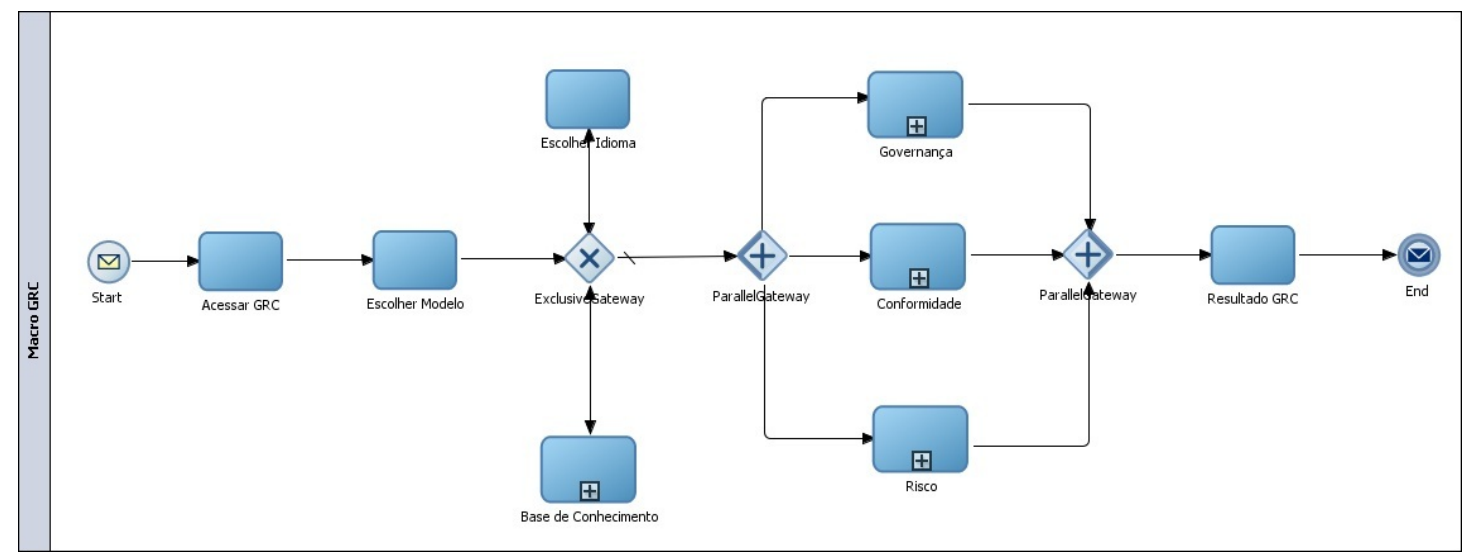

\subsubsection{Base de Conhecimento}

Local onde o usuário, caso sinta necessidade, terá acesso a: Conceitos relacionados ao GRC, Glossário, Princípios de Referência e Metodologia de Referências.

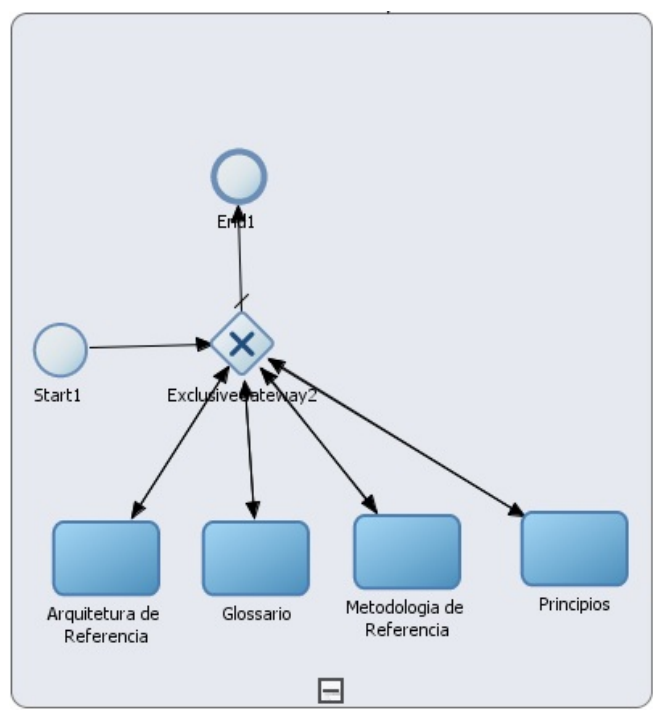

\subsubsection{Gerenciamento de Riscos}

Identifica e cataloga os riscos, utilizando as técnicas de priorização GUT, afim de listar os possíveis riscos. 


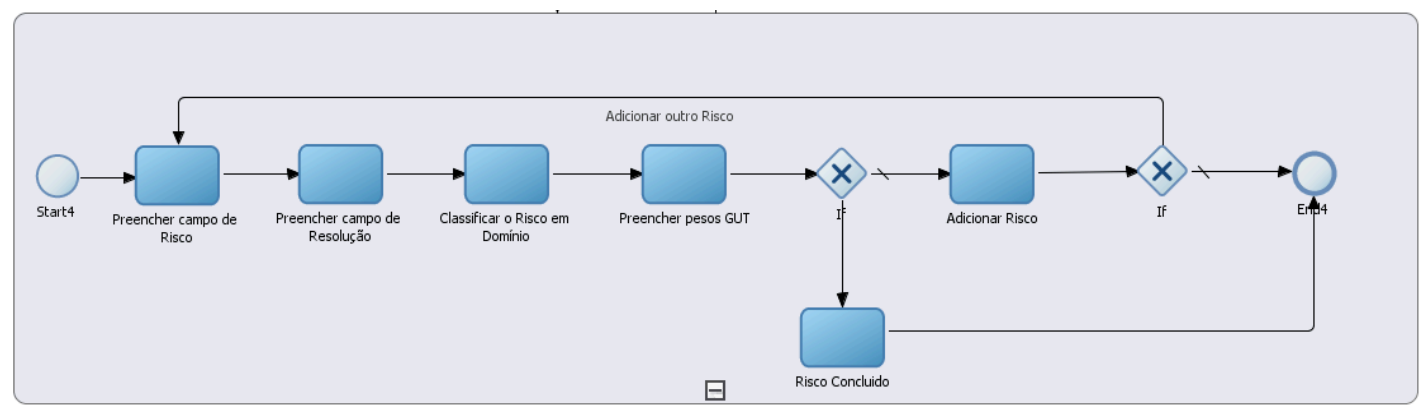

Obs: veja HISTÓRICO DAS REVISÕES (0.3) na qual foi retirado este escopo (Gerenciamento de Riscos) do produto final.

\subsubsection{Avaliação de Conformidade}

Identifica o nível de maturidade atual da organização, segundo o modelo.

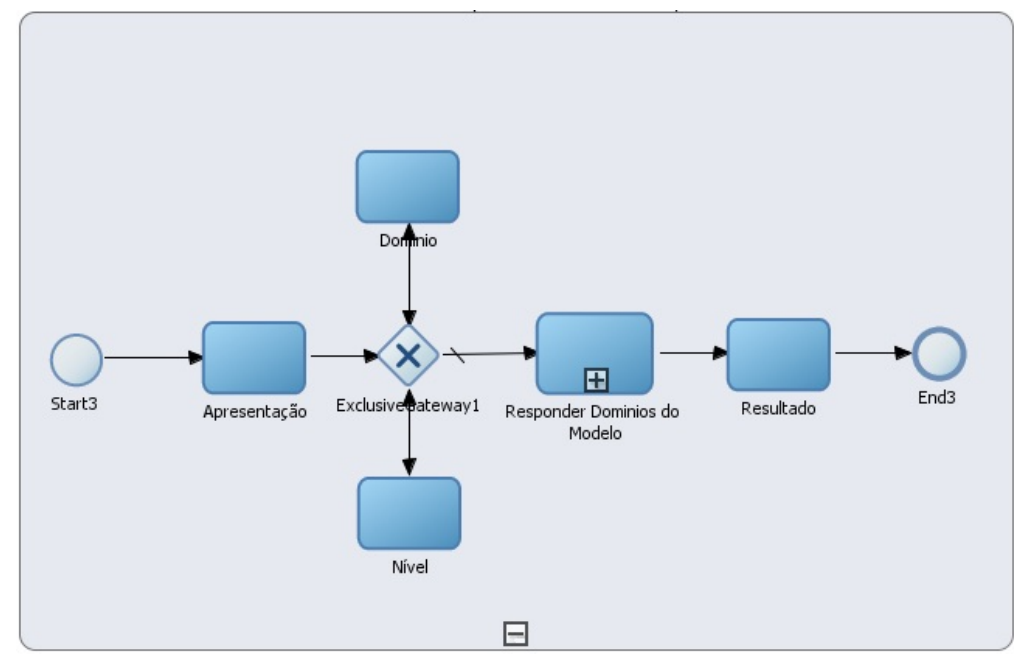

\subsection{Resultados Esperados}

A Arquitetura Orientada a Serviços (SOA) tem como meta identificar, tratar e integrar Serviços (unidade fundamental da lógica orientada a serviço) comuns através de componentes de serviços. Os sistemas tradicionais cliente/servidor sempre focaram a interação com o usuário, e os dados de forma centralizada o que tornava difícil qualquer mudança estrutural pelo fato de exigir um grande esforço, até mesmo nas novas aplicações clientes. A proposta da arquitetura SOA quebra este paradigma já que decompõem os 
sistemas em forma de serviços, permitindo que estes serviços sejam consumidos por aplicações clientes, através de uma comunicação padronizada.

Uma das características problemáticas do serviço é a intangibilidade. Para minimizar este problema o mercado de serviços conta com o apoio de diversos modelos que servem como balizadores para a melhor compreensão da SOA.

O Resultado esperado deste projeto é a especificação e implementação de um produto de software de conteúdo inédito que alia uma base de conhecimento escrita de forma estruturada, acessível e utilizável para aferição do nível de maturidade de uma organização em relação aos preceitos de $\mathrm{SOA}$, bem como a avaliação de conformidade com as melhores práticas e aplicação dos controles de governança. 
Modelo para Avaliação de Maturidade SOA

Documento de Análise (Requisitos e Casos de Uso)

Documento de Requisitos do Sistema

Modelo para Avaliação de Maturidade SOA

Versão 1.0 
Modelo para Avaliação de Maturidade SOA

Documento de Análise (Requisitos e Casos de Uso)

Histórico de Alterações

\begin{tabular}{|c|c|l|l|}
\hline Data & Versão & \multicolumn{1}{|c|}{ Descrição } & \multicolumn{1}{|c|}{ Autor } \\
\hline $17 / 04 / 2012$ & 0.1 & Requisitos Iniciais do Sistema GRC & Felipe Fonseca \\
\hline $10 / 10 / 2014$ & 1.0 & $\begin{array}{l}\text { Nome do sistema alterado para } \\
\text { "Modelo para Avaliação de Maturidade SOA" }\end{array}$ & Claynor Mazzarolo \\
\hline
\end{tabular}




\section{CONTEÚDO}

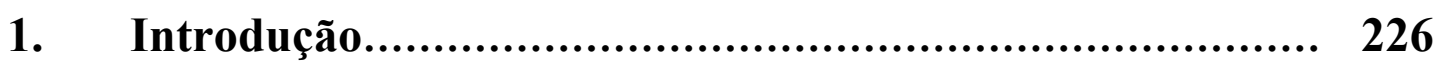

1.1 Visão geral do documento................................. 226

1.2 Convenções, termos e abreviações......................... 227

1.2.1 Identificação dos requisitos........................ 227

1.2.2 Prioridades dos requisitos........................... 227

2. Entregáveis / Módulos..................................................... 228

3. Requisitos funcionais.................................................. $\quad 230$

4. Requisitos não-funcionais......................................... 233

5. Casos de Uso................................................................... 234

6. Heurística do Modelo de Tomada de Decisão................... 236

7. Referenciais Adicionais ............................................... 238 


\section{INTRODUÇÃO}

Este documento especifica os requisitos do sistema, fornecendo aos desenvolvedores as informações necessárias para o projeto e implementação, assim como para a realização dos testes e homologação do sistema.

A descrição geral do sistema se encontra junto ao Documento de Visão ora desenvolvido / apresentado.

Uma visão geral de seu funcionamento se encontra junto a Documento de Apresentação dos Requisitos de Prototipação.

\subsection{VISÃO GERAL DO DOCUMENTO}

Além desta seção introdutória, as seções seguintes estão organizadas tendo por foco a definição inicial de :

- Requisitos funcionais: especifica todos os casos de uso do sistema, descrevendo os fluxos de eventos, prioridades, atores, entradas e saídas de cada caso de uso a ser implementado.

- Requisitos não-funcionais: especifica todos os requisitos não funcionais do sistema, tais como requisitos de usabilidade, confiabilidade, desempenho, segurança, distribuição, adequação a padrões e requisitos de hardware e software. 


\subsection{CONVENÇÕES, TERMOS E ABREVIAÇÕES}

A correta interpretação deste documento exige o conhecimento de algumas convenções e termos específicos, que são descritos a seguir.

\subsubsection{Identificação dos requisitos}

Por convenção, a referência a requisitos é feita através do nome do entregável onde eles estão posicionados, seguidos do identificador do requisito, de acordo com a especificação a seguir:

[entregável / identificador do requisito].

\subsubsection{Prioridades dos requisitos}

Para priorização dos requisitos foi utilizada as denominações "essencial”, "importante" e "desejável”.

1. Essencial é o requisito sem o qual o sistema não entra em funcionamento. Requisitos essenciais são requisitos imprescindíveis, que têm que ser implementados impreterivelmente. 
2. Importante é o requisito sem o qual o sistema entra em funcionamento, mas de forma não satisfatória. Requisitos importantes devem ser implementados, mas, se não forem, o sistema poderá ser implantado e usado mesmo assim.

3. Desejável é o requisito que não compromete as funcionalidades básicas do sistema, isto é, o sistema pode funcionar de forma satisfatória sem ele. Requisitos desejáveis podem ser deixados para versões posteriores do sistema, caso não haja tempo hábil para implementá-los na versão que está sendo especificada.

\section{ENTREGÁVEIS/MÓDULOS}

\subsection{BASE DE CONHECIMENTO}

Base de conhecimento estruturada e navegável, disponibilizada em formato HTML e integrada com os demais componentes do produto, onde for apropriado.

Entregável:

- BASE DE CONHECIMENTO 


\subsection{GERENCIAMENTO DE RISCOS}

Modelo de gerenciamento e priorização de riscos utilizando-se de registro da matriz GUT.

Entregável:

- RISCOS

(Obs: veja HISTÓRICO DAS REVISÕES (0.3) do Documento de Visão na qual este entregável foi retirado do escopo (Gerenciamento de Riscos) do produto final.

\subsection{AVALIAÇÃO DE CONFORMIDADE}

Módulos referente a disponibilização dos questionários de avaliação e outro de informações de saídas para suporte a tomada de decisão.

Entregáveis:

- AVALiAÇÃO - CADASTRAMENTO

- avaliação - SAÍdA 
Modelo para Avaliação de Maturidade SOA

Documento de Análise (Requisitos e Casos de Uso)

OBS: Requisitos classificados como GLOBAL referem-se a requisitos para atender o conjunto de entregáveis / módulos do sistema ou perpassam todo o conjunto de módulos.

\section{REQUISITOS FUNCIONAIS}

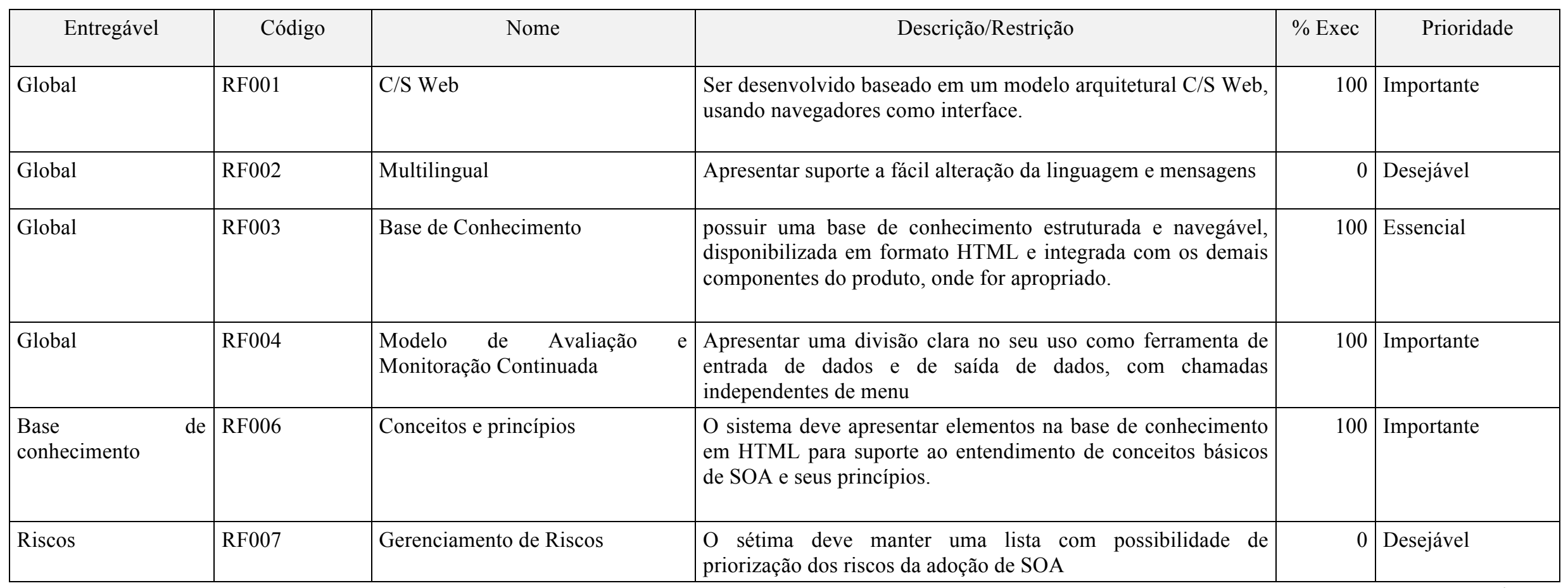

Continua 
Modelo para Avaliação de Maturidade SOA

Documento de Análise (Requisitos e Casos de Uso)

\begin{tabular}{|c|c|c|c|c|c|}
\hline Entregável & Código & Nome & Descrição/Restrição & $\%$ Exec & Prioridade \\
\hline Riscos & RF007 & Gerenciamento de Riscos & $\begin{array}{l}\text { Se o risco deixar de existir o sistema deve permitir sua retirada } \\
\text { lógica (e não física) da lista. }\end{array}$ & 0 & Desejável \\
\hline $\begin{array}{l}\text { Base de } \\
\text { conhecimento }\end{array}$ & RF007 & Glossário & $\begin{array}{l}\text { O sistema deve apresentar elementos na base de conhecimento } \\
\text { em HTML como um sistema de glossário indexado e a presença } \\
\text { de termos desse glossário no conjunto da aplicação devem } \\
\text { remeter a estes elementos. }\end{array}$ & 100 & Importante \\
\hline $\begin{array}{l}\text { Avaliação } \\
\text { cadastramento }\end{array}$ & RF008 & Registro do Modelo & $\begin{array}{l}\text { O modelo deve prever alguma forma de adaptação / } \\
\text { customização, e assim persistido e calculado de forma } \\
\text { independente a sua quantidade de elementos / estrutura. }\end{array}$ & 100 & Essencial \\
\hline $\begin{array}{l}\text { Avaliação } \\
\text { cadastramento }\end{array}$ & RF008 & Estrutura do Modelo & $\begin{array}{l}\text { O sistema deve estruturar o modelo no formato: DOMINIO } \\
(1: \mathrm{N}) \text { CONTROLE }(1: \mathrm{N}) \text { QUESTÃO }(1: \mathrm{N}) \text { ITEM [1] }\end{array}$ & 100 & Essencial \\
\hline $\begin{array}{l}\text { Avaliação } \quad- \\
\text { cadastramento }\end{array}$ & RF009 & Preenchimento & $\begin{array}{l}\text { O preenchimento se dará em formulários distintos para cada } \\
\text { domínio, permitindo assim o preenchimento "à tempo" de cada } \\
\text { domínio por responsáveis separados. [1] }\end{array}$ & 100 & Essencial \\
\hline Avaliação - resposta & RF010 & Saídas & $\begin{array}{l}\text { O Modelo de Maturidade deverá permitir a avaliação } \\
\text { quantitativa de cada um dos domínios em separado e no seu } \\
\text { conjunto. }\end{array}$ & 100 & Essencial \\
\hline Avaliação - saída & RF011 & Saídas II & $\begin{array}{l}\text { O sistema deve privilegiar visualização de avaliações de } \\
\text { maturidade na forma de painéis gráficos interativos tais como } \\
\text { histogramas e gráficos de radar, barra, pizza, etc. }\end{array}$ & 100 & Essencial \\
\hline Avaliação - saída & RF012 & Divisão das saídas & $\begin{array}{l}\text { O sistema deverá possibilitar a avaliação automática do índice } \\
\text { (SCORE de } 0 \text { a 5) que refletirá o nível de maturidade associado } \\
\text { a caad domínio. }\end{array}$ & 100 & Essencial \\
\hline
\end{tabular}


Modelo para Avaliação de Maturidade SOA

Documento de Análise (Requisitos e Casos de Uso)

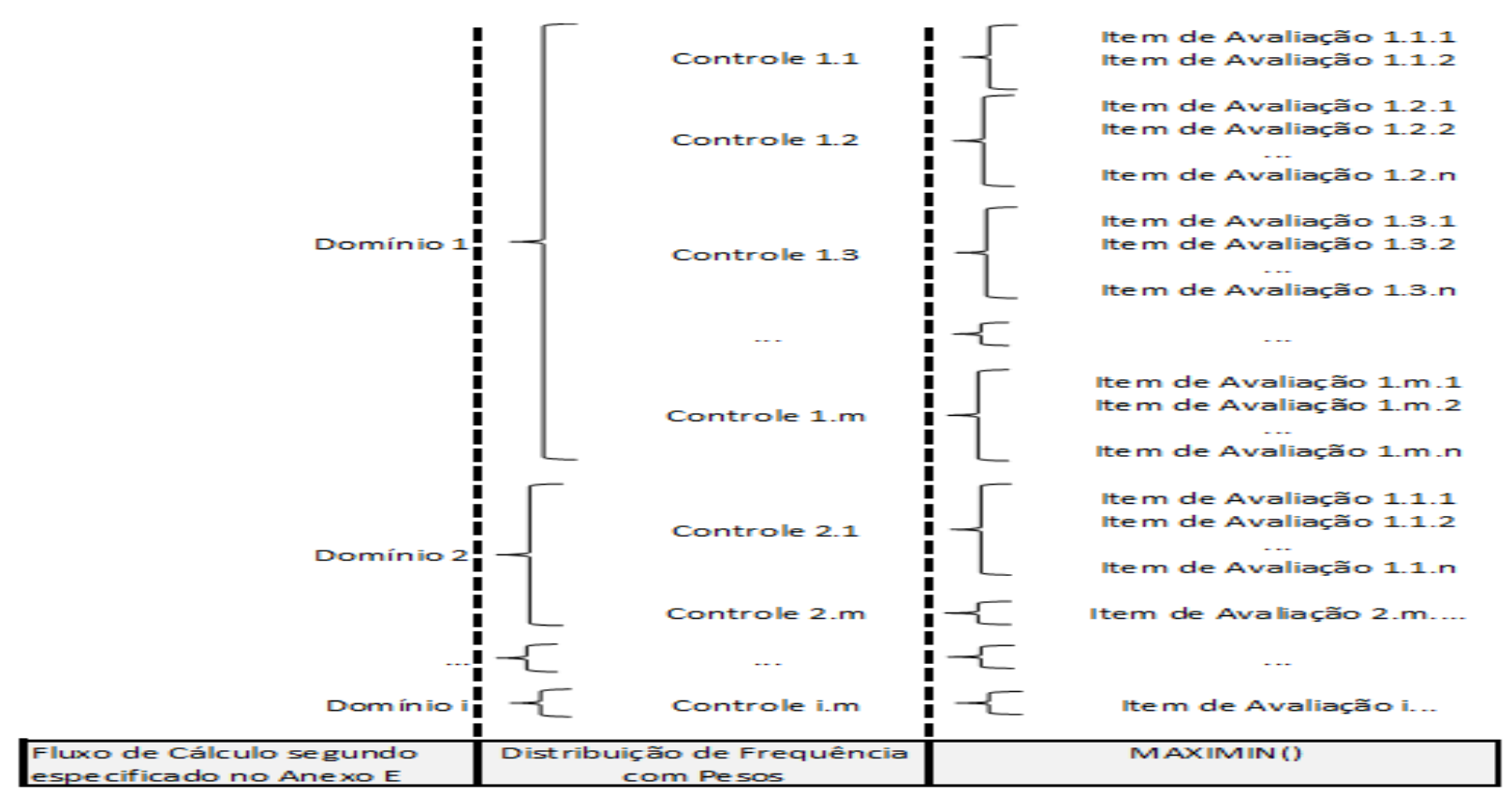

[1] Estando preenchidos, intempestivamente, quaisquer questionários por representantes organizacionais diversos, cada última versão desses são utilizadas na valoração dos controles. Assim, é de interesse que a tempestividade de preenchimento seja acordada pelas partes ou, senão, que cada responsável mantenha atualizado "em tempo" a posição de cada questionário aplicado, provendo assim uma situação atualizada referente aos aspectos de SOA sob sua competência. 
Modelo para Avaliação de Maturidade SOA

Documento de Análise (Requisitos e Casos de Uso)

\section{REQUISITOS NÃO-FUNCIONAIS}

\begin{tabular}{|c|c|c|c|c|c|}
\hline Entregável & Código & Nome & Descrição/restrição & $\%$ exec & Prioridade \\
\hline Global & RNF001 & Usabilidade & $\begin{array}{l}\text { O sistema terá uma interface amigável ao usuário primário sem se } \\
\text { tornar cansativa aos usuários mais experientes. Em especial, o } \\
\text { módulo de publicação HTML possuirá um wizard para ajudar o } \\
\text { usuário. }\end{array}$ & 100 & Essencial \\
\hline Global & RNF002 & Suporte Poliglota & $\begin{array}{l}\text { O sistema deverá permitir um modelo configurável de suporte } \\
\text { poliglota para o SGBD, isto é, uma fácil mudança de SGBD usado. }\end{array}$ & 100 & Essencial \\
\hline Avaliação & RNF003 & Acesso ao Sistema & $\begin{array}{l}\text { O sistema deverá em todos os módulos estar protegido por um } \\
\text { modelo de login e senha, impedindo o acesso diretro por links } \\
\text { internos nas páginas. }\end{array}$ & 50 & Importante \\
\hline Avaliação & RNF004 & $\mathrm{C} / \mathrm{S}$ com foco em scripts & $\begin{array}{l}\text { O sistema deve dar foco na resolução de suas heurísticas junto a } \\
\text { interface cliente, através de linguagens de script (Javascript) }\end{array}$ & 100 & Importante \\
\hline Avaliação & RNF005 & Execução da Heurística & $\begin{array}{l}\text { Visão minimizar o impacto de recálculo o sistema deve calcular a } \\
\text { heurística no momento de gravação do modelo.[1] }\end{array}$ & 0 & Desejável \\
\hline
\end{tabular}

Obs.: [1] Após o preenchimento dos questionários referente a cada domínio, e posterior ação de "Salva" os valores dos itens das questões são coletados e analisados segundo um modelo de tomada de decisão multiatributo (cap. 6 desse documento), observando os controles dispensados, e o tratamento das situações de múltiplas questões em um controle que tenham inter-relação por detalhamento de um escopo ou por escopo diferenciado, como citado anteriormente. Esses valores estabelecem a quantificação de cada controle dentro de cada domínio. 


\section{CASOS DE USO}

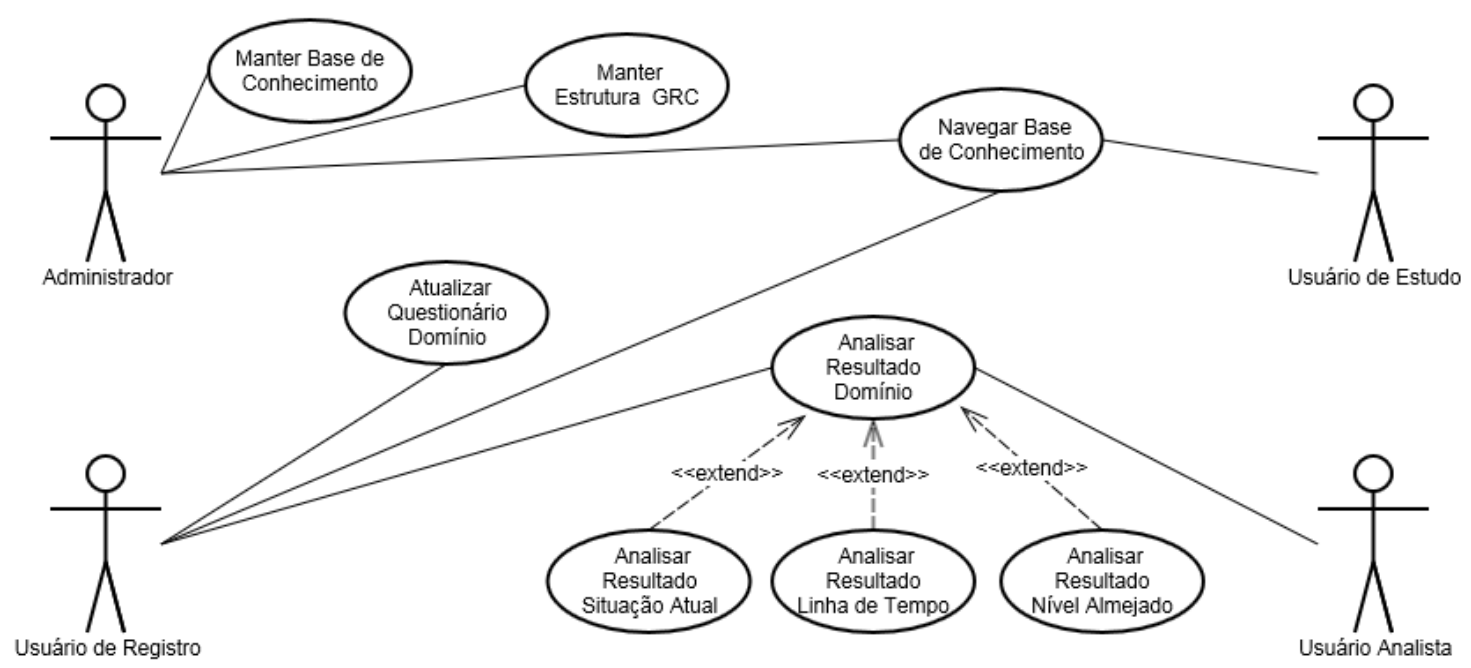

Obs.: Mesmo que não conste do diagrama acima, os requisitos iniciais estabelecem que (...) "o sistema deverá em todos os módulos estar protegido por um modelo de login e senha, impedindo o acesso direto por links internos nas páginas.", o que estabelece um modelo de $<<$ include $>>$ automático de todos os caso de uso para o caso de uso específico de: $<<$ Solicitar Autenticação $>>$.

\subsection{SOLICITAR AUTENTICAÇÃO}

- O usuário informa seu login, senha e organização que está associado.

- O sistema realiza a autenticação e libera ao usuário todo acesso a Base de Conhecimento, à atualização dos Domínios ao qual o mesmo está associado e a visualização dos resultados do domínio, segundo sua atribuição de Usuário de Registro, Usuário Analista ou Usuário de Estudo.

\subsection{MANTER BASE DE CONHECIMENTO}

- O usuário Seleciona o menu "Manter Base de Conhecimento".

- Deste menu, o usuário seleciona uma das opções: "Conteúdo", "Glossário", "Princípios", "Metodologia", "Modelo", "Domínios", "Níveis".

- Aparecerá a tela de Consulta, Inclusão, Exclusão e Atualização correspondente. 


\section{Modelo para Avaliação de Maturidade SOA}

Documento de Análise (Requisitos e Casos de Uso)

\subsection{NAVEGAR BASE DE CONHECIMENTO}

- O usuário acessa o menu "Base de Conhecimento".

- Deste menu, o usuário seleciona uma das opções: "Conteúdo", "Glossário", "Princípios", "Metodologia", "Modelo", "Domínios", "Níveis".

\subsection{MANTER ESTRUTURA GRC}

- O usuário Seleciona o menu "Manter Estrutura".

- Deste menu, seleciona uma das opções: "Dominio", "Controle", "Questão" ou "Item".

- Aparecerá a tela de Consulta, Inclusão, Exclusão e Atualização correspondente.

\subsection{ATUALIZAR QUESTIONÁRIO DOMÍNIO}

- O usuário Seleciona o menu "Questionários".

- Deste menu, aparecerá a lista de Domínios que o usuário pode selecionar.

- Ao selecionar um desses, o usuário poderá marcar os seletores de rádio conforme seu desejo ou selecionar os símbolos de "check" ao lado dos controles de forma a definir se o controle é dispensável ou não.

- Como todos os itens das questões de cada controle não dispensado marcado o usuário poderá acionar o botão de "Salva" presente no topo ou no final da tela.

- Se o domínio for salvo em dia diferente de qualquer outro dia registrado o sistema irá incluir o registro,

- Se o domínio for salvo em um dia igual (podendo ser em horas diferentes) à um existente, o sistema irá atualizar todo registro de respostas daquele domínio.

\subsection{ANALISAR RESULTADO DOMÍNIO}

- O usuário Seleciona o menu "Avaliação". 


\section{Modelo para Avaliação de Maturidade SOA}

Documento de Análise (Requisitos e Casos de Uso)

- $\quad$ Deste menu, seleciona uma das opções: "Situação Atual", "Linha do Tempo" ou "Nível Almejado".

\subsubsection{Analisar Resultado Situação Atual}

- Aparecerá a tela com as saída respectiva do relatório solicitado.

\subsubsection{Analisar Resultado Linha de Tempo}

- Aparecerá a tela com as saída respectiva do relatório solicitado.

\subsubsection{Analisar Resultado Nível Almejado}

- Aparecerá a tela com as saída respectiva do relatório solicitado.

\section{HEURÍSTICA DO MODELO DE TOMADA DE DECISÃO}

Em cada questão os itens representam uma faixa de valores de mínimo e de máximo que aquele item descreve dentro da estrutura de níveis de maturidade estabelecidos. Como limitação do modelo, cada questão deve ter um ou mais itens iniciais que observe o valor mínimo de 1 (um), e uma ou mais respostas válidas que compreendam no seu máximo o valor máximo estabelecido para nível de maturidade (no caso 5).

Assim, a partir da resposta aos questionários atualizados em cada domínio, aonde questões estão associada a cada controle, é utilizado o valor do campo de limite superior de cada resposta de menor valor encontrada. Neste sentido, o processo de valoração de cada controle se dá segundo uma ótica conservadora (sem otimismo) através de aproximações Minimax.

Entende-se que o método Minimax é comumente usado quando todos os atributos são comparáveis, de modo que todos podem ser medidos com uma escala comum", onde esse 


\section{Modelo para Avaliação de Maturidade SOA}

Documento de Análise (Requisitos e Casos de Uso)

método ou a aplicação da regra Hurwitz com um baixo índice de otimismo são consideradas alternativas válidas. Cabe lembrar que a relação entre a quantidade de controles dentro de cada domínio é intempestiva, já que domínios podem demandar mais ou menos controles e controles podem ser dispensados junto ao ciclo de avaliação corrente.

A realização desta etapa provê os correspondentes valores para os controles, que são os objetos de avaliação e mensuração do nível de maturidade dos domínios e que são utilizados também para geração dos roteiros desta estabilização/evolução. Nesse sentido, ao final da quantificação dos controles, tem-se uma situação de controles com pesos diferenciados que irão formar diversas situações de análise de frequência de frequência.

No passo seguinte, a execução de uma heurística de avaliação, tem-se então uma primeira preocupação que é do critério de decisão a ser imposto no modelo de avaliação de cada controle a partir das questões correlacionadas dentro do mesmo. Assim, uma vez definido o valor de cálculo de controles, o modelo proposto realiza uma série de avaliações heurísticas para determinar o nível de maturidade no domínio utilizando-se das respostas ao questionário de cada domínio. A heurística desenvolvida baseia-se que em processos decisórios multiatributos.

Esse processo decisório baseia-se fundamentalmente na análise de frequência e sua correlação com as situações prováveis identificadas durante o ciclo de adoção de SOA, com atenção na busca de um equilíbrio dos mesmos com suas importâncias relativas, estabelecida na ótica de seus pesos, que é repassada ao modelo heurístico pela combinação em cada controle do nível identificado e o peso do mesmo.

Assim, nesta etapa, controles e seus pesos serão utilizados na formação de um modelo de distribuição de frequência a ser utilizada na etapa de valoração dos domínios, que permite a a análise da situação atual - de estabilização ou evolução, para qualificação dos estágio de maturidade em SOA e formação de roteiros de evolução para os controles que não se encontrem em conformidade - segundo a distribuição de frequência - em cada domínio. 


\section{Modelo para Avaliação de Maturidade SOA}

Documento de Análise (Requisitos e Casos de Uso)

A distribuição de frequência calculada para cada controle (com seu peso) em cada domínio será então a entrada para realização do fluxo referente ao processo de tomada de decisão apresentado na Figura 9. Essa ilustração descreve o processo realizado pelo modelo heurístico para determinação das situações organizacionais, no que se refere à adoção de SOA, bem como será adicionalmente determinado como controles podem ser imperativos ou não, e como são realizadas as agregações para que se estabeleça cada situação e o indicador de nível de maturidade atingido

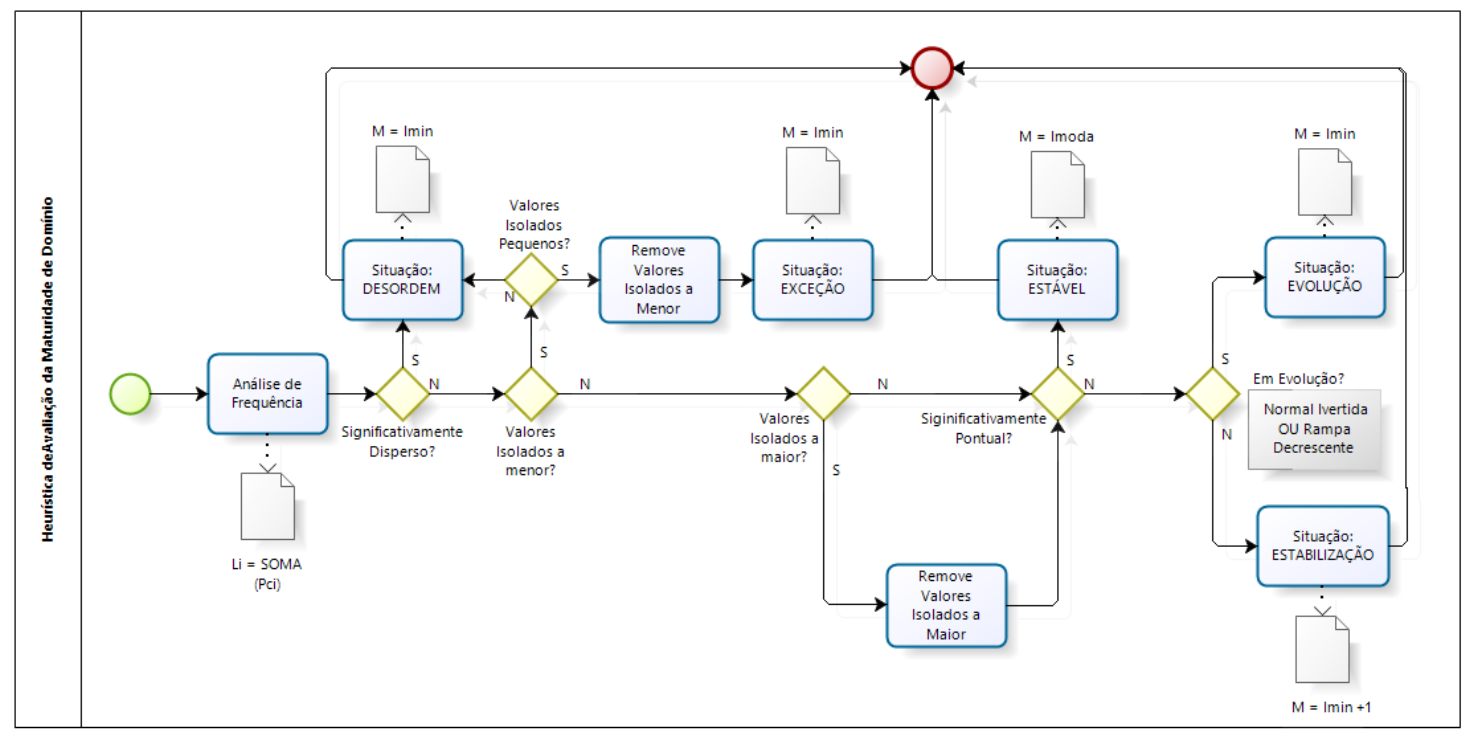

Obs.: Mais detalhes no desenvolvimento do trabalho.

\section{REFERENCIAIS ADICIONAIS}

Para consecução do desenvolvimento do modelo, destaca-se a realização dos estudos e análises conjuntas dos modelos de avaliação de níveis de maturidade existentes. Dentre esses destacam-se:

- Open Group SOA Maturity Model Integration (OSIMM): é um modelo que permite estimar o grau em que uma organização já assumiu dos princípios de SOA dentro de seus departamentos de TI e de negócios. Há sete níveis, sendo o Nível 1 o menor e o Nível 7 o maior. Os graus mais elevados de maturidade permitem a condução de uma 


\section{Modelo para Avaliação de Maturidade SOA}

Documento de Análise (Requisitos e Casos de Uso)

maior agilidade nos negócios, porém não são necessariamente "melhores", já que cada organização pode ter um nível de maturidade ideal dependendo das necessidades do seu negócio de e do contexto de sua TI. Este modelo especifica: um modelo contra o qual o grau de maturidade serviço de integração de uma organização pode ser avaliada; e um processo para avaliar o grau atual e o almejado de maturidade serviço de integração de uma organização, usando o modelo.

- Serviço Oriented Maturity Model (SOMM): é um modelo de maturidade criado como uma tentativa de ajudar as organizações a definir as diretrizes de arquitetura e um processo para alcançar um maior nível de maturidade e previsibilidade nas suas tecnologias de informação geral (TI). O modelo é projetado para permitir que organizações possam identificar em uma escala de 1 a 5 (sendo 5 a mais avançada, ou maduro, nível) sua situação em termos de maturidade no uso de SOA. O modelo também ajuda a construir um caminho real para alcançar uma Arquitetura Orientada a Serviços (SOA). A aplicação iterativa do modelo de maturidade SOMM permite que as organizações de TI evoluam rapidamente para atender às necessidades de negócios objetivando a efetiva de custo e de tempo.

- Gartner Gartner Application Architecture, Development and Integration (AADI): um novo modelo de Avaliação de Maturidade desenvolvido pela Gartner Inc. 
Modelo para Avaliação de Maturidade SOA - Prototipação Versão 1.0 


\section{GRC / SOA}

Governança, Risco e Conformidade para SOA

Governance, Risk and Compliance for SOA

\section{Premissas}

- Com a pressão cada vez maior dos interesses internos e externos sobre as organizações, as decisões se tornaram mais difíceis, acarretando na perda da agilidade tão necessária na gestão das organizações.

- É neste contexto que se observa a necessidade de estruturação e unificação das iniciativas corporativas de governança e de gestão organizacional, associada com uma avaliação contínua dos resultados obtidos por essas junto aos diversos estágios do ciclo de - melhoria contínua. 


\section{O que é GRC}

- Refere-se à coordenação de pessoas, processos e tecnologias envolvidas em cada área dentro de uma organização, com o objetivo de tornar os processos mais eficientes, reduzindo a redundância e facilitando os processos, proporcionando uma melhor supervisão e tomada de decisões.

- Um dos pontos fundamentais de um ambiente de GRC é a capacidade de avaliação do nível de maturidade da organização no assunto baseado em modelos aceitáveis pelo mercado.

$\bullet$

\section{GRC - Significado}

* Governança: refere-se a forma com que as decisões são tomadas nas organizações, e envolve definições e controle de políticas, procedimentos, responsabilidades e autoridades; coordenando pessoas, processos, e tecnologias para alcançálos.

* Gerenciamento de Risco: pode ser definido como o efeito das incertezas nos objetivos, logo é relacionado a probabilidade de um evento ocorrer e os possíveis impactos nos objetivos do negócio.

* Conformidade: mensura o quanto a organização está aderente a procedimentos e boas práticas segundo um modelo. 


\section{Objetivo}

- Propor uma arquitetura com o devido suporte sistêmico para apoio a Governança Corporativa - em atenção especial a elementos da Governança de TI visando a gestão dos princípios de Governança, Risco e Conformidade em organizações que pretendam ou que já estão estabelecendo estruturas empresariais baseadas em Arquitetura Orientada a Serviços - SOA.

\section{Projeto GRC/SOA}

* Apoio do IBTI no desenvolvimento do modelo de GRC/SOA.

* Desenvolvido em fases:

- Fase 1 - Base de Conhecimento e Conformidade;

- Fase 2 - Gerenciamento de Riscos; e

- Fase 3 - Governança e Indicadores. 


\section{GRC - Fase 1}

* Base de Conhecimento: * Requisitos Básicos:

- Glossário

- Gravação e Leitura

- Princípios

- Multi-lingual (configurável)

- Metodologia de Referência

- Multi-modelo (configurável)

- Arquitetura de Referência

- Configuração em XML

* Conformidade:

- Questionários Avaliativos

- Resultados

- Recomendações

- Avaliações Históricas

\section{Base de Conhecimento}

Elementos normativos e documentais para suporte as ações de Governança SOA.

* Glossário: reúne de forma objetiva, os significados de variados termos, expressões e palavras usadas no GRC.

* Princípios: norteiam o uso de SOA e são aplicados a um domínio específico.

* Metodologia de Referência: especificam os perfis, competências e atividades a serem realizadas durante o ciclo de vida de construção de soluções baseadas em SOA.

* Arquitetura de Referência: é um padrão ou conjunto de padrões predefinidos, com artefatos de suporte que permitam a realização das atividades metodológicas. 


\section{Glossário}

* Modelo "Explorer-like" e suporte automático a geração de hiperlinks em todo texto com similaridade de sintaxe dentro da estrutura do sistema.

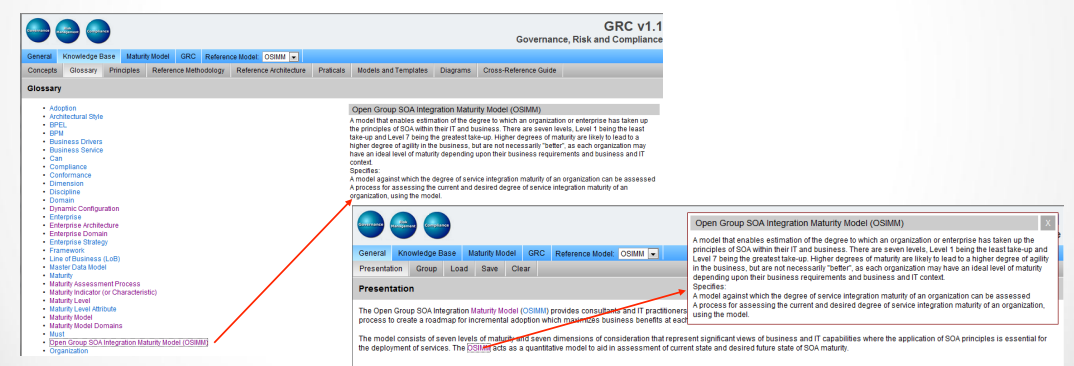

\section{Princípios}

- Apresentação de modelo resumido de princípios e padrões de projeto recorrentes ao site SOAGlossary.com.

Padrões de projeto na arquitetura de serviços

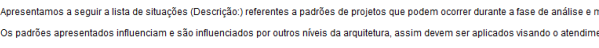

Contratos concorrentes (Concurrent Contracts) (Contrato)

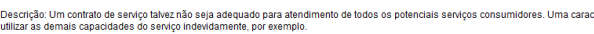

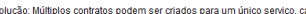




\section{Metodologia de Referência}

* Documento-referência com um proposição de uma metodologia para uso durante a fase de adoção

de SOA.

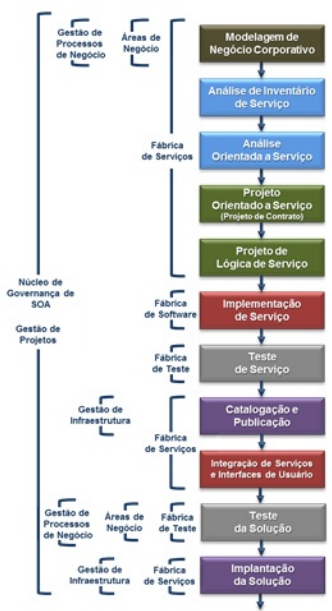

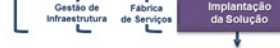

\section{Arquitetura de Referência}

* Exposição de um modelo de base para suporte ao estabelecimento de uma Arquitetura de Referência.

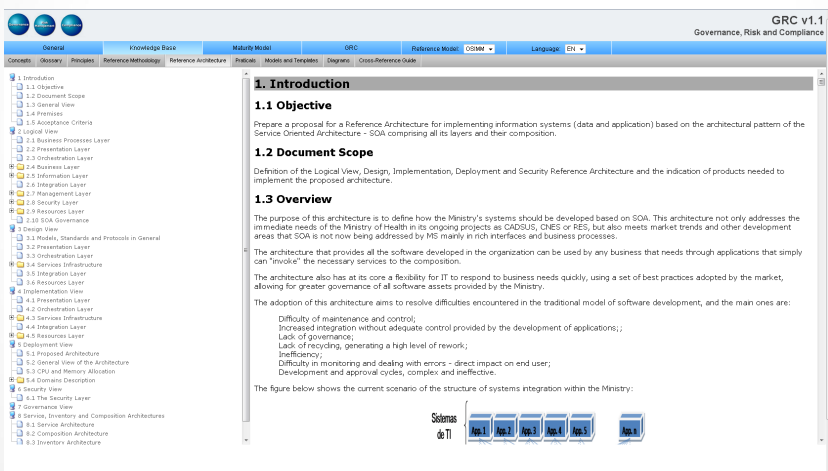




\section{Conformidade}

Antes de entrarmos no assunto conformidade é importante compreender os conceitos utilizados para a elaboração do modelo de conformidade proposto.

* Modelo: é um plano que permite estabelecer um limiar entre os diferentes domínios dentro de uma organização e mensurar o nível de cada um, com vistas à correta aplicações dos princípios SOA

* Domínios: eixo que representa visões significativas dentro de uma organização pelas quais se pode medir seu nível de maturidade

* Níveis: eixo que define o grau de maturidade SOA de um domínio

* Questionários: questionário avaliativo por níveis disposto em domínios, fundamentado em modelos específicos

* Resultado: revela o nível atual de maturidade da organização e exibe recomendações para níveis de maturidade desejados

\section{Conformidade}

Suporte a análise de maturidade baseado em técnicas de perguntas e respostas suportado por um modelo matemático avaliativo.

* Questionários Avaliativos: Modelos estabelecendo perguntas e respostas prédefinidas por domínios e com valores mínimos e máximos para cada item.

* Resultados: valores calculados por questão, totalizando valores por domínio e um valor global.

* Recomendações: especificam os perfis, competências e atividades a serem realizadas por domínio durante o ciclo de vida de construção de soluções baseadas em SOA segundo o valor encontrado por domínio.

* Avaliações Históricas: suporta a comparação dos valores encontrados por domínio e global segundo os diversos resuiltados gravados (ponto de controle). 


\section{Modelagem Inicial}

* E como realizamos isso ...

* Pesquisa básica e aplicada: elaboração de um modelo inicial com o suporte de casos de testes iniciais para comprovação da efetividade do modelo proposto.

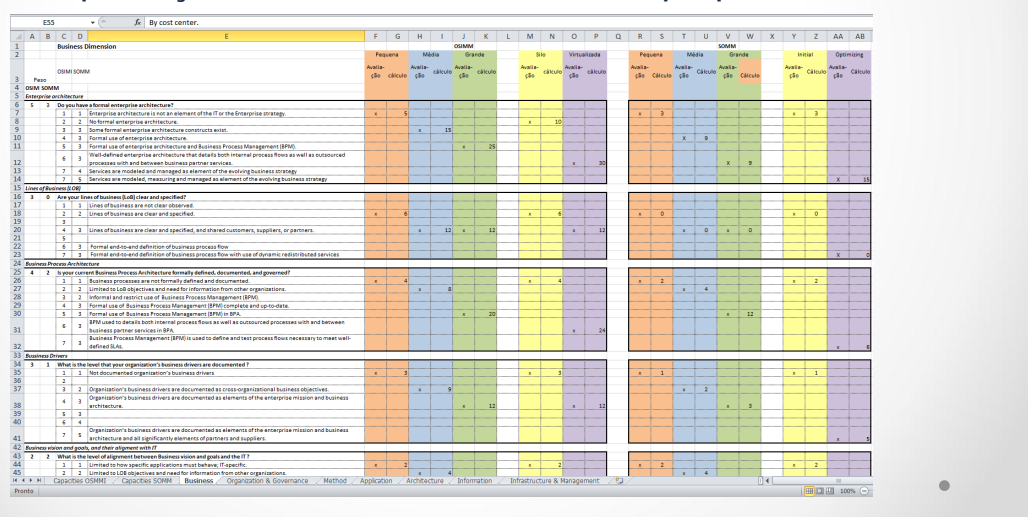

\section{Modelo Matemático}

* Modelos matemáticos que irão explicitar o quanto a organização está aderente aos níveis organizacionais estabelecidos segundo os modelos de conformidade em SOA reconhecidos no mercado.

Modelo proposto: $\min (\max ())$ Menor valor dos maiores valores em cada item de resposta.
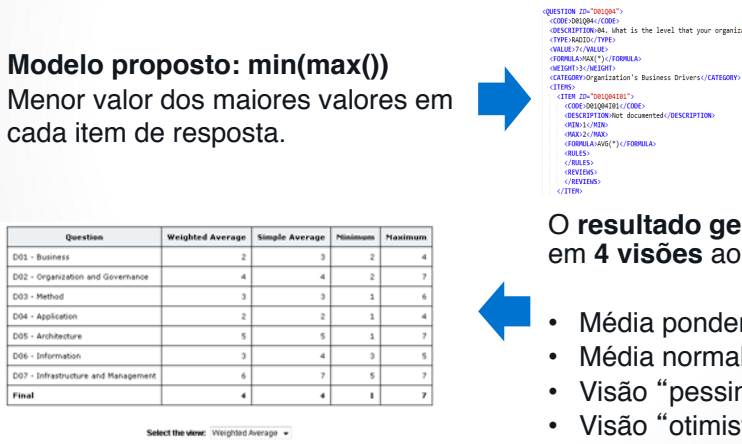

O resultado geral é apresentado em 4 visões ao usuário segundo:

- Média ponderada (avg(wight))

- Média normal (avg())

- Visão "pessimista” (min())

- Visão “otimista" $(\max ())$ 


\section{Questionário de avaliação}

* Formulário eletrônico gerado automaticamente a partir de modelos sugeridos pelo IBTI ou formulados / atualizados pelos usuários.

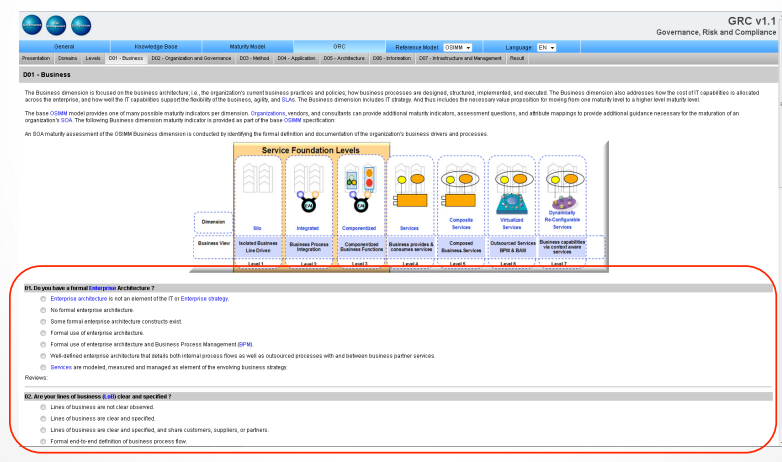

\section{Avaliação - Situação Atual}

* Os resultados das avaliações são suportados por gráficos e relatórios suplementares.

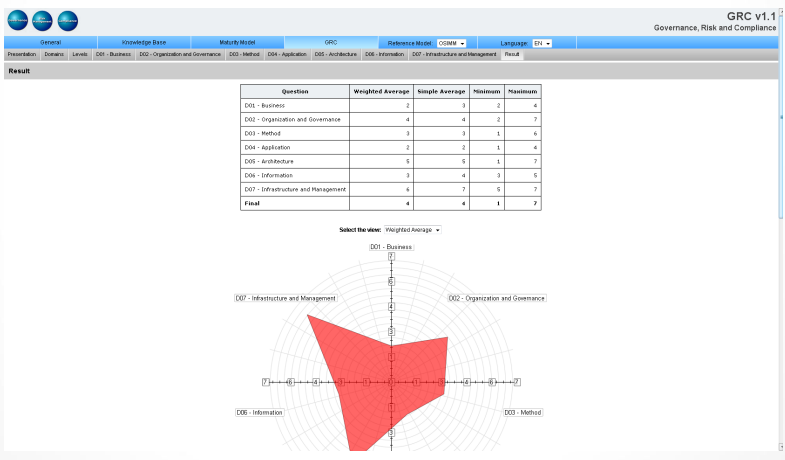




\section{Recomendações}

* Com os resultados das avaliações, recomendações são apresentadas seja para atingimento do limiar do nível de maturidade existente ou para a mudança do nível de maturidade desejado.

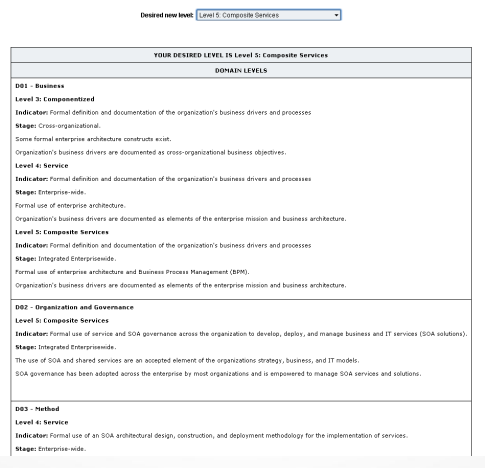

\section{Gerenciamento de Riscos}

Gestão de uma lista de riscos ordenada conforme valor calculado segundo um critérios matemáticos estabelecidos utilizando valores de Gravidade, Urgência e Tendência.

* Modelo: Define o modelo matemático a ser aplicado para cálculo do fator de risco segundo as métricas de Gravidade. Urgência e Tendência avaliadas de 1 a 5.

- Gravidade: quão grave o risco representa?

- Urgência: qual a urgência de sua solução?

- Tendência: qual a tendência de sua ocorrência?

* Situação: refere-se a gestão dos riscos existentes (elenco) com as informações de mitigações / transferência / resoluções, os valores de GUT e a situação de cada risco elencado (resolvido=S/N).

\section{EM IMPLEMENTAÇÃO}




\section{Gravação e Leitura}

* Gravação, leitura e exclusão de resultados.

- Por Modelo (SOMM e OSSIM)

- Por idioma (Inglês e Português)

- Versionado por ID (Definido pelo usuário)

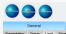

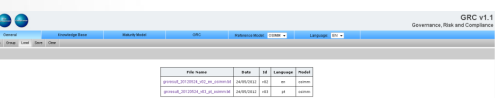

Tela de leitura

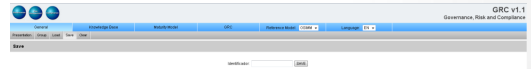

Tela de gravação com ID

\section{Benefícios Esperados}

* redução de custos causados por redundância nos controles internos e processos da organização;

* melhoria da integração entre as áreas e, por consequência, diminuição dos custos com a Gestão da Informação;

* aumento da eficiência das diversas ações de melhorias já em curso nas empresas;

* aumento do grau de previsibilidade;

* aumento da transparência entre as gestões internas e partes interessadas externas da organização; melhoria

* aumento da sensibilidade da organização a respeito de incertezas e qualquer tipo de indício de oportunidade ou ameaça a ser tratada;

* aumento da competitividade e melhoria na capacidade das organizações inovarem em ambientes dinâmicos e incertos; e

* maior resistência das organizações à situações ambientais adversas. 
Modelo para Avaliação de Maturidade SOA - Modelagem de Dados 


\section{HISTÓRICO DAS REVISÕES}

\begin{tabular}{|c|c|c|c|}
\hline Data & Versão & Descrição & Autor \\
\hline $01 / 07 / 2012$ & 0.1 & Versão Inicial & $\begin{array}{c}\text { Arthur Magalhães e } \\
\text { Valério Martins }\end{array}$ \\
\hline $10 / 10 / 2014$ & 1.0 & $\begin{array}{c}\text { Nome do Sistema alterado para } \\
\text { "Modelo para Avaliação de Maturidade SOA" }\end{array}$ & Claynor Mazzarolo \\
\hline
\end{tabular}




\section{CONTEÚDO}

\section{PROJETO DE DADOS}

Modelo Conceitual............................................... 255

Modelo Lógico................................................. 256

Dicionário de Dados................................................... 257 


\section{PROJETO DE DADOS}

Modelo Conceitual

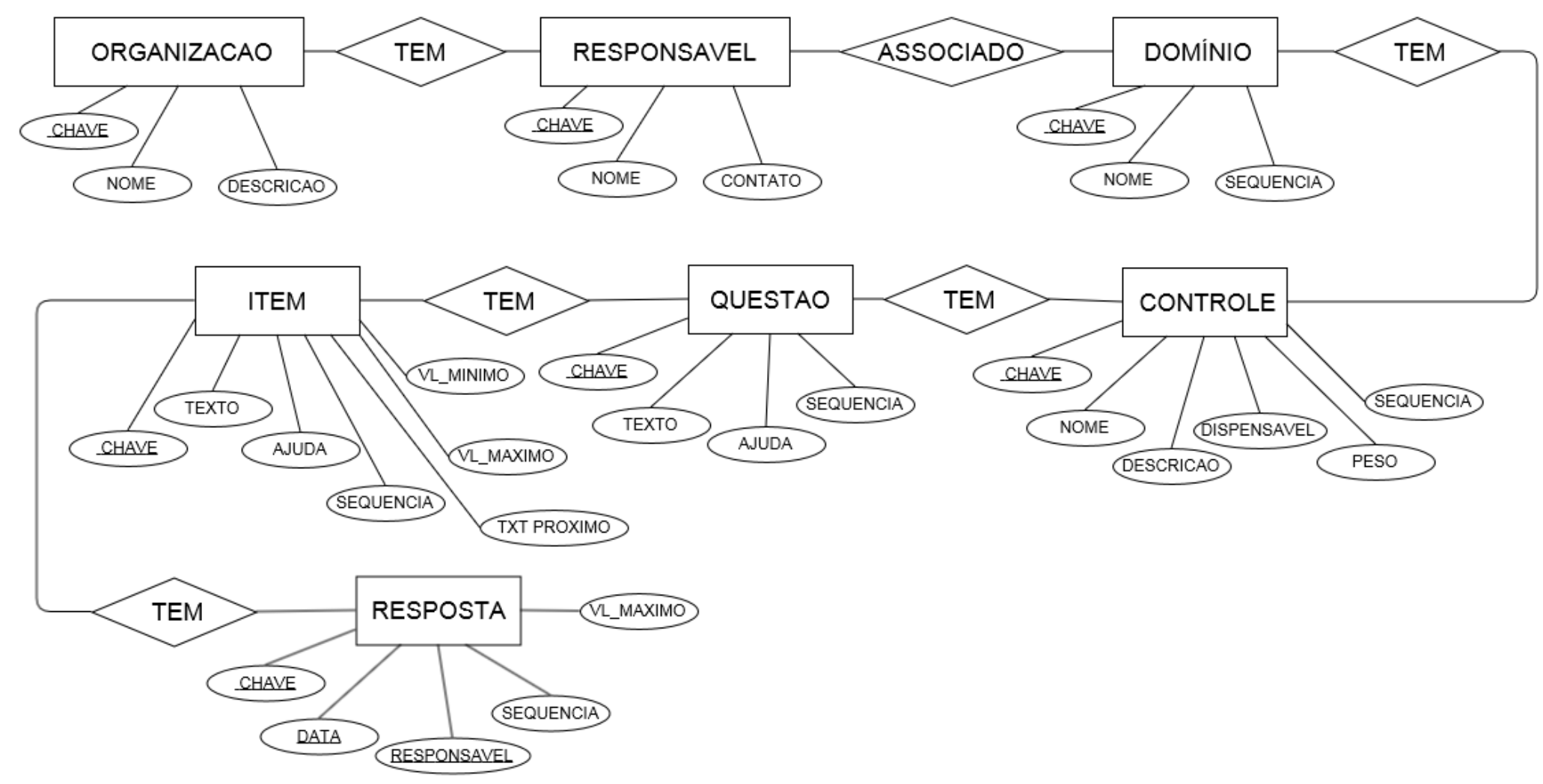


Modelo Lógico

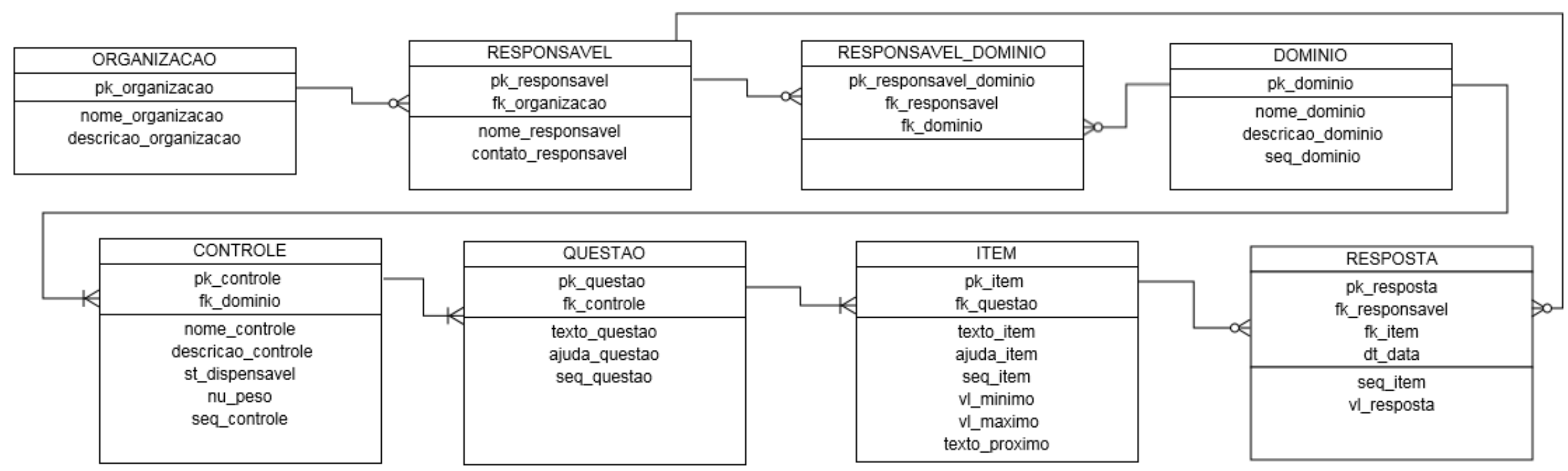




\section{Dicionário de Dados}

\begin{tabular}{|l|l|l|}
\hline \multicolumn{2}{|l|}{ Tabela: ORGANIZACAO } \\
\hline pk_organizacao & serial & (PK) chave primária auto-incremental \\
\hline nome_organizacao & varchar(50) & nome da organização na forma de sigla \\
\hline descricao_organizacao & varchar(255) & nome da organização por extenso \\
\hline
\end{tabular}

\section{Tabela: RESPONSAVEL}

\begin{tabular}{|l|l|l|}
\hline pk_responsavel & serial & (PK) chave primária auto-incremental \\
\hline fk_organizacao & integer & (FK) RELATIONS ORGANIZACAO(pk_organizacao) \\
\hline nome_responsavel & $\operatorname{varchar}(50)$ & nome do responsavel pelo preenchimento \\
\hline contato_responsavel & varchar(255) & contatos para o responsável pelo preenchimento \\
\hline
\end{tabular}

\begin{tabular}{|l|l|l|}
\hline \multicolumn{2}{|l|}{ Tabela: RESPONSAVEL_DOMINIO } \\
\hline pk_responsavel_dominio & serial & (PK) chave primária auto-incremental \\
\hline $\mathrm{fk}$ responsavel & integer & (FK) RELATIONS RESPONSAVEL(pk_responsavel) \\
\hline $\mathrm{fk}$ dominio & varchar(3) & (FK) RELATIONS DOMINIO(pk_dominio) \\
\hline
\end{tabular}

\begin{tabular}{|l|l|l|}
\hline \multicolumn{2}{|l|}{ Tabela: DOMINIO } & (PK) chave primária no formato "Dnn" \\
\hline pk_dominio & varchar(50) & nome do domínio na forma de sigla \\
\hline nome_dominio & varchar(255) & descrição do domínio \\
\hline descricao_dominio & integer & sequencial que ordena os domínio no menu/respostas \\
\hline seq_dominio &
\end{tabular}




\begin{tabular}{|c|c|c|}
\hline \multicolumn{3}{|c|}{ Tabela: CONTROLE } \\
\hline pk_controle & $\operatorname{varchar}(6)$ & (PK) chave primária no formato "DnnCnn" \\
\hline $\mathrm{fk}$ _dominio & varchar(3) & (FK) RELATIONS DOMINIO(pk_dominio) \\
\hline nome_controle & varchar(255) & nome do controle \\
\hline descricao_controle & $\operatorname{varchar}(1024)$ & descrição do controle \\
\hline st_dispensavel & $\operatorname{varchar}(1)$ & Flag com "S" ou "N" indicando se permite a dispensação do controle \\
\hline nu_peso & integer & peso do controle \\
\hline seq_controle & integer & sequencial que ordena os controles no questionário \\
\hline \multicolumn{3}{|l|}{ Tabela: QUESTAO } \\
\hline pk_questao & $\operatorname{varchar}(9)$ & (PK) chave primária no formato "DnnCnnQnn" \\
\hline fk_controle & $\operatorname{varchar}(6)$ & (FK) RELATIONS CONTROLE(pk_controle) \\
\hline texto_questao & $\operatorname{varchar}(255)$ & texto da questão \\
\hline ajuda_questao & $\operatorname{varchar}(1024)$ & ajuda da questão \\
\hline seq_questao & integer & sequencial que ordena as questões no questionário \\
\hline
\end{tabular}

\begin{tabular}{|c|c|c|}
\hline \multicolumn{3}{|c|}{ Tabela: ITEM } \\
\hline pk_item & $\operatorname{varchar}(12)$ & (PK) chave primária no formato "DnnCnnQnnInn" \\
\hline fk_questao & $\operatorname{varchar}(9)$ & (FK) RELATIONS QUESTAO(pk_questao) \\
\hline texto_item & $\operatorname{varchar}(255)$ & texto do item de questão \\
\hline ajuda_item & $\operatorname{varchar}(1024)$ & ajuda item de questão \\
\hline seq_item & integer & sequencial que ordena os itens na questão \\
\hline vl_minimo & integer & menor valor na faixa da questao (vide caput para entendimento) \\
\hline
\end{tabular}




\begin{tabular}{|l|l|l|}
\hline \multicolumn{2}{|l|}{ Tabela: ITEM } \\
\hline vl_maximo & integer & menor valor na faixa da questao (vide caput para entendimento) \\
\hline texto_proximo & varchar(1024) & texto com a sugestão de implementação para evoluir \\
\hline
\end{tabular}

\begin{tabular}{|c|c|c|}
\hline \multicolumn{3}{|c|}{ Tabela: RESPOSTA } \\
\hline pk_resposta & serial & (PK) chave primária auto-incremental \\
\hline fk_responsavel & integer & (FK) RELATIONS RESPONSAVEL(pk_responsavel) \\
\hline $\mathrm{fk}$ item & integer & (FK) RELATIONS ITEM(pk_item) \\
\hline dt_data & varchar(8) & data no formato "AAAAMMDD" [1] \\
\hline seq_item & integer & aponta para ITEM(seq_item) [2] \\
\hline vl_resposta & integer & equivale ao vl_maximo do item marcado \\
\hline
\end{tabular}

Obs: [1] permite ordenação e garante regravação no caso de preenchimento na mesma data do mesmo domínio).

[2] redundância do modelo para garantir acesso no caso de modificação na estrutura da tabela ITEM. Na mudança da pk irá dar ajuste/garantir a manutenção da Integridade Referencial. 